\title{
Pregnancy-related pelvic girdle pain : diagnostics and intervention
}

Citation for published version (APA):

Bastiaenen-Heuts, C. H. G. (2005). Pregnancy-related pelvic girdle pain : diagnostics and intervention.

[Doctoral Thesis, Maastricht University]. https://doi.org/10.26481/dis.20051214cb

Document status and date:

Published: 01/01/2005

DOI:

10.26481/dis.20051214cb

Document Version:

Publisher's PDF, also known as Version of record

\section{Please check the document version of this publication:}

- A submitted manuscript is the version of the article upon submission and before peer-review. There can be important differences between the submitted version and the official published version of record.

People interested in the research are advised to contact the author for the final version of the publication, or visit the DOI to the publisher's website.

- The final author version and the galley proof are versions of the publication after peer review.

- The final published version features the final layout of the paper including the volume, issue and page numbers.

Link to publication

\footnotetext{
General rights rights.

- You may freely distribute the URL identifying the publication in the public portal. please follow below link for the End User Agreement:

www.umlib.nl/taverne-license

Take down policy

If you believe that this document breaches copyright please contact us at:

repository@maastrichtuniversity.nl

providing details and we will investigate your claim.
}

Copyright and moral rights for the publications made accessible in the public portal are retained by the authors and/or other copyright owners and it is a condition of accessing publications that users recognise and abide by the legal requirements associated with these

- Users may download and print one copy of any publication from the public portal for the purpose of private study or research.

- You may not further distribute the material or use it for any profit-making activity or commercial gain

If the publication is distributed under the terms of Article $25 \mathrm{fa}$ of the Dutch Copyright Act, indicated by the "Taverne" license above, 


\title{
PREGNANCY-RELATED PELVIC GIRDLE PAIN
}

\author{
Diagnostics and Intervention
}

Berthe Bastiaenen-Koenen Jan en Hanneke Koetje-Bastiaenen 
ISBN: $905278504 \mathrm{X}$

Cover: Gijs Heuts, Carolien Bastiaenen

Lay-out: Carolien Bastiaenen

Printed by: Datawyse / Universitaire Pers Maastricht

2005. CHG Bastiaenen

All rights reserved. No part of this thesis may reproduced or transmitted in any form or by any means, electronic or mechanical, including photocopying. recording or any information storage or retrieval system, without permission in writing from the author, or, when. appropriate, from the publishers of the publications 


\title{
PREGNANCY-RELATED PELVIC GIRDLE PAIN
}

Diagnostics and Intervention

\author{
Proefschrift \\ ter verkrijging van de graad van doctor \\ aan de Universiteit Maastricht, \\ op gezag van de Rector Magnificus, \\ Prof. mr. GPMF Mols, \\ volgens het besluit van het College van Decanen, \\ In het openbaar te verdedigen \\ op woensdag 14 december 2005 om 14:00 uur \\ door \\ Caroline Henrice Germaine Bastiaenen
}

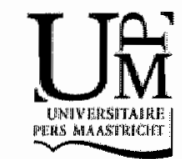




\section{Promotores}

Prof. dr. RA de Bie

Prof. dr. ir. PA van den Brandt

Prof. dr. GGM Essed

\section{Beoordelingscommissie}

Prof, dr. JMJP van der Linden (voorzitter)

Prof. dr. FBuntinx

Prof. dr. Mvan Kleef

Prof. dr. RAB Oostendorp (Radboud Universiteit Nijmegen)

Prof. dr. ir. HCW de Vet (Vrije Universiteit Amsterdam)

The studies presented in this thesis were conducted at Maastricht University, at the Department of Epidemiology and was embedded in the Care and Public Health Research Institute (Caphri). Caphri participates in the Netherlands School of Primary Care Research (CaRe), which was acknowledged in 1995 by the Royal Netherlands Academy of Arts and Sciences (KNAW).

This project was funded by grants from the College voor zorgverzekeringen $(C V Z)$. 


\section{Contents}

7 Chapter one

13 Chapter Two

29 Chopter Three

49 Chapter Four

71 Chapter Five

95 Chapter Six

123 Chapter Seven

159 Chapter Eight

167 Appendix

223 Summary/

Samenvatting

231 Acknowledgements
Introduction

Pregnancy-related pelvic girdle pain

Disparity in classification strategies

Cluster analysis, a way to describe

clinical findings of pregnancy-related pelvic girdle pain

Treatment of pregnancy-related pelvic

girdle pain after delivery

Design of a randomized clinical trial within a comprehensize prognostic cohort study

Short-term effectiveness of a tailor-

made intervention for pregnancy-related pelvic girdle pain

Long-term effectiveness and costs of a tailor-made intervention for pregnancy-related pelvic girdle pain

Consequences of the Mastricht Cohort and Intervention study on pregnancy-related pelvic girdle pain for the development of a clinical practice guideline for the physiotherapy

Epilogue

A clinical practice guideline for the physiotherapy management 
a 


\section{CHAPTER ONE}

Introduction 


\section{Background}

Interviewer: "If I tell you that pregnancy-related pelvic girdle pain is a common physical symptom during pregnancy, do you agree with we?"

Respondent 1: "To sone extent you're right but it is difficult to recognize where the difference is between real complaints and common symptomis during pregnancy like feelings of sickness. I haze read and heard that it gets worse the longer it goes on. That frightens me."

Pregnancy-related pelvic girdle pain (PPGP) still attracts a lot of attention being an important and frustrating complaint during pregnancy and after delivery. Women are faced with a multitude of questions and doubts about pain control and which activities can cause (recurrent) injury and therefore must be avoided. They have also doubts about the prospects. These complaints and doubts play a considerable role in the interaction between pregnant women and their caregivers. Caregivers such as physiotherapists are frequently concerned about their patients' perceived pain and highly motivated to guide them in their way to recuperation.

Interviewer: "You told me about crutches and a wheelchair. Did the physiotherapist make those suggestions to you?

Respondent 2: "Yes".

Interviewer: "Why?"

Respondent 2: "Well, she said, I am an extreme case, a very extreme case."

Interviewer: "And?"

Respondent 2: "The complaints started early, very early. Just shopping, for two hours and then the next two days, I staggered along the house. And then when I sat down and wanted to get up there was a sudden feeling of giving away in wy legs. That is why the plysiotherapist said I am an extreme case. I started very early.

However, that is a complicated task, even much more complicated than one would imagine at first sight. Pelvic girdle pain is a frequently occurring phenomenon during pregnancy in the Netherlands, although the real magnitude of the problem still remains unclear. Even more difficult to answer is the question about a potentially prognosis, an aspect that is spoken and rumored about by many but satisfactory answered by no one. Moreover, 
pregnant women are often burdened by the media, family and friends and sometimes even by caregivers with stories in which things go from bad to worse. Also, the unjustified suggestion that the complaints can be clearly diagnosed with a few simple physical tests has far-reaching consequences. After all, effective treatment depends to a large extent on the adequate interpretation of the outcome of a diagnostic process. Women with PPGP rely heavily on such a diagnosis assuming this will guide them to a proper treatment proposal and idea of the future. These expectations play a significant role in the interaction between a woman and a physiotherapist.

The research field of pregnancy-related pelvic girdle pain is characterized by considerable differences of opinions about etiology, diagnosis, prognosis and treatment. During the last two decades, researchers in this field have focused their attention on biomedical factors. Unfortunately, the developed diagnostic classification criteria seem insufficient in guiding to an intervention approach that meets the worries of women with PPGP. Results of various therapeutic interventions have been published but effectiveness remains largely unproven.

Interviewer: "So, the care of your elder son was a help for you to accept your limitations in actioities?"

Respondent 3: "Yes, with ups and downs. Of course, there are still mowents I think:" Why me?". But on the other hand, I arranged some help in housekeeping for the time being. I just noticed that when I am mentally less able to cope with everything, it has its repercussions on my back."

Nowadays, it is for an individual physiotherapist in daily care an almost impossible task to get overview of the entire field including the existing controversies and gaps in the knowledge. Women's worries about their pain during pregnancy and also after delivery remain still unclear. More research is needed that meets the wishes and concerns of women with PPGP and their caregivers.

Interviewer (hands over a photograph of a daily activity): "What do you think you will feel when performing this activity?"

Respondent 3: "I don't know because I don't do that anymore."

Interviewer: "And?"

Respondent 3: "I don't do it as a precaution. It cannot be right for my pelvis or back doing that. I don't know what I will feel because I don't try it. 
Interviewer: "Is there a causal comvection between your complants and something else, do you think?"

Respondent 4: "Yes, the hypermobility of the joints during pregnancy."

Interviewer: Your feelings are in line with this iden?"

Respondent 4: "Oh yes, I can feel the laxity in the jownts of the pelvis."

Intevoiewer: "Can you describe more dearly what you wean?"

Respondent 4: "As I said, it creaks and crunches in eoveryway like someone twists my pelvis or groins."

\section{Aim of the study}

The chapters of this thesis are part of a large research project on pregnancyrelated pelvic girdle pain during pregnancy until one year after delivery: the Maastricht Cohort and Intervention study on pregnancy-related pelvic girdle pain. The aim of this research project is to examine the aetiology, prevalence, progmosis, diagnostics and intervention options in the Southern part of the Netherlands. Because of the lack of a clear definition we used in this thesis an extensive description of pregnancy-related pelvic girdle pain (PPGP) including all women who experience some form of pregnancy-related pain in the lower back and/or pelvic girdle originated within the musculoskeletal system.

The project is designed as a large cohort study in which a randomised controlled trial is embedded. The cohort study $(n=7526)$ is designed as a longitudinal prospective study, which studies the prevalence, aetiology, severity and prognosis of pregnancy-related pelvic girdle or low back pain during pregnancy untill one year after delivery. Women are included in the cohort if they are at least 18 years old, pregnant and well versed in Dutch language. Women with persistent complaints shortly after delivery are invited to participate in the studies written down in this thesis.

The current thesis focuses on the evaluation of an intervention for pregnancyrelated pelvic girdle pain. It is mainly based on the results of a cognitive behavioural trial shortly after delivery $(n=126)$. We performed a randomised controlled trial in primary care to determine whether a tailor-made program with respect to biopsychosocial factors benefits women with PPGP more in terms of effectiveness and costs than usual care would on the current pain 
contingent basis. Parts of this thesis deals with diagnostic questions and with a clinical guideline focusing on the guidance by a physiotherapist.

\section{Outline of the thesis}

The outline of the thesis shows how the questions generated in the aim of the study have been addressed. Chapter two reflects on the concepts of pregnancyrelated pelvic girdle pain of some of the most cited authors in this research field. The agreement on definitions of pregnancy-related pelvic girdle pain is explored. Chapter three provides more insight into a new way of describing clinical findings of women with PPGP by means of cluster analyses.

The next three chapters of the thesis describe a randomized controlled trial of a physiotherapy intervention for pregnancy-related pelvic girdle pain. Chapter four describes the design of the randomized controlled trial shortly after delivery. The short-term results of the trial are reported in chapter five and the long-term effectiveness and costs six months and one year after delivery are described in chapter six. Women's worries about their condition are major targets of the intervention. Theoretical concepts of self-management and exposure techniques are included in the protocol of the experimental intervention. A time contingent policy is followed in which women set the pace by means of action plans. Outcomes are evaluated within the dimensions a biopsychosocial approach.

Chapter seven provides a discussion of the findings in this thesis as background for the development of a clinical practice guideline for the physiotherapy management.

Chapter eight, an epilogue discussed the embedding of the intervention study in the cohort study.

Finally, an appendix fulfils the needs for guidance of a physiotherapist in daily care to guide a woman with PPGP in the best possible way according to the state-of-the-art. In this chapter, a description is given of contents of a clinical practice guideline for the physiotherapy management of women with pregnancy-related pelvic girdle pain.

Fragnents of interviews with women of the Manstricht Cohort study on pregnancyrelated pelvic girdle pain (umpublished qualitative research 2001) 


\section{CHAPTER TWO}

\section{Pregnancy-related pelvic girdle pain after delivery Disparity in classification strategies}

Caroline HG Bastidenen, Rob A de Bie, Jan SAG Schouten, Aldegonda

BA Klabbers, Anton F Lenssen, Pieter MJC Wolters, Conny de Zwart. Gerard GM Essed, Plet A van den Brandt.

Submitted 


\section{Abstract}

\section{Introduction:}

The purpose of this paper is to explore the agreement on definitions of pregnancy-related pelvic girdle pain used by 4 commonly used diagnostic strategies.

\section{Methods:}

This validity study is embedded in an ongoing cohort study $(n=7526)$, which studies the aetiology and prognosis of pregnancy-related pelvic girdle pain. The first 89 women who had persistent pregnancy-related pelvic girdle pain and limitations in activity about three weeks after delivery, participated in this study. A research-physiotherapist visited all included wonen at home. During this visit a standardized history was taken and physical examination was performed. A researcher not involved in the home visits, allocated the women by means of the gathered data into a positive or negative diagnosis. Every woman was classified four times running on the same data but every time by means of a different strategy. Kappa is used to measure agreement between the examined strategies. Disagreement is interpreted as a difference in the definition.

Results:

Differences turned out to be outweighing the similarities. Sources of disagreement originated in the large amount of problems conceming content validity, biases in the work-tip evaluation of the strategies, a non-systematic application of validated and standardized questionnaires and a limited knowledge about etiology. Research results about both dingnostic and treatment concerning patients selected by one of the strategies may not be generalized to all populations with pregnancy-related pelvic girdle pain. 


\section{Introduction}

Research in the field of pregnancy-related pelvic girdle pain shows that during pregnancy $48-78 \%$ of all women complain about pain in the lumbar-pelvic region, feelings of instability and "catching of the leg" when walking [1-8]. Pain is often located in the sacrum, sacroiliac joints and the symphysis [9, 10]. After delivery most symptoms subside, but some women report persisting pain and a small group develop complaints not until after delivery [11, 12]. Often

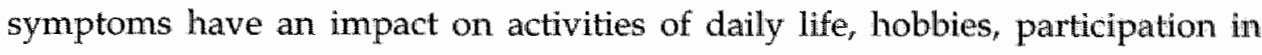
society, planning of next pregnancies and sometimes lead to a chronic disabling condition with considerable work absenteeism in the future [13].

Several international and national authors in the field of pregnancy-related pelvic girdle pain have developed a classification method to diagnose the syndrome. However, sound research about etiology and factors influencing the prognosis is limited. Existing classification strategies are in essence a matter of clinical pattern recognition rather then theory-driven. Signs and symptoms are the main elements of the data-collection tools. Moreover, a first inspection of the classification strategies showed various opinions about both the most important determining criterion as well as in the architecture of the diagnostic procedure [5, 7, 9, 13-17]. It seems that a clear idea of the concept "needed to be measured $^{\prime \prime}$ is lacking. The dimensions or contents of the syndrome are not explored methodically and therefore to a large extent unknown.

Content validity is the extent to which a particular method or measurement includes all dimensions of the construct being measured. During the process of validating, a content map is often created that covers the dimensions within the syndrome or disease is represented fairly. Evaluation of content validity tends to be subjective, but ideally includes systematic comparison of a new strategy (or measure) with existing theoretical definitions, expert opinions and interviews with individuals for whom the measure is targeted[18]. Present strategies are almost exclusively based on expert-opinions. In spite of these shortcomings, the strategies are used increasingly in research and clinical practice. An interesting question is whether different diagnostic strategies represent a similar selection of women having pregnancy-related pelvic girdle pain or not. For example, if a certain strategy is applied for diagnostic purposes in a particular patient group it is not yet clear whether the research results are valid in patient groups selected by another strategy. This uncertainty counts 
both for diagnostic as well as to some extent for treatment studies, since both relied heavily on sound classification.

The purpose of this paper is to investigate the agreement (similarity) on definitions of pregnancy-related pelvic girdle pain used by 4 commonly used diagnostic strategies. A definition of a strategy can be considered as a weighted composite of several variables to diagnose women with pregnancy-related pelvic girdle pain. Sources of (dis) agreement that are relevant to the establishment of the symptoms will be explored. Diagnostic moment of interest in this study is about three weeks after delivery. A number of studies show that most women recuperate within the first weeks after delivery, $[9,11,12]$ whereas women with persisting pain and limitations in activities, three weeks after delivery often become chronic pain patients.

\section{Methods}

\section{Design}

This diagnostic research is embedded in an ongoing cohort study ( $\mathrm{n}=7526)$ [19] and is approved by the medical ethics committee of the Maastricht University Hospital. After a woman signed informed consent, she entered the cohort study that is designed as a longitudinal, prospective study, which studies the prevalence, etiology, severity and prognosis of pregnancy-related pelvic girdle pain until one year after delivery. Midwives and gynecologists recruited the women during early pregnancy (10-14 weeks). A research-physiotherapist visited all women with persistent pain at home, about three weeks after delivery. This visit is called for on basis of a short seli-administered questionnaire and/or initiated by midwives. A positive answer on the question: "Is intervention by a physiotherapist necessary?" took a central position in these questionnaires. During the home visit, standardized history was taken and physical examination is performed. Finally, the women filled in a pain drawing $[20,21]$. The research-physiotherapist was unaware of the structure of the different classification strategies during this visit.

\section{History taking and physical examination}

History taking started with questions about main presenting symptoms and is based on a diagnostic triage $[22,23]$. Questions were asked about on-going pain, its location, intensity and modalities, variation of symptoms with physical activities, radiation and back pain versus leg pain, neurological signs, 
deformity, obstetric complications and other differential diagnoses. History taking continued with some questions specifically related to pelvic girdle pain and pregnancy such as hypermobility of joints and pelvis, pain history during present and earlier pregnancies, pain at the symphysis and pelvis, limitations in activities, recuperation to health after pregnancy, course of delivery and earlier episodes of common low back pain. The answers were presented in a dichotomous "yes or no"-format.

Standardized physical examination (Table 1) comprised tests of configuration (scolliosis), nerve root radiation, pain provocation, stability and hypermobility $[9,13,16,17,24,25]$. History taking and physical examination was the same in all women, the protocol covered all the necessarily items of the investigated strategies (Table 2). Every woman was only examined once.

\section{Table 1 Physical examination}

Pain provocation

The posterior pelvic pain prowocation test (PPPP tesit)

Patrick's "fabere" sigm homolateral (PFSH test)

Iliac gapping test ${ }^{\text {t7 }}$

Direct pressure over the symphyseal jount t"

Hiac separation testit? is performed with the hip and the knee flexed to an angle of $90^{\circ}$ on the side to be examined. A light manual pressure is applied on the flexed knee allong the longitudinal axis of the femur while the pelvis is stabilized by the other hand of the examiner resting on the contra lateral superior anterior illac spinae of the woman. The test is positive when the woman feels a familiar well-localized pain deep in the gluteal area on the provoked side.

is accomplished by asking the woman to place her heel on the opposite knee and to let the knee of the test log fall passively outwards. The test is positive if pain occurs in the homolateral lliac joint.

is cartied out by crossing the outstretched arms of the investigator and then placing her palms close to the superior anterior illac spinae inside the crista iliac on both sides. The test is positive if pain occurs in the sacro-iliac joints. is performed by palpating the entire front side of the pubic symhysis gently: The test is positive if pain persists for more than 5 seconds after removal of the hand of the investigetor.

is realized when the woman is lying on her side. The palm of the investiglator's hand is placed on the outside of the uppermost anterior superior iliac spine. The investigator presses with the other hand gently on the back of the first hand. The test is positive if pain occurs in the homo-lateral sacro-lliac joint. 
Pelvic stabitity

The Trendelenturg test

is completed while the woman stands with the back to the investigator. She is asked to stand on one leg and flex the other with hip and knee at 900 . The test is positive if the pelvis descends on the flexed side

The active straight leg raise test (ASLR test) ${ }^{23}$

(ASLR) is performed when lying in a supine position with straight legs and feet 20 centimeter apart. The woman should raise her legs, one after the other above the couch for 20 centimeter without bending the knee. The test is scored on a four-point scale ranging from 0 to 3 points. As score of 0 means no problem, a score of 1 means subjective difficulties in the performiance of the test: A. score of 2 means objective difficulties in performance and 3 means the test is not practicable. In this study the test result is translated to a dichotomy scale. A score of $\geq 2$ means a positive test result.

Hypermobility

General joint laxily at (questionnaire)

is assessed by means of the Beighton scoring system. $A$ score of $\geq 4$ points means generalized hypermobility

Exclusion criteria

Red flags ${ }^{\text {t2 }}$

During history taking and physical examination a discrimination is made between "red" and "yellow" flags. "Red flags" were excluded.

Red flags: nerve root pain and serious spinal, urinary, gynecologic or systematic pathology.

Nerve root pain: unilateral leg pain is worse than back pain, pain generally radiates to foot or toes, numbness of paresthesia in the same distribution, nerve irritation signs \{reduced straight leg raising (SLR test) which reproduces leg pain\} and motor, sensory or reflex changes \{limited to one nerve root\}.

Serious pathology: constant, progressive, nonmechanical pain, thoracic pain, previous history (carcinoma, systematic steroids, drug abuse, HIV, violent trauma $9 . \mathrm{g}$. fall from a height), systematically unwell, persisting severe restricling of lumbar flexion, struclural deformity, plain X-ray \{vertebral collapse or bone destruction?, cauda equina syndromeiwidespread neurological disorder, inflammatory disorders

Yellow flags: Psycho-social factors The pain varies with physical activity and fime. The patient is generally well

\section{Classification criteria}

Classification strategies of the four most widely quoted international authors [9, $13,16,26,27 \mid$ were summarized in Table 2. For both Albert and Ostgaard $[9,16]$ the basic premise was a distinction between low back pain and posterior pelvic pain (pain localized around the sacro-iliac joints) as two different syndromes. Ostgaard hypothesized that this condition is different from low back pain because it does not emerge from the low back area and should not be treated as 
low back pain. Mens [24, 26] on the other hand concentrated on decreased stability of the pelvic girdle, a hypothesis that originally was developed to explain the etiology of non-pregnancy related low back. Hansen offered no statements about this issue but focused on limitation in activities as a determining criterion. Albert [28] reported the positive prognostic importance of pain around the symphysis and classified women into separate sub-groups when the symptom was positive but Ostgaard regarded this as not relevant for classification. The separate strategies partly used also different diagnostic tests. Procedures developed by Albert and Ostgaard used the posterior pelvic pain provocation test (PPPP-test)[16]. The active straight leg-raising test (ASLR-test) was introduced in the field of pregnancy-related pelvic girdle pain by Mens [24]. Although in literature test-retest reliability of specific physical examination tests is examined to some extent and evaluated satisfactory Ipain provocation and ASLR $[9,29]\}$, no report is published on how a combination in any way of tests with standardized history taking influenced the reported reliability of a separate test nor any report that examined test-retest reliability of one of the described diagnostic strategies in its entirely.

\section{Statistical analyses}

Kappa is used to measure agreement. Disagreement in this validity study is interpreted as a difference in the definition of the strategies examined in the present study. If two diagnostic strategies disagreed then at least one of them must be incorrect. In the absence of a reference standard to diagnose pregnancy-related pelvic girdle pain, possible sources of disagreement will play an important role in the evaluation of the appropriateness of a diagnostic strategy in future research. Strategies developed by Hansen[13] and Mens [26] guided to a clearly positive or negative diagnosis. There were cut-off points chosen additional to the strategies of Ostgaard[27] and Albert[9]. Four classification groups as reported by Albert (pelvic girdle syndrome, symphysiolysis, one-sided sacroiliac syndrome and double-side sacroillac syndrome) were considered as having a positive diagnosis, however the miscellaneous group not. We regarded the posterior pelvic pain group according to Ostgaard as having a positive diagnosis, the other groups not. A blinded researcher not involved in the home visits, allocated the women by means of the gathered data four times into a positive or negative diagnosis. The allocation was done with aid of a predefined statistical syntax in SPSS. Every 


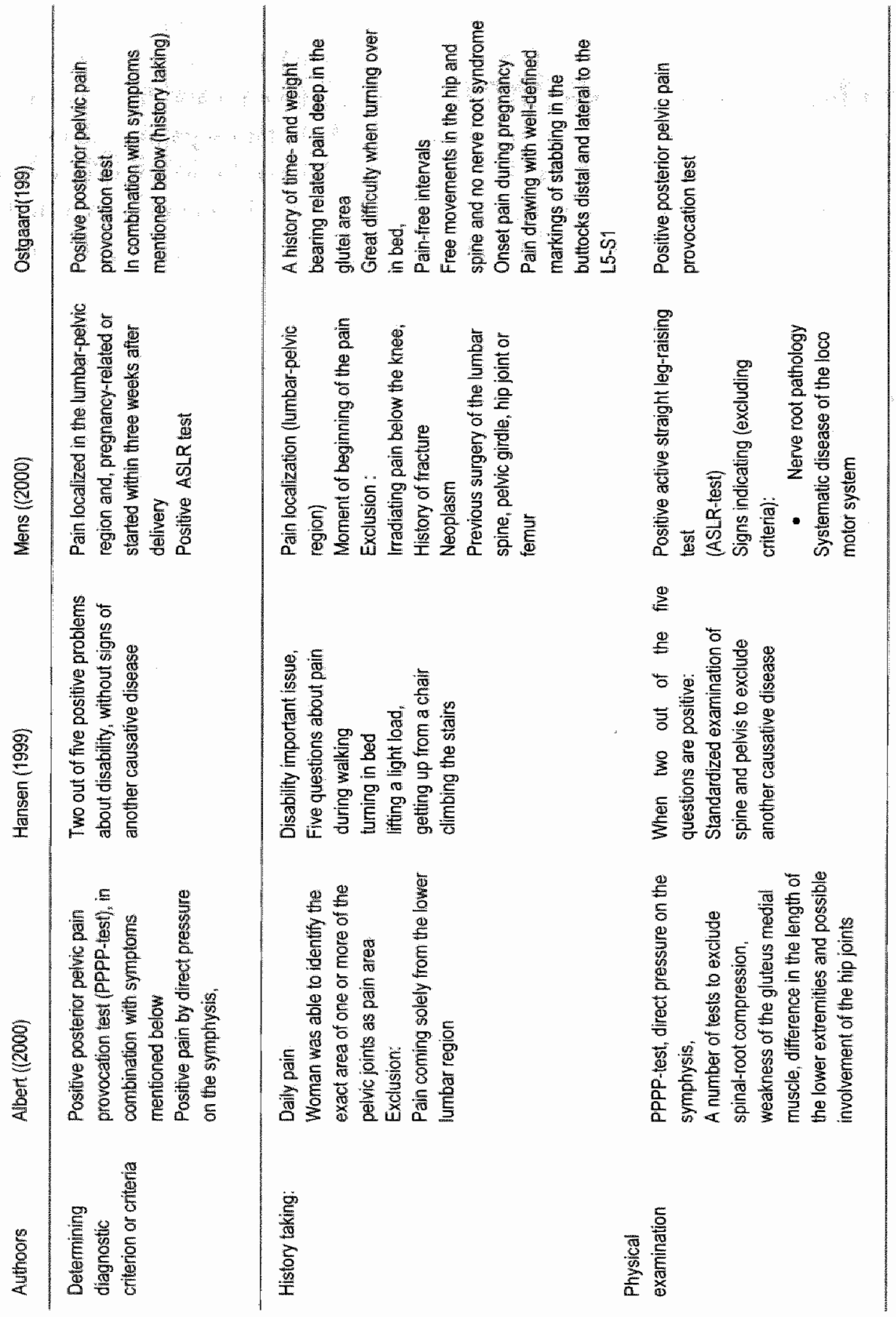


Table 2 Continued

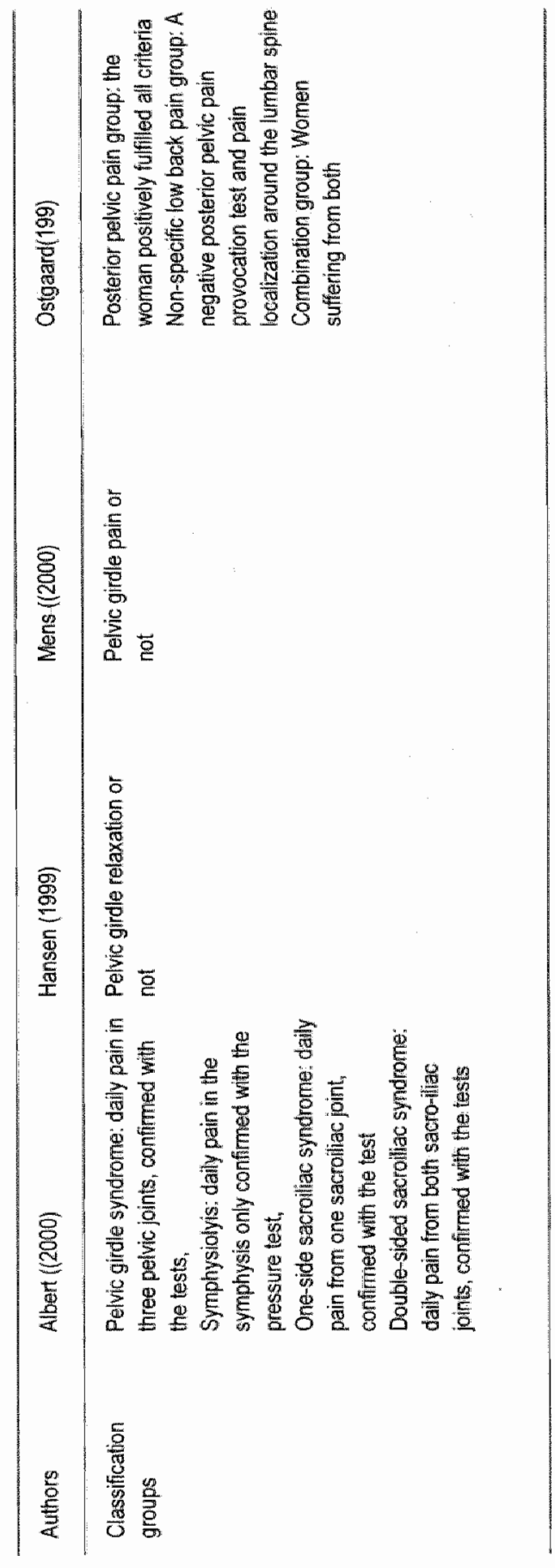


woman was classified four times using the same data but every time by means of a different strategy.

\section{Results}

\section{Participants}

The study was performed in June 2002. Between November 2000 and November 2002 a total of 7526 women enrolled in the cohort in the Southeast of the Netherlands. Until June 20022932 women gave birth. During pregnancy, $73 \%$ of all women in the cohort reported pain somewhere in the lumbar and/or pelvic region, leveling off to $35.9 \%$ three weeks after delivery. The prevalence rate of "intervention needed by a physiotherapist" just after delivery was $14.3 \%$ of the total cohort ( $\mathrm{n}=423$ in June 2002) that has given birth. However, within three weeks after delivery 334 women were excluded (June 2002); 280 women because of their quick recuperation to health and 54 women for various other reasons; not motivated $(n=41)$, currently living outside the research area $(n=4)$, neurological signs $(n=1)$, illness in the family $(n=2)$ rheumatism $(n=2)$ or did not sign informed consent for this part of the study $(n=4)$. Finally, a total of 89 women with persistent pain and limitations three weeks after delivery enrolled in this study out of the ongoing cohort study in June 2002.

The mean age was 31.5 year (SD 3.3); the mean age of the total cohort was 31.8 year (SD 3.7). Table 3 presented data obtained from history taking and clinical examination. A minority experienced pain not until after delivery (5.6\%) and some were not entirely recuperated $(9 \%)$ from a previous pregnancy. Pain occurred frequently in the symphysis, sacroiliac joints, sacrum and groins but also quite regular in the lumbar spine. Radiation in one or two upper legs was observed in more than half of the women. Only results of the posterior pelvic pain provocation test (PPPP-test) and direct pressure over the symphyseal joint were regularly positive.

The frequencies of the Trendelenburg and ASLR test more often led to a negative test result than a positive one. The Beighton score for hypermobility with a mean of 2.38 (SD 2.02) was significantly negative (Beighton positive $\geq 4$ ).

\section{Classification}

According to the classification criteria (Table 4) from Ostgaard, 37 women were diagnosed as having "posterior pelvic pain", 33 women with a combination of 
Table 3 History and clinical examination $(n=89)$

\begin{tabular}{|c|c|c|c|}
\hline $\begin{array}{l}\text { Primipara } \\
\text { Multi para }\end{array}$ & $\begin{array}{l}28.1 \%(25) \\
71.9 \%(64)\end{array}$ & : & \\
\hline Cument complaints & & & \\
\hline Started during pregnancy: & $85.4 \%(76)$ & & \\
\hline Started during a previous pregnancy & $9.0 \%(8)$ & & \\
\hline Started jusl after delivery: & $5.6 \%(5)$ & & \\
\hline Pain with radiation to ane ar two uppe & & & \\
\hline & $58.4 \%(52)$ & & \\
\hline Localization pain (pain drawing) & & & \\
\hline Lumbar spine: & & & \\
\hline Sacro-illac joint & $38.2 \%(34)$ & & \\
\hline Right: & & & \\
\hline Left: & $46.1 \%(41)$ & & \\
\hline Symphysis & $48.3 \%(43)$ & & \\
\hline Sacrum taill bone: & $68.5 \%(61)$ & & \\
\hline Groins: & $47.2 \%(42)$ & & \\
\hline Right: & 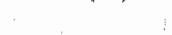 & & \\
\hline Left: & $32.6 \%(29)$ & & \\
\hline & $34.8 \%(31)$ & & \\
\hline Clinical examination & Negativie test & Positive test & Missing \\
\hline Posterior pain provocation test & & & \\
\hline Right: & & & \\
\hline Left: & $24.7 \%(22)$ & $\begin{array}{l}74.2 \%(60) \\
77.5 \%(69)\end{array}$ & $2.1 \%(7)$ \\
\hline Both & $20.2 \%(18)$ & $\begin{array}{l}17.3 \%(03) \\
61.1 \%(58)\end{array}$ & $2.2 \%(2)$ \\
\hline Direct pressure symphysis & $20.8 \%(23)$ & $\begin{array}{l}67.1 \%(68) \\
71.9 \%(64)\end{array}$ & $200 \%(2)$ \\
\hline Patricks "fabere sign homolateraal & & $\begin{array}{l}17.9 \%(64) \\
472 \%(42)\end{array}$ & $2.2 \%(2)$ \\
\hline Right: & $51.7 \%(46)$ & & $1.1 \%(1)$ \\
\hline Leff: & $47.2 \%(42)$ & $51.7 \%(46)$ & $1.1 \%(1)$ \\
\hline lliac gapping test: & $46.1 \%(41)$ & $517 \%(46)$ & $2.2 \%(2)$ \\
\hline lliac separation test & $68.5 \%(6)$ & & $9,0 \%(8)$ \\
\hline Right: & $629 \%(56)$ & $22.07 \%(25)$ & $9,0 \%(0)$ \\
\hline Left: & & $28.1 \%(25)$ & $9.0 \%(0)$ \\
\hline Trendelenburg & $88.8 \%(79)$ & $6.7 \%(6)$ & $4.5 \%(4)$ \\
\hline Right: & $85.4 \%(76\rangle$ & $9.0 \%(8)$ & $5.6 \%(5)$ \\
\hline Left: & & & \\
\hline ASLR & (no trouble and & (obj. trouble or & \\
\hline ABLR & subjective & performance & \\
\hline & troublole & not possible & \\
\hline & $69.7 \%(62)$ & $30.3 \%(27)$ & \\
\hline $\begin{array}{ll}\text { Right: } \\
\text { Jefi. }\end{array}$ & $60.7 \%(54)$ & $39.3 \%(35)$ & \\
\hline Let. & & & \\
\hline SLR & & $0 \%$ & \\
\hline Right: & & $0 \%$ & \\
\hline
\end{tabular}

vanables occurred less than $10 \%$ omitted

posterior pelvic pain and low back pain and one woman with low back pain. There were also $18(10+8)$ women with a positive posterior pelvic pain 
provocation test but not confirmed with the other criteria or a negative posterior pelvic pain provocation test but with the other criteria positive. Albert classified $63(20+9+17+17)$ women to the 4 subgroups of women with pregnancy-related low back and/or posterior pelvic pain. Nine of them were allocated to the symphysiolyis group; the posterior pelvic pain provocation test was negative in those women. Hansen classified 71 women into the pelvic girdle relaxation group. Mens was the only author who did not make any difference between low back pain and posterior pelvic pain. After meeting the formulated exclusion criteria, diagnosis was confirmed with a positive ASLR in only 22 of the 89 women.

Kappa was used to measure the agreement between the classification strategies (Table 4). The only kappa with a moderate agreement (0.462) was between Albert and Hansen. Between Ostgaard and the other three authors, there was even a very slight negative agreement about the diagnosis.

\section{Discussion}

The goal of this paper was a very basic validity question (agreement about the definition of pregnancy-related pelvic girdle pain). Differences turned out to be outweighing the similarities. The same dataset generated different diagnoses for the very reason that the four authors used only for a part the same items and also in a different order. The disagreement was influenced by a clash of opinions about the determining criterion/criteria as well as the procedure and final classification.

Limited knowledge about both etiology and dimensions in which the syndrome manifest oneself was important for the differences in the choice of a determining criterion. The authors relayed for the most part on their own clinical pattern recognition and specific range of the clinical spectrum of patients referred to them. Dimensions such as pain and disability were unsatisfactorily explored. Moreover ${ }_{y}$ use of available, validated and standardized questionnaires in these domains was not common practice.

The procedures also showed several methodological flaws. In the procedure of Hansen, only part of the women who were seen was also submitted to further testing (serial testing). A positive answer on a question about disability prompted the researcher to continue pursuing the diagnosis "pelvic girdle relaxation". On the other hand, a negative answer resulted in abandon further tests. In both case of Ostgaard and Albert, the result of a test (PPPP-test) was 
Table 4 Classification and agreement $(n=89)$

\begin{tabular}{|c|c|c|c|c|c|c|c|c|}
\hline Authors & $\begin{array}{l}\text { Classi } \\
\text { Freq. }\end{array}$ & $\%$ & $\begin{array}{l}\text { Final d } \\
\text { Positiv } \\
\text { Freq. }\end{array}$ & $\begin{array}{l}\% \\
\%\end{array}$ & $\begin{array}{l}N \\
F_{r}\end{array}$ & the & $\begin{array}{l}\text { Kappa } \\
\text { \& author }\end{array}$ & $95 \% \mathrm{Cl}$ \\
\hline $\begin{array}{l}\text { Albert (2000) } \\
\text { Pelvic girdle syndrome } \\
\text { Symphysiolysis } \\
\text { One-sided sacroiliac } \\
\text { syndrome } \\
\text { Double-sided sacroiliac } \\
\text { syndrome } \\
\text { Miscellaneous group }\end{array}$ & $\begin{array}{l}20 \\
9 \\
17 \\
17 \\
26\end{array}$ & $\begin{array}{l}22.5 \\
10.1 \\
19.1 \\
19.1 \\
29.2\end{array}$ & 63 & 70.8 & 26 & 29.2 & $\begin{array}{l}\text { \& Hansen } \\
\text { \& Mens } \\
\text { Osigarar }\end{array}$ & $\begin{array}{rr}.462 & (239 ; 685) \\
.127 & (.037 ; 319) \\
-.092 & (-.267: 083)\end{array}$ \\
\hline $\begin{array}{l}\text { Hansen (1999) } \\
\text { Pelvic girdle relaxation } \\
\text { No pelvic girdle } \\
\text { relaxation }\end{array}$ & $\begin{array}{l}71 \\
18\end{array}$ & $\begin{array}{l}79.8 \\
20.2\end{array}$ & 71 & 79.8 & 18 & 20.2 & $\begin{array}{l}\text { \& Abert } \\
\text { \& Mens } \\
\text { \& Ostgaard }\end{array}$ & $\begin{array}{lr}.462 & (239 ; .685) \\
.05 & (-12) \\
.021 & (-.05: 09)\end{array}$ \\
\hline $\begin{array}{l}\text { Mens (2000) } \\
\text { Pregnancy-related } \\
\text { low back pain } \\
\text { Miscellaneous group }\end{array}$ & $\begin{array}{l}22 \\
67\end{array}$ & $\begin{array}{l}24.7 \\
75.3 \\
\end{array}$ & 22 & 24.7 & 67 & 75.3 & $\begin{array}{l}\text { \& Albert } \\
\text { \& Hansen } \\
\text { Ostgaard }\end{array}$ & $\begin{array}{lr}.127 & (.037 .319) \\
.05 & (-.1: 2) \\
-.105 & (-.268 ; 058)\end{array}$ \\
\hline $\begin{array}{l}\text { Ostgaard (1994) } \\
\text { Posterior pelvic pain } \\
\text { group } \\
\text { Low back pain group } \\
\text { Combination group } \\
\text { Not lo classify: } \\
\text { Positive pppp test but } \\
\text { not confirmed with } \\
\text { other criteria } \\
\text { All criteria fulfilled but } \\
\text { negative pppp test }\end{array}$ & $\begin{array}{l}37 \\
1 \\
33\end{array}$ & $\begin{array}{l}41.6 \\
1.1 \\
37.1\end{array}$ & 37 & 41.6 & 52 & 58.4 & $\begin{array}{l}\text { 8 Albert } \\
\text { \& Hansen } \\
\text { \& Mens }\end{array}$ & $\begin{array}{c}-.092 \cdot(-.267: 083) \\
-.021 \quad(-.05 ; 09) \\
-.105(-.268 ; 058)\end{array}$ \\
\hline
\end{tabular}

interpreted taking other clinical information (pain location) into account. In this case, test results and clinical information were used in parallel.

Whenever applying parallel of serial testing, not only information about the validity of a single test but also the overall validity of multiple testing (parallel or serial) should be available. However, research about this subject is still in the initial period and therefore essential information about the overall validity is not yet available [30]. Using these approaches the authors encountered great difficulties in their designs and interpretation of the results. They obviously did not take action to limit these kinds of introduced biases in their protocols.

The limited knowledge and consensus about both etiology and prognosis provided the differences in the designs of the classification systems. The difference in opinion about a likely positive prognosis of localized pain in the 
symphysis had a negative effect on the agreement between Albert and Ostgaard.

Mens made in contrast with Albert and Ostgaard no distinction between low back pain and posterior pelvic pain. This opinion and results of the ASLR-test clearly influenced the agreement with the other authors.

The outcomes of this study were anticipated from random error by using the same dataset every time. Nevertheless, a limitation was that because of a lack of information about test retest- (within) reliability of the entire strategies, it was possible that a test retest-error of a separate diagnostic strategy biased the results of the present study to some extent. However, it was not likely that this test-retest error was large enough to account for the large disagreement seen in this study.

\section{Conclusion}

The investigated diagnostic strategies represented different selections of women having pregnancy-related pelvic girdle pain. The large amount of problems concerning content validity, biases in the work-up evaluation of the classification strategies, a non-systematic application of validated and standardized questionnaires and the limited knowledge about etiology contributed to disagreement in the final diagnosis of the investigated authors.

This study clearly demonstrated that using the different diagnostic procedures yield different outcomes, i.e. different diagnosis and classifications. As a consequence research results about both diagnostic and treatment concerning patients selected by one of the strategies may not be generalized to all populations of women with pregnancy-related pelvic girdle pain. Future studies are needed to investigate etiology and explore new ways to describe all relevant dimensions of the syndrome.

\section{Acknowledgements}

The funding for this study was provided by the Health Care Insurance Board (College voor zorgverzekeringen (VZ) in the Netherlands as a part of a research project titled "Peripartum pelvic pain during pregnancy and after delivery". We would like to express our gratitude to all the participating 
women, Gonnie Klabbers as research-physiotherapist and Conny de Zwart for the logistic assistance.

\section{References}

1. A Fast, D Shapiro, EJ Ducommun, LW Friedmann, T Bouklas, Y Floman: Lowback pain in pregnancy. Spine 1987, 12:368-71.

2. A Fast: Low back pain during pregnancy. Phys Med Rehabil 1999, 13.509-519.

3. MJ Mantle, RM Greenwood, HL Currey: Backache in pregnancy. Rheumatol Rehabil 1977, 16:95-101.

4. M MacEvilly, D Buggy: Back pain and pregnancy: a review. Pain 1996, 64:40514.

5. JM Mens, A Vleeming, R Stoeckart, HJ Stam, CJ Snijders: Understanding peripartum pelvic pain. Implications of a patient survey. Spine 1996, 21:1363-9.

6. HC Ostgaard, GB Andersson, M Wennergren: The impact of low back and pelvic pain in pregnancy on the pregnancy outcome. Acta Obstet Gynecol Scand 1991, 70:21-4.

7. HC Ostgaard, G Zetherstrom, E Roos Hansson, B Svanberg: Reduction of back and posterior pelvic pain in pregnancy. Spine 1994, 19:894-900.

8. B Sturesson, G Uden, A Uden: Pain pattern in pregnancy and "catching" of the leg in pregnant women with posterior pelvic pain. Spine 1997, 22:1880-3.

9. H Albert, M Godskesen, I Westergaard: Evaluation of clinical tests used in classification procedwres in pregnancy-related pelvic joint pain. Eur Spine J 2000, 9:161-6.

10. HC Ostgaard, E Roos Hansson, G Zetherstrom: Regression of back and posterior pelvic pain after pregnancy. Spine 1996, 21:2777-80.

11. HC Ostgaard, GB Andersson: Postpartum low-back pain. Spine 1992, 17:53-5.

12. F Turgut, M Turgut, $M$ Cetinsahin: A prospective study of persistent back pain after pregnancy. Eur J Obstet Gynecol Reprod Biol 1998, 80:45-8.

13. A Hansen, D Jensen, M Wormslev, H Minck, S Johansen, E Jarsen, C WilkenJensen, $M$ Davidsen, $T$ Hansen: Symptom-giving pelvic girdle relaxation in pregnancy II:Symptoms and clinical signs. Acta Obstet Gynecol Scand 1999. 78:111-115.

14. P Kristiansson, $K$ Svardsudd, B von Schoultz: Back pain during pregnancy: a prospective study. Spine 1996, 21:702-9.

15. JM Mens: Bekkenpijn door zwangerschap; een nieuwe aandoening? Ned Tijdschr Geneeskd 1995, 139:1964-6.

16. HC Ostgaard, G Zetherstrơm, E Roos Hansson: The posterior pelvic pain provocation test in pregnant women. Eur Spine J 1994, 3:258-60. 

examination of pelvic insufficiency during pregnancy. An evaluation of the interobserver wariation, the relation between clinical signs and pain and the relation between clinical signs and physical disability. Scand J Rheumatol 1994, 23:96-102.

18. D Jackowski, G Guyatt: A guide to health measurement. Clin Orthop 2003:80-9.

19. JM Bastiaanssen, RA de Bie, CHG Bastiaenen, A Heuts, MEAL Kroese, GGM Essed, PA wan den Brandt. Etiology and prognosis of pregnancy-related pelvic girdle pain design of a longitudinal study. BMC Public Health 2005, 5:1

URL.http/ / www biomedcentral.com/1471-2458/5/1

20. AO Ransford, $D$ Caims, $M$ Vert: The pain drawing as an aid to the psychologic evaluation of patients with low-back pain. Spine 1976, 1:127-134.

21. C Ohlund, C Eek, S Palmbald, B Areskoug, A Nachemson: Quantified pain drawing in subacute low back pain. Validation in a nonselected outpatient industrial sample. Spine 1996, 21:1021-30.

22. RA Deyo, I Rainville, DL Kent: What can the history and physical examination tell us about low back pain? JAMA 1992, 268:760-5.

23. G Waddell: Diagnostic triage. In: The Back Pain Revolution, vol. Chapter 2. pp. 9-26. Edinburgh, London, New York, Philadelphia, Sydney, Toronto: Churchill Livingstone; 1998: 9-26.

24. JMA Mens, H] Stam, A Vleeming, CJ Snijders: Active straight leg raising; a clinical approach to the load transfer function of the pelvic girdle. In: Integrating functions of the lumbar spine and sacroiliac joint Edited by A Vleeming, V Mooney, CI Snijders, T Dorman. pp. 207-220. Rotterdam: European Conference Organizers; 1995: 207-220.

25. M Calguneri, HA Bird, V Wright: Changes in joint laxity occurring during pregnancy. Ann Rheum Dis 1982, 41:126-8.

26. IMA Mens: Pregnancy-related low back pain; 2000.

27. HC Ostgaard, GB Andersson, AB Schultz, JA Miller: Influence of some biomechanical factors on low-back pain in pregnancy. Spine 1993, 18:61-5.

28. H Albert, $M$ Godskesen, J Westergaard: Prognosis in four syndromes of pregnancy-related pelvic pain. Acta Obstet Gynecol Scand 2001, 80:505-10.

29. JM Menss, A Vleeming, CJ Snijders, BW Koes, HJ Stam: Reliability and validity of the active straight leg raise test in posterior pelvic pain since pregnancy. Spine 2001, 26:1167-71.

30. P Kristiansson, K Svardsudd: Discriminatory power of tests applied in back pain during pregnancy. Spine 1996, 21:2337-43. 


\section{CHAPTER THREE}

Cluster analyses, a way to describe clinical findings of pregnancy-related pelvic girdle pain

Caroline HG Bastiaenem, Rob A de Bie, Jan SAG Schouten, Jonneke M Bastiaanssen. Aldegonda BA Klabbers, Gerard GM Essed, Plet A van den Brandt

Submitted 


\section{Abstract}

Introduction:

The purpose of the study was to generate a new way of describing clinical findings of women having persistent pregnancy-related pelvic girdle pain through cluster analyses within the biopsychosocial approach.

\section{Methods:}

This study is embedded in a colort study ( $n=7526)$, which studies prevalence, etiology and prognosis of pregnancy-related pelvic girdle pain. The first 100 women, who had persistent pregnancy-related pelvic girdle pain and limitations in activities about three weeks after delivery, participated in this study. A research-physiotherapist visited all included women at home, three weeks after delivery. During this visit a standardized history was taken and physical examination was performed. Additionally, a random sample of one hundred women from the cohort without pregnancy-related pelvic girdle pain received the sane examination about three weeks after delizery.

Results:

A first group of cluster analyses based on similarity in the outcomes of current diagnostic procedures could not localize clusters that significantly and clinically differed from each other. A second group of cluster analyses was perfornted on the responses of a number of the most important risk factors in the transition from acute to chronic pain. A solution with three clusters was the maximal subdivided classification. Biopsychosocial variables were powerful in delecting subgroups. However, after meeting exclusion criteria for specific pathology, currently used bionedical variables did not contribute to an adequate understanding of pregnancy-related pelvic girdle pain after delivery. In daily practice, the focus on a history taking in which biopsychosocial uariables takes a central position is of great importance. 


\section{Introduction}

Pregnancy-related pelvic girdle pain (PPGP) is attracting a lot of attention being an important and frustrating health problem during pregnancy and after delivery. During pregnancy $48-78 \%$ of all women complain about pain in the lumbar-pelvic region, feelings of instability and "catching of the $\operatorname{leg}^{\text {" when }}$ walking [1-8]. Pain is often located in the sacrum, sacroiliac joints and the symphysis $[9,10]$. Most symptoms subside in the first weeks after delivery, but some women report persisting pain $(35 \%)$ and disability [11, 12]. Often symptoms have an impact on activities of daily life, hobbies, and participation in society and sometimes lead to a chronic disabling condition with considerable work absenteeism in the future [13].

There is little evidence to indicate that PPGP is an entity that can be clearly diagnosed and described right now. Consensus must therefore be reached about the key assumptions of the syndrome [14] but various authors in the field of PPGP disagree about this subject. Some issues where disagreement persists are the relative value of pain at the symphysis or the importance of questions about disability and the question whether pelvic girdle pain is a syndrome separate from low back pain outside pregnancy. Until now, the focus of different diagnostic processes in this field has been directed towards a biomedical approach. The outcomes of pain provocation and stability tests and the exact localization of pain take a central position in present strategies. Outcomes like limitations in activities, restrictions in participation and personal factors are only used in a very limited way alongside the outcomes of pain provocation and stability tests. Nevertheless, important questions in the communication with patients and clinicians are how to describe a set of clinical findings and how to treat the patient. Are there subgroups of women with PPGP identifiable on the basis of their responses to history taking, relevant characteristics and physical examination and can we then get more insight in processes needing therapeutic interventions? Could the outcomes of current biomedical variables deliver sufficient information to tailor an intervention or should our attention be more focused on other factors alongside the biomedical?

An important aspect of interest in the diagnostic process is a possible timespecific moment in the course of PPGP, the moment of transition from an acute to a chronic problem. A number of studies showed that most women recover in 
the first three weeks after delivery [15] [16], whereas women with persisting complaints 4-6 weeks after delivery often become chronic pain patients. In the transition from acute to chronic musculoskeletal pain, the importance of psychological factors besides pain and functional disability is evident. [17] [18] There is a growing belief that the biomedical approach by medical practitioners and physiotherapists provides insufficient effect and that biopsychosocial prognostic factors appear even to be more potent than biomedical factors [18] [19]. Although the group of musculoskeletal disorders holds many different biomedical labels, the process of developing chronic disability has shown surprising similarities with regard to prognostic factors [20]. Some important prognostic factors are pain-related fear, pain-catastrophizing, depression, pain and limitations in activities [19]. Both clinical and population-based studies suggest that a high level of pain catastrophizing or a high level of pain-related fear increases the risk of future low back pain and disability [21].

The major purpose of the present study is to identify homogeneous subgroups of women having persistent PPGP by cluster analyses within the biopsychosocial approach. Identifying those subgroups could be the first step in the development of tailored interventions. Before identifying subgroups of women with PPGP it is necessary to make a comparison of women with and without PPGP about three weeks after delivery on the issues physical examination, pain, disability, participation and personal factors.

The goals of the present study are fourfold:

1. To determine whether women without PPGP differ from women with PPGP on physical examination, pain, disability, participation and personal factors,

2. To determine whether homogeneous subgroups through cluster analyses can be identified among women with PPGP based on currently used diagnostic procedures,

3. To determine whether homogeneous subgroups through cluster analyses can be identified among women with PPGP based on prognostic factors,

4. To determine whether identified subgroups differ in terms of history, physical examination, pain, disability, participation and personal factors. 


\section{Methods}

\section{Design}

This diagnostic research is embedded in an intervention $(n=126)[22]$ and cohort study ( $\mathrm{n}=7526)$ [23] and is approved by the medical ethics committee of the Maastricht University Hospital. After a woman signed informed consent, she entered the cohort study that is designed as a longitudinal, prospective study and investigates the prevalence, etiology, severity and prognosis of pregnancy. related pelvic girdle pain until one-year delivery. Midwives and gynecologists recruited the women during early pregnancy (10-14 weeks). A researchphysiotherapist visited all women with persistent PPGP at home about three weeks after delivery. This visit is called for on the basis of a short selfadministered questionnaire and/or initiated by midwives. A positively answered question by the woman or midwife: "Is an intervention by a physiotherapist necessary?" took a central position in these questionnaires. During this home visit standardized history is taken and physical examination is performed. The physical examination (Table 1) $[18,24]$ included tests of configuration (scoliosis), nerve root radiation, pain provocation $[9,25,26]$, stability [25, 27] and hypermobility [28]. After physical examination the research-physiotherapist filled out a questionnaire about overt pain behavior (Pain Behavior Scale) [29] [30]. The first 100 women out of the cohort with persistent PPGP shortly after delivery were included in this study and the intervention study. Additionally, a random sample of one hundred women from the cohort without complaints received the same examination as women with complaints at about three weeks after delivery.

\section{Measurements}

Self-administered questionnaires were used to ask questions about pain [31] [32], disability [33-35], pain-related fear [36, 37], pain catastrophizing [38], positive and negative affectivity [39], depression [40-42], quality of life [43, 44] and participation $[45,46]$. The questionnaires contained clear instructions to complete them with no help or support from others.

Low back-related disability is assessed with the Roland Disability Questionnaire (RDQ) [33]. In this study we supplement the plurase "because of my back" with "and/or pelvic girdle pain". 
Pain was measured with the two Visual Analogue Rating Scales (VAS) scales of the McGill Pain Questionnaire (MPQ-DLW) [47] [31] to record the intensity of pain the last week and day.

The Pain Catastrophizing Scale (PCS) [38] is developed to asses catastrophizing in clinical and non-clinical populations. Recent research showed that catastrophizing might be an important factor that affects the perception of and response to persistent pain.

The Tampa Scale for Kinesiophobia (TSK) [48] [37, 49] is a developed to assess fear of (re) injury due to movement. The both subscales "activity avoidance" and "harm" are also used [49,50].

Positive and megative affectivity [39] was originally used as subscales from the Multidimensional Personality Questionnaire. High PEM (positive affectivity) scorers describe themselves as happy and enthusiastic, having a lot of energy and leading an interesting live. High NEM (negative affectivity) scorers describe themselves as nervous, upsetting, irritable, highly sensitive and emotionally labile.

\section{Table 1 Physical examination}

Pain prowocation

The posterior pelvic pain proviciation test (PPPP test)"

Patrick"s "fabere" sign homolateral (PFSH lest)

llac gapping testio

Direct pressure over the symphyseal joint 10,12

liac separation teston is performed with the thip and the knee flexed to an angle of $90^{\circ}$ on the side to be examined. A light mamual pressure is applied on the flexed knee along the longitudinal axis of the femur while the pelvis is stabilized by the other hand of the examiner resting on the contra lateral superior anterior iliac spinae of the woman. The test is positive when the woman feels a farniliar well-tocalized pain deep in the gluteal area on the provoked side.

is accomplished by asking the woman to place her theel on the opposite knee and to let the knee of the lest leg fall passively outwards. The test is positive if pain occurs in the homolateral liac joint.

is carried out by crossing the outstretched arms of the investigator and then plaking her palms close to the superior anterior lliac spinae inside the crista liac on both sides. The lest is positive if pain occurs in the sacro-liac joints.

is periormed by palpaling the entire front side of the pubic symhysis genty. The test is positive if pain persists for more than 5 seconds after remowal of the hand of the investigator.

is realized when the wamlan is lying on her side. The palm of the inwestigator's hand is placed on the outside of the uppermost anterior superior iliac spine. The inwestigator presses with the other hand gently on the back of the first hand. The test is positive if pain occurs in the homo-lateral sacro-iliac joint. 
Pelvic stability

The Trendelenburg lesting

is completed while the woman stands with the back to the investigator. She is asked to stand on one leg and flex the other with hip and knee at 90\%. The test is posilive if the pelvis descends on the flexed side

The active straight leg raise test (ASLRtest)
(ASLR) is perfiomed when lying in a supine position with straight legs and feet 20 centimeter apart The woman should raise her legs $s_{\mathrm{s}}$ one after the other above the couch for 20 centimeter without bending the knee. The test is scored on a four-point scale ranging from 0 to 3 points. A score of 0 means no problem, a score of 1 means subjective difficulties in the pertormance of the lest. A score of 2 means objective difficuttes in perfonmance and 3 means the fest is not practicable. In this study the tost rosult is translated to a dictiotomy scale. A score of $\geq 2$ means a positive test result.

Hypermobility

is assessed by means of the Beighton scoring sysitem. A score of $\geq 4$ points

General joint laxity ${ }^{14}$ (questionnaire) means generalized hypermobility

Exclusion criteria

Red Hagsidi

During history laking and physical examination a discrimination is made between "red" and "yellow" nags. "Red flachs" were exctuded.

Red flags: nerve root pain and serious spinal, urinary, gynecologic or systematio pathology.

Nerwe root pain: unilateral leg pain is worse than back pain, pain generally radiates to foot or toes, numbness of paresthesia in the same distribution. nerve irritation signs (reduced straight leg raising (SLR tesl) which reproduces leg pain) and motor, sensory or reflex changes (linited to one nerve root?. Serrous pathology: constant, progressive, nonmechanical pain, thoracic pain, previous history fcarcinoma, systematio steroids, drug abuse, HW, violent trauma e.g. fall from a height\}, systematically unwall, persisting severes restricting of lumbar flexion, stuctural deformity, plain X-ray fuetebral collapse or bone destruction, cauda equina syndromelwidespread neturological disorder, inflammatory disonders

Vellow flags: Psycho-social tactors The pain varies with physical acliwity and time. The patient is generally well

The Beck Depression Inventory (BDI) [42] [41] is measuring supposed manifestations of depression. It has been argued that the somatic content of the BDI may lead to false-positives among patients with physical problems. Therefore items associated with weight loss, sleeping disturbance and work inhibition [51] were excluded in this study. 
The Impact on Participation and Autonomy (IPA) [45] [46] focuses on autonomy and participation of people with chronic disorders. In this study were the three subscales concerned family role and autonomy in-and outdoors used. For each subscale the participation score is calculated by summing the item scores.

The Pain Behavior Scale (PBS) is a questionnaire that the physiotherapist fi]ls out after physical examination. $[29,30]$ The PBS is an observation scale tapping 8 pain behaviors. These are verbal complaints, vocal complaints, facial grimaces, standing posture, mobility, body language, use of visible supportive equipment and stationary movement.

Expectancy of therapy result [52] is measured by means of a $100 \mathrm{~mm}$ visual analog scale (VAS). The woman is asked to what extent she believes that a treatment is beneficial to her. Quality of life is evaluated by the short-form 36 (SF-36) [43]. On behalf of this study, there were four dimensions selected: physical functioning, role limitation because of physical health, bodily pain and general health.

\section{Data analyses}

Data analyses involved the following steps:

1. A comparison of women with and without PPGP by means of one-way ANOVA and Chi-square tests about three weeks after delivery,

2. Hierarchical and k-means cluster analyses based on the responses on currently used diagnostic procedures to identify subgroups of women with PPGP,

3. Hierarchical and $\mathrm{k}$-means cluster analyses based on prognostic factors to identify subgroups of women with PPGP,

4. Discriminant function analysis to examine the fit of the data to the structure provided by cluster analyses by the "leaving one out method".

5. A comparison of the identified subgroups of women with complaints by means of Chi-square tests, one-way ANOVA and post hoc tests to determine inter-subgroup differences.

Cluster analysis [53] is an exploring technique aimed to uncover groups of observations from initially unclassified data. By means of a hierarchical stepwise cluster analysis, those cases that showed the lowest squared Euclidean distances were combined to one cluster. Once a cluster is formed, it cannot be split; it can only be combined with other clusters. The optimum number of 
groups has to be a compromise between available recommendations and clinical relevance. To achieve a standardized contribution of the variables for the cluster analyses, the scores of each variable were converted into $\mathrm{z}$-scores.

A $\mathrm{k}$-means clustering is a method that produces a partition of the data into a previously settled number of groups. From an initial partition, women are moved into other groups if they are "closer" to its mean vector than that of their current group. The technique seeks to minimize the variability within the clusters and maximize the variability between them. In this study we used the optimal number of groups derived from hierarchical clustering. The derived clusters can then be interpreted to determine whether they are in agreement with the theoretical model.

A multivariate discriminant function analysis works with data that is already classified into groups to derive rules for classifying new individuals on the basis of their observed variable values. In this study is chosen for the "leaving one out method," in which the discriminant function is first derived from only $\mathrm{n}-1$ sample members, and then used to classify the observation left out. The procedure is repeated $\mathbf{n}$ times, each time omitting a different observation. In this study, we used the classification derived from the k-means clustering method to cross-validate the model. For post-hoc analyses, ANOVA, $X^{2}$, Student's $t$ tests were used. All tests were two-tailed and we used the Bonferroni correction to adjust for multiple comparison.

\section{Results}

\section{Participants}

The first 100 included women who enrolled in the intervention study participated in this study. Between November 2000 and September 20026565 healthy pregnant women enrolled in the cohort in the Southeast of the Netherlands. Until September 2002, 4491 women gave birth. During pregnancy, $73 \%$ of all women in the cohort reported pain in the lumbar/pelvic girdle region leveling off to $35.9 \%$ three weeks after delivery. The prevalence rate of "is an intervention necessary by a physioherapist" three weeks postpartum was $4.8 \%$ of the total cohort that has given birth. We excluded a total of 134 women for the following reasons; 102 women gave no informed consent for this part of the study. Other reasons were illness in the family $(n=2)$, rheumatism $(n=3)$, neurological signs $(n=1)$ and currently living outside the research area $(n=26)$. 
Table 2 Outcomes of physical examination of women with and without PPGP

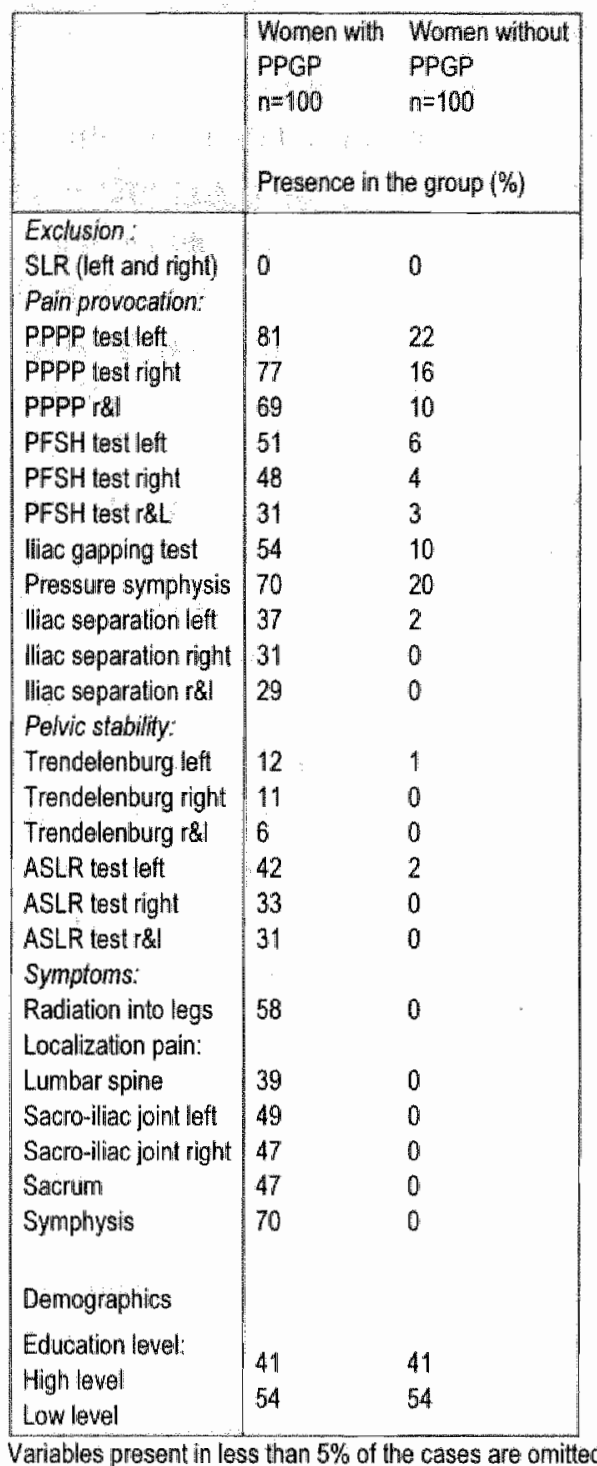

A random sample of 100 women without PPGP from the cohort was recruited during the same period in this study. The data obtained from history taking, physical examination and questionnaires are presented in tables 2 and 3. Only 81 of the examined women without PPGP finally completed the selfadministered questionnaires. 
Women without PPGP scored considerably less or negative on pain provocation and stability tests and there were no positive symptoms noticed (table 2). At least one pain provocation was in more than $50 \%$ of women with PPGP positive but also in $22 \%$ of women without PPGP. A test for pelvic stability was positive in $42 \%$ of women with PPGP but also in $2 \%$ of women without PPGP.

Table 3 Questionnaires women with and without PPGP

\begin{tabular}{|c|c|c|c|c|c|}
\hline \multirow[b]{2}{*}{ Questionnaires } & \multicolumn{2}{|c|}{$\begin{array}{l}\text { Women with PPGP } \\
n=100\end{array}$} & \multicolumn{2}{|c|}{$\begin{array}{l}\text { Women without PPGP } \\
n=81\end{array}$} & \multirow{2}{*}{$\begin{array}{c}\text { ANOVA } \\
\text { (2-lailed) } \\
\text { p-yalue }\end{array}$} \\
\hline & Mean & $(S D)$ & Mean & (SD) & \\
\hline \multicolumn{6}{|l|}{ MPQ scalles: } \\
\hline VAS pain today $(0-100)$ & 53.8 & $(18.2)$ & 1.8 & $(8.6)$ & 0.00 \\
\hline VAS pain lasl week (0-100) & 58.1 & $(18.0)$ & 2.7 & $(10.4)$ & 0.00 \\
\hline $\mathrm{RDQ}(0-24)$ & 13.7 & $(4.3)$ & 0.9 & $(3.1)$ & 0.00 \\
\hline $\operatorname{PCS}(0-52)$ & 12.0 & $(9.2)$ & 6.8 & 6.81 & 0.00 \\
\hline $\operatorname{PEM}(0-11)$ & 8.2 & $(25)$ & 8.6 & $(2.3)$ & 0.25 \\
\hline $\operatorname{NEM}(0-14)$ & 2.8 & (2.8) & 2.7 & 260 & 0.87 \\
\hline TSK $(17-68)$ & 34.6 & $(5.7)$ & 29.0 & (5.3) & 0.00 \\
\hline $\mathrm{BD}=(0.54)$ & 5.1 & $(4.4)$ & 3.0 & $(3.2)$ & 0.00 \\
\hline \multicolumn{6}{|l|}{ IPA scales: } \\
\hline Family role $(0-28)$ & 14.8 & $(5.8)$ & 3.9 & (4.3) & 0.00 \\
\hline Autonomy in self-care $(0-28)$ & 9.4 & $(5.5)$ & 2.0 & $(3.1)$ & 0,00 \\
\hline Mobility and leisure $(0-20)$ & 10.5 & $(4.3)$ & 3.4 & $(2.9)$ & 0.00 \\
\hline \multicolumn{6}{|l|}{ SF-36 subscalles: } \\
\hline Physical functioning $(0-100)$ & 39.2 & $(189)$ & 95.4 & $(20.8)$ & 0.00 \\
\hline Role physical $(0-100)$ & 13.0 & $(22.0)$ & 83.3 & $(32.4)$ & 0.00 \\
\hline Badily pain $(0-100)$ & 48.7 & $(9.6)$ & 50.5 & $(8.4)$ & 0.82 \\
\hline General health $(0-100)$ & 56.4 & $(12.7)$ & 62.4 & $(9,9)$ & 0.00 \\
\hline Agge & 321 & $(3.0)$ & 320 & $(3.8)$ & 0.74 \\
\hline \multicolumn{6}{|l|}{ Number of } \\
\hline Pregnancies: & 2.2 & $(1.0)$ & 1.9 & $(1.0)$ & 0,73 \\
\hline PBS $(0-8)$ & 1.6 & $(4.65)$ & 0.003 & $(0,2)$ & 0.00 \\
\hline $\begin{array}{l}\text { Beighton score (0-9) } \\
\text { (hypermobility) }\end{array}$ & 2.4 & $(20)$ & 1.9 & $(1.7)$ & 0.08 \\
\hline
\end{tabular}

mean BDI calculaled without items $15,16,19$

Both groups did not differ in mean age, education level, and number of pregnancies and generalized hypermobility. One-way ANOVA (table 3) showed significant differences between data from women with and without PPGP on pain, limitations in activities, participation, pain-related fear, pain catastrophizing, depression and quality of life. Bodily pain measured by a subscale of the SF-36 was moderate to high in both groups. This result was in 
glaring contrast with pain measured by the VAS-scales of the MPQ. These scales showed significant differences between the two groups. This contradiction could possibly be explained by the fact that the sub-scale of the SF-36 covered a range of the last 4 weeks (including delivery and period of lying-in) and the VAS-scales of the MPQ specified only the last week and day. All women considered the last 4 weeks including delivery and period of lyingin on the whole as moderately too highly painful without regard to their pain experience during the last week and last day. There were no significant differences between positive and negative emotionally scores of women with and without PPGP. Most women with PPGP described feelings of reluctance against picking up their full range of normal activities again.

\section{Cluster and discriminant analyses}

The first group (hierarchical and $k$-means) of cluster analyses was used to identify subgroups of women that were similar with respect to their responses to present diagnostic procedures.

Outcomes of a physical examination test from the right and left side of the body were combined to one variable. Results of the hierarchical and $k$-means cluster analysis showed (table 4) a two-group solution $(n=64, n=36)$. There was a slight contrast in the number of positive test results between the derived groups and the iliac separation test and the ASLR test showed significant differences. There were although no clinical relevant and significant differences between them and between the groups and the total sample on those variables that reflected the immediate cause of a woman searching for treatment (pain and limitations in activities). However the cluster with the highest number of positive tests $(n=36)$ had also the highest, significantly different scores on depression (BDI), family role and pain behavior (PBS). This suggests that depression and pain behavior have possibly some influence on the outcomes of pain provocation and instability (ASLR) tests. Therefore, a clinical relevant and significant model is not found, a "leave one out" discriminant validation is not performed.

A second group (hierarchical and k-means) of cluster and discriminant analyses was used to identify subgroups of women who were similar with respect to their responses on a number of the most important prognostic factors. To avoid loss of clinical detail the solution with three clusters was the maximal subdivided classification (table 5). There were significant and clinical relevant differences between the clusters and also between the three groups and the total sample on the pain level last week and day, limitations in activities, restrictions 
Table 4 Results of k-means cluster analyses based on the outcones of present dingnostic procedures(two cluster solution)

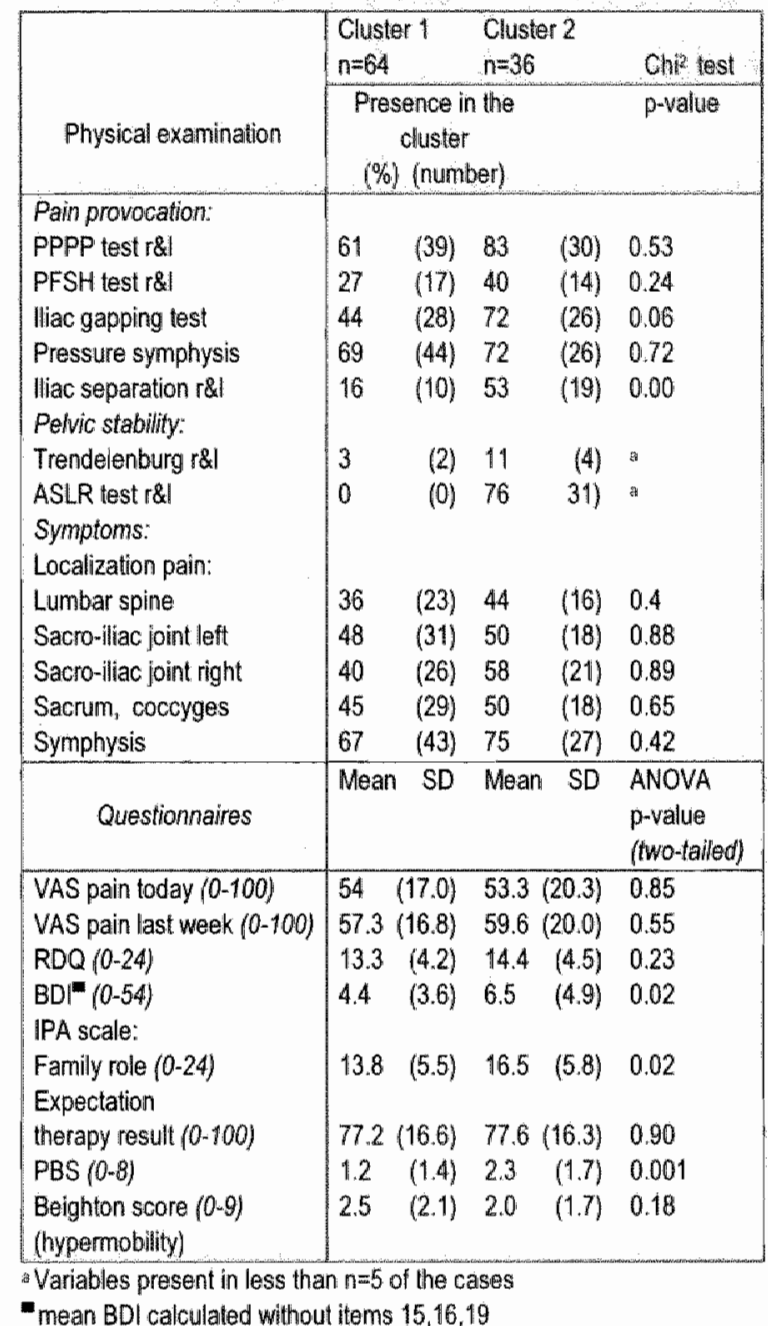

in participation and personal factors like depression, the subscale harm of the TSK, pain catastrophizing and expectation of treatment result. Discriminant analysis of a three -cluster solution showed that $95 \%$ of the cross-validated grouped cases were classified correctly. Women in cluster $1(n=26)$ reported the lowest levels of pain, limitations in activities and pain catastrophyzing but a significant higher level of depression and lower level of expectancy of treatment result than cluster 3 . Cluster $2(n=30)$ was the cluster with overall the highest level of pain, limitations in activities, restriction in 
Table 5 Results $k$-means cluster analysis based on the outcomes of prognostic factors

\begin{tabular}{|c|c|c|c|c|c|c|c|}
\hline \multirow[b]{2}{*}{ Questionnalres } & \multicolumn{2}{|c|}{$\begin{array}{l}\text { Cluster } 1 \\
n=26\end{array}$} & \multicolumn{2}{|c|}{$\begin{array}{l}\text { Cluster } 2 \\
n=30\end{array}$} & \multicolumn{2}{|c|}{$\begin{array}{l}\text { Cluster } 3 \\
n=44\end{array}$} & \multirow{2}{*}{$\begin{array}{l}\text { ANOVA } \\
\text { p-value } \\
\text { (2-tailed })\end{array}$} \\
\hline & Mean & $(S D)$ & Mean & $(\mathrm{SD})$ & Mean & (SD) & \\
\hline VAS pain today $(0-100)$ & 40.0 & $(15.7)$ & 66.6 & $(197)$ & 53.3 & $(18.2)$ & 0.00 \\
\hline WAs pain last week $(0-100)$ & 39.6 & $(14.5)$ & 77.5 & $(8.7)$ & 55.9 & $(10.0)$ & 0.00 \\
\hline $\operatorname{RDQ}(0-24)$ & 11.1 & $(3.7)$ & 15.4 & $(5.0)$ & 14.0 & $(3.4)$ & 0.001 \\
\hline $\operatorname{PCS}(0.52)$ & 6.7 & $(5.0)$ & 20.3 & $(10.8)$ & 9.5 & $(5.7)$ & 0,00 \\
\hline PEM $(0-11)$ & 8.1 & (2.4) & 7.6 & $(3.1)$ & 8.6 & (2.2) & 0.26 \\
\hline NEM $(0-14)$ & 2.8 & $(2.8)$ & 3.6 & (2.9) & 2.3 & (2.3) & 0.11 \\
\hline \multicolumn{8}{|l|}{ TSK subscales: } \\
\hline Fear avoidance $(8-32)$ & 17.3 & (3.3) & 19.0 & $(3.0)$ & 17.9 & $(3.8)$ & 0.11 \\
\hline Harm* $(5-20)$ & 7.7 & (1.5) & 9.0 & (2.5) & 8.2 & $(2.6)$ & 0.09 \\
\hline$B D=(0-54)$ & 5.2 & $(4.2)$ & 6.9 & $(4.8)$ & 3.8 & $(3.5)$ & 0.01 \\
\hline \multicolumn{8}{|l|}{ IPA scalies: } \\
\hline Family role $(0-28)$ & 11.6 & (5.4) & 17.0 & (6.9) & 15.3 & $(4.3)$ & 0.001 \\
\hline Autonomy in sell-care $(0-28)$ & 6.1 & $(3.8)$ & 13.1 & $(6.6)$ & 8.9 & (3.8) & 0.00 \\
\hline Mobility and leisure $(0-20)$ & 8.0 & $(3.6)$ & 12.6 & $(4.5)$ & 10.5 & $(4.3)$ & 0.00 \\
\hline \multicolumn{8}{|l|}{ Expeclation } \\
\hline therapy result: $(0-100)$ & 60.6 & $(14.5)$ & 77.5 & $(8.7)$ & 89.0 & $(8.2)$ & 0,00 \\
\hline PBS $(0-8)$ & 1.5 & $(1.3)$ & 1.9 & $(2.0)$ & 1.6 & $(1.6)$ & 0.47 \\
\hline $\begin{array}{l}\text { Beighton score }(0-9) \\
\text { (hypermobility) }\end{array}$ & 2.2 & $(1.9)$ & 2.3 & $(2.0)$ & 25 & $(1.9)$ & 0.73 \\
\hline Physical examination & \multicolumn{6}{|c|}{$\begin{array}{l}\text { Presence in the cluster } \\
(\%, \text { number })\end{array}$} & $\begin{array}{l}\text { Chip test } \\
\text { p-value }\end{array}$ \\
\hline Pain provacation: & & & & & & & \\
\hline PPPP test r\&l & 65.4 & $(17)$ & 70.0 & (21) & 70.5 & $(31)$ & 0.49 \\
\hline PFSH test r\&l & 42.3 & (11) & 33.3 & (10) & 22.7 & $(10)$ & 0.47 \\
\hline lliac gapping test & 53.8 & (14) & 56.7 & (17) & 52.3 & $(23)$ & 0.93 \\
\hline Pressure symphyse & 80.8 & (21) & 70,0 & (21) & 63.6 & (28) & 0.32 \\
\hline Iliac separation r\&l & 34.6 & (9) & 40.0 & $(12)$ & 18.2 & (8) & 0.05 \\
\hline Palvic stability: & & & & & & & \\
\hline Trendelenburg r\& & 11.5 & (3) & 10.0 & (3) & $a$ & 0 & a \\
\hline ASLR tost r\&l & 38.4 & (10) & 33.4 & (10) & 15.0 & (11) & 0.47 \\
\hline
\end{tabular}

participation and personal factors but also a high level of expectancy of treatment result. Cluster $3(n=44)$ reported a moderate to high level of pain and limitations in activities, a significant lower level of depression and the highest level of treatment expectancy. However, differences between the derived groups could not be reduced into differences between the outcomes of currently used diagnostic procedures (table 5). No clinical relevant differences on that 
matter were found. The only significant different outcome was the iliac separation test.

No differences were found between the clusters on the average score of hypermobility, positive and negative emotionally scores and subscales of painrelated fear although there was a trend in cluster 2 to report higher levels of both subscales.

\section{Discussion}

This study was conducted to generate a new way to describe clinical findings of PPGP so that important information probably could be more effectively communicated between care providers and between patients and care providers. Cluster analyses are a group of empirical techniques to describe clinical findings in an unprejudiced way. These methods are primarily intended for hypotheses generating rather then testing. For the very reason that in this study the part of the cohort that already gave birth $(n=4491)$ generated a sample of only 100 women having persistent PPGP after delivery, we used a "leave one out $^{\prime \prime}$ validating method to examine the maximal sub-dived classification. As a consequence of the sample size and the concept of cluster analysis, results can only be interpreted as generating a new hypothesis to describe clinical findings but not yet as a robust taxonomy. Nevertheless, it is an important first step in the development of a new set of criteria to detect distinct relevant subgroups of women having pregnancy-PPGP after delivery to tailor treatment interventions for the different groups or to control for subgroup differences when evaluating treatment outcome. Variables such as limitations in activities, depression, painrelated fear and pain-catastrophyzing appeared to be powerful to distinct "natural subgroups". On the contrary, currently used biomedical variables were not able to detect any significant and clinical relevant "natural subgroups" in our sample. Another major point is that derived subgroups through cluster analysis with above-mentioned powerful variables could not be reduced to meaningful differences in those biomedical variables.

A limitation of this study was the relative small study sample $(n=100)$, too small for a half split validation. For such a validation technique, a sample of at least 200 women is preferable. Future studies are needed to replicate and validate these findings, to develop a set of criteria to detect the subgroups and to investigate the prognosis of these subgroups. 


\section{Conclusion}

Taken together, after meeting the exclusion criteria for specific pathology, currently used biomedical variables did not contribute to an adequate understanding of PPGP three weeks after delivery. Future diagnostic research has to focus more attention on variables such as the impact of limitations in activities, restrictions in participation, pain experience last week, depression, pain-related fear, pain catastrophyzing and expectancy of treatment result. Throughout the diagnostic process in daily practice, it is important to focus attention to a history taking in which biopsychosocial variables occupy a major place. The additional use of standardized and validated questionnaires in this matter is preferable.

\section{Acknowledgements}

The funding for this study was provided by the Health Care Insurance Board (College voor zorgverzekeringen CVZ) in the Netherlands as a part of a research project titled "Peripartum pelvic pain during pregnancy and after delivery". We would like to express our gratitude to all the participating women and Conny de Zwart for the logistic assistance.

\section{Reference}

1. A Fast, D Shapiro, EJ Ducommun, LW Friedmann, T Bouklas, Y Floman: Lowback pain in pregnancy. Spine 1987, 12:368-71.

2. A Fast: Low back pain during pregnancy. Phys Med Rehabil 1999, 13.509-519.

3. MI Mantle, RM Greenwood, HL Currey: Backache in pregnancy. Rheumatol Rehabil 1977, 16:95-101.

4. M MacEvilly, D Buggy: Back pain and pregnancy: a review. Pain 1996, 64:40514.

5. JM Mens, A Vleeming, R Stoeckart, HJ Stam, CJ Snijders: Understanding peripartum pelvic pain. Implications of a patient survey. Spine 1996, 21:1363-9.

6. HC Ostgaard, GB Andersson, $M$ Wennergren: The impact of low back and pelvic pain in pregnancy on the pregnancy outcome. Acta Obstet Gynecol Scand 1991, 70:21-4.

7. HC Ostgaard, G Zetherstrom, E Roos Hansson, B Svanberg: Reduction of back and posterior pelvic pain in pregnancy. Spine 1994, 19:894-900. 
8. B Sturesson, G Uden, A Uden Pain pattern in pregnancy and catching of the leg in pregnant women with posterior pelvic pain Spine 1997, 22:1880-3.

9. H Albert, M Godskesen, I Westergaard: Evaluation of clinical tests used in classification procedures in pregnancy-related pelvic joint pain. Eur Spine 2000, 9:161-6.

10. HC Ostgaard, E Roos Hansson, G Zetherstrom: Regression of back and posterior pelvic pain after pregnancy. Spine 1996, 21:2777-80.

11. HC Ostgaand, GB Andersson: Postpartum low-back pain. Spine 1992, 17:53-5.

12. F Turgut, M Turgut, M Cetinsahin: A prospective study of persistent back pain after pregnancy. Eur J Obstet Gynecol Reprod Biol 1998, 80:45-8.

13. A Hansen; D Jensen, M Wormslev, H Minck, S Johansen, E Larsen, C WilkenJensen, $M$ Davidsen, $T$ Hansen: Symptom-giving pelvic girdle relaxation in pregnancy IISymptoms and clinical signs. Acta Obstet Gynecol Scand 1999, 78:111-115.

14. J Knottnerus: Challenges in dia-prognostic research. J Epidemiol Community Health 2002, 56:340-341.

15. HC Ostgaard, GB Andersson, K Karlsson: Prevalence of back pain in pregnancy. Spine 1991, 16:549-52.

16. H Albert, M Godskesen, I Westergaard: Prognosis in four syndromes of pregnancy-related pelvic pain. Acta Obstet Gynecol Scand 2001, 80:505-10.

17. L Klenerman, PD Slade, IM Stanley, B Pennie, JP Reilly, LE Atchison, ID Troup, MJ Rose: The prediction of chronicity in patients with an acute attack of low back pain in a general practice setting. Spine 1995, 20:478-84.

18. GWaddell: Diagnostic triage. In: The Back Pain Revolution, vol. Chapter 2. pp. 9-26. Edinburgh, London, New York, Philladelphia, Sydney, "Toronto: Churchill Livingstone; 1998: 9-26.

19. SJ Linton, $\mathbb{K}$ Boersma: Early identification of patients at risk of developing a persistent back problem: the predictive validity of the Orebro Musculoskeletal Pain Questionnaire. Clin J Pain 2003, 19:80-6.

20. PM Bongers, CR de Winter, MA Kompier, VH Hildebrand: Psychosocial. factors at work and musculoskeletal disease. Scand J Work Environ Health 1993, 19:297-312.

21. HS Picavet, JS Schouten: Musculoskeletal pain in the Netherlands: prevalences, consequences and risk groups, the DMC(3)-study. Pain 2003, 102:167-78.

22. CHG Bastiaenen, RA de Bie, PMJC Wolters, JWS Vlakyen, JM Bastiaanssen, ABA Klabbers, A Heuts, PA van den Brandt, GGM Essed: Treatment of pregnancy-related pelvic girdle and/or low back pain alter delivery design of a randomized clinical trial within a comprehensive prognostic cohort study. BMC Public Health 2004, 4:67.

URL:http//www biomedcentral.com/1471-2458/4/67

23. JM Bastiaanssen, RA de Bie, CHG Bastiaenen, A Heuts, MEAL Kroese, GGM Essed, PA van den Brandt: Etiology and prognosis of pregnancy-related pelvic girdle pain; design of a longitudinal study. BMC Public Health 2005, 5:1.

URL:http/ / www.biomedcentral.com/1471-2458/5/1 
24. $\mathrm{G}$ Waddell, DC Turk: Clinical Assessment of Low Back Pain. In: Handbook of pain assessment Edited by DC Turk, R Melzack, vol chapter 2 . Pp. 15-37. New York London: The Guilford Press; 1992: 15-37.

25. M Wormslev, AM Juul, B Marques, H Minck, L Bentzen, TM Hansen: Clinical examination of pelvic insufficiency during pregnancy. An evaluation of the interobserver variation, the relation between clinical signs and pain and the relation between clinical signs and physical disability. Scand J Rheumatol 1994, 23:96-102.

26. HC Ostgaard, $\mathrm{G}$ Zetherstrom, E Roos Hansson: The posterior pelvic pain provocation test in pregnant women. Eur Spine J 1994, 3:258-60.

27. JMA Mens, HJ Stam, A Vleeming; CI Snijders: Active straight leg raising; a clinical approach to the load transfer function of the pelvic girdle. In: Integrating functions of the lumbar spine and sacroiliac joint Edited by A Vleeming, V Mooney, CJ Snijders, T Dorman. pp. 207-220. Rotterdam: European Conference Organizers; 1995: 207-220.

28. M Calguneri, HA Bird, V Wright: Changes in joint laxity accurring during pregnancy. Ann Rheumatic Dis 1982, 41:126-8.

29. JWS Vlaeyen, DFM Pernot, AMJ Kole-Snijders, JA Schuerman, vH Eek, NH Groenman: Betrouwbaarheid en valliditeit van een Nederlandse versie van de Pain Behavior Scale (PBS). Ned Tijdschr Psychol 1990, 45:184-189.

30. IS Richards, C Nepomuceno, M Rilles, Z Suer: Assessing pain behavior: the UAB Pain Behavion Scale. Pain 1982, 14:393-8.

31. R Melzack: The MoGill Pain Questionnaire: major properties and scoring methods. Pain 1975, 1:277-99.

32. E Kremer, JH Atkinson, Jr.: Pain measurement: construct validity of the affective dimension of the McGill Pain Questionnaire with chronic benign pain patients. Pain 1981, 11:93-100.

33. M Roland, R Morris: A study of the natural history of back pain. Part I: development of a reliable and sensitive measure of disability in low-back pain. Spine 1983, 8:141-4.

34. LE Schoppink, MW van Tulder, BW Koes, SA Beurskens, RA de Bie: Reliability and validity of the Dutch adaptation of the Quebec Back Pain Disability Scale. Phys Ther $1996,76: 268-75$.

35. JA Kopec, JM Estaile, M Abrahamowicz, L Abenhaim, S Wood Dauphinee, DL Lamping, II Williams: The Quebec Back Pain Disability Scale. Measurement properties. Spine 1995, 20:341-52.

36. RW Ruesink, JWS Vlaeyen, C Pons, PHTG Heuts: Bewegingsvrees bij aspecifieke chronische lage rugpijn. Ned Tijdschr Geneeskd 1996, 140:2067.

37. IW Vlaeyen, AM Kole Snijders, RG Boeren, $H$ van Eek: Fear of movement/(re)injury in chronic low back pain and its relation to behavioral performance. Pain 1995, 62:363-72.

38. MJL Sullivan, SR Bishop, I Pivik: The pain catastrophizing scale: development and validation. Psychol Assess 1995, 7:524-532. 
39. D Watson, LA Clark, G Carey: Positive and negative affectivity and their relation to anxiety and depressive disorders. J Abnorm Psychol 1988, 97:346-53.

40. T Bouman: De 'Beck Depression Inventory" (BDI). Gedragstherapie 1994, 27:69. 71.

41. AT Beck, CH Ward, M Mendelson, J Mock, I Erbaugh: An inventory for measuring depression. Arch General Psychiatry 1960, 4:561-571.

42. AT Beck, RA Steer, MG Garbin: Psychometric properties of the beck depression inventory: twenty-five years of evaluation. Clin Psychol Rev 1988, 8:77-100.

43. JE Ware, Jr, CD Sherboume: The MOS 36-item short-form health survey (SF36). 1. Conceptual framework and item selection. Med Care 1992, 30;473-83.

44. JE Ware, Jr., M Kosinski, MS Bayliss, CA McHorney, WH Rogers, A Raczek: Comparison of methods for the scoring and statistical analysis of SF-36 health profile and summary measures: summary of results from the Medical Outcomes Study. Med Care 1995, 33:As264-79.

45. M Cardol, RJ de Haan, GA van den Bos, BA de Jong, I] de Groot: The development of a handicap assessment questionnaire: the Impact on Participation and Autonomy (IPA). Clin Rehabil 1999, 13:411-9.

46. $M$ Cardol, $\mathbb{R}$ de Haan, BA de Jong, GAM van den Bos, IIM de Groot: Psychometric properties of the impact on participation and autonomy questionnaire. Anch Phys Med Rehabil 2001, 82:210-216.

47. WA van der Kloot, RA Oostendorp, J van der Meij, J van den Heuvel: De Nederlandse versie van 'MoGill pain questionnaire': een betrouwbare pijnvragenlijst. Ned Tijdschr Geneeskd 1995, 139:669-73.

48. SH Kori, RP Miller, DD Todd: Kinisophobia" a new view of chronic pain behavior. Pain Management 1990:35-43.

49. EJ Swinkels Meewisse, RA Swinkels, AL Verbeek, JW Vlaeyen, RA Oostendorp: Psychometric properties of the Tampa Scale for kinesiophobia and the fearavoidance beliefs questionnaire in acute low back pain. Man Ther 2003, 8:29-36.

50. L Goubert, G Crombez, S Van Damme, JW Wlaeyen, P Bijttebier, J Roelof's: Confirmatory factor analysis of the Tampa Scale for Kinesioplhobia: invariant two-factor model across low back pain patients and fibromyalgia patients. Clin J Pain 2004, 20:103-10.

51. AL Wesley, RI Gatchel, JP Garofalo, PB Polatin: Toward more accurate use of the Beck Depression Inventory with chronic back pain patients. Clin I Pain $1999,15: 117-21$.

52. IW Vlaeyen, NI Teeken Gruben, ME Goossens, MP Rutten van Molken, RA Pelt, H van Eek, PH Heuts: Cognitive-educational treatment of fibromyalgia: a randomized clinical trial. I. Clinical effects. I Rheumatology 1996, 23:1237-45.

53. S Landau, BS Everitt: A handbook of statistical analyses using SPSS: Chapman \& $\mathrm{Hall} / \mathrm{CRC} ; 2003$. 
48 ClUSTERANALYSES 


\section{CHAPTER FOUR}

Treatment of pregnancy-related pelvic girdle pain after delivery [ISRCTN08477490]

Design of a randomized clinical trial within a comprehensive prognostic cohort study

Caraline HO Bastigenen, Rob A de Bie, Pieter MJC Wolters, Johan Ws Waeven, Janneke M Bastiaanssen, Aldegonda BA Klobbers, Annie Heuts. Piet A vain der: Brand. Gerard GM Essed

BMC Public Health 2004,4:67 


\section{Abstract}

\section{Introduction:}

Pregnancy-related pelvic girdle pain is a controversial syndrome because insight in etiology and prognosis is lacking. The controversy relates to factors eliciting pain and some prognostic factors such as the interpretation of pain at the symphysis. Recent research about treatment strategies also reflects those various opinions, in fact suggesting there is professional uncertainty about the optimal approach. Currently, physiotherapist often prescribe a pain-contingent treatnent regime of relative rest and avoiding several day-to-day activities. Additionally, treatment more often includes an exercise program to guide rectification of the muscle imbalance and alignment of the pelvic girdle. Effectiveness of those interventions is not proven and the majority of the studies are methodologically flawed. Investigators draw particular attention to biomedical factors but there is growing evidence that important prognostic issues such as biopsychosocial factors appear to be even more important as point of action in a treatment program.

Methods:

This pragmatic randomized controlled trial is designed to evaluate the effectiveness of a twilor-made treatnent program with respect to biopsychosocial factors in primary care. The effect of the experimental intervention and usual care are evaluated as they are applied in primary health care. The trial is embedded in a cohort study that is designed as a longitudinal, prospective study, which studies prevalence, etiology, severity and prognosis during pregnancy until one year after delivery. The present paper focuses on choices regarding recruitment procedures, in-fexclusion criteria and the development of a well-timed intervention.

\section{Discussion}

This section briefly discusses the actions taken to miniwize bias in the design, the proper time-window for the experimental intervention and the contrast between the experimental intervention and usual care. 


\section{Introduction}

Since 1962[1], diagnosis, prognosis and treatment of pregnancy-related pelvic girdle pain have inflicted debate and have led to considerable differences of opinions. Many articles appeared mainly in International journals and some etiological mechanisms were hypothesized. However, the subject remains controversial, mainly because insight in etiology and prognosis is lacking. Moreover, diagnostic investigation into the exact definition and classification of pregnancy-related pelvic girdle pain shows various opinions between leading experts on this topic. The controversy relates to factors eliciting pain[2] and prognostic factors such as the interpretation of pain at the symphysis $[3,4]$, the question whether pelvic girdle pain is a syndrome separate from low back pain $[4,5]$ and the importance of questions about limitations in activities [6]. Also recent research about treatment strategies reflects those various opinions [7], in fact suggesting there is professional uncertainty about the optimal approach. Investigators draw particular attention to biomedical factors but there is growing evidence that important prognostic issues such as biopsychosocial factors appear to be even more important as basis in a treatment program [8,9]. Although the group of musculoskeletal disorders holds many different biomedical labels, the process of developing chronic disability has shown surprising similarities with regard to biopsychosocial factors [10]. For the moment, pregnancy-related pelvic girdle pain is a subjective experience comprising pain in the lumbopelvic region and limitations in activities for which classification criteria are insufficient in guiding to a treatment approach (Chapter 3). Results of various therapeutic interventions have been published but excepting for one recent study focusing on specific stabilizing exercises [11], their effectiveness remain unproven. Furthermore, the majority of the studies are methodologically flawed [7].

Currently, physicians and physiotherapists usually prescribe a pain contingent treatment regimen of relative (bed) rest and avoiding several day-to-day activities such as using the stairs, bending, twisting, lifting and cycling. Additionally, the current treatment approach of a physiotherapist more often includes an exercise program to guide rectification of the muscle imbalance and alignment of the pelvic girdle [12]. Therapists rely on knowledge of pain duration and intensity during goal setting for treatment, for a great deal. 
Why publish a study protocol

There are several reasons for publishing a study protocol before obtaining research data. The main reason is to reflect on the study design independently of the results. Considerations and choices concerning methodology and treatment can be described more detailed. The present paper focuses on choices about recruitment procedures, in-/exclusion criteria and the development of a well-timed experimental intervention. We also present details about the enrollment of women with pregnancy-related pelvic girdle pain in the controlled trial.

\section{Methods}

\section{Study design and research question}

The trial is embedded in a cohort study that is designed as a longitudinal, prospective study, which studies the prevalence, etiology, severity and prognosis of pregnancy-related pelvic girdle pain until one year after delivery (Figure 1). The present study is designed as a pragmatic trial aimed to compare the effects of interventions carried out in primary health care.

We performed a randomized controlled trial in primary care to determine whether a tailor-made program with respect to biopsychosocial factors (intervention group) benefits women with pregnancy-related pelvic girdle pain more in terms of effectiveness and costs than usual care would on a pain contingent basis (control group).

\section{Recruitruent and informed consent}

The medical ethics committee of the Maastricht University Hospital approved the intervention and cohort study. The study is performed in the Southeast of the Netherlands. Midwives and gynecologists recruited the women during early pregnancy (10-14 weeks). Participation of midwives and gynecologists in the recruitment of eligible pregnant women is of major importance for the success of the cohort and intervention study [13]. We have paid a lot of attention to difficulties in recruitment such as busy consultation hours and not feasible recruitment procedures. Therefore, we designed a recruitment protocol that is as simple as possible, not restrictive, and demanding a minimum of time from midwives and gynecologists. Standardized written information about the cohort and intervention study is available for every potentially eligible woman and to be handed out by the midwife or gynecologist. Several steps are taken to 


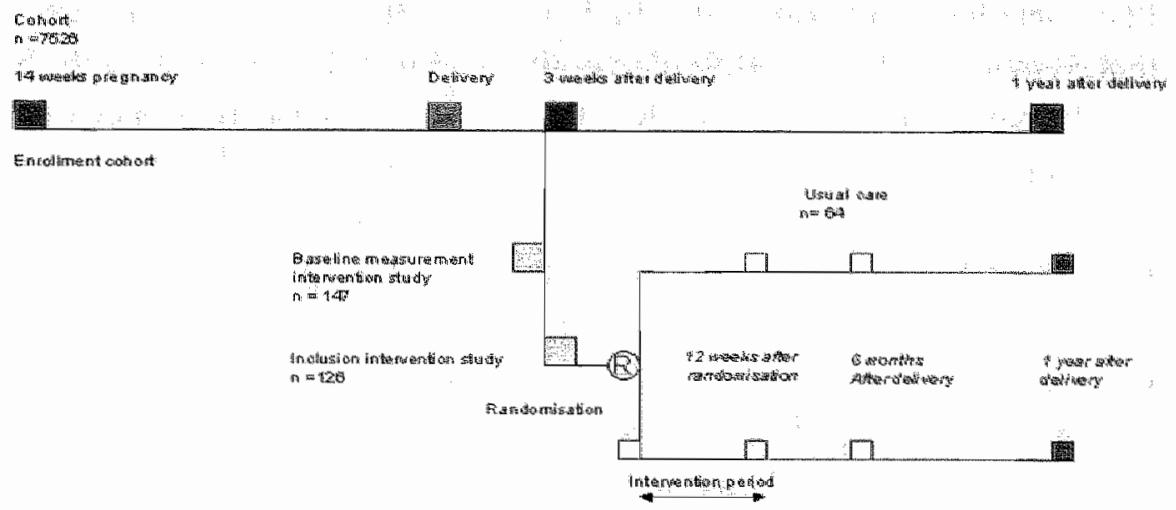

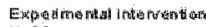

N. 62

Figure 1 Design of the study

encourage participation of the midwives and gynecologists. We distributed newsletters about the developments in the cohort and intervention study every three months and visited the practices and meetings of midwives on a regular basis. Any questions regarding trial questions received prompt feedback. The flexibility of the trial procedure is also guaranteed by assessing potential candidates for the trial at home.

Women are included in the cohort if they are at least 18 years old, pregnant and well versed in Dutch language. Women are given written information explaining the aims and contents of the cohort and intervention study before they decide to participate. Concerning the intervention study they are told that to current knowledge the two investigated treatment options are considered to be equally effective. The moment of inclusion for the intervention study lies at about three weeks after delivery. An individual woman enters the intervention study after signing informed consent for both the cohort and intervention study during early pregnancy and meets the in- and exclusion criteria of the intervention study three weeks after delivery. Women are included when having pain in the pelvic girdle and/or low back with an onset during pregnancy or just after delivery (cohort data), are restricted in their normall daily activities because of pelvic girdle pain and if there is a delay in 
recuperation (not yet in the condition to participate satisfactory in housekeeping and care of children because of the complaints under investigation). The severity of symptoms must be varying with physical activities and time during the day. Women diagnosed with a relevant specific pathology (such as nerve root pathology, rheumatoid disorders, carcinoma, obstetric complications) that affects pain and activities of daily life are excluded. Exclusion also occurs in case of family related or psychosocial problems or when a disablement procedure is not yet finished:

Final important aspects for in-/exclusion are the willingness of a woman to participate in the study or having a clear treatment preference[13]. We only included women who did not indicate such a preference and who were willing to take the $50 \%$ risk of receiving a referral to a participating physiotherapist (and treatment option) or the freedom of choosing a therapist by themselves (usual care). Including only women who are naïve (who never received treatment for their complaints during this pregnancy or earlier pregnancies) will result in an unacceptable reduction in the number of eligible patients. However, we excluded all the women who already received treatment after their current delivery.

A basic principle for selection of eligible women in this study is that inclusion criteria must have a meaningful influence in goal setting for treatment. We therefore focused on criteria such as a delay in recuperation and restrictions in normal daily activities caused by pregnancy-related pelvic girdle pain. However, other studies in this field formulated inclusion/exclusion criteria based on certain diagnostic classification strategies. Although rationales of these strategies greatly differ, they all attach great importance to the outcomes of particular (albeit different) diagnostic tests. In the absence of a clear definition and reference standard to diagnose pregnancy-related pelvic girdle pain, the outcomes of these procedures not only led to different selections of women having complaints, the prognostic and diagnostic importance of these subgroups also remain unclear (Chapter 2 and 3).

Exclusion of differential diagnoses is a major point of concern. For that reason we included a history taking and a physical examination protocol that focuses on differential diagnoses at first and then on the formulated inclusion criteria. The various specific physical examination tests to diagnose pregnancy-related pelvic girdle pain are left aside. For a better understanding of the complaints and tailoring treatment, application of these tests has no supplemental value (Chapter 3). 
An experienced research-physiotherapist visited women at home, about three weeks after delivery. This visit is called for on the basis of a short selfadministered questionnaire and/or initiated by midwives. A positive answer from a participating woman from the cohort and/or her midwife on the question: "Is an intervention by a physiotherapist necessary?" took a central position in these questionnaires. In advance of a possible home visit, a short history taking by telephone took place about two weeks after delivery. History taking focuses on exclusion criteria such as: willing to participate in this part of the study, a diagnosis with relevant specific pathology, limitations in daily life and a delay in recuperation. During a home visit, a standardized history is taken and physical examination to exclude specific pathology is performed. Self-administered questionnaires are used to question the women about pain, limitations in activities, restrictions in participation, pain-related fear, pain catastrophizing, positive and negative affectivity, depression, expectancy of treatment result and quality of life. The questionnaires contain clear instructions for completion with no help or support from others. If a woman meets the selection criteria, she is informed about the aim and method of the intervention study and if she is willing to participate, the informed consent procedure is completed. The research-physiotherapist collecting the baseline data is trained in performing the measurements in a standardized way and is unaware of the women's treatment assignments.

\section{Randomization and blinding}

Randomization takes place after collecting the baseline data. In this study we used a block randomization (size of four). An independent research assistant (unaware of the baseline data) carried out the randomization procedure according to a random computer-generated list. When a woman is allocated to the intervention group, the participating physiotherapist in the environment of the woman is contacted and we ensured that treatment could start as soon as possible (within one week). Treatment is covered for all participants in the intervention group on a research-physician's referral. Women, allocated to the usual care group, are free to choose for the current treatment approach by a (not participating) physiotherapist. Information about a possible guidance by a general practitioner and feasible treatments received after randomization is collected by means of questionnaires in the follow-up period. 
Women are blinded to a certain extent to the allocated treatment because they are kept naive of the exact content of both treatment options. Participating physiotherapists are not blinded to the treatment option but not involved in the baseline and effect measurements. Researchers dealing with the baseline and outcome data are unaware of the treatment assignments.

\section{History taking and physical examination}

During a home visit a standardized history is taken [8] and physical examination is performed. History taking focuses on on-going pain, its location, intensity and modalities, variation of symptoms with physical activities, radiation into the legs, back pain versus leg pain, neurological signs, deformity, obstetric complications, a case history of low back and pelvic girdle pain prior to this pregnancy and other differential diagnoses. The format of the answers is presented as a dichotomous "yes or no". Demographic characteristics and data about education, work, income, use of alcohol, smoking, medication, the onset of pain and functional status during pregnancy have allready been gathered as part of the cohort study at 14 and 30 weeks gestation period and two weeks after dellivery.

After history taking a short standardized clinical examination program is performed, which includes tests of nerve root radiation (exclusion)[8]. The research-physiotherapist fills out the Pain Behavior Scale, a standardized observation scale for quantifying pain behavior $[14,15]$, after clinical examination.

\section{Interventions}

\section{Usual care}

Women, allocated to the usual care group, are free to choose usual care treatment by a physiotherapist not providing the educational program of the experimental intervention, guidance by a general practitioner or do nothing. Information about the option chosen is collected by means of questionnaires during the follow-up period. All physiotherapists are experienced and specialized in treating women with PPGP.

Prior to the trial, detailed information is gathered about the contents of current treatment options. Part of the information is collected by means of group discussions with experienced physiotherapists and occupational therapists and interviews on an individual basis with affected women out of the cohort 
(during pregnancy). An independent rehabilitation specialist, specialized in pain treatment chaired the meetings with the therapists. Some subjects for discussion were: differences in clinical spectrum seen by the therapists, contents of treatment programs during pregnancy and after delivery, common knowledge by the therapists about etiology, prognosis and prevalence of the syndrome, the optimal time-window for treatment in the course of complaints and the therapist-patient relationship. Items that provided important topics of conversation between the therapists were: the moment of taking up and finishing off treatment, the contents of education and advice given to the patient and the (lack of) compliance. The most striking characteristics of a current treatment were the character of the therapist-patient relation and the way of goal setting, focusing on disease management [16]. There was an explicit professional input and an accent on biomedical factors. A pain contingent regimen of avoiding and limiting several day-to-day activities was important. Compliance based on these goals played an important part. Therapists were often highly concerned about their patient's pain themselves.

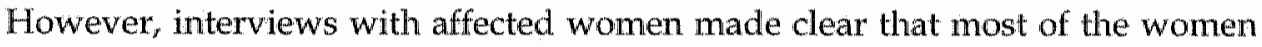
were irritated about this regimen in an increasing degree after starting the treatment sessions. The regimen was too strict and on a number of points not geared to the wishes and concerns of the women. These aspects caused a lack of compliance and an unremitting hesitation about a good prognosis and in particular about reassuming certain day-to-day activities after delivery. Therapists did not realize the nature of this problem although they did mention problems with compliance. Some women were not able to get a grip on their condition and left management of their pain and activities of daily life to the therapist. A larger part of the women was more or less uncertain about picking up their full range of activities again after delivery. Their beliefs and concerns about origin and prognosis of their complaints clearly bore the stamp of the introduced biomedical label. The relatively favorable prognosis after delivery was largely unknown to the women as well as to the physiotherapists.

\section{Experimental interontion}

Women, allocated to the intervention group, are referred to a participating physiotherapist in their own neighborhood. These physiotherapists received an educational course about the treatment protocol prior and during the study. All physiotherapists were already experienced and specialized in treating women with pregnancy-related pelvic girdle pain prior to the study. The contents of the 
experimental therapy are based on the latest literature, results of interviews with affected women (participating in the cohort study) and group discussions with experienced physical and occupational therapists.

A search procedure in literature resulted in various therapeutic interventions. However, effectiveness of those interventions remains largely unproven. An important common goal of these treatments is restoration of optimal biomechanics, although this is not based on established theoretical principles [7]. The search did not provide enough possibilities to design a treatment protocol. However, as mentioned above, results of interviews and group conversations showed interesting contradictions.

During development of the experimental intervention we focused on the following contradictions: patient-therapist relationship, education, and hesitation or avoiding of activities. Theoretical concepts of self-management [16, 17] and fear avoidance techniques [18] were integrated in the treatment protocol. A treatment program that demands a much more active involvement of a participating woman was designed. Interventions with a self-management approach are considered to be able to build a bridge between patients' needs and caregivers' services to meet those needs. Self-management refers to the individual's ability to manage the symptoms, treatment, physical and psychosocial consequences and life style changes inherent to living with a chronic condition [17]. Self-management approaches are either group-based or individualized. We performed an individuallized approach of 7-9 sessions of 30 minutes spread in a period of 12 weeks. Standardized information is presented through a treatment protocol for the therapists and booklets for the patients [16, 19]. Topics included back and pelvis anatomy " red flags" indicating a serious medical condition, factors contributing to fluctuations in pain, appropriate pacing of exercises [12] and activity; handling pain flare-ups, cognitive restructuring, some fear avoidance techniques $[18,20,21]$, communication and social persuasion. Therapists had to employ problem-solving techniques that engaged women in identifying day-to-day problems or limitations related to pelvic girdle pain, setting personal goals, brainstorming options for achieving these goals and developing personal action plans. In subsequent sessions, women reviewed their action plans and their progress towards goals and engaged in problem-solving skills around difficulties that arose in trying to implement their plans. Information about two opposing behavioral responses of pain-related fear (avoidance and confrontation) is given, and a hierarchy of individual fear-eliciting movements and activities is made. Therapists 
encouraged women in making action plans for specific activities that were avoided.

Complaint-related problem solving is a key skill. The role of the therapist is to encourage women to identify possible causes of a problem, find a number of potential solutions, select one, then try it and finally evaluate the results and possibly adjust the solution. The second important key skill is action planning or goal setting. Often a plan must have been generally unacceptable (such as "go skiing") for a therapist in the usual care. Nevertheless, the protocoll of the experimental intervention embraced the point of view that a woman is her own best judge of what is possible. Another major point of action planning is that a woman could not only receive but also give feedback on her own accomplishments. Endorsement by the therapist is very important for a woman to accept her new role. This way of collaborating with a therapist on short-term action planning enabled women to master new skills and to make changes that are realistic and feasible for them.

Therapists also have a role in assisting women in understanding their symptoms. Knowledge of the course of the complaints during pregnancy and after delivery including pain flare-ups in the year after delivery, factors contributing to fluctuations in pain, evidence-based knowledge about etiology and the concept about pain-related fear are essential. Symptoms are explained as having many but not alarming causes, which offers the possibility to choose different actions by the concerning woman. Finally, therapists have a task in practicing social persuasion. A woman is more likely to change her behavior and have confidence in doing so if she perceives those around her, including the therapist to be supportive.

A relationship in which the physiotherapist and the woman make health care decisions together is the basic assumption of the intervention. Generally, a time contingent policy is followed in which women set the pace by means of action plans. The expertise of the physiotherapists of the condition in general and of the women about their own specific condition and lives are equally important [22].

Women, allocated to the experimental intervention group, were referred to a participating physiotherapist in their own neighborhood. These physiotherapists received an educational course about the treatment protocol prior and during the study. All physiotherapists were already experienced and specialized in treating women with PPGP. The intervention focused particularly on patient-therapist relationship, education and the promotion of an active life 
style rather than avoiding activities. Results of interviews with women out of the cohort and group discussions with experienced physical and occupational therapists prior to the trial further defined the program.

Theoretical concepts of self-management [16] and fear-avoidance [18] were integrated in the intervention protocol. We provided an individualized selfmanagement approach of 7-9 sessions for 30 minutes in a period of time of 12 weeks. Standardized information was presented by means of an intervention protocol for the therapists and booklets [23] for the patients [16, 19]. Topics included back and pelvis anatomy, "red flags" indicating a serious medical condition, factors contributing to fluctuations in pain, appropriate pacing of exercises [12] and activity, handling pain flare-ups, cognitive restructuring, some fear avoidance techniques $[18,21,24]$, and communication. Therapists had to employ simple problem-solving techniques that engaged women in identifying day-to-day problems or limitations related to PPGP, setting personal goals, brainstorming options for achieving these goals and developing personal action plans. In subsequent sessions, women reviewed their action plans and their progress towards goals and engaged in problem-solving skills around difficulties that arose in trying to implement their plans. Information about two opposing behavioral responses of pain-related fear (avoidance and confrontation) was given, and a hierarchy of individual fear-eliciting movements and activities was made. Therapists encouraged women in making action plans for specific activities that were avoided. They (therapists) were explicitly asked not to "label" the complaints in terms of medical diagnosis.

Generally, a time contingent policy was followed in which women set the pace by means of action plans. The expertise of the physiotherapists of the condition in general and of the women about their own specific condition and lives were equally important. [22].

\section{Outcowe mensurements}

Outcome measures (Table 1) chosen to explore the success of any intervention need to match the desired aims of that intervention. It is a process in which a standardized attempt is made to observe an often-complex clinical picture. Primary domain for improvement of the treatment under investigation is limitations in activities. Other important domains are the severity of the main complaints, the woman's global feeling of recovery, pain and participation.

Limitations in activities are measured with the Dutch translation of the Roland Disability Questionnaire (RDQ) [25] and the Quebec Back Pain Disability Scale 
(QBPDS) [26] [27]. We added the phrase "because of my back and/or pelvic girdle pain" in both questionnaires.

Subjective measurements like global feeling of recovery (global perceived effect, GPE) and severity of the main complaints (MC) reflecting a patient-specific approach are also selected. Global Perceived Effect (GPE) is measured by selfassessment on a 7-point scale ( $1=$ completely recovered, $7=$ worse than ever). The main complaints (MC) are selected by the woman in a standardized approach by selecting three activities, which are an essential and frequently performed part of her everyday life. However, the performance is difficult or impossible because of low back and/or pelvic girdle complaints at the moment of baseline measurement. Severity of a main complaint is rated on a Visual Analog rating Scale (VAS). [28, 29].

Pain is measured with two Visual Analog rating Scales (VAS) of the MoGill Pain Questionnaire (MPQ-DLV) [30,31] to record the intensity of pain the last week and day.

The impact on participation and autonomy (IPA) is used to measure personperceived restriction in participation and autonomy [32,33]. The used subscales are autonomy in self-care, mobility and leisure, social relationships and family role. Perceived participation is graded on a 5-point rating scale ranging from 0 (very good) to 4 (very poor).

Other important prognostic factors that can influence treatment results are fear of movement, pain catastrophizing, depression, negative and positive affect, and expectancy of treatment result and pain behavior.

Fear of movement is measured by the Dutch translation of the Tampa Scale for Kinesiophobia(TSK) $[34,35]$. We used the TSK and the both subscales "activity avoidance" and "harm" $[36,37]$

Pain catastrophizing is measured by the Pain Catastrophizing Scale (PCS) [38, 39].

The Beck Depression Inventory (BDI) [40] measures depressive symptoms [41]. Analyses of the BDI in this study did not include items concerning weight loss, sleeping disturbance and work inhibition [42]

To measure the experience of negative affect we used the 14-item Negative Emotionality Scale (NEM) [43]. To measure positive affect we used the 11-item Positive Emotionality Scale (PEM) [43]. Both are subscales of the Multidimensional Personality Questionnaire.

Health status is evaluated by the Short-Form 36 (SF-36)[44, 45] and the EuroQol [46]. We used the subscale "general health". 


\begin{tabular}{|c|c|c|c|c|}
\hline 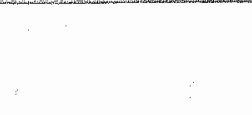 & $\begin{array}{l}\text { Baseline } \\
\text { aboul } 3 \text { weeks } \\
\text { after dellwery }\end{array}$ & $\begin{array}{c}3 \text { months } \\
\text { after } \\
\text { randomization }\end{array}$ & $\begin{array}{l}6 \text { monthis } \\
\text { after delivery }\end{array}$ & $\begin{array}{c}1 \text { year } \\
\text { after deliwery }\end{array}$ \\
\hline History taking & $\mathbf{x}$ & & & \\
\hline Physical examination & $x$ & & & \\
\hline : PBS & $\cdots$ & & & . \\
\hline $\mathrm{RDO}$ & * & $x$ & $x$ & $x$ \\
\hline QBPDQ & $*$ & * & * & $\times$ \\
\hline $\mathrm{MC}$ & x & * & $x$ & $x$ \\
\hline GPE & × & * & x & $x$ \\
\hline VAS (pain) & * & * & x & $x$ \\
\hline $\mathbb{P} A$ & * & * & $\mathbf{x}$ & * \\
\hline TSK & x & * & $x$ & $x$ \\
\hline SF 36 & $x$ & 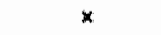 & $x$ & $x$ \\
\hline Expectancy treaiment & $x$ & & & \\
\hline PCS & * & & & \\
\hline NEM & x & & & \\
\hline PEM & * & & & \\
\hline $\mathrm{BDI}$ & * & & & \\
\hline Co-interveritions & & * & $x$ & $x$ \\
\hline Compliance & & * & $x$ & \\
\hline Recurrence complaints & 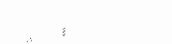 & & $x$ & $x$ \\
\hline Satisfaction treatment & & & $x$ & \\
\hline EuroQol & * & $x$ & $x$ & $\mathrm{x}$ \\
\hline Cost-diary & * & $x$ & $x$ & $x$ \\
\hline Subsequent pregnancy & & $x$ & $x$ & $x$ \\
\hline
\end{tabular}

$P B S=$ Pain Behavior Scale, $R D Q=$ Roland Disability Questionnaire, $M C=$ Main Complaint, GPE $=$ Global Perceived Effect, VAS = Wisual Analogue rating Scale, IPA = Impact on Participation and Autonomy, TSK = Tampa Scale for Kinesiophobia, SF-36 = Short Form 36, PCS = Pain Catastrophizing Scale, NEM = Negative Emotionality Scale, PEM = Positive Emotionality Scale, $B D I=$ Beck Depression Inventory, EuroQol = European Quality of Life Scale

A cost-diary [47] is used to obtain data on physical activities, health care utilization, and days of sick leave. Women are instructed to record costs on a weekly basis until one year after delivery.

Expectancy of therapy result [48] is measured by means of a $100 \mathrm{~mm}$ Visual Analog rating Scale (VAS). The woman is asked to what extent she believes that a treatment is beneficial to her.

The Pain Behavior Scale (PBS) [14; 15] is an observation scale tapping 8 pain behaviors that the physiotherapist completes after physical examination. These are verbal complaints, vocal complaints, facial grimaces, standing posture, mobility, body language, use of visible supportive equipment and stationary movement. 


\section{Follow up}

Women are asked to complete follow-up questionnaires at 12 weeks after randomization, 6 months after delivery and one year after delivery. Women who did not return their follow-up questionnaires were contacted by mail or phone and were asked to continue participation.

\section{Compliance, other interoentions and confounding}

The follow-up questionnaires ask all women how many treatment sessions they have followed in the previous period of time. Furthermore, information on contents, satisfaction and the aspects of the (experimental) treatment that benefited them most, is gathered. Co-interventions, medication, aids, additional medical consumption, recurrence of complaints, return to gainful employment and a possible subsequent pregnancy are also registered.

Physiotherapists who treat the participants of the intervention group also answered questions about the number and contents of the treatment sessions after conducting the last meeting.

\section{Statistical analyses}

Statistical analyses are carried out according to the "intention-to-treat" approach. The baseline status of the study groups is compared with respect to the distribution of all independent prognostic variables and each outcome measure according to the intention to treat approach. Primary analysis is done by means of analysis of an independent $t$-test (for continuous outcome variables) and chi-square test (for categorical outcome variables). In order to adjust for possible baseline differences a multiple linear regression analysis for continuous outcome measures is performed with the change scores as dependent variable, treatment option as independent variable and base line scores of the prognostic variables as co-variables. Missing data at the baselinemeasurement are substituted by the "mean of series" imputation method. Longitudinal missing data are substituted with the "last value carried forward method". In all comparisons between the two treatment options a two-tailed pvalue of 0.05 is considered to indicate statistical significance. Prognostic status at baseline for women with and without missing values for the outcome variables is compared for both groups. Analyses are done by using SPSS statistical software, version 12.0 (SPSS, Inc., Chicago, Illinois). Short term and long term effect analyses are performed separately. 


\section{Economic analyses}

An economic analysis compares the costs and health effects of the experimental intervention to assess whether it is beneficial from an economic perspective. For the whole study group all relevant health care costs, production loss and patient and family costs are measured by means of a cost-diary [47] and followup questionnaires collected 6 months and one year after delivery. Both direct healt th care costs (such as physician visits, the number of treatment sessions and medication), direct non-health care costs (such as transport to therapist) and indirect costs associated to the complaints (like sick leave, professional as well as voluntary aid and extra baby sitter) are registered until one year after delivery. Quality of life is measured using the EuroQol. [46]. For the validation of the healthcare costs, patient and family costs, an update of the Dutch manual for costing in economic evaluations is used. The primary outcome measure for the cost-effectiveness analysis is the difference in limitations in activities (RDQ)[25].

\section{Details about enrolment in the study}

During the study, 397 of the 7526 women (5\%) signed only for the cohort study $(n=7526)$ and were therefore beforehand excluded for taking part in the intervention study. Throughout pregnancy, $73 \%$ of all women in the cohort reported pain in the lumbar/pelvic region leveling off to $35.9 \%$ three weeks after delivery (Figure 2). The "three weeks after delivery" prevalence rate of "wanted to be referred for treatment" was $4.8 \%$ at that moment and remained remarkably stable in the year after delivery.

Since November 2000 (Figure 3), 682 women reported that they need treatment during pregnancy ( $9 \%$ of the total cohort). 384 times midwives indicated that a woman needs treatment at the time of 10 days after delivery $(5 \%$ of the total cohort). On 197 occasions, both the woman and her midwife responded positive. The outcomes resulted in 869 possible eligible participants (11.5\% of the total cohort). However, these data resulted in only 147 home visits, 99 visits indicated by a midwife ( 67 times in combination with the woman concerned) and 115 indicated by the woman (Figure 3). On basis of history taking by telephone, 722 women were excluded from participation. Ten women did not give informed consent for the intervention study, 3 women moved outside the 

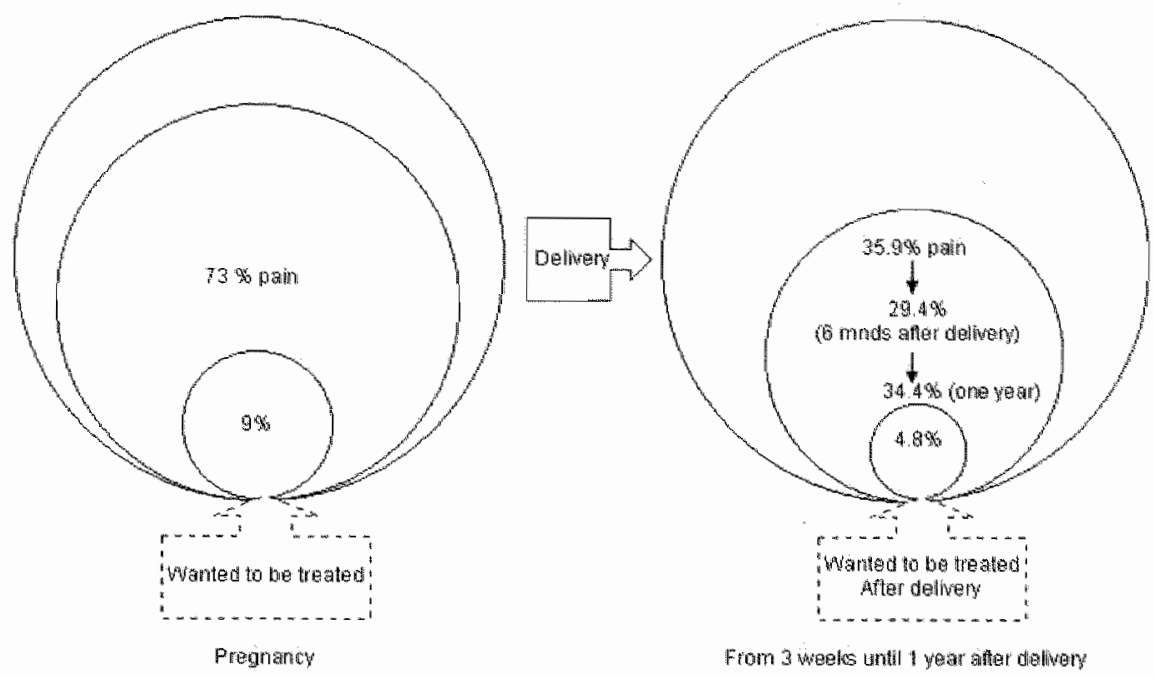

Figure 2 Prevalence of peloric girdle pain during pregnancy and after delitery

area intervention was provided, 13 women were excluded because of specific pathology, 49 women did not want to be randomized (clear treatment preference deviating from the study protocol) and 12 women did not feel like participation on second thought. The majority, 635 women, was excluded because of a quick recovery.

After the home visits, 21 women were excluded. Indicated by a midwife; one because of family reasons, one because of specific pathology and two women because of quick recovery. Indicated by them, 17 women were excluded. Two women because of family and social problems, one woman because of specific pathology, one because of a clear treatment preference and 13 women because of quick recovery.

Eventually, 126 women were included in the intervention study. 93 times indicated by midwives, 56 times indicated both by the woman and her midwife and 89 times by themselves. Finally, only $24.2 \%$ of the women indicated by a midwife were included and $13 \%$ indicated by themselves. Indicated by both the woman and her midwife, $28.4 \%$ was included. 


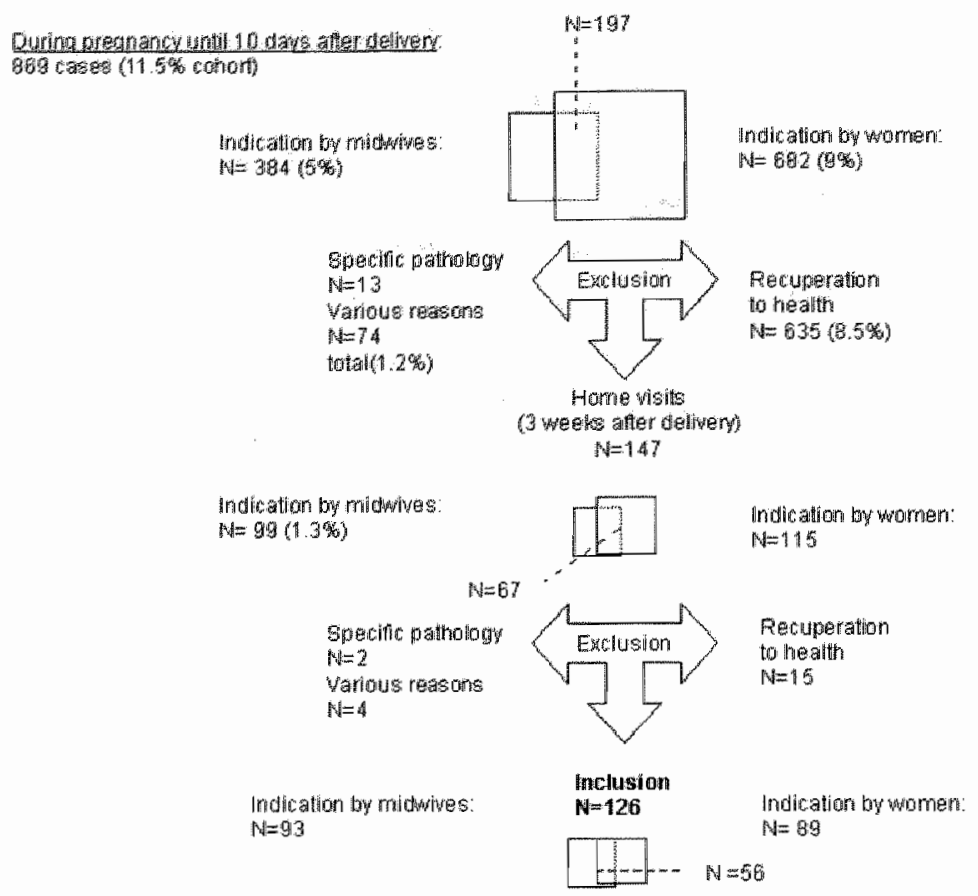

Figure 3 Enrolment in the intervention study

\section{Discussion}

This study is designed to evaluate the effectiveness of a tailor-made program with respect to biopsychosocial factors. A pragmatic design provides the opportunity to evaluate the value of the experimental intervention without depriving participating patients of the best current treatment option. Including only women who would take the $50 \%$ risk of depriving any treatment at all for their complaints during the first 12 weeks after delivery was not a realistic option. The effects of the experimental intervention and usual care are evaluated as they are applied in primary health care. It is not feasible to blind a woman to the applied treatment option, which increases the risk of information bias. We have tried to minimize this type of bias by assessing treatment preference before randomization and excluding women with a clear treatment preference. Details about the enrollment of the trial underscored this necessity $(\mathrm{N}=50$ excluded because of a clear treatment preference). The research- 
physiotherapist dealing with the baseline measurement was therefore unaware of treatment allocation.

Details about the enrollment out of the cohort into the trial also show that the start of the experimental intervention is reasonable well timed. Most women have complaints during pregnancy. However, a considerable drop in the number of women having persistent complaints in the first weeks after delivery is observed. Then again, numbers of women having one or more episodes of pain complaints remained stable in the year after delivery. We have seen similar trends of proportions of women with a request for treatment for their complaints during pregnancy $(9 \%)_{r}$ just after delivery (4.8\%) and in the year following delivery.

The aim of the experimental intervention is to increase the level of activities. Therefore the primary outcome measure is limitations in activities. "The contrast between both interventions is an important issue in this study. Major features that underscore the contrast are the character of the patient-therapist relationship, pain-contingent versus time-contingent treatment, compliance to a regime of avoiding and limiting activities versus action planning and personal goal setting by the women themselves. Among therapists, the approach of the experimental intervention is not widespread at all. The participating therapists are explicitly asked to not give any information about the contents of the experimental treatment to therapists who do not participate in the experimental intervention. It is necessary to interest physiotherapists in the trial for an efficient performing of the experimental treatment option, which can be achieved by a relevant research question and in practice applicable results.

\section{Acknowledgements}

The funding for this study was provided by the Health Care Insurance Board(College voor zorgverzekeringen $\mathrm{Cvz}$ ) in the Netherlands as a part of a research project titled "Peripartum pelvic pain during pregnancy and after delivery" ${ }^{\prime \prime}$. We would like to express our gratitude to all the participating women, thank Foekje Stelma as the research-physician of this project and Conny de Zwart for the logistic assistance (including randomization).

We also like to thank Gerda Kraag for performing and analyzing the interviews, Jeroen de Jong and Peter Heuts for their contribution to the training of the therapists in the experimental intervention group and Peter Heuts also for 
chairing the group meetings. Also very important for the project were the participating policlinics gynecology and midwives. Leonie van Gemert and Jacqueline Heesters, both occupational therapists from Blixembosch rehabilitation center Eindhoven provided important information and advices for the booklets, especially the ergonomic hints for young mothers. Finally, we thank the entire group of therapists for their enthusiastic participation during the project.

\section{References}

1. J Walde: Obstetrical and gynaecological back and pelvic pains, especially those contracted during pregnancy. Obstet Gynecol Scand 1962, 2:11-53.

2. L Damen, HM Buyruk, F Guler Uysal, FK Lotgering, CJ Snijders, HJ Stam: Pelvic pain during pregnancy is associated with asymmetric laxity of the sacroiliac joints. Acta Obstet Gyn Scand 2001, 80:1019-24.

3. H Albert, $M$ Godskesen, $J$ Westergaard: Prognosis in four syndromes of pregnancy-related pelvic pain. Acta Obstet Gyn Scand 2001, 80:505-10.

4. HC Ostgaard, G Zetherström, E Roos Hansson: The posterior pelvic pain provocation test in pregnant women. Eur Spine J 1994, 3:258-60.

5. JM Mens, A Vleeming; CJ Snijders, BW Koes, HJ Stam: Reliability and validity of the active straight leg raise test in posterior pelvic pain since pregnancy. Spine 2001, 26:1167-71.

6. A Hansen, D Jensen, M Wormslev, H Minck, S Johansen, E Larsen, C WilkenJensen, M Davidsen, T Hansen: Symptom-giving pelvic girdle relaxation in pregnancy II: Symptoms and clinical signs. Acta Obstet Gyn Scand 1999, 78:111115.

7. B Stuge, G Hilde, N Vollestad: Physical therapy for pregnancy-related low back and pelvic pain: a systematic review. Acta Obstet Gyn Scand 2003, 82:983-90.

8. G Waddell: Diagnostic triage. In: The Back Pain Revolution, vol. Chapter 2. pp. 9-26. Edinburgh, London, New York, Philadelphia, Sydney, Toronto: Churchill Livingstone; 1998: 9-26.

9. SJ Linton, K Boersma: Early identification of patients at risk of developing a persistent back problem: the predictive validity of the Orebro Musculoskeletal Pain Questionnaire. Clin J Pain 2003, 19:80-6.

10. PM Bongers, CR de Winter, MA Kompier, VH Hildebrandt: Psychosocial factors at work and musculoskeletal disease. Scand J Work Environ Health $1993,19: 297-312$.

11. B Stuge, E Laerum, $G$ Kirkesola, $N$ Vollestad: The efficacy of a treatment program focusing on specific stabilizing exercises for pelvic girdle pain after pregnancy: a randomized controlled trial. Spine 2004, 29:351-9.

12. JA Hides, GA Jull, CA Richardson: Long-term effects of specific stabilizing exercises for first-episode low back pain. Spine 2001, 26:E243-8.

13. DA van der Windt, BW Koes, M van Aarst, MA Heemskerk, LM Bouter: Practical aspects of conducting a pragmatic randomised trial in primary care: patient recruitment and outcome assessment. Br IGen Pract 2000, 50:371-4.

14. IS Richards, C Nepomuceno, $M$ Riles, $Z$ Suer: Assessing pain behavior: the UAB Pain Behavior Scale. Pain 1982, 14:393-8. 
15. JWS Vlaeyen, DFM Pernot, AMI Kole-Snijders; JA Schuerman; vH Eek, NH Groenman: Betrouwbaarheid en validiteit van een Nederlandse versie van de Pain Behavior Scale (PBS). Ned Tijdschr Psychol 1990, 45:184-189.

16. K Lorig: Partnerships between expert patients and physicians. Lancet 2002, 359:814-5.

17. I Barlow, C Wright, I Sheasby, A Tumer, I Hainsworth: Self-management approaches for people with chronic conditions: a review. Patient Educ Couns $2002,48: 177-87$.

18. IWS Vlaeyen, SI Linton: Fear-avoidance and its consequences in chronic musculoskeletall pain: a state of the art. Pain 2000, 85:317-332.

19. JE Moore, M Von Korff, D Cherkin, K Saunders, K Lorig: A randomized trial of a cognitive-behavioral program for enhancing back pain self care in a primary care setting. Pain 2000, 88:145-53.

20. IWS Vlaeyen, HA Seelen, M Peters, $\mathrm{P}$ de Jong, E Aretz, E Beisiegel, WE Weber: Fear of movement/(re)injury and muscular reactivity in chronic low back pain patients: an experimental investigation. Pain 1999, 82:297-304.

21. JWS Vlaeyen, J de Jong. M Geilen, PHTG Heuts, G van Breukelen: Graded exposure in vivo in the treatment of pain-related fear: a replicated single-case experimental design in four patients with chronic low back pain. Behav Res Ther 2001, 39:151-66.

22. T Bodenheimer, K Lorig, H Holman, K Grumbach: Patient self-management of chronic disease in primary care. JAMA 2002, 288:2469-75.

23. CHG Bastiaenen, RA die Bie, PMJC Wolters, JWS Vlaeyen, JM Bastiaaanssen, ABA Klabbers, A Heuts, PA van den Brandt, GGM Essed: Treatment of pregnancy-related pelvic girdle and/or low back pain after delivery design of a randomized clinical trial within a comprehensive prognostic cohort study. BMC Public Health 2004, 4:67

URL:http/ / www.biomedcentral.com/1471-2458/4/67

24. JWS Vlaeyen, G Crombez: Fear of movement/(re)injury, avoidance and pain disability in chronic low back pain patients. Man Ther 1999, 4:187-195.

25. M Roland, R Morris: A study of the natural history of back pain. Part I: development of a reliable and sensitive measure of disability in low-back pain. Spine 1983, 8:141-4.

26. JA Kopec, NM Esdaile, M Abrahamowicz, L Abenhaim, S Wood Dauphinee, DL. Lamping, II Williams: The Quebec Back Pain Disability Scale. Measurement properties. Spine 1995, 20:341-52.

27. LE Schoppink, MW van Tulder, BW Koes, SA Beurskens, RA de Bie: Reliability and validity of the Dutch adaptation of the Quebec Back Pain Disability Scale. Phys Ther: 1996, 76:268-75.

28. GH Guyatt, B Kirshner, R Jaeschke: Measuring health status: what are the necessary measurement properties? J Clin Epidemiol 1992, 45:1341-5.

29. Al Beurskens, HC de Vet, AJ Koke, E Lindeman, GJ van der Heijden, W Regtop, PG Knipschild: A patient-specific approach for measuring functional status in low back pain. I Manipulative Physiol Ther 1999, 22:144-8.

30. WA van der Kloot, RA Oostendorp, J van der Meij, J wan den Heuvel: De Nederllandse versie van 'McGill pain questionnaire': een betrouwbare pijnvragenlijst. Ned Tijdschr Geneeskd 1995, 139:669-73.

31. R Melzack: The MoGill Pain Questionnaire: major properties and scoring methods. Pain 1975, 1:277-99. 
32. M Cardol, RI de Haan, GA van den Bos, BA de Jong, If de Groot: The development of a handicap assessment questionnaire: the Impact on Participation and Autonomy (IPA). Clin Rehabil 1999, 13:411-9.

33. M Cardol, RJ de Haan, BA de Jong, GAM van den Bos, IM de Groot: Psychometric properties of the impact on participation and autonomy. questionnaire. Arch Phys Med Rehabil 2001, 82:210-216.

34. PHTG Heuts, IWS Vlaeyen, R Ruesink: Bewegingswrees bij lage rugpijn. Ned Tijdschr Pijn pijnbestr 1996,4:45-48.

35. SH Kori, RP Miller, DD Todd: Kinisophobia: a new view of chronic pain behavior. Pain Management 1990:35-43.

36. IE Swinkels Meewisse, I Roelof, AL Verbeek, RA Oostendorp, JW Vlaeyen: Fear of movement/(re)injury, disability and participation in acute low back pain. Pain 2003, 105:371-9.

37. L Goubert, G Crombez, S Van Damme, JW Vlaeyen, P Bijttebier, J Roelofs: Confirmatory factor analysis of the Tampa Scale for Kinesiophobia: invariant two-factor model across low back pain patients and fibromyalgia patients. Clin J Pain 2004, 20:103-10.

38. MJL Sullivan, SR Bishop, J Pivik: The pain catastrophizing scale: development and validation. Psychol Assess 1995, 7:524-532.

39. Sv Damme, G Crombez, P Bijttebier, L Goubert, Bv Houdenhove: A confirmatory factor analysis of the Pain Catastrophizing Scale: invariant factor structure across clinical and non-clinical populations. Pain 2002, 96:319-324.

40. AT Beck, CH Ward, M Medndelson, J Mock, J Erbaugh: An inventory for measuring depression. Arch Gen Psychiatry 1960, 4:561-571.

41. AT Beck, RA Steer, MG Garbin: Psychometric properties of the beck depression inventory: twenty-five years of evaluation. Clin Psychol Rev 1988, 8:77-100.

42. AL Wesley, RJ Gatchel, JP Garofalo, PB Polatin: Toward more accurate use of the Beck Depression Inventory with chronic back pain patients. Clin J Pain 1999, 15:117-21.

43. D Watson, Clark, L.A., Carey, G.: Positive an Negative Affectivity and Their Relation to Anxiety and Depressive Disorders. J Abnorm Psychol 1988, 97:346353.

44. J Ware, M Kosinski, $S$ Keller: SF-36 physical and mental summary scales: A user's manual. The Health Institute, New England Medical 1994.

45. J Ware, K Snow, M Kosinski: SF-36 Health Survey: manual and interpretation guide. The Health Institute, New England Medical 1993.

46. P Dolan: Modeling valuations for EuroQol health states. Med Care 1997, 35:1095-108.

47. ME Goossens, MP Rutten van Molken, JW Vlaeyen, SM van der Linden: The cost diary: a method to measure clirect and indirect costs in cost-effectiveness research. IClin Epidemiol 2000, 53:688-95.

48. IW Vlaeyen, NJ Teeken Gruben, ME Goossens, MP Rutten van Molken, RA Pelt, H van Eek, PH Heuts: Cognitive-educational treatment of fibromyalgia: a randomized clinical trial. I. Clinical effects. J Rheumatol 1996, 23:1237-45.

49. M Von Korff, BH Balderson, K Saunders, DL Miglioretti, EH Lin, S Berry, JE Moore, JA Turner: $A$ trial of an activating intervention for chronic back pain in primary care and physical therapy settings. Pain 2005, 113.323-30. 


\section{CHAPTER FIVE}

Short-term effectiveness of a tailor-made intervention for pregnancy-related pelvic girdle pain after delivery [ISRCTN08477490]

Caroline HG Bastiaenen, Rob A de Bie, Pieter MJC Wolters, Johan WS Vaeyen, Pieter Leffers, Foekje Stelma, Janneke M Bastiaanssen, Gerard GM Essed. Plet A van den Brondt.

Submitted 


\section{Abstract}

\section{Introduction:}

For the moment, results of recent studies on treatment of pregnancy-related pelvic girdle pain are reflecting lack of a scientific basis for a comprehensiac treatment program, suggesting uncertainty about the optinal appronch. Investigators araw particular attention to bionedical factors but there is growing evidence that biopsychosocial factors appear to be even more important as a basis of an intervention program.

Methods:

We studied the effectiveness of a tailor-made program with respect to biopsychosocial factors (intervention group) in women with pregnancy-related peloic girdle pain versus usual care based on a pain contingent basis (control group) shortly after delivery in a randomized controlled trial. Women with severe complaints shortly after delivery were selected from a longitudinal prospective cohort study $(n=7526)$, ained at pregnancyrelated pelvic girdle pain in the Netherlands. A concealed block madomization was performed after collecting baseline data. Researchers were blinded to treatment assignment. Ontcones were evaluated within the domains of the biopsychosocial npproach. Primary outcome concemed limitations in actionities (RDQ). Follow-up measurements were performed 12 weeks after delioery.

\section{Results:}

Since May 2001 until July 2003, 869 women out of the cohort made a request for treatment by a physiotherapist, 10 days after delioery. Because of a quick recovery in two weeks time, we included only 126 wonten three weeks after delivery. There was a statistionlly significant and dinically relevant difference in improvement on the primary outcome (RDQ) between the two groups in favor of the experimental interoention. The results froored the hypotheses. Women's worries about their condition were major targets. The prognosis after delivery, especially in de first weeks, turned out to be favorable. 


\section{Introduction}

Effective therapy depends to a large extent on the adequate interpretation of early symptoms and the outcome of the diagnostic process [1]. These outcomes make a positive contribution to the communication between caregiver and patient and have a meaningful influence in goal setting for intervention. The research field of pregnancy-related pelvic girdle pain is characterized by considerable differences of opinions about etiology, diagnosis and prognosis: The controversies relate to factors eliciting pain [2] and prognostic factors such as the interpretation of pain at the symphysis $[3,4]$, the question whether pelvic girdle pain is a syndrome separate from low back pain $[4,5]$ and the importance of questions about limitations in activities [6].

Currently, the intervention program aims at increasing disease-specific education and encouraging compliance with prescribed exercises and a pain contingent regime of relative (bed) rest and avoiding and limiting several dayto-day activities such as using the stairs, bending, twisting, lifting and cycling. Therapists rely heavily on reported pain duration and intensity during goal setting for intervention. Moreover, the usual intervention approach of a physiotherapist more often includes an exercise program to address the muscle imbalance and alignment of the pelvic girdle $[7,8]$. The underlying hypothesis of such an exercise program is developed as an explanation why recurrence of low back pain outside pregnancy occurred with seemingly little provocation [9]. However, results of recent treatment research on pregnancy-related pelvic girdle pain reflect a lack of scientific basis for such a comprehensive intervention program. Results of various therapeutic interventions have been published but except for one study focusing on specific stabilizing exercises [8] effectiveness remains unproven [10]. Furthermore, the majority of the studies show methodological flaws [10].

At the moment, most investigators in this field draw particular attention to biomedical factors but there is growing evidence that important prognostic problems such as biopsychosocial factors appear to be even more important as a basis in an intervention program $[11,12]$.

We therefore performed a double-blind randomized controlled trial in primary care to determine the effectiveness of a tailor-made program with respect to biopsychosocial factors (intervention group) for women with pregnancy-rellated pelvic girdle pain after dellivery versus usual care on a pain contingent basis 
(control group). Because of the relatively unknown etiology and the lack of a clear definition, we used an extensive description of pregnancy-related pelvic girdle pain including all women who experience some form of pregnancyrelated pain in the lower back and/or pelvic girdle originated within the musculosketal system.

The trial is embedded in a longitudinal, prospective cohort study [13], which studies the prevalence, etiology, severity and prognosis of pregnancy-related pelvic girdle pain until one year after delivery. The trial is designed and reported according to the Consolidated Standards of Reporting Trials (CONSORT) statement [14] and is registered in the International Standard Randomised Controlled Trial Number Register [ISRCTN08477490]. The present article describes the short-term results. The study design has been described elsewhere [15]. Long-term results and costs are reported separately.

\section{Methods}

\section{Recruitment and informed consent}

The medical ethics committee of the Maastricht University Hospital approved the intervention and cohort studies which were performed in the Southeast of the Netherlands. Midwives and gynecologists recruited the women during early pregnancy (10-14 weeks). Women were included in the cohort if they were at least 18 years old, pregnant and well versed in the Dutch language $(n=7526)$. Women were given written information explaining the aims and contents of the cohort and intervention studies before they decided to participate. Concerning the intervention study they were told that according to current knowledge, the two investigated treatment options are considered to be equally effective. The moment of inclusion for the intervention study was about three weeks after delivery. An individual woman entered the intervention study after signing informed consent for both the cohort and the intervention studies during early pregnancy and meeting the in-and exclusion criteria of the intervention study shortly after delivery. A basic principle was that inclusion criteria must have a meaningful influence in goal setting for treatment. Women were included when having pain in the pelvic girdle with an onset during pregnancy or just after delivery (cohort data), were restricted in their normal daily activities because of pelvic girdle pain and if there was a delay in recuperation (unable to participate satisfactorily in housekeeping and care of children because of the complaints under investigation). The severity of symptoms should vary with physical 
activities and time during the day. Women diagnosed with relevant specific pathology (such as nerve root pathology, rheumatoid disorders, carcinoma, obstetric complications) that affects pain and activities of daily life were excluded. Exclusion also occurred in case of severe family-related or psychosocial problems or when a disablement procedure was not yet finished. Final aspects for in-/exclusion were the willingness of a woman to participate in the study or having a clear treatment preference. We only included women who did not indicate such a preference [16].

An experienced research-physiotherapist visited the women at home, about three weeks after delivery. This visit was called for on the basis of a short selfadministered questionnaire or initiated by midwives. A positive answer from a participating woman from the cohort or her midwife: "Is an intervention by a physiotherapist necessary?" took a central position in these questionnaires. Preceding a possible home visit, a short history taking by telephone took place about two weeks after delivery. The telephone interview focused on exclusion criteria such as willingness to participate, specific pathology and inclusion criteria such as limitations in daily life caused by pregnancy-related pelvic girdle pain and a delay in recuperation. During the home visit, a standardized history was taken and physical examination to exclude specific pathology was performed. Self-administered questionnaires were used to asses pain, limitations in activities, restrictions in participation, pain-related fear, pain catastrophizing, positive and negative affectivity, depression, expectancy of treatment result and quality of life. The questionnaires contained clear instructions to complete them with no help or support from others. If a woman met the selection criteria, she was informed about the aim and method of the intervention study and if she was willing to participate, the informed consent procedure was completed. The research-physiotherapist collecting the baseline data was trained at performing the measurements in a standardized way and was blinded for treatment assignment.

\section{Randomization and blinding}

Randomization took place after collecting the baseline data and obtaining informed consent. An independent research assistant (unaware of the base line data) carried out the concealed randomization procedure using a random computer-generated list. Block size for the randomization was four. When a woman was allocated to the intervention group, a physiotherapist trained in the experimental intervention practicing in the neighborhood of the woman was 
contacted and we ensured that treatment could start within one week. Treatiment costs were covered for all participants in the intervention group. Women, allocated to the usual care group, were free to choose usual care treatment by a physiotherapist who was not trained in the experimental intervention protocol.

Women were blinded to a certain extent to the allocated intervention option because they were kept naive of the exact content of both intervention options. Physiotherapists were not involved in the baseline and effect measurements. Researchers dealing with the baseline and outcome data were blinded to the intervention assignments.

\section{Interventions}

\section{Experimental intervention}

Women, allocated to the intervention group, were referred to a participating physiotherapist in their own neighborhood. These physiotherapists received an educational program about the treatment protocol prior and during the study. All physiotherapists were already experienced and specialized in treating women. with pregnancy-related pelvic girdle pain prior to the study. "The content of the experimental intervention was based on the latest literature findings. It focused particularly on patient-therapist relationship, education and the promotion of an active life style rather than avoiding activities. Results of interviews with women from the cohort and group discussions with experienced physiotherapists prior to the trial further defined the program.

Theoretical concepts of self-management $[17,18]$ and fear-avoidance [19] were integrated in the intervention protocol. We provided an individualized selfmanagement approach of 7-9 sessions for 30 minutes once a week. Standardized information was presented by means of an intervention protocol for the therapists and by booklets for the patients [18, 20]. Topics included back and pelvis anatomy, "red flags" indicating a serious medical condition, factors contributing to fluctuations in pain, appropriate pacing of activity, handling pain flare-ups, cognitive restructuring, some graded exposure techniques [19, $21,22]$ and communication. Therapists had to employ simple problem-solving techniques that engaged women in identifying day-to-day problems or limitations related to pelvic girdle pain, setting personal goals, brainstorming options for achieving these goals and developing personal action plans. In subsequent sessions, women reviewed their action plans and their progress 
towards goals and engaged in problem-solving skills conceming difficulties that arose in trying to implement their plans, Information about two opposing behavioral responses of pain-related fear (avoidance and confrontation) was given and a hierarchy of individual fear-eliciting movements and activities was made. Therapists encouraged women in making action plans with respect to graded exposure techniques in specific activities that were avoided. They were explicitly asked not to "label" the complaints in terms of medical diagnostics.

Generally, a time contingent policy was followed in which women set the pace by means of action plans. The expertise of the physiotherapists of the condition in general and of the women about their own specific condition and lives were equally important [23].

\section{Usual care}

Women, allocated to the usual care group, were free to choose usual care treatment by a physiotherapist who did not followed the educational program about the treatment protocol, guidance by a general practitioner or do nothing. All physiotherapists were experienced and specialized in treating women with pregnancy-related pelvic girdle pain. Information about the option chosen was collected by means of questionnaires in the follow-up period. When a woman opted in favor of treatment, the sessions started within one week. Prior to the trial, detailed information was gathered about the contents of traditional treatment options. Part of the information was gathered by means of group discussions with experienced physiotherapists and occupational therapists and interviews on an individual basis with affected women out of the cohort. The most striking characteristics of the traditional treatment were the character of the therapist-patient relation and the way of goal setting, focusing on disease management [18]. There was an explicit professional input and an accent on biomedical aspects. A pain contingent regimen of avoiding and limiting several day-to-day activities was considered important. Compliance based on these goals played an important part. An exercise program focusing on the muscle imbalance and alignment of the pelvic girdle was a standard part of the intervention [7]. Therapists were often highly concerned about their patient's pain themselves. A biomechanical label with highlighting the attention on pain and emphasizing the vulnerability of the spine and pelvis to damage characterized the patient information. 
Contrast between the experimental intervention and the usual care

The contrast between the experimental intervention and usual care was an important issue in this study. Major features that underscore the contrast were the contents of the patient information, character of patient-therapist relationship, pain-contingent versus time-contingent intervention and compliance to a regime of avoiding and limiting activities versus action planning and personal goal setting by the women themselves. Among therapists, the approach of the experimental intervention is not widlespread at all. The participating therapists were explicitly asked not to give any information about the contents of the experimental treatment to therapists who do not participate in the experimental intervention.

\section{Measurements}

\section{History and physical examination}

During the visit at home a standardized history was taken [24] and physical examination was performed. During history taking, questions about on-going pain, its location, intensity and modalities, variation of symptoms with physical activities, radiation into the legs, back pain versus leg pain, neurological signs, deformity, obstetric complications, a case history of low back and pelvic girdle pain prior to this pregnancy and other differential diagnoses. The format of the answers was presented as a dichotomous "yes or no". Demographic characteristics and data about education, work, income, use of tobacco, medication, the onset of pain and functional status during pregnancy were already gathered as part of the cohort study at 14 and 30 weeks gestation period and two weeks after delivery.

After history taking, a short standardized clinical examination program was performed, which included tests of nerve root radiation (exclusion)[24].

The research-physiotherapist filled out the Pain Behavior Scale, a standardized observation scale for quantifying pain behavior $[25,26]$.

\section{Primary outcomes}

Primary domain (Table 1) for improvement of the intervention was limitations in activities. Other important domains were the severity of the main complaint and global feeling of recovery.

Limitations in activities were measured with the Dutch translation of the Roland Disability Questionnaire (RDQ) [27]. We replaced the phrase "because 
of my back or pelvic girdle pain" to all questions instead of "because of my back"

Table 1 Timing of the measures

\begin{tabular}{|c|c|c|}
\hline ? & $\begin{array}{c}\text { Baseline } \\
\text { about } 3 \text { weeks after } \\
\text { delivery }\end{array}$ & $\begin{array}{l}3 \text { months } \\
\text { after randomization }\end{array}$ \\
\hline History taking & $x$ & \\
\hline Physical examination: & $x$ & \\
\hline PBS & $x$ & \\
\hline Expectancy treatment result & x & \\
\hline PCS & $x$ & \\
\hline $\mathrm{BDI}$ & $x$ & \\
\hline NEM & $\mathrm{x}$ & \\
\hline PEM & $x$ & \\
\hline Primary outcomes & & \\
\hline RDQ & $\mathbf{x}$ & x \\
\hline$M C$ & $x$ & $\mathbf{x}$ \\
\hline GPE & $\mathbf{x}$ & $x$ \\
\hline Secondary outcomes & & \\
\hline VAS pain & $x$ & $x$ \\
\hline TSK & $x$ & $x$ \\
\hline SF-36 & $x$ & $x$ \\
\hline IPA & $x$ & $x$ \\
\hline Subsequent pregnancy & & $x$ \\
\hline Compliance & & $x$ \\
\hline Co-intervention & & $x$ \\
\hline
\end{tabular}

PBS = Pain Behavior Scale GPS = Global Perceiwed Effect, $M C=$ Main Complaint, MPQ $=$ McGill Pain Questionnaire, $R D Q=$ Roland Disability Questionnaire, $T S K=$ Tampa Scale For Kinesiophobia, $P C S=$ Pain Catastrophizing Scale, $B D I=$ Beck Depression Inventory, NEM = Negative Emotionality Scale, $P E M=$ Positive Emotionality Scale, SF-36 = Short-Form36. $\mathrm{VPA}=$ Impact on Participation and Autonomy

The Quebec Back Pain Disability Scale (QBPDS) [28] [29] was initially also selected [15] but immediately after the start of the data-collection it became clear that the missing value rate on a number of items $(4,11,12,19$ and 20) was rather high, shortly after delivery. Those items focus on activities as driving a car, throwing a ball, running and lifting or pushing a heavy weight. Performance of those activities was unlikely for most of the women so shortly after delivery and the scoring possibilities left not enough possibilities to answer those items satisfactorily.

Subjective measurements like global feeling of recovery (global perceived effect, GPE) and severity of the main complaints (MC) reflecting a patient-specific approach were also selected. Global Perceived Effect [30] (GPE) was measured 
by self-assessment on a 7 -point scale $(1=$ completely recovered, $7=$ worse than ever). The main complaints (MC) were selected by the women in a standardized approach by sellecting three activities, which are an essential and frequently performed part of her everyday life. However, performance of those activities was difficult or impossible because of pelvic girdle complaints at the moment of baseline measurement. The severity of the selected main complaints was rated with Visual Analog rating Scales (VAS). [30,31].

\section{Secoridary outcomes}

Pain was measured with two Visual Analog rating Scales (VAS) of the McGill Pain Questionnaire (MPQ-DLV) [32, 33] to record the intensity of pain the last week and day. The impact on participation and autonomy (IPA) measured person-perceived restriction in participation and autonomy [34, 35]. The used subscales were self-care and appearance, mobility, leisure, social relationships and family role.

Fear of movement was measured by the Dutch translation of the Tampa Scale for Kinesiophobia (TSK) [36, 37]. We used the TSK and the both subscales "fear avoidance" and "harm". [38, 39]

The Short-Form 36 (SF-36) [40] evaluated health status [41]. We used the subscale "general health".

Baseline measurements

Pain catastrophizing is measured by the Pain Catastrophizing Scale (PCS)[42, 43].

The Beck Depression Inventory (BDI) [44] was used to measure depressive symptoms [45]. [t has been argued that the somatic content of the BDI may lead to false-positives among patients with physical problems. Therefore, items associated with weight loss, sleeping disturbance and work inhibition were excluded in this study [46].

To measure the experience of negative affect we used the 14-item Negative Emotionality Scale [47]. To measure positive affect we used the 11-item Positive Emotionality Scale [47]. Both were subscales of the Multidimensional Personality Questionnaire.

Treatment expectancy [48] was measured by means of a $100 \mathrm{~mm}$ visual analog rating scale (VAS). The women were asked to what extend they believed that the treatment is beneficial to them.

The Pain Behavior Scale (PBS) $[25,26]$ is an observation scale tapping 8 behaviors that the physiotherapist completes after physical examination. These 
are verbal complaints, facial grimaces, standing posture, mobility, body language, use of visible supportive equipment and stationary movement:

\section{Follow-up}

Women were asked to complete a follow-up questionnaire (Table 1) at 12 weeks after randomization. Those women who did not return their follow-up questionnaires were contacted by (e) - mail or phone and were asked to continue participation.

\section{Compliance, other interventions and confounding}

The follow-up questionnaire (Table 1) asked all women how many treatment sessions they had followed since baseline measurement. Furthermore, information on contents, satisfaction and which aspects of the (experimental) treatment they found benefit in. Co-intervention, medication, aids, additional medical consumption were also registered.

\section{Statistical analyses}

The baseline status of the study groups was compared with respect to the distribution of all variables known at baseline. For the outcome measures recorded at baseline and follow-up, we computed the difference between the baseline and follow-up score for each woman. Differences between group and 95\% CI 's were calculated for each outcome measure according to the intentionto-treat approach [49]. Primary analysis was done by means of analysis of an independent $t$-tests (for continuous outcome variables) and chi-square tests (for: categorical outcome variables). Longitudinal missing data were substituted with the "baseline carried forward method". In all comparisons between the two treatment options a two-tailed p-value of 0.05 was considered to indicate statistical significance. Analyses were done by using SPSS statistical software, version 12.0 (SPSS, Inc., Chicago).

\section{Results}

\section{Recruitment}

From November 2000 until November 2002, 7526 women were included in the cohort study.

Results of the self-administrated question: "Is an intervention by a physiotherapist necessary?" resulted in 869 eligible participants; 384 times 
indicated by midwives, 682 times indicated by women themselves and 197 times both the women and midwives responded positively. (Figure 1) On the basis of history taking by telephone two weeks after delivery, 722 of the 869

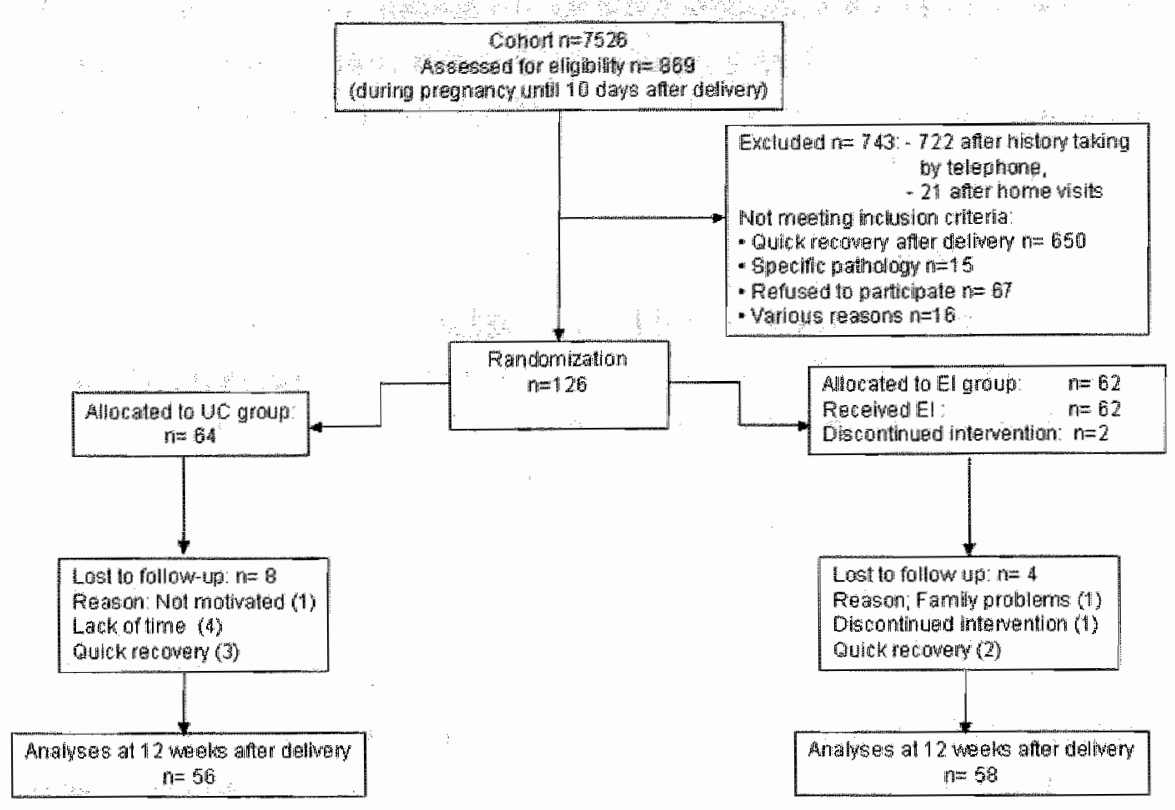

Figure 1. Flow participants through the study

women were excluded from participation. The majority of them, 635 women, were excluded because of a quick recovery, 13 women because of specific pathology, 49 women did not want to be randomized (clear treatment and therapist preference deviating from the study protocol), 12 women preferred not to participate on second thought, 10 women did not give informed consent for the intervention study and 3 women had moved outside the area where intervention was provided. History taking by telephone resulted in 147 home visits three weeks after delivery. Based on the home visits, 21 women were excluded: 15 women because of quick recovery, 2 women because of specific pathology, 1 woman because of a clear treatment preference and 3 women because of family or social reasons. Finally, from May 2001 until July 2003, 126 women were included in the intervention study. 


\section{Baseline Characteristics}

Baseline status of the participants is given in Table 2. Both groups were highly similar in prognostic variables and baseline values of outcome measures.

Table 2. Baseline characteristics and mensures according to treatment group

\begin{tabular}{|c|c|c|c|c|}
\hline \multirow[t]{2}{*}{ Variable } & \multicolumn{2}{|c|}{$\begin{array}{l}\text { Usual Care } \\
n=64\end{array}$} & \multicolumn{2}{|c|}{$\begin{array}{l}\text { Experimental intervention } \\
\qquad n=62\end{array}$} \\
\hline & mean & $\mathrm{SD}$ & mean & $S D$ \\
\hline Age & 31.5 & 3.1 & 31.4 & 3.6 \\
\hline Localization of pain: & & & & \\
\hline Lumbar spine & 25 & 39.1 & 24 & 38.7 \\
\hline Sl joints (one or two) & 34 & 53.1 & 34 & 54.8 \\
\hline Symphysis & 43 & 67.2 & 42 & 67.7 \\
\hline History of PPGP pain & 43 & 67.2 & 44 & 71.0 \\
\hline Parity & 2.1 & 1.0 & 2.3 & 1.0 \\
\hline Measures & & & & \\
\hline VAS (pain today) $(0-100)$ & 54.3 & 17.5 & 53.5 & 19.1 \\
\hline VAS (pain this week) $(0-100)$ & 59.2 & 17.9 & 57.0 & 17.8 \\
\hline $\begin{array}{l}\mathrm{RDQ}(0-24) \\
\text { IPA }\end{array}$ & 13.5 & 4.3 & 13.3 & 4.6 \\
\hline Autonomy in self-care $(0-28)$ & 9.6 & 5.7 & 8.8 & 5.1 \\
\hline Mobility and leisure $(0-20)$ & 10.9 & 3.7 & 10.0 & 4.7 \\
\hline Family role $(0-28)$ & 15.4 & 5.8 & 14.4 & 5.6 \\
\hline Social relationships $(0-24)$ & 5.8 & 3.3 & 5.5 & 3.4 \\
\hline MC (VAS) $(0-100)$ & 69.5 & 17.5 & 72.0 & 15.7 \\
\hline TSK: & & & & \\
\hline Total score $(17-68)$ & 35.7 & 5.9 & 32.9 & 50 \\
\hline Feal avoidance $(8-32)$ & 18.8 & 3.6 & 17.0 & 3.0 \\
\hline Harm $4(5-20)$ & 8.5 & 2.2 & 7.9 & 2.3 \\
\hline $\operatorname{PCS}(0-52)$ & 12.2 & 9.8 & 11.2 & 8.4 \\
\hline$B D \mid \cdot(0-54)$ & 5.3 & 4.9 & 5.1 & 4.2 \\
\hline $\operatorname{NEM}(0-14)$ & 3.3 & 3.4 & 2.4 & 2,3 \\
\hline $\operatorname{PEM}(0-11)$ & 7.8 & 2.6 & 8.5 & 24 \\
\hline SF-36: & & & & \\
\hline General health $(0-100)$ & 54.6 & 12.5 & 57.8 & 13.1 \\
\hline Expectancy treatment $(0-100)$ & 79.0 & 17.8 & 78.3 & 16.6 \\
\hline$P B S *(0-8)$ & 1.3 & 1.3 & 1.5 & 1.6 \\
\hline
\end{tabular}

- mear BD/ calculated without items 15,16,19, "first main complaint (MC) was selected. TSK sutbscale fear avoidance (items $1,2,9,10,13,14,15,17), \triangle S K$ subscale harm (items $3,5,6,7,11), P$ ain behawior Scalle filled our by research physiotherapist after physical examination

\section{Follow-up}

After randomization, 64 patients were assigned to the usual care group (UC group) and 62 to the experimental intervention group (EI group). In all patients, baseline data were complete. In the usual care group, for 56 patients $(88 \%)$ data were available for all outcome measures at 12 weeks after delivery. In the 
experimental intervention group, the corresponding number was $58(94 \%)$. In the usuall care group 8 patients were lost to follow-up because of quick recovery within the first weeks after randomization and did not want the fill out the outcome assessments anymore $(n=3)$, lack of time $(n=4)$, or not motivated to fill out the outcome assessments $(n=1)$. In the experimental intervention group 4 patients were lost to follow-up because of family reasons $(n=1)$, discontinued intervention ( $n=1)$ and quick recovery within the first weeks after randomization $(n=2)$. All patients who were lost to follow-up in both study groups were contacted by telephone.

\section{Compliance and co-intervention}

In the experimental intervention group, two patients discontinued intervention. One woman because of lack of motivation and one woman because she could not endorse the basic principle of the experimental intervention (preferred a pain contingent treatment option on second thought). Nevertheless, the last mentioned patient completed all the outcome questionnaires and did not receive another treatment during the investigation period.

In the usual care group 22 women were treated by a physiotherapist, 4 women by a manual therapist, and 4 women were guided by their general practitioner. The other $(n=34)$ chose not to seek help for their complaints during the same period.

In the experimental group 6 women used pain medication, one woman used an elastic belt and $X$-ray examined 2 women. In the control group 5 women used pain medication, 9 women an elastic belt and $X$-ray examined $5 X$-ray.

Neither of the women in both study groups reported a subsequent pregnancy, three months after delivery.

Effectiveness of the experimental intervention (EI) compared to the usual care option (UIC)

Measurement at 12 weeks after delivery showed a consistent difference in favor of the experimental intervention but only the primary outcome limitations in activities measured with the RDQ reached statistical significance (Table 3). More women in the experimental intervention group reported full recovery or very large improvement $(74.1 \%)$ than women in the usual group (66.1\%) did. The outcomes of the main complaint, pain, general health and the subscale 
Table 3 Outcomes, mean change and differences between groups in outcome measures

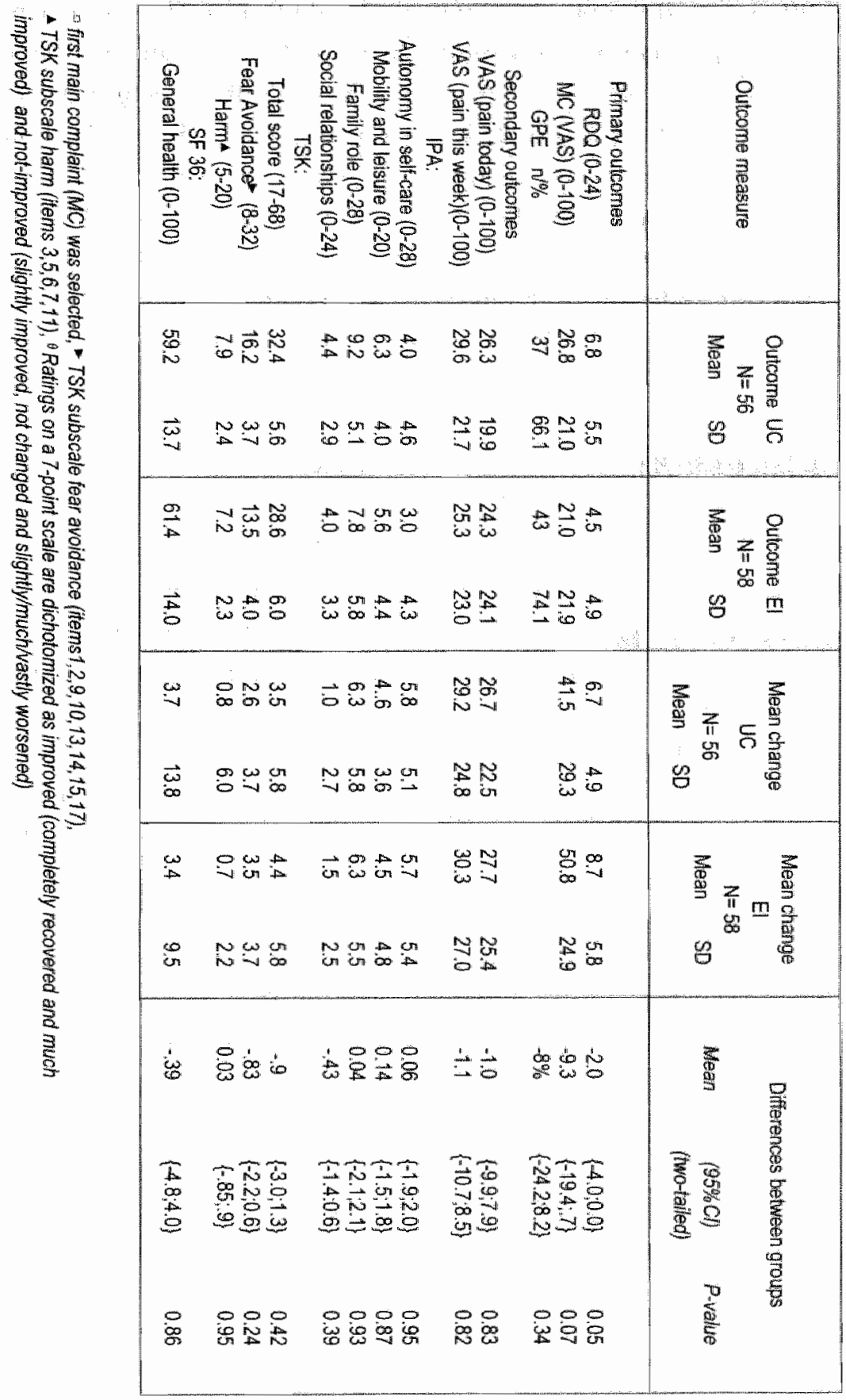


fear-avoidance of the TSK favored the experimental intervention, but differences did not reach statistical significance.Therefore, we performed a subgroup analysis to explore a possible different intervention effect in subgroups of women with severe limitations in activities at baseline. We expected that women with severe limitations in activities benefited more from the experimental intervention than from the usual care. We performed a median split on the baseline data of the RDQ and compared the both subgroups (baseline score $R D Q<13$ versus $\geq 13$ ). We found a statistically significant and clinically relevant difference of 4.3 points in favor of the experimental intervention in the subgroup $R D Q \geq 13$ (Table 4). However we did not find a statistically significant difference in the subgroup $\mathrm{RDQ}<13$.

\section{Discussion}

In our study, women with pregnancy-related pelvic girdle pain benefited more from a tailor-made program with respect to biopsychosocial factors than from a usual care program on a traditional pain contingent basis. At 12 weeks after delivery, we found a statistically significant difference in improvement between the two study groups in favor of the experimental intervention group that was clinically relevant ( 2 points) in limitations in activities measured with the RDQ. Other outcomes, such as global perceived effect, main complaint, pain, fearavoidance and general health supported our main finding but did not reach statistical significance.

Although a substantial number of the participants of the cohort $(n=869)$ reported complaints and limitations in activities to the extent that treatment seems to be necessary during pregnancy, the prognosis (when not receiving treatment) is very good in the first weeks after delivery. For that reason the recruitment of women with persistent complaints and limitations in activities after delivery was lower than expected. We used the maximum of participants out of the cohort $(n=7526)$ and still included only 126 women. Nevertheless, we reached sufficient statistical power for the primary outcome, limitations in activities. But the smaller than planned study sample could have influenced the results of the other outcomes who were in line with the primary outcome but failed to reach statistical significance. 
Table 4 Subgroup analyses primary outcomes

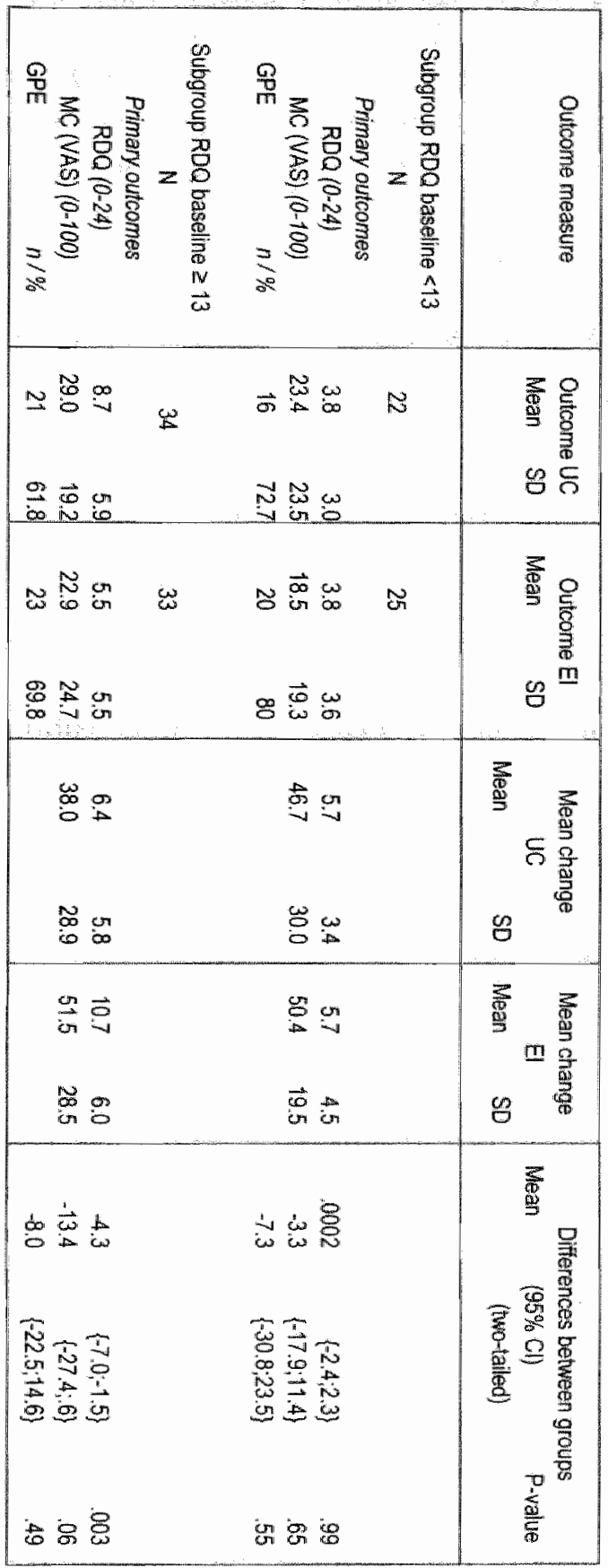


The favorable prognosis shortly after delivery influenced probably also the improvement in both study groups. The recovery rates of both study groups were still relatively high, 12 weeks after delivery.

Subgroup analysis showed that women with moderate limitations in activities (score RDQ at baseline <13 points) improved quite well and nearly in the same extent in both study groups. However, in the subgroups with severe limitations in activities (score $R D Q$ at baseline $\geq 13$ points) the improvement favored the experimental intervention group compared to women in the usual care group. This finding underscored the main conclusion of the study clearly that women who received the experimental intervention benefited more from treatment than women who received usual care.

In general we did not deviate from the original study design, which was described independently of the study results [15]. At randomization, treatment groups were similar on demographics, patient characteristics and putative prognostic factors. To improve the transparency of the experimental intervention, we used a detailed protocol and standardized patient information by means of booklets.

Because of the nature of the experimental intervention, blinding of the therapists and women was not possible however the latter were kept naîve of the exact content of both intervention options. A clear treatment or therapist preference could influence responses regarding outcome measures. Therefore women who had a priori a treatment preference for a special treatment or therapist were excluded $(n=50)$.

Embedding the trial in a large cohort study had several advantages. Details about the enrollment out of the cohort into the trial showed that the start of the experimental intervention (three weeks after delivery) was reasonably well timed. A substantial number of women in whom intervention seemed to be necessary during pregnancy, recuperated quickly without treatment in the first weeks after delivery.

Prior to the trial, we arranged interviews on an individual basis with women out of the cohort and groups' discussions with experienced physiotherapists and occupational therapists. Results of those interviews were compared with literature findings and the outcomes of the group discussions. The answers of affected women about their perception of the contents of the traditional treatment approach and the patient-therapist relationship formed a sharp contrast with the view of the therapists about those topics. The results also 
showed that worries about their condition in this population are not minor concerns. The worries referred to an unremitting source of anxiety about the etiology and prognosis. The degree of distress may contribute to avoidance of picking up the full range of activities again after delivery and the feeling that a wrong movement could lead to a serious problem, making individual concerns and worries an important target of care. These results and the contrast in perception between therapist and patient were important reasons to introduce, within the scope of a biopsychosocial approach, the theoretical concepts of selfmanagement and fear-avoidance. The developed standardized patient information focused therefore on positive attitudes, an active response to the complaints and a physiological rationale about pain. It did not include information about a possible vulnerability of the spine or pelvis to damage and a relation with pain.

In general, women were willing to accept the responsibility to manage their own condition and solve their problems with guidance from the physiotherapists. They picked up the time contingent approach quickly. Nevertheless, there was some hesitation of a number of participating physiotherapists about their role in the intervention protocol during the educational training prior to the trial. Once they were be engaged with patients, they liked their supporting role of the women to create plans that will help her to achieve their goals. The shift from a pain contingent approach to a time contingent approach and the radical change in the character of the patienttherapist relationship seemed to be easier for the women than for the physiotherapists. Finally, both the women and the physiotherapists found the intervention protocol attractive and useful.

\section{Conclusion}

The results of the trial supported the hypothesis. Although the biopsychosocial approach as a basis for intervention already is largely investigated in several musculoskeletal disorders and generated significant results, in the field of pregnancy-related pelvic girdle or low back pain it is a new approach. Women's individual worries and concerns about their condition were major targets. 


\section{Acknowledgements}

The funding for this study was provided by the Health Care Insurance Board (College voor zorgverzekeringen $\mathrm{CVZ}$ ) in the Netherlands as a part of a research project titled "Peripartum pelvic pain during pregnancy and after delivery". We would like to express our gratitude to all the participating women, Gonnie Klabbers as research-physiotherapist and Conny de Zwart for the logistic assistance.

Finally, we thank the entire group of therapists for their enthusiastic participation during the project.

\section{References}

1. J Knottnerus: Challenges in dia-prognostic research. J Epidemiol Community Health 2002, 56:340-341.

2. L Damen, HM Buyruk, F Guler Uysal, FK Lotgering, CJ Snijders, HJ Stam: Pelvic pain during pregnancy is associated with asymmetric laxity of the sacroiliac joints. Acta Obstet Gynecol Scand 2001, 80:1019-24.

3. H Albert, $M$ Godskesen, J Westergaard: Prognosis in four syndromes of pregnancy-related pelvic pain. Acta Obstet Gynecol Scand 2001, 80:505-10.

4. HC Ostgaard, G Zetherström, E Roos Hansson: The posterior pelvic pain provocation test in pregnant women. Eur Spine J 1994, 3:258-60.

5. JM Mens, A Vleeming, R Stoeckart, H] Stam, C] Snijders: Understanding peripartum pelvic pain. Implications of a patient survey. Spine 1996, 21:1363-9.

6. A Hansen, D Jensen, M Wormslev, H Minck, S Johansen, E Larsen, C WilkenJensen, $M$ Davidsen, T Hansen: Symptom-giving pelvic girdle relaxation in pregnancy II:Symptoms and clinical signs. Acta Obstet Gynecol Scand 1999, 78:111-115.

7. JA Hides, GA Jull, CA Richardson: Long-term effects of specific stabilizing exercises for first-episode low back pain. Spine 2001, 26:E243-8.

8. B Stuge, E Laerum, G Kirkesola, N Vollestad: The efficacy of a treatment program focusing on specific stabilizing exercises for pelvic girdle pain after pregnancy: a randomized controlled trial. Spine 2004, 29:351-9.

9. PW Hodges, CA Richardson: Inefficient muscular stabilization of the lumbar spine associated with low back pain. A motor control evaluation of transversus abdominis. Spine 1996, 21:2640-50.

10. B Stuge, G Hilde, N Vollestad: Physical therapy for pregnancy-related low back and pelvic pain: a systematic review. Acta Obstet Gynecol Scand 2003, 82:98390.

11. PM Bongers, CR de Winter, MA Kompier, VH Hildebrandt: Psychosocial factors at work and musculoskeletal disease. Scand J Work Environ Health $1993,19: 297-312$. 
12. SJ Linton, K Boersma: Early identification of patients at risk of developing a persistent back problem: the predictive validity of the Orebro Musculoskeletal Pain Questionnaire. Clin I Pain 2003, 19:80-6.

13. JM Bastiaanssen, RA de Bie, CHG Bastiaenen, A Heuts, MEAL Kroese, GGM Essed, PA van den Brandt. Etiology and prognosis of pregnanoy-related pelvic girdle pain; design of a longitudinal study. BMC Public Health 2005, 5:1

URL:http//www:biomedcentral.com/1471-2458/5/1

14. D Moher, KF Schulz; DG Almam: The CONSORT statement: revised recommendations for improving the quality of reports of parallel group randomized trials. BMC Med Res Methodol 2001, 1:2.

URL:http/ / www biomedcentral.com/1471-2288/1/2

15. CHG Bastiaenen, RA de Bie, PMJC Wolters, JWS Vlaeyen, JM Bastiaanssen, ABA Klabbers, A Heuts, PA van den Brandt, GGM Essed: Treatment of pregnancy-related pelvic girdle and/or low back pain after delivery design of a randomized clinical trial within a comprehensive prognostic cohort study. BMC Public Health 2004, 4:67

URL:http//www.biomedcentral.com/1471-2458/4/67

16. DA van der Windt, BW Koes, $M$ van Aarst, MA Heemskerk, LM Bouter: Practical aspects of conducting a pragmatic randomised trial in primary care: patient recruitment and outcome assessment. Br J Gen Pract 2000, 50:371-4.

17. J Barlow, $\mathbb{C}$ Wright, J Sheasby, A Turner, J Hainsworth: Self-management approaches for people with chronic conditions: a review. Patient Educ Couns $2002,48: 177-87$.

18. K Lorig: Partnerships between expert patients and physicians. Lancet 2002, 359:814-5.

19. JWS Vlaeyen, SI Linton: Fear-avoidance and its consequences in chronic musculoskeletal pain: a state of the art. Pain 2000, 85:317-332.

20. JE Moore, M Von Korff, D Cherkin, K Saunders, K Lorig: A randomized triall of a cognitive-behavioral program for enhancing back pain self care in a primary care setting. Pain 2000, 88:145-53.

21. JW Vlaeyen, HA Seelen, M Peters, $\mathbb{P}$ de Jong, E Aretz, E Beisiegel, WE Weber: Fear of movement/(re)injury and muscular reactivity in chronic low back pain patients: an experimental investigation. Pain 1999, 82:297-304.

22. JW Vlaeyen, J de Jong, M Geilen, PH Heuts, $G$ van Breukelen: Graded exposure in vivo in the treatment of pain-related fear: a replicated single-case experimental design in four patients with chronic low back pain. Behav Res Ther 2001, 39:151 66.

23. T Bodenheimer, K Lorig, H Holman, K Grumbach: Patient self-management of chronic disease in primary care. JAMA 2002, 288:2469-75.

24. G Waddell: Diagnostic triage. In: The Back Pain Revolution, vol. Chapter 2. pp. 9-26. Edinburgh, London, New York, Philladelphia, Sydsney, Toronto: Churchill Livingstone; 1998: 9-26.

25. IS Richards, C Nepomuceno, M Riles, Z Suer: Assessing pain behavior: the UAB Pain Behavior Scale. Pain 1982, 14:393-8.

26. JWS Vlaeyen, DFM Pernot, AMJ Kole-Snijders, JA Schuerman, vH Bek, NH Groenman: Betrouwbaarheid en validiteit van een Nederlandse versie van de Pain Behavior Scale (PBS). Ned Tijdschr Psychol 1990, 45:184-189. 
27. M Roland, R Morris: A study of the natural history of back pain. Part $\mathrm{L}$. development of a reliable and sensitive measure of disability in low-back pain. Spine 1983, 8:141-4.

28. IA Kopec, M Esdaile, M Abrahamowicz, L Abenhaim, S Wood Dauphinee, DL Lamping, II Williams: The Quebec Back Pain Disability Scalle. Measurement properties. Spine $1995,20: 341-52$.

29. LE Schoppink, MW van Tulder, BW Koes, SA Beurskens, RA de Bie: Reliability and validity of the Dutch adaptation of the Quebec Back Pain Disability Scale. Phys Ther $1996,76: 268-75$.

30. Al Beurskens, HC de Vet, AJ Koke, E Lindeman, GJ van der Heijden, W Regtop, PG Knipschild: A patient-specific approach for measuring functional status in low back pain. J Manipulative Physiol Ther 1999, 22:144-8.

31. GH Guyatt, B Kirshner, R Jaeschke: Measuring health status; what are the necessary measurement properties? J Clin Epidemiol 1992, 45:1341-5.

32. WA van der Kloot, RA Oostendorp, J van der Meij, J van den Heuvel: De Nederlandse versie van 'McGill pain questionnaire': een betrouwbare pijnvragenlijst. Ned Tijdschr Geneeskd 1995, 139:669-73.

33. R Melzack: The McGill Pain Questionnaire: major properties and scoring methods. Pain 1975, 1:277-99.

34. M Cardol, RJ de Haan, GA van den Bos, BA de Jong, II de Groot: The development of a handicap assessment questionnaire: the Impact on Participation and Autonomy (IPA). Clin Rehabil 1999, 13:411-9.

35. M Cardol, RJ de Haan, BA de Jong, GAM van den Bos, IJM de Groot: Psychometric properties of the impact on participation and autonomy questionnaire. Arch Phys Med Rehabil 2001, 82:210-216.

36. PHTG Heuts, JWS Vlaeyen, R Ruesink:Bewegingsvrees bij lage rugpijn. Ned Tijdschr Pijn Pijnbestr. 1996, 4:45-48.

37. SH Kori, RP Miller, DD Todd: Kinisophobia: a new wiew of chronic pain behavior. Pain Management 1990:35-43.

38. L Goubert, G Crombez, S Van Damme, JW Vlaeyen, P Bijttebier, J Roelofs: Confirmatory factor analysis of the Tampa Scale for Kinesiophobia: invariant two-factor model across low back pain patients and fibromyalgia patients. Clin J Pain 2004, 20:103-10.

39. IE Swinkels Meewisse, I Roelofs, AL. Verbeek, RA Oostendorp, JW Vlaeyen: Fear of movement/(re)injury, disability and participation in acute low back pain. Pain 2003, 105:371-9.

40. J Ware, M Kosinski, S Keller: SF-36 physical and mental summary scales: A user's manual. The Health Institute, New England Medical 1994.

41. J Ware, K Snow, M Kosinski: SF-36 Health Survey: manual and interprelation guide. The Health Institute, New England Medical 1993.

42. MIL Sullivan, SR Bishop, J Pivik: The pain catastrophizing scalle development and validation. Psychol Assess 1995, 7:524-532.

43. S v Danme, G Crombez, P Bujttebier, I Goubert, Bv Houdenhove: A confirmatory factor analysis of the Pain Catastrophizing Scale: invariant factor structure across clinical and non-clinical populations. Pain 2002, 96:319-324.

44. AT Beck, CH Ward, M Mendelson, J Mock, J Erbaugh: An inventory for measuring depression. Arch Gen Psychiatry 1960, 4:561-571.

45. AI" Beck, RA Steer, MG Garbin: Psychometric properties of the beck depression inventory: twenty-five years of evaluation. Clin Psychol Rev 1988, 8:77-100. 
46. AL Wesley, RJ Gatchel, JP Garofallo, PB Polatin: Toward more accurate use of the Beck Depression Inventory with chronic back pain patients. Clin I Pain $1999,15: 117-21$.

47. D Watson, Clark, L.A., Carey, G.: Positive an Negative Affectivity and Their Relation to Anxiety and Depressive Disorders. J Abnorm Psychol 1988, 97:346353.

48. JWS Vlaeyen, NJ Teeken Gruben, ME Goossens, MP Rutten van Molken, RA Pelt, H van Eek, PHTG Heuts: Cognitive-educational treatment of fibronyalgia: a randomized clinical trial. I. Clinical effects. J Rheumatol 1996; 23:1237-45.

49. CC Wright, I Sin: Intention-to-treat approach to data from randomized controlled trials: a sensitivity analysis. J Clin Epidemiol 2003, 56:833-42. 
94. SHORT TERM RESULTS 


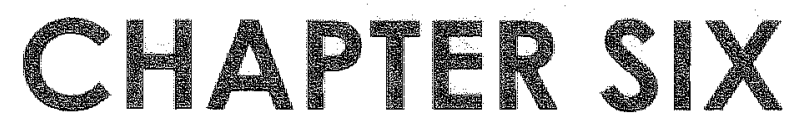

\section{Long-term effectiveness and costs of a tailor-made intervention for pregnancy-related pelvic girdle pain after delivery [ISRCTN08477490]}

Caroline HG Bastiaenen. Rob A de Bie, Johan WS Vlaeyen. Mariëlle EJB Goossens, Pleter Leffers. Pieter MJC Wolters, Janneke M Bastiaanssen.

Piet A van den Brandt, Gerard GM Essed

Submitted 


\section{Abstract}

Introduction:

Pregnancy-related pelvic girdle pain is considered an important and frustrating health problem and potentially leads to long-lasting pain and disability. Investigators draw particular attention to biomedical factors but there is growing evidence that psychosocial and social factors might be more important.

\section{Methods:}

In a randomized controlled trial we studied the effectiveness of a tailor-made program targeting biopsychosocial factors in women with pregnancy-related pelvic girdle pain compared to a bionedical program. Women with severe complaints shortly after delivery were selected from a longitudinal prospective cohort study $(n=7526)$, aimed at pregnancy-related peloic girdle pain in the Netherlands. A concealed block randomization was performed after collecting baseline data. Researchers were blinded to treatment assignment. Outcomes were evaluated within the framework of the biopsychosocial approach. Primary outcome concerned limitations in activities (RDQ). Additionally an economic evaluation zuas performed. Follow-up measurements zoere performed until one year after delivery.

\section{Results:}

Between May 2001 and July 2003, 869 women out of the cohort requested for trentment by a physiotherapist, 10 days after delivery. Because of a quick recovery in two weeks time, we included only 126 women with persistent complaints three weeks after delivery. Results of this trial indicate a rapid and significant improvement of women attending on the interoention progran relatioe to usual care. The improzement was also persisting at one year after delivery. Althongh not statistically significant, costs of sick leave in the UC group were about twice as high when compared to the intervention group. Differences remained stable in subgroup analyses. 


\section{Introduction}

Pregnancy-related pelvic girdle pain is attracting a lot of attention for being an important and frustrating health problem during pregnancy and after delivery and could lead to long-lasting pain and disability. The management of the disorder is mainly based on a biomedical approach with pain as a signal of tissue damage in the region of the lower back or pelvic girdle and the assumption that serious tissue damage would lead to high levels of pain and disability [1]. Over the last decade in the musculoskeletal disorders research field, we have seen a change from a biomedical approach to a biopsychosocial approach. The latter emphasizes the role of psychological and social factors in the development and persistence of pain and disabilities [2]. An important underlying assumption of this approach is that biomedical findings do not eliminate the possibility that psychological or social factors contribute to the level of disability associated with pain [3]. Although there is substantial variation in the contents of intervention programs that adopt this approach, considerable evidence exists that patients with long-lasting pain and disability that participate in one of those programs can improve their level of physical functioning. However, in the research of pregnancy-related pelvic girdle pain this approach has never been explored.

Therefore, we performed a double-blind randomized controlled trial to determine the effectiveness and costs of a tailor-made program with respect to biopsychosocial factors (experimental intervention group) for women with pregnancy-related pelvic girdle pain versus intervention based on pain contingent basis (usual care).

Because of the lack of a clear definition we used an extensive description of pregnancy-related pelvic girdle pain (PPGP) including all women who experience some form of pregnancy-related pain in the lower back and/or pelvic girdle originated within the musculoskeletal system. The trial is embedded in a longitudinal, prospective cohort study, which studies the prevalence, etiology, severity and prognosis of pregnancy-related pelvic girdle pain until one year after delivery [4]. The trial is designed and reported according the Consolidated Standards of Reporting Trials (CONSORT) Statement [5] and is registered in the International Standard Randomised Controlled Trial Number Register [ISRCTN08477490]. The present article describes the longitudinal effectiveness and costs during the year after delivery. 
The study design [6] and the short-term results (3 months after randomization) are described elsewhere. The short-term results support the hypothesis of the study (Bastiaenen et al, submitted).

\section{Methods}

\section{Recruitment and informed consent}

The medical ethics committee of the Maastricht University Hospital approved the intervention and cohort study that were performed in the Southeast of the Netherlands. Midwives and gynecologists recruited the women during early pregnancy (10-14 weeks). Women were included in the cohort if they were at least 18 years old, pregnant and well versed in Dutch language $(n=7526)$. Women were given written information explaining the aims and contents of the cohort and intervention study before they decide to participate. Concerning the intervention study they were told that to current knowledge, the two investigated treatment options are considered to be equally effective. The moment of inclusion for the intervention study was at about three weeks after delivery. An individual woman entered the intervention study after signing informed consent for both the cohort and intervention study during early pregnancy and meeting the in- and exclusion criteria of the intervention study three weeks after delivery. Women were included when having pain in the pelvic girdle pain with an onset during pregnancy or just after delivery (cohort data), were restricted in their normal daily activities because of PPGP and if there is a delay in recuperation (unable to participate satisfactory in housekeeping and care of children because of the complaints under investigation). Severity of symptoms should be varying with physical activities and time during the day. Women diagnosed with relevant specific pathology (such as nerve root pathology, theumatoid disorders, carcinoma, obstetric complications) that affects pain and activities of daily life were excluded. Exclusion also occurred in case of family related or psychosocial problems or when a disablement procedure was not yet finished. Final important aspects for in-/exclusion were the willingness of a woman to participate in the study or having a clear treatment preference [7]. We only included women who did not indicate such a preference.

An experienced research-physiotherapist visited the women at home, about three weeks after delivery. This visit was called for on the basis of a short self- 
administered questionnaire or initiated by midwives. A positive answer from a participating woman from the cohort or her midwife: "Is an intervention by a physiotherapist necessary?" took a central position in these questionnaires: Preceding a possible home visit, a short history was taken by telephone about two weeks after delivery. The telephone interview focused on exclusion criteria such as willingness to participate, specific pathology and inclusion criteria such as limitations in daily life caused by PPGP and a delayed recuperation. During the home visit, a standardized history was taken and physical examination was performed to exclude specific pathology. Self-administered questionnaires were used to asses pain, limitations in activities, restrictions in participation, painrelated fear, pain catastrophizing, positive and negative affectivity, depression, expectancy of treatment result and quality of life. The questionnaires contained clear instructions for completion with no help or support from others. If a woman met the selection criteria, she was informed about the aim and method of the intervention study and if she was willing to participate, the informed consent procedure was completed. The research-physiotherapist collecting the baseline data was trained in performing the measurements in a standardized way and was blinded for treatment assignment.

\section{Randonization and blinding}

Randomization took place after collecting the baseline data and obtaining informed consent. An independent research assistant (unaware of the baseline data) carried out the concealed randomization procedure using a random computer-generated list. Block size for the randomization was four. When a woman was allocated to the intervention group, a participating physiotherapist practicing in the neighborhood of the woman was contacted and we ensured that treatment could start within one week. Treatment costs was covered for all. participants in the intervention group. Women, allocated to the usual care group, were free to choose usual care treatment by a physiotherapist who was not trained in the experimental intervention protocol.

Women were blinded to a certain extent to the allocated intervention option because they were kept naĩve of the exact content of both intervention options. Physiotherapists were not involved in the baseline and effect measurements. Researchers dealing with the baseline and outcome data were blinded to the intervention assignments. 


\section{Usuat are}

Women, allocated to the usual care group, were free to choose usual care treatment by a physiotherapist not providing the educational program of the experimental intervention, guidance by a general practitioner or do nothing. Information about the option chosen was collected by means of questionnaires during the follow-up period. When a woman opted in favor of treatment, the sessions started within one week. All physiotherapists were experienced and specialized in treating women with PPGP.

Prior to the trial, detailed information was gathered about the contents of current treatment options. The most striking characteristics of a current intervention were the character of the therapist-patient relation and the way of goal setting, focusing on disease management [8]. There was an explicit professional input and an accent on biomedical factors. A pain contingent regimen of avoiding and limiting several day-to-day activities was considered important. Compliance based on these goals played an important part. An exercise program focusing on muscle imbalance and alignment of the pelvic girdle was a standard part of the intervention [9]. Therapists were often highly concerned about their patient's pain themselves. A biomechanical label highlighting the attention on pain and emphasizing the vulnerability of the spine and pelvis to damage, characterized the patient information.

\section{Experimental interoention}

Women, allocated to the experimental intervention group, were referred to a participating physiotherapist in their own neighborhood. These physiotherapists received an educational course about the treatment protocol prior and during the study. All physiotherapists were already experienced and specialized in treating women with PPGP. The intervention focused particularly on patient-therapist relationship, education and the promotion of an active life style rather than avoiding activities. Results of interviews with women out of the cohort and group discussions with experienced physical and occupational therapists prior to the trial further defined the program.

Theoretical concepts of self-management [8] and fear-avoidance [10] were integrated in the intervention protocol. We provided an individualized selfmanagement approach of 7-9 sessions for 30 minutes in a period of time of 12 weeks. Standardized information was presented by means of an intervention protocol for the therapists and booklets [6] for the patients $[8,11]$. Topics 
included back and pelvis anatomy, "red flags" indicating a serious medical condition, factors contributing to fluctuations in pain, appropriate pacing of exercises [9] and activity, handling pain flare-ups, cognitive restructuring, some fear avoidance techniques $[10,12,13]$, and communication. Therapists had to employ simple problem-solving techniques that engaged women in identifying day-to-day problems or limitations related to PPGP, setting personal goals, brainstorming options for achieving these goals and developing personal action plans. In subsequent sessions, women reviewed their action plans and their progress towards goals and engaged in problem-solving skills around difficulties that arose in trying to implement their plans. Information about two opposing behavioral responses of pain-related fear (avoidance and confrontation) was given, and a hierarchy of individual fear-eliciting movements and activities was made. Therapists encouraged women in making action plans for specific activities that were avoided. They (therapists) were explicitly asked not to "label" the complaints in terms of medical diagnosis.

Generally, a time contingent policy was followed in which women set the pace by means of action plans. The expertise of the physiotherapists of the condition in general and of the women about their own specific condition and lives were equally important. [14].

\section{Measurements}

\section{History and physical examination}

During the visit at home a standardized history was taken [15] and physical examination was performed. During history taking, questions about on-going pain, its location, intensity and modalities, variation of symptoms with physical activities, radiation into the legs, back pain versus leg pain, neurological signs, deformity, obstetric complications, a case history of low back or pelvic girdle pain prior to this pregnancy and other differential diagnoses. The format of the answers was presented as a dichotomous "yes or no". Demographic characteristics and data about education, work, income, use of alcohol, smoking, medication, the onset of pain and functional status during pregnancy were already gathered as part of the cohort study at 14 and 30 weeks gestation period and two weeks after delivery.

After history taking a short standardized clinical examination program was performed, which includes tests of nerve root radiation (exclusion) [15]. The 
research-physiotherapist filled out the Pain Behavior Scale, a standardized observation scale for quantifying pain behavior. $[16,17]$

\section{Primaryoulcomes}

Primary domain for improvement of the intervention was limitations in activities. Other important domains were the severity of the main complaints and global feeling of recovery.

Limitations in activities were measured with the Dutch translation of the Roland Disability Questionnaire (RDQ) [18]. We replaced the phrase "because of my back or pelvic girdle pain" to all questions instead of "because of my back".

The Quebec Back Pain Disability Scale (QBPDS) [19, 20] was initially also selected but immediately after the start of the data-collection it became clear that the missing vallue rate on a number of items $(4,11,12,19$ and 20) was rather high, shortly after delivery. Those items focus on activities as driving a car, throwing a ball, running and lifting or pushing a heavy weight. Performance of those activities was unlikely for most of the women shortly after delivery.

Subjective measurements like the global feeling of recovery (global perceived effect, GPE) and severity of the main complaints (MC) reflecting a patientspecific approach were also selected. Global Perceived Effect [21](GPE) was measured by self-assessment on a 7 -point scale $(1=$ completely recovered, $7=$ worse than ever). The main complaints (MC) were selected by the woman in a standardized approach by selecting three activities, which are an essential and frequently performed part of her everyday life. However, performance of those activities was difficult or impossible because of low back or pelvic girdle complaints at the moment of base-line measurement. The severities of the selected main complaints were rated with Visual Analog rating Scales (VAS) $[21,22]$.

\section{Secondary outcomes}

Pain was measured with two Visual Analog rating Scales (VAS) of the McGill Pain Questionnaire (MPQ-DLV) $[23,24]$ to record the intensity of pain the last week and day.

The impact on participation and autonomy (IPA) measured person-perceived restriction in participation and autonomy $[25,26]$. The used subscales were selfcare and appearance, mobility, leisure, social relationships and family role. 
Fear of movement was measured by the Dutch translation of the Tampa Scale for Kinesiophobia (TSK) $[27,28]$. We used the TSK and the both subscales "fear avoidance" and "harm" $[29,30]$.

\section{Table 1 Timing of the measures}

\begin{tabular}{|c|c|c|c|c|}
\hline & $\begin{array}{l}\text { Baseline } \\
\text { about } 3 \text { weeks } \\
\text { after delivery }\end{array}$ & $\begin{array}{c}3 \text { months } \\
\text { after } \\
\text { randonization }\end{array}$ & $\begin{array}{c}6 \text { months } \\
\text { aftel delivery }\end{array}$ & $\begin{array}{c}1 \text { year } \\
\text { atter delwery }\end{array}$ \\
\hline History laking & $x$ & & & \\
\hline Physical examination & $x$ & & & \\
\hline PES & $x$ & & & \\
\hline $\mathrm{RDQ}$ & $*$ & $x$ & $x$ & $x$ \\
\hline $\mathrm{MC}$ & $x$ & $x$ & $x$ & $x$ \\
\hline GPE & $\times$ & $x$ & $x$ & $x$ \\
\hline VAS (pain today) & $\mathbf{x}$ & $\times$ & $x$ & $x$ \\
\hline VAS (pain this week) & $\mathbf{x}$ & $x$ & $x$ & $x$ \\
\hline UPA: & & & - & \\
\hline Autonomy in self-care & $x$ & $x$ & $x$ & $x$ \\
\hline Family role & $\mathbf{x}$ & $x$ & $x$ & $\mathbf{x}$ \\
\hline $\begin{array}{l}\text { Social relationships } \\
\text { TSK: }\end{array}$ & $x$ & $x$ & $x$ & $\times$ \\
\hline Total score & $x$ & $\mathbf{x}$ & * & $\mathbf{x}$ \\
\hline Fear Avoidance & $x$ & $x$ & $x$ & $\mathbf{x}$ \\
\hline Harm & $\mathbf{x}$ & * & $x$ & * \\
\hline SF 36: & & & & \\
\hline General health & $x$ & * & $x$ & $x$ \\
\hline Expectancy treatment & $x$ & & & \\
\hline PCS & $x$ & & & \\
\hline NEM & $x$ & & & \\
\hline PEM & $x$ & & & \\
\hline $\mathrm{BDI}$ & $x$ & & & \\
\hline Caminterventions & & $x$ & $\mathbf{x}$ & $*$ \\
\hline Compliance & & $x$ & $x$ & x \\
\hline Recurrence complaints & & & $x$ & * \\
\hline Satisfaction treatment & & & * & \\
\hline Subsequent pregnancy & & $x$ & * & $*$ \\
\hline EuroQol & $x$ & $x$ & $x$ & $x$ \\
\hline Costudian & $x$ & $\star x$ & $x$ & $x$ \\
\hline
\end{tabular}

PBS = Pain Behavior Scale, $R D Q=$ Roland Disability Questionnaire, MC $=$ Main Complaint. GPE = Global Perceived Effect: VAS = Visual Analogue rafing Scale, IPA = Impact on Panticipation and Autonomy, TSK = Tampa Scale for Kinesiophobia, SF-36 = Short Form 36, PCS = Pain Catastrophizing Scale, NEM = Negative Emotionality Scale, PEM $=$ Pasilive Emotionality Scale, BDH = Beck Depsession Inventory, EuroQol = European Quality of Life Scale

The Short-Form 36 (SF-36) [31, 32] evaluated health status. We used the subscale "general health". 
The EuroQol was used for obtaining a self-description of mobility, self-care, used activities, pain/discomfort and anxiety/depression [33].

A cost-diary [34] was used to obtain data on physical activities, health care utilization, and days of sick leave. Women were instructed to record costs on a weekly basis until one year after delivery.

\section{Base-line measurements}

Pain catastrophizing was measured with the Pain Catastrophizing Scale (PCS) $[35,36]$.

The Beck Depression Inventory (BDI) $[37,38]$ was used to measure depressive symptoms. It has been argued that the somatic content of the BDI may lead to false-positives among patients with physical problems. Therefore, items associated with weight loss, sleeping disturbance and work inhibition were excluded in the analyses of this study [39].

To measure the experience of negative affect we used the 14-item Negative Emotionality Scale (NEM) [40]. To measure positive affect we used the 11-item Positive Emotionality Scale (PEM) [40]. Both are subscales of the Multidimensional Personallity Questionnaire.

Treatment expectancy [41] was measured by means of a $100 \mathrm{~mm}$ Visual Analog rating Scale (VAS). The women were asked to what extent they believed that the treatment is beneficial to her.

The Pain Behavior Scale (PBS) $[16,17]$ is an observation scale tapping 8 pain behaviors that the physiotherapist completes after physical examination. These are verbal complaints, vocal complaints, facial grimaces, standing posture, mobility, body language, use of visible supportive equipment and stationary movement.

\section{Follow-up}

Women were asked to complete follow-up questionnaires at 3 months after randomization (short-term results), 6 months and one year after delivery. Women who did not return their follow-up questionnaires were contacted by (e)- mail or phone and were asked to continue participation. 


\section{Compliance, other interaentions and confounding}

The follow-up questionnaires assessed in all women how many treatment sessions they have followed in the previous period of time. Furthermore, information on contents, satisfaction and the aspects of the (experimental) treatment they found benefit in. Co-interventions, medication, aids, additional medical consumption, recurrence of complaints, return to gainful employment and a possible subsequent pregnancy were also registered.

\section{Statistical analyses}

The baseline status of the study groups was compared with respect to the distribution of all independent prognostic variables and the baseline values of the outcome variables. For the outcome measures $R D Q$, main complaint, pain and subscales of the TSK, subscale of the IPA, the subscale general health of the SF-36 and the EuroQol, series of mixed models were considered [42]. For each dependent variable, terms were added to a basic model including only baseline values of the dependent variable, treatment assignment and time. Additional terms were judged for inclusion by significance level of a likelihood-ratio test. Such models assume that missing values are missing at random (MAR) [42]. The models described later were fitted using the linear mixed function in SPSS 12.0. [43] All analyses were intention to treat (ITT) [44]. Within each ITT group, women will not be included in the model-fitting process if all follow-up values were missing. For all women, pre-randomization values of outcomes and covariates were complete. Any response values of a woman will be included in the analyses. No attempt was made to replace missing response values with imputed values. In all comparisons between the two treatment options a twotailed p-value of 0.05 was considered to indicate statistical significance. Subgroup analyses will be performed for the subgroups baselines scores RDQ < 13 and $\geq 13$ (median split) to explore a possible different intervention effect in subgroups of women with severe limitations in activities at baseline. Prognostic status at baseline for women with and without missing values for the outcome variables at 3 and 6 months and one year after delivery was compared for both groups.

\section{Economic analyses}

An economic evaluation compared the costs and health effects of the experimental intervention with the usual care option from a societal 
perspective. For the whole study group all relevant health care costs, production loss and patient and family costs were measured with the aid of a cost-diary [34] during the year after delivery and by follow-up questionnaires collected at 6 months and one year after delivery: Both direct health care costs (such as physician visits, the number of treatment sessions and medication) and indirect costs associated with PPGP (like sick leave, professional as well as voluntary aid and extra baby sitter) were registered until one year after delivery. Resources recorded in the diaries were valued by cost estimates for the year 2003. True cost estimates are available in the Dutch guidelines for pharmaco-economic studies $[45,46]$. Costs for over the counter medicine (OTC) and aids like an elastic belt were reported directly by the women in their diaries. The productivity costs resulting from loss of paid labour were calculated by applying the friction costs method, which limits the period of production loss to the time during the work of the person is not replaced. In 2003 the friction period was set at 22 weeks or 154 days. In this study, the regular period of maternity leave was excluded from the friction period. The length of maternity leave after delivery is set at 10 weeks in the Netherlands. Paid production was valued by the average national gross wage per hour, broken down by sex (female) and age category (25-44 year). Quality of life was measured using the EuroQol.

Between-group differences in outcomes of mean costs will be analyzed by Student's t-tests for unpaired observations. Not normally distributed data will be analyzed by Mann-Whitney $U$ test. If relevant, cost-effectiveness ratios will be calculated by dividing the difference between the mean costs of the two interventions by the difference in mean effects of the two treatment options. The primary outcome measure for the cost-effectiveness ratio will be the difference in limitations in activities (RDQ).

\section{Results}

\section{Recruitment}

Between November 2000 and November 2002, 7526 women were included in the cohort study. Results of the self-administrated question: "Is an intervention by a physiotherapist necessary?" resulted in 869 eligible participants; 384 times indicated by midwives and 682 times indicated by women themselves. In 197 instances both the women and midwives responded positively. On the basis of 
history taking by telephone two weeks after delivery, 722 of the 869 women were excluded from participation. The majority of them, 635 women, were excluded because of a quick recovery, 13 women because of specific pathology, 49 women did not want to be randomized (clear treatment and therapist preference deviating from the study protocol), 22 women did not give informed consent for the intervention study (onlly for the cohort study) and 3 women had

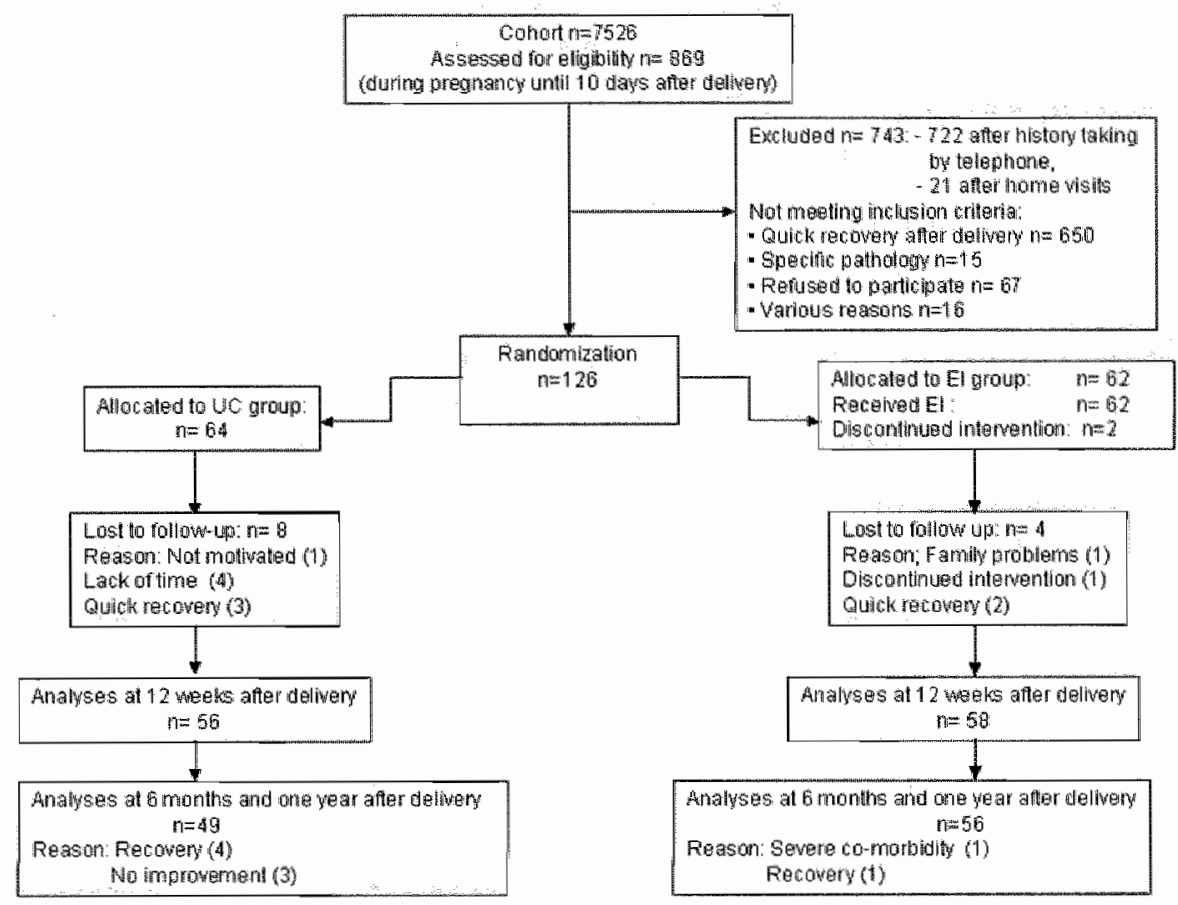

Figure 1 Flow participants through the study

moved outside the area where intervention was provided. History taking by telephone resulted in 147 home visits about three weeks after delivery. Based on the home visits, 21 women were excluded: 15 women because of quick recovery, 2 women because of specific pathology, 1 woman because of a clear treatment preference and 3 women because of family or socia $\rrbracket$ reasons. Finally, from May 2001 until July 2003, 126 women were included in the intervention study three weeks after delivery. 


\section{Baseline Characteristics}

Baseline status of the participants is given in Table 2. Both groups were highly similar in prognostic variables and baseline values of outcome measures.

Table 2 Baseline characteristics and measures according to treatment group

\begin{tabular}{|c|c|c|c|c|}
\hline \multirow[t]{2}{*}{ Variable } & \multicolumn{2}{|c|}{$\begin{array}{c}\text { Usual Care } \\
n=64\end{array}$} & \multicolumn{2}{|c|}{$\begin{array}{l}\text { Experimental intervention } \\
\qquad n=62\end{array}$} \\
\hline & mean & $\mathrm{SD}$ & mean & SD \\
\hline Age & 315 & 3.1 & 31.4 & 3.6 \\
\hline Localization of pain: & & & & \\
\hline Lumbar spine & 25 & 39.1 & 24 & 38.7 \\
\hline St joints (one or two) & 34 & 53.1 & 34 & 54.8 \\
\hline Symphysis & 43 & 67.2 & 42 & 67.7 \\
\hline History of PPGP pain & 43 & 67.2 & 44 & 71.0 \\
\hline $\begin{array}{c}\text { Parity } \\
\text { Measures }\end{array}$ & 2.1 & 1.0 & 23 & 1.0 \\
\hline VAS (pain today) (0-100) & 54.3 & 17.5 & 53.5 & 19.1 \\
\hline VAS (pain this week) $(0-100)$ & 59.2 & 17.9 & 57.0 & 17.8 \\
\hline $\begin{array}{l}\operatorname{RDQ}(0-24) \\
\text { IPA: }\end{array}$ & 13.5 & 4.3 & 13.3 & 4.6 \\
\hline Autonomy in sell-care $(0-28)$ & 9.6 & 5.7 & 8.8 & 5.1 \\
\hline Mobility and leisure $(0-20)$ & 10.9 & 3.7 & 10.0 & 4.7 \\
\hline Family role $(0-28)$ & 15.4 & 5.8 & 14.4 & 5.6 \\
\hline Social relationships $(0.24)$ & 5.8 & 3.3 & 5.5 & 3.4 \\
\hline $\begin{array}{c}\text { MC (VAS) }(0-100) \\
\text { TSK: }\end{array}$ & 69.5 & 17.5 & 72.0 & 15.7 \\
\hline Total score: $(17-68)$ & 35.7 & 5.9 & 32.9 & 5.0 \\
\hline Fear avoidance $-(8-32)$ & 18.8 & 3.6 & 17.0 & 3.0 \\
\hline Harm^ $(5-20)$ & 8.5 & 2.2 & 7.9 & 2.3 \\
\hline $\operatorname{PCS}(0-52)$ & 12.2 & 9.8 & 11.2 & 8.4 \\
\hline BDH $=(0-54)$ & 5.3 & 4.9 & 5.1 & 4.2 \\
\hline $\operatorname{NEM}(0-14)$ & 3.3 & 3.4 & 2.4 & 2.3 \\
\hline PEM $(0-11)$ & 7.8 & 2.6 & 8.5 & 2.4 \\
\hline SF $-36:$ & & & & \\
\hline General health $(0 m-100)$ & 54.6 & 12.5 & 57.8 & 13.1 \\
\hline Expectancy treatment $(0-100)$ & 79.0 & 17.8 & 78.3 & 16.6 \\
\hline PBS $4(0-8)$ & 1.3 & 1.3 & 1.5 & 9.6 \\
\hline
\end{tabular}

- mean BOI calculated without items 15,16,19, "first main complaini (MC) was selected, $\rightarrow$ TSK subscale fear avoidance (ilems $1,2,9,10,13,14,15,17)$, TSK subscale harm (items 3,5,6,7,11). Pain behavior Scale filled out by research physiotherapist after physical examination

\section{Follow-up}

After randomization, 64 women were assigned to the usual care group (UC group) and 62 to the experimental intervention group (EI group). In all women, baseline data were complete. For 114 women $(90 \%)$ data were available for all 
outcome measures 3 months after randomization (Figure1). In the UC group 8 women were lost to follow up because of a quick recovery within the first weeks after randomization and did not want to fill out the outcome assessments anymore $(n=3)$, lack of time $(n=4)$, or not motivated to fill out the outcome assessments ( $n=1$ ). In the EI group 4 women were lost to follow up because of family reasons $(n=1)$, discontinued intervention $(n=1)$ and quick recovery within the first weeks after randomization $(n=2)$.

For 105 women $(83 \%)$ all outcome measures were complete at six months and one year after delivery. In the experimental intervention group two women were lost to follow-up between 3 and 6 months after delivery. In the usual care group 7 women were lost to follow-up between 3 and 6 months after delivery. Al women who were lost to follow-up in both study groups were contacted by telephone or (e)-mail. In the experimental intervention group women were lost to follow-up 6 months after delivery because of severe co-morbidity that affects activities of daily life $(n=1)$ and fully recovery $(n=1)$ and therefore not motivated anymore to fill out the questionnaires. In the usual care group 4 women were recovered and 3 women did not improved at all and therefore not motivated anymore to fill out the questionnaires. The prognostic similarity on baseline of women who were lost to follow-up and women who filled out all the outcome measures was compared. Both groups turned out to be highly similar.

\section{Co-intervention, recurrence of pain, retum to gainful employment and a possible subsequent pregnancy.}

19 women of the UC group did not receive treatment by a physiotherapist or guidance by a general practitioner in the year after delivery. $X$-ray examined 5 women, 9 women used pain medication and 10 women an elastic belt in the year after delivery. $X$-ray examined 2 women, 7 women used pain medication and 4 women an elastic belt in the EI group. 4 women in the EI group received treatment after finishing the prescribed number of treatment sessions of the experimental intervention some time in the year after delivery. However in the UC group 19 women received treatment in the period between 3 months and one year after delivery.

In both groups a considerable number of women reported recurrence of pain after they became free of any pain. 18 of the 20 women in the UC group reported recurrence of pain in the year after delivery after a period free of any pain. The same goes for 15 out of 28 women in the El group. 
34. women reported return to gainful employment one year after delivery and 11 women applied for a benefit due to PPGP in the UC group. For 4 women return to gainful employment was not applicable because they were out of a job. 45 women returned to gainful employment one year after delivery in the EI group. In this group 5 women applied for a benefit due to PPGP. For 6 women gainful employment was not applicable because they were out of a job. Six women (three in both study groups) reported a subsequent pregnancy one year after delivery.

Effectiveness of the experimental intervention (EI) compared to the usual care option (UC).

The proposed statistical evaluation of the treatment effect in the original study design was a comparison of change over time in the outcome measures between both study groups [6]. However, data showed that the development of the outcome measures over time was important. That implied that the analyses had to be tailored to the situation. Therefore longitudinal analyses were carried out to investigate the difference in the total development of recovery between the both groups over the period of the year after delivery.

The results of the main effects models after the experimental intervention compared to usual care fitted to each outcome variable are shown in Table 4. The estimated treatment assignment effect demonstrates a significant greater reduction of 1.6 points in the $R D Q$, after EI compared to UC. Other significant estimated treatment assignment effects were in the TSK and subscale Activity Avoidance and the IPA subscale Autonomy in self-care. However, the subscale Harm of the TSK did not demonstrate such a significant reduction in favor of one of the study groups. The estimated treatment effect in the IPA subscale Autonomy in self-care also demonstrates a significant greater reduction after EI compared to UC. Depression measured with the BDI was a significant covariate in all models.

Other estimated treatment assignment effects were not significant although there was an extensive improvement in both study groups for all outcomes In both groups more than $80 \%(82.1 \%$ versus $83.6 \%)$ reported full recovery or very large improvement one year after delivery (Table 3 ). 
Table 3 Outcomes of both study groups antil one year after delivery

\begin{tabular}{|c|c|c|c|c|c|c|}
\hline 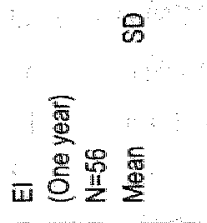 & 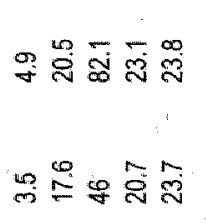 & $\begin{array}{l}\stackrel{9}{*} \\
: \\
\infty\end{array}$ & $\underset{+\infty}{\infty}$ & ¿ & 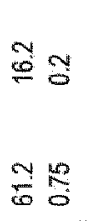 & \multirow{7}{*}{ 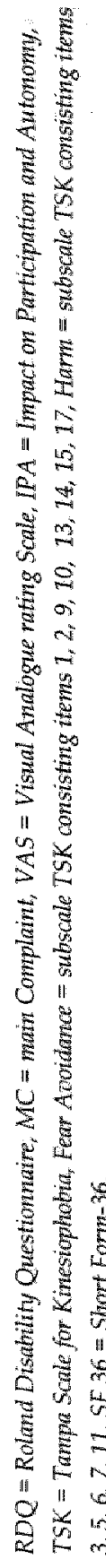 } \\
\hline 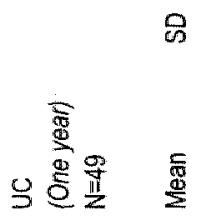 & 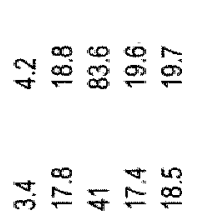 & $\stackrel{\infty}{i j}$ & 욤 & 웅용 & 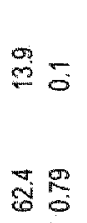 & \\
\hline 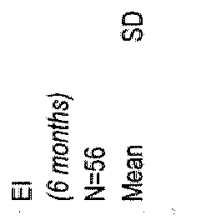 & 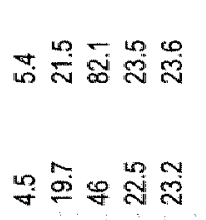 & $\underset{\sim}{\sim}$ & $\underset{+\infty}{\infty}$ & 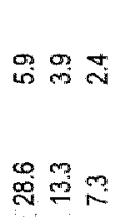 & 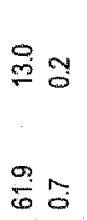 & \\
\hline 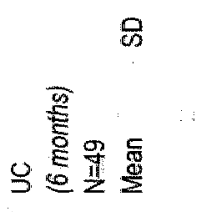 & 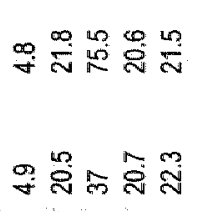 & y & 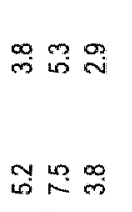 & in & 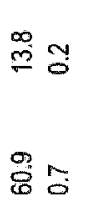 & \\
\hline 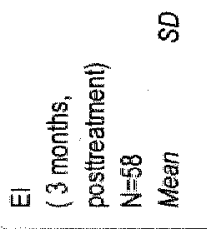 & 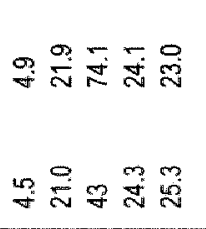 & $\stackrel{\circ}{m}$ & तो & 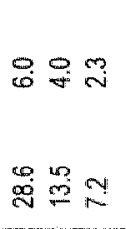 & $\begin{array}{l}\text { 웅 } \\
\frac{1}{60}\end{array}$ & \\
\hline \multirow[t]{2}{*}{ 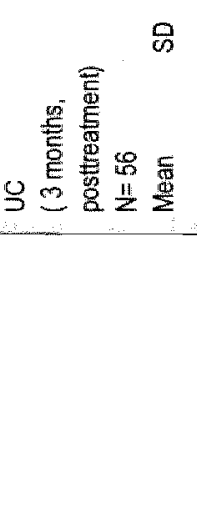 } & 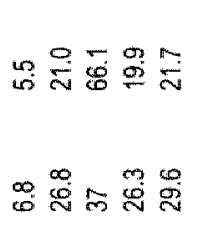 & $\stackrel{\infty}{+\infty}$ & ㅇำ in & 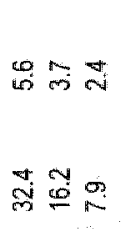 & 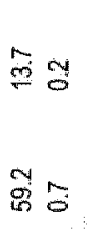 & \\
\hline & 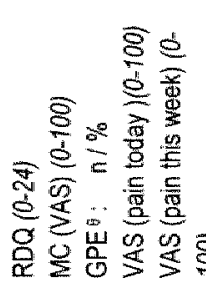 & 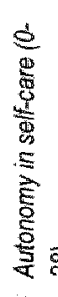 & 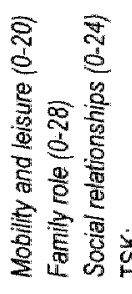 & 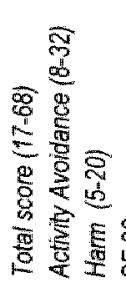 & 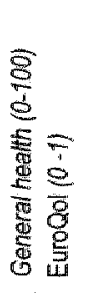 & \\
\hline
\end{tabular}


Analyses of subgroups showed that results were in line with the results of the main analyses. The subgroup baseline values $R D Q \geq 13$ showed a significantly greater reduction on the same outcomes in favor of the experimental intervention (RDQ, TSK, Activity Avoidance and Autonomy in self-care) as the main analyses (Table 4). Additionally, results of the subgroup RDQ $<13$ showed a significantly greater reduction in the Activity Avoidance scale and the total score of the TSK, after EI compared with UC. Women in both groups reported a substantial reduction in pain (VAS pain today and last week) in the year after delivery (Table 3), but there were no significant differences between the both whole study groups and sub groups assessed (Table 4).

\section{Costs of the experimental intervention compared to the ustual care option.}

Costs were collected from a societal perspective alongside the randomized controlled trial. Table 5 provides an overview of the costs analyzed. Direct and indirect costs were included. The volumes of direct and indirect health care utilization costs are listed in Table 6. The physiotherapists" sessions of the experimental intervention (7-9) were included in the data of the total amount of physiotherapists' sessions. Costs were listed in Table 7. Differences between the mean total costs were in favor of the El group (Table 7). Although not significant, the huge differences between the groups were almost entirely due to the differences in costs of sick leave after finishing maternity leave. Costs of sick leave were about doubled in the UC group compared to the El group. The mean total costs without and without sick leave of the subgroups baseline RDQ score $<13$ and $\geq 13$ were in line with the costs of the total study groups applying the friction costs method.

There were large differences in costs of sick leave within both study groups that was still apparent in the subgroup analyses (Table 7). 25 women in the UC care group and 37 women in the EI group reported no sick leave after finishing maternity leaves. The distribution of the amount of direct and indirect costs without sick leave was also quite large within both groups. $19 \%$ of the women in the UC group generated no direct costs and an additional $23.5 \%$ generated direct costs comparable with the direct costs of the experimental intervention (7-9 sessions). $67.5 \%$ of the women in the UC group generated the majority of the direct costs. In the EI group $66.1 \%$ of the women generated direct costs in line with the direct costs of the experimental intervention ( $€ 204.75$ [intervention\} $+€ 5.18$ (transport\} $=€ 209.93$ ), 33.9\% generated more direct costs. Indirect costs were in line with direct costs. 
Table 4 Longitudinal analyses for main linear mixed models $(n=114)$. Pamneter estimates and $\mathrm{CI}$ interoals for treatment effects in ontcomes, after EI compared to $\mathrm{UC}$

\begin{tabular}{|c|c|c|c|}
\hline Outcome measure & $\begin{array}{l}\text { Estimated } \\
\text { regrassion } \\
\text { coefficient }\end{array}$ & $95 \% \mathrm{Cl}$ & $\begin{array}{l}\text { p-value } \\
\text { (two- } \\
\text { talled) }\end{array}$ \\
\hline \multicolumn{4}{|l|}{ Primary outcomes } \\
\hline $\operatorname{RDQ}(0-24)$ & -1.6 & $(-2,9 ;-0.5)$ & 0.005 \\
\hline MC (VAS) $(0-100)$ & -4.9 & $(-10.3 ; 0.4)$ & 0.07 \\
\hline Secondary outcames & & & \\
\hline VAS (pain today) $(0-100)$ & -1.4 & $\{-6,6 ; 3,8\}$ & 0.58 \\
\hline VAS (pain this week) (0-100) & -3.6 & $\{-9.3,2.0\}$ & 0.20 \\
\hline \multicolumn{4}{|l|}{$\mathbb{P P A}$} \\
\hline Autonomy in self-care $(0-28)$ & -1.0 & $(-1.9 ;-0.03)$ & 0.04 \\
\hline Mobility and leisure $(0-20)$ & .0 .4 & $\{-1.3 ; 0.5\}$ & 0.40 \\
\hline Family role $(0-28)$ & -0.7 & $\{-1,9,0.5\}$ & 0.27 \\
\hline \multicolumn{3}{|l|}{ TSK: } & 0.318 \\
\hline Total score $(17-68)$ & -2.4 & $\{-3.8 ;-1.1\}$ & 0.000 \\
\hline Activity Avoidance (8-32) & -1.7 & $\{-2,6,-0.8\}$ & 0.000 \\
\hline $\begin{array}{l}\text { Harm } 15-20) \\
\text { SE } 36\end{array}$ & 0.3 & $\{-0.8 ; 0.2\}$ & 0.23 \\
\hline General health $(0.100)$ & -0.7 & $\{-3.3: 1.8\}$ & 0.57 \\
\hline EuroQol & -0.005 & $\{-0.04: 0.03\}$ & 0.87 \\
\hline \multicolumn{4}{|l|}{ Subgroup $R D Q<13$} \\
\hline TSK (total) $(17-68)$ & -1.9 & $(-3.6 ;-0.15)$ & 0.03 \\
\hline Aclivity Avoidance (8-32) & -1.3 & $\{-2.3 ;-0.3\}$ & 0.02 \\
\hline \multicolumn{4}{|l|}{ Subgroup $R D Q \geq 13$} \\
\hline $\operatorname{ROQ}(0-24)$ & -1.8 & $(-3,4 ;-0.14)$ & 0.03 \\
\hline Autonomy in self-care $(0-28)$ & -1.7 & $\{-3,0 ;-0.4\}$ & 0,01 \\
\hline Activity Ayoidance $(8-32)$ & -1.5 & $\{-2.7 ;-0.3\}$ & 0.01 \\
\hline
\end{tabular}

First main complaint was selected, TSK subscale activity auoidance (items $1,2,9,10,13,14,15,17$ ). 4 TSK subscale harm (items $3,5,6,7,11$ )

Calculation of cost-effectiveness ratios was not relevant because both the effectiveness of the outcomes such as RDQ, TSK and the subscale of the IPA (autonomy in self-care) and the reduction in costs were in favor of the experimental intervention. 
Table 5 Costs included in the economic evaluation

\begin{tabular}{|c|c|c|}
\hline \multicolumn{3}{|l|}{$\operatorname{Cos}(6)$} \\
\hline Direct healthcare costs & & \\
\hline General practitioner & (per visisit) & $€ 20.20$ \\
\hline Physiotherapist: & & $€ 22.75$ \\
\hline Medical specialist & & $€ 43$ \\
\hline Alternative therapist & & 627.20 \\
\hline Radiograph & (per unit) & 638 \\
\hline Over the counter medication & & - \\
\hline Prescribed medication & & - \\
\hline Elastic beit & & $€ 64$ \\
\hline Transport to therapist specialis! & $($ per km) & $\in 0.16$ \\
\hline Mear distance to GP & $1.8 \mathrm{~km}$ & \\
\hline Mean distance to physiotherapist & $1.8 \mathrm{~km}$ & \\
\hline Mean distance to hospital & $7.0 \mathrm{~km}$ & \\
\hline Indirect healtheare costs & & \\
\hline Professional aid & (per hour) & $€ 21.70$ \\
\hline Voluntary aid & & $€ 8.30$ \\
\hline Extra baby sitter & & $€ 8.30$ \\
\hline Sick laavo (after finishing maternily leave) & (per hour) & $€ 33.60$ \\
\hline
\end{tabular}

Prices accorting to Dutch guidelines for economic evaluations 2003, Drug specific price according the tariff of the Royal Dutch Society of Pharracy, Indirect costs for paid work was calculated based on mean incone of the Dutch poprilation according to age (25-44 year) and sex (women), mean distance from a household to a hospital, GP or physiotherapist according Dutch guidelines for economic evaluations 2003

\section{Discussion}

Longitudinal results demonstrate significant and rapid improvement, relative to usual care, of the tailor-made program including a self-management approach and fear-reduction techniques. The improvement was lasted till one year after delivery. Both the study groups were comparable for descriptive and outcome variables at baseline. Although there also was an extensive improvement in the usual care group, the mean scores of the RDQ fell directly to the near-normal range after treatment in the experimental group in significant contrast with the mean scores of the RDQ in the usual care group. [6] Importantly, improvement was accompanied by improvement in autonomy in self-care measured with the subscale of the IPA and a decrease in avoidance activity measured with the subscale of the TSK. These issues were major 
objectives in the experimental intervention that address women's needs and worries about their condition. So the improvement was of clinical relevance.

Table 6 Volumes of direct health care and indirect health care utilization during the study period

\begin{tabular}{|c|c|c|c|c|}
\hline & $\begin{array}{l}\text { El } \\
\text { Mlean }\end{array}$ & $\begin{array}{c}N=56 \\
S D\end{array}$ & $\begin{array}{l}\text { UC } \\
\text { Mean }\end{array}$ & $\begin{array}{r}N=49 \\
S D\end{array}$ \\
\hline Visits to general practitioner & 0.5 & 1.1 & 1.4 & 3.6 \\
\hline Visits to medical specialist & 0.02 & .1 & 0.3 & 1.2 \\
\hline Physiotherapisis sessions & 9.7 & 73 & 9.8 & 11.0 \\
\hline Visits to alternative therapist & 1.6 & 4.4 & 1.7 & 4.4 \\
\hline OTC medication (per unili) & 0.4 & 1.8 & 0.6 & 2.1 \\
\hline Voluntary aid & 24.7 & 58.8 & 27.0 & 66.6 \\
\hline Professional aid & 7.8 & 21.0 & 9.9 & 20.5 \\
\hline Extra baby sitter & $a$ & 0.0 & 3.0 & 18.5 \\
\hline $\begin{array}{l}\text { Sick leave after finishing maternity leave without } \\
\text { applying friction costs method (pert } \\
\text { week) }\end{array}$ & 4.1 & 11.2 & 7.5 & 13.4 \\
\hline $\begin{array}{l}\text { Sick leave after finishing maternity leave applying } \\
\text { friction costs method (per weak) }\end{array}$ & 2.3 & 6.7 & 5.4 & 8.8 \\
\hline
\end{tabular}

Number of physiotherapists' sessions included the sessions of the experimental interventiont for women of the El group

Women in the usual care group also improved during the year after delivery but improvement occurred significantly later. Results of subgroup analyses indicate that major effects of the experimental intervention were to some extent dependent on baseline values of the RDQ. Women with more severe limitations in activities benefited more from the experimental intervention compared to women in the UC group on the primary outcome RDQ. However, women with mild limitations in activities also improved significantly at the same level as women in the subgroup baseline score $\mathrm{RDQ}<13$ on the outcomes in activity avoidance and the total score of the TSK compared to women in the UC group. An explanation could be that the promotion of an active style rather than avoiding activities, being an important feature of the experimental intervention, generated these results. 
Table 7 Mean (SD), total costs ( $E$ ) and differences between the EI and UC groups

\begin{tabular}{|c|c|c|c|c|c|c|}
\hline & \multirow{3}{*}{$\begin{array}{l}\text { El } \\
\text { Mean }\end{array}$} & \multirow{3}{*}{$\begin{array}{l}N=56 \\
S D\end{array}$} & \multirow{2}{*}{\multicolumn{2}{|c|}{ UC $N=49$}} & \multicolumn{2}{|c|}{ Differences between groups } \\
\hline & & & & & Mean & $95 \% \mathrm{Cl}$ \\
\hline & & & Mean & SO & & \\
\hline Direct costs & 288.7 & 248.1 & 354.3 & 336.9 & -656 & $(-180 ; 49)$ \\
\hline $\begin{array}{l}\text { Indirect costs } \\
\text { (without sick leawe) }\end{array}$ & 388.6 & 864,4 & 470.2 & 741.8 & -81.6 & $\{-397.7 ; 234\}$ \\
\hline Indirect costs (including sick leave) & 3601.6 & 8576 & 7689.3 & 12012.7 & -4087.7 & $-8501 ; 326.4\}$ \\
\hline Total costs (without sick leave) & 671.2 & 978 & 834.5 & 967.4 & -163.3 & $\{-546.8 ; 220\}$ \\
\hline Total costs (including sick leave) & 38626 & 8700 & 8203.7 & 12229.5 & -4341.1 & $(-8850 ; 167.7)$ \\
\hline $\begin{array}{l}\text { Subgroup baseline scores } \\
\mathrm{RDQ} \geq 13\end{array}$ & $N=32$ & & $N=27$ & & & \\
\hline $\begin{array}{l}\text { Total cosits (without sick } \\
\text { leave) }\end{array}$ & 814.2 & 1219.2 & 1113.3 & 1097.1 & -299.1 & $\{-920,1,322\}$ \\
\hline Total costs (including sick leawe) & 3902,3 & 8887 & 8628 & 12451.4 & -47256 & $\{-110827 ; 1631\}$ \\
\hline $\begin{array}{l}\text { Subgroup baseline score } \\
\mathrm{RDQ}<13\end{array}$ & $N=24$ & & $N=22$ & & & \\
\hline $\begin{array}{l}\text { Total costs (without sick } \\
\text { leawe) }\end{array}$ & 486.6 & 493.6 & 489.4 & 649.4 & -2.84 & {$[-347,2,341,5\}$} \\
\hline Total cosls (including sick leave) & 3815.4 & 8690.6 & 7734.8 & 12302 & -3919.4 & $\{-10686 ; 3006.3\}$ \\
\hline
\end{tabular}

Although results showed that pain decreased extensively in both study groups, recurrence of pain episodes was a quite common phenomenon in the year after delivery. Importantly, the decrease in the level of pain experience (measured with MPQ-VAS) was similar in both study groups and independent from the differences in improvement on resumption of normal activities, participation and reduced fears between the both study groups measured with the RDQ, autonomy in self-care (IPA) and activity avoidance (TSK). It seems that pain flare-ups are rather common but they are better manageable in the EI group than in the UC group.

The economic evaluation showed that although there was a slight positive trend in the UC group to make more use of health services the differences in outcomes of direct costs were only minor. However, costs were generated by only part of the women in the UC care group. In spite of the large differences of costs due to sick leave within both study groups, the mean costs of sick leave in the UC group were about doubled compared to the EI group. Differences remained stable in the subgroup analyses. Probably other factors than PPGPrelated factors could have caused the large differences in costs of sick leave after finishing maternity leave within both study groups. There are still many unknown reasons why a considerable number of young mothers are reluctant 
to return to gainful employment after finishing maternity leave; More research in this field in general and in the Dutch situation is necessary.

A deciding factor for conducting this trial was to develop and test a practical method of reactivating and addressing worries and activity avoidance of women with PPGP shortly after delivery that might be worthwhile in a physiotherapy setting. As discussed before, the developed intervention differed considerably from the current management [6]. The focus of the intervention changed from a biomedical to a biopsychosocial approach. In the field of PPGP, this is the first study including an economic evaluation alongside the trial.

Overall, results of this trial are for the greater part in line with trials using selfmanagement approach with chronic low back pain patients[11, 47, 48]. The results also showed that women's worries about their condition in this population are major concerns. The worries referred to an unremitting source of anxiety about the etiology and prognosis. The degree of distress may contribute to avoidance of picking up the full range of activities again after delivery and the feeling that a wrong movement could lead to a serious problem. However, the results do not indicate what component of the intervention was effective.

Embedding the trial in a large cohort study had several advantages. Details about the enrollment out of the cohort into the trial showed that the start of the experimental intervention (three weeks after delivery) was reasonably well timed. A substantial number of women in whom intervention seemed to be necessary during pregnancy, recuperated quickly without treatment in the first weeks after delivery. The favorable prognosis shortly after delivery also influenced probably the improvement in both study groups. The recovery rates of both study groups were still relatively high the year after delivery. However, there were still a small number of women with persistent disability. Moreover, there also were some women in the UC group that did not opt for treatment by a physiotherapist or guidance by a general practitioner but improved instead. Those women did not generated any direct or indirect costs due to PPGP. An important issue for research in this field should be how long should dysfunction due to PPGP continue after delivery before women should be referred for interventions seeking to reduce activity limitations. Results of the trial indicate that a period of 3 to 6 weeks seems reasonable. Moreover, persistent needs and worries by the women themselves is an important indication. Future studies will need to address the effectiveness of the experimental intervention in more highly selected groups. 


\section{Conclusion}

Finally, results of this trial indicate a rapid and significant improvement of women attending of the intervention program relative to usual care. The improvement was also enduring during the year after delivery. Although not significant, costs of sick leave in the UC group were about doubled compared to the El group. Differences remained stable in subgroup analyses.

\section{Acknowledgements}

The funding for this study was provided by the Health Care Insurance Board (College voor zorgverzekeringen CVZ) in the Netherlands as a part of a research project titled "Peripartum pelvic pain during pregnancy and after delivery". We would like to express our gratitude to all the participating women, Gonnie Klabbers as research-physiotherapist and Conny de Zwart for the logistic assistance.

Finally, we thank the entire group of therapists for their enthusiastic participation during the project.

\section{References}

1. B Stuge, G Hilde, N Vollestad: Physical therapy for pregnancy-related low back and pelvic pain: a systematic review. Acta Obstet Gyn Scand 2003, 82:983-90.

2. SJ Linton: A review of psychological risk factors in back and neck pain. Spine 2000, 25:1148-56.

3. IWS Vlaeyen, S Morley: Cognitive-behavioral treatments for chronic pain: what works for whom? Clin J Pain 2005, 21:1-8,

4. JM Bastiaanssen, RA de Bie, CHG Bastiaenen, A Heuts, MEAL Kroese, GGM Essed, PA van den Brandt: Etiology and prognosis of pregnancy-related pelvic girdle pain; design of a longitudinal study. BMC Public Health 2005,5:1.

URL: http/ / www.biomedcentral.com/1471-2458/5/1

5. D Molher, KF Schulz, DG Altman: The CONSORT statement: revised recommendations for improving the quality of reports of parallel group randomized trials. BMC Med Res Methodol 2001, 1:2. URL.http// www.biomedcentral.com/1471-2288/1/2

6. CHG Bastiaenen, RA de Bie, PMJC Wolters, JWS Vlaeyen, JM Bastiaanssen, ABA Klabbers, A Heuts, PA vd Brandt, GGM Essed: Treatment of pregnancyrelated pelvic girdle and/or low back pain after delivery design of a randomized clinical trial within a comprehensive prognostic cohort study. BMC Public Health 2004, 4:67 
URL: http//www.biomedcentralicom/1471-2458/4/67

7. DA van der Windt, BW Koes, M van Aarst, MA Heemskerk, LM Bouter: Practical aspects of conducting a pragmatic randomised trial in printary care: patient recruitment and outcome assessment. Br I Gen Pract 2000, 50,371 4 .

8. K Lorig: Partnerships between expert patients and physicians. Lancet 2002, 359:814-5.

9. JA Hides, GA Jull, CA Richardson: Long-term effects of specific stabilizing exercises for first-episode low back pain. Spine 2001, 26:E243-8.

10. JWS Vlaeyen, SI Linton: Fear-avoidance and its consequences in chronic musculoskeletal pain: a state of the art. Pain 2000, 85:317-332.

11. JE Moore, M Von Korff, D Cherkin, K Saunders, K Lorig: A randomized trial of a cognitive-behavioral program for enhancing back pain self care in a primary care setting. Pain 2000, 88:145-53.

12. JWS Vlaeyen, J de Jong, M Geilen, PHTG Heuts, G van Breukelen: Graded exposure in vivo in the treatment of pain-related fear: a replicated single-case experimental design in four patients with chronic low back pain. Behr Res Ther 2001, 39:151-66.

13. JWS Vlaeyen, G Crombez: Fear of movement/(re)injury, avoidance and pain disability in chromic low back pain patients. Man Ther 1999, 4:187-195.

14. T Bodenheimer, $K$ Lorig, H Holman, K Grumbach: Patient self-management of chronic disease in primary care. JAMA 2002, 288:2469-75.

15. GWaddell: Diagnostic triage. In: The Back Pain Revolution, wol. Chapter 2. pp. 9-26. Edinburgh, London, New York, Philadelphia, Sydney, Toronto: Chunchill Livingstone; 1998: 9-26.

16. IS Richards, C Nepomuceno, M Riles, Z Suer: Assessing pain behavior: the UAB Pain Behavior Scalle. Pain 1982, 14:393-8.

17. IWS Vlaeyen, DFM Pernot, AMJ Kole-Snijders, JA Schuerman, vH Eek, NH Groenman: Betrouwbaarheid en validiteit van een Nederlandse versie van de Pain Behavior Scale (PBS). Ned Tijdschr Psychol 1990, 45:184-189.

18. M Roland, $R$ Morris: A study of the natural history of back pain. Part I: development of a reliable and sensitive measure of disability in low-back pain. Spine $1983,8: 141-4$

19. JA Kopec, JM Esdaile, M Abrahamowicz, L Abenhaim, $S$ Wood Dauphinee, DL Lamping, II Williams: The Quebec. Back Pain Disability Scale. Measurement properties. Spine 1995, 20:341-52.

20. LE Schoppink, MW van Tulder, BW Koes, SA Beurskens, RA de Bie: Reliability and validity of the Dutch adaptation of the Quebec Back Pain Disability Scale. Phys Ther 1996, 76:268-75.

21. AJ Beurskens, HC de Vet, AJ Koke, E Lindeman, Gl van der Heijden, W Regtop, PG Knipschild: A patient-specific approach for measuring functional status in low back pain. J Manipulative Physiol Ther 1999, 22:144-8.

22. GH Guyatt, B Kirshner, $R$ Jaeschke: Measuring health status: what are the necessary measurement properties? J Clin Epidemiol 1992, 45:1341-5. 
23. $\mathbb{R}$ Melzack: The McGill Pain Questionmaire: major properties and scoring methods. Pain 1975, 1:277-99.

24. WA van der Kloot, RA Oostendorp, J van der Meij, J van den Heuvel: De Nederlandse verste van "McGill pain questionnaire: een betrouwbare pijnvragenlijst. Ned Tijdscllw Geneeskd 1995, 139:669-73.

25. M Cardol, Ry de Haan, GA van den Bos, BA de Jong, IT de Groot: The development of a handicap assessment questionnaire: the Impact on Participation and Autonomy (IPA). Clinl Rehabil 1999, 13:411-9.

26. $M$ Cardol, RI de Haan, BA de Jong, GAM van den Bos, IIM de Groot: Psychometric properties of the impact on participation and autonomy questionnaire. Arch Phys Med Rehabil 2001, 82:210-216.

27. SH Kori, RP Miller, DD Todd: Kinisophobia: a new view of chronic pain behavior. Pain Management 1990:35-43.

28. PHTG Heuts, JWS Vlaeyen, R Ruesink: Bewegingsvrees bij lage rugpijn. Ned Tijdschr Pijn Pijnbestr 1996, 4:45-48.

29. EJ Swinkels Meewisse, RA Swinkels, AL Verbeek, JW Vlaeyen, RA Oostendorp: Psychometric properties of the Tampa Scale for kinesiophobia and the fearavoidance beliefs questionnaire in acute low back pain. Manl Ther 2003, 8:29-36.

30. L Goubert, $\mathrm{G}$ Crombez, $\mathrm{S}$ Van Damme, IW Vlaeyen, $\mathrm{P}$ Bijttebier, J Roelofs: Confirmatory factor analysis of the Tampa Scale for Kinesiophobia: invariant two-factor model across low back pain patients and fibromyalgia patients. Clin J Pain 2004, 20:103-10.

31. J Ware, K Snow, M Kosinski: SF-36 Health Survey: manual and interpretation guide. The Health Institute, New England Medical 1993.

32. I Ware, M Kosinski, $S$ Keller: SF-36 physical and mental summary scales: A user's manual. The Health Institute, New England Medical 1994.

33. P Dolan: Modeling valuations for EuroQol health states. Med Care 1997, 35:1095-108.

34. ME Goossens, MP Rutten van Molken, IW Vlaeyen, SM van der Linden: The cost diary: a method to measure direct and indirect costs in cost-effectiveness research. J Clinical Epidemiol 2000, 53.688-95.

35. Sv Damme, G Crombez, P Bijttebier, L Goubert, Bv Houdenhove: A confirmatory factor analysis of the Pain Catastrophizing Scale: invariant factor structure across clinical and non-clinical populations. Pain 2002, 96:319-324.

36. MJL Sullivan, SR Bishop, J Pivik: The pain catastrophizing scale: development and validation. Psychol Assess 1995, 7:524-532.

37. AT Beck, RA Steer, MG Garbin: Psychometric properties of the beck depression inventory: twenty-five years of evaluation. Clin Psychol Rev 1988, 8:77-100.

38. AT Beck, CH Ward, M Medndelson, I Mock, J Erbaugh: An inventory for measuring depression. Arch Gen Psychiatry 1960, 4:561-571.

39. AL Wesley, RJ Gatchel, JP Garofalo, PB Polatin: Toward more accurate use of the Beck Depression Inventory with chronic back pain patients. Clin I Pain 1999, 15:117-21. 
40. D Watson, LA Clark, G Carey: Postive and negative affectivity and their relation to anxiety and depressive disorders. I Abnorm Psychol 1988, 97:346-53.

41. JWS Vlaeyen, NJ Teeken Gruben, ME Goossens, MP $\mathbb{R} u t t e n$ van Molken, RA Pelt, $H$ van Eek, PH Heuts: Cognitive-educational treatment of fibromyalgia: a randomized clinical trial. I. Clinical effects. J Rheumatol 1996, 23:1237-45.

42. CH Mallinckrodt, JG Watkin, G Molenberghs, RJ Carroll: Choice of the primary analysis in longitudinal clinical trials. Pharmaceutical Stat 2004, 3:161-169.

43. S Landau, BS Everitt: A handbook of statistical analyses using SPSS: Chapman \& Hall/CRC; 2003.

44. CC Wright, J Sim: Intention-to-treat approach to data from randomized controlled trials: a sensitivity analysis. J Clin Epidemiol 2003, 56:833-42.

45. JB Oostenbrink, CAM Bouwmans, MA Koopmanschap, FFH Rutten: Handleiding voor kostenonderzoek, methoden en standaard kostprijzen voor economische evaluaties in de gezondheidszorg. Diemen: College voor zorgverzekeringen; 2004.

46. JB Oostenbrink, CAM Bouwmans, MA Koopmanschap, FFH Rutten: Standaard kostprijzen en rekenwaarden

Bijlage bij "Handleiding voor kostenonderzoek, methoden en standaard kostprijzen voor economische evaluaties in de gezondheidszorg". Diemen: College voor zorgverzekeringen; 2004.

47. J Barlow, C Wright, I Sheasby, A Turner, J Hainsworth: Self-management approaches for people with chronic conditions: a review. Patient Educ Couns 2002, 48:177-87.

48. M Von Korff, BH Balderson, K Saunders, DL Miglioretti, EH Lin, S Berry, JE Moore, JA Turner: A trial of an activating intervention for chronic back pain in primary care and physical therapy settings. Pain 2005, 113:323-30. 
122 LONG TERM RESULTS 


\section{CHAPTER SEVEN}

\section{Consequences of the Maastricht Cohort and}

Intervention study on pregnancy-related pelvic girdle pain for the development of a clinical practice guideline for the physiotherapy management 


\section{Abstract}

Introduction:

The purpose of this article is to describe the consequences of the outcomes of the Maastricht Cohort and Intervention study on pregnancy-related pelvic girdle pain (PPGP) for the development of a clinical practice guideline based for physiotherapists. The guideline is developed in the Netherlands and consists a methodological approach to the diagnostic and therapeutic processes involved.

Methods:

The guideline was developed according to the method of guideline development and implementation for the physiotherapy in the Netherlands. Evidence from prospective cohort studies, randomized clinical trials, and diagnostic studies was identified by a computerized search in electronic databases. Recommendations were based on the strength of evidence. The guideline was constructed according to the different phases of the physiotherapy process: diagnosis, therapy and evaluation.

\section{Results:}

PPGP is a common physical symptom during pregnancy with a good prognosis after delivery. A distinction between the treatment approach during pregnancy and after delivery is adrocated. Diagnostics should take place in all domains of ICF. Management of women with PPGP should take place within the biopsychosocial approach. The Mastricht Cohort and Intervention study guided to a change in the way of thinking about PPGP. The biomedical aspects have to be required within the biopsychosocial approach mather than presented as something separate and apart. The basic assumption of the therapeutic process is women's needs and worries. A stay active approach is advacated during pregnancy. The primary goal of an intervention shortly after delivery is a quick return to normal daily activities and secondary prevention of chronic disability. 


\section{Infroduction}

At the moment, pregnancy-related pelvic girdle pain is a considerable problem in health care with a high prevalence of pain and disability during pregnancy [1-7]. Although prevalence of these complaints drops considerably after delivery [1, 8-10], remaining patients are faced with long-lasting symptoms that have important physical and psychosocial consequences.

The purpose of this article is to describe the consequences of the Maastricht Cohort and Intervention study [1,8] for the development of a clinical practice guideline for physiotherapists that treat women with pregnancy-related pelvic girdle pain, related impairments, limitations in activities and restrictions in participation during pregnancy and after delivery. The guideline is developed in the Netherlands and consists of a methodological approach to the diagnostic and therapeutic processes involved. The Maastricht PPGP Cohort and Intervention study started in 2000 and studied the etiology, prognosis, prevalence, diagnosis and intervention of pregnancy-related pelvic girdle pain during pregnancy until one year after delivery. The cohort study included 7526 women during their early stages of pregnancy [1] and followed them until one year after delivery. Women with persistent complaints resulting from PPGP after delivery were invited to participate in an intervention study, shortly after delivery $(n=126)[8]$.

Because of the lack of a clear definition we used an extensive description of PPGP including all women who experience some form of pregnancy-related pain in the lower back and/or pelvic girdle originated within the musculoskeletal system.

The following research questions of the Maastricht PPGP Cohort and Intervention study were of interest for developing a clinical practice guideline:

1. Can we classify and describe PPGP in such a way that it provides not only a scientific basis for understanding and studying the disorder but also establish a common language in order to improve communication in daily clinical practice?

2. What are the etiological factors of PPGP?

3. What is the prevalence of PPGP during pregnancy and after delivery?

4. What is the prognosis of PPGP and which prognostic factors influence the course of recovery and can be influenced by physiotherapy? 
5. What is the objective of physiotherapy in patients suffering the consequences of PPGP?

6. Which parts of the physiotherapy diagnostic process are valid, reliable and useful in daily practice?

7. Which treatment and preventive interventions produce clinical significant results?

\section{Methods}

Development process of the clinical practice guideline

The guideline is developed according to the method of guideline development and implementation for the physiotherapy in the Netherlands [11, 12]. This method is based on the international methods of guideline development. Experts using "best evidence" drafted the guideline. When evidence was unavailable, the recommendations were formulated on the basis of consensus. The principles used for assigning levels of evidence to the relevant articles and making and grading recommendations were drawn from the guidelines literature (Table 1a-b). Clinical practice guidelines are defined as "a systematic development from a centrally formulated guide, which has been developed by professionals, that focuses on the context in which the methodical physical therapy of certain health problems is applied and that takes into account the organization of the profession." [11-13]

\section{Literature Search}

An extensive literature search was carried out concerning articles relevant for the research questions. A comprehensive computer-aided search of Medline, CINAHLl, the Cochrane database (Rehabilitation and Therapies Field), PEDRO and the database of the Dutch Institute for Allied Health Care were performed until. May 2005. References of relevant articles were also screened. Articles concerning the etiology, prevalence, prognosis, diagnostics and intervention were searched for. In addition, a search focused on classification, pain and clinical outcome measures was performed.

Articles concerning etiology, prevalence, prognosis, diagnostics and intervention were considered relevant and selected if (1) the study population included only pregnancy-related pelvic girdle pain during pregnancy or after delivery, (2) outcome measures were related to pain, functions, activities and 
Table Ia Criteria used to assign a level of evidence to studies of diagnosis, prognosis and intervention

\begin{tabular}{|c|c|}
\hline \multicolumn{2}{|c|}{ Diagnosis } \\
\hline \multirow[t]{5}{*}{ A. } & i. Independent interpretation of test resullts \\
\hline & 肖. Independent interpretalion of the diagnostic standard \\
\hline & 酒. Selection of people suspected, but not known, to hawe the disorder \\
\hline & IV. Reproducible description of the test and diagnostic standard \\
\hline & v. At least 50 people with and 50 people without the disorder \\
\hline B. & Meets 4 of the Level A criteria \\
\hline C. & Meets 3 of the Level A criteria \\
\hline D. & Meets 1 or 2 of the Level A criteria \\
\hline \multicolumn{2}{|c|}{ Prognosis } \\
\hline \multirow[t]{5}{*}{ A. } & 1. Inception cohor of people with the condition of interest, but free of the outcome of interesl \\
\hline & U. Repraducible inclusion and exclusion criteria \\
\hline & iii. Follow-up of at least $80 \%$ of participants. \\
\hline & Iv. Statistical adjustment for confounders \\
\hline & v. Repraducible description of the outcome measures \\
\hline B. & Meets 4 of the Level A criteria \\
\hline c. & Meets 3 of the Level A criteria \\
\hline D. & Meels 1 or 2 of the Level A criteria \\
\hline \multicolumn{2}{|r|}{ Intervention } \\
\hline A.1 & $\begin{array}{l}\text { Systematic reviews (meta-analyses) which include at least some randomized clinical trials at quality level A2 } \\
\text { that show consistent results between studies }\end{array}$ \\
\hline A.2 & $\begin{array}{l}\text { Randomized clinical trials of a good methodological quality (randomized double-blind controlled studies) with } \\
\text { sufficient power and consistency }\end{array}$ \\
\hline B. & $\begin{array}{l}\text { Randomized clinical trials of a moderate melhodological quality or with insufficient power, or other non- } \\
\text { randomized, cohort or patient-control group study designs that involve inter-group comparisons }\end{array}$ \\
\hline C. & Patient series \\
\hline D. & Expert opinion \\
\hline
\end{tabular}

participation, (3) outcome measures were within the scope of current physiotherapy practice, (4) the treatment consisted of physiotherapy interventions and (5) the language of publication was English, French, German or Dutch.

\section{Results}

\section{Classification}

To classify PPGP as a basis for better scientific and clinical understanding, the Maastricht PPGP Cohort and Intervention study referred to the International Classification of Functioning, Disability and Health (ICF). In the World Health Organization [14] functioning (encompassing all body functions, activities and participation) and disability (an umbrella term for impairments, activity 
Table 16 Grades of the recommendations for clinical practice guidelines

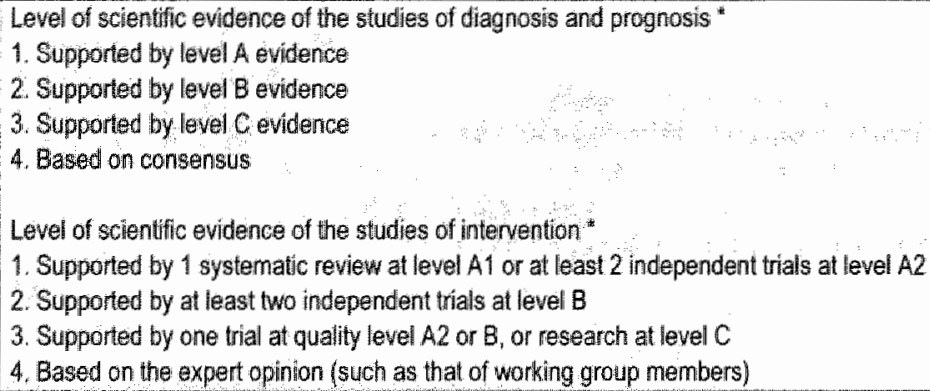

\section{"Consersus was required in addition}

limitations or participation restrictions) are classified in the ICF [14]. During the last decade, ICF has moved away from a "consequence of disease" concept to a "components of health" classification system. The ICF takes a neutral stand with regard to etiology and includes a description of the context in which
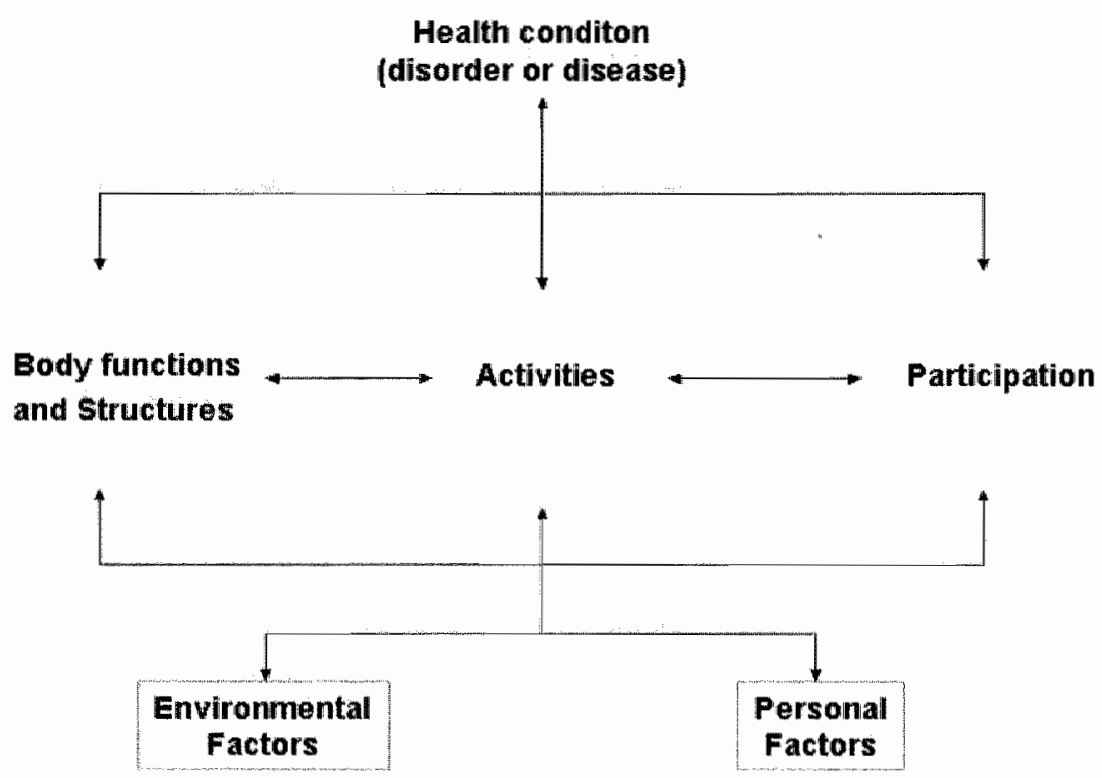

Figure 1 Interactions befween the components of ICF (International Classification of Functions) 
individuals live. The ICF describes functioning and disability as an interactive process (Figure 1). It is a process with dynamic interaction among the presented components (body functions and structures, activities, participation, environmental factors, personal factors and health condition): interventions in one component have the potential to modify one or more components (Figure 1). These interactions are specific and not always in a predictable one-to-one relationship. The interaction works in two directions; the presence of disability may even modify the health condition itself. It is important, however, to collect data on these constructs independently and thereafter explore associations between them. Figure 1 also shows the role of the context in which people live (environmental and personal factors). These factors interact with the individual and determine the level and extent of the individuals" functioning:

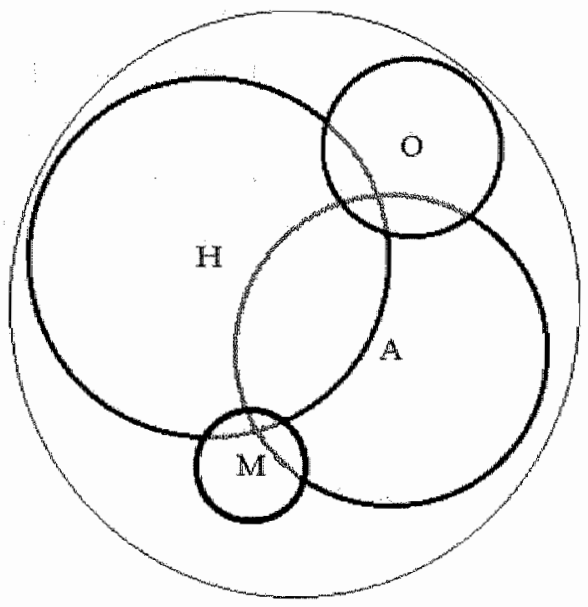

Figure 2 Classification of women with PPGP according to carrent strategies in the field of PPGP

Environmental factors (the physical, social and attitudinal environment in which people live and conduct their lives) are extrinsic to the individual whereas personal factors are considered intrinsic (such as gender, age, lifestyle and coping style). A symptom such as pain is classified as a category of body 
functions and structures in order to identify patients' needs and should to be used along the activities and participation domains. The domains for the activities and participation components cover the full range of life areas (from basic learning, mobility and self-care to areas such as interpersonal interactions and employment).

A variety of conceptual models have been proposed to understand and explain disability and functioning. These may be expressed and summarized in a "medical model" versus a "social model". The medical model views disability as a problem of the person, directly caused by disease, which requires medical care provided in the form of individual treatment by professionals. The social model of disability sees the issue mainly as a socially created problem. The ICF is based on an integration of the two opposing models. In order to capture the integration of the various perspectives of functioning, a "biopsychosocial" approach is used. In this approach, a person is seen as a system integrating biological, psychological and social dimensions[15]. The approach takes into account prognostic factors that may influence recovery and emphasizes the role of psychological and social factors in the development and persistence of symptoms and limitations in activities $[16,17]$.

It is now widely accepted that low back pain and disability can only be understood and managed by a biopsychosocial model [18]. However, in the field of PPGP, the use of this approach is not common practice. The biomedical model is still deeply entrenched in the way most researchers, caregivers and patients think. Moreover, despite many years of research no structural lesion (a clear-cut diagnosis) that causes the pain and disability can be identified.

The Maastricht PPGP Cohort and Intervention study explored the usefulness of the biopsychosocial approach in the research field of PPGP in several ways.

First, we explored the agreement on definitions or classification strategies used by the most cited authors in this field (Chapter 2). Although their respective classifications were all based on a medical model, the differences between them turned out to be outweighing the similarities. The investigated classification strategies represented clearly different selections of women having pregnancyrelated pelvic girdle pain (Figure 2). An important source of disagreement (besides a number of methodological flaws) was a limitation of knowledge in which domains of activities and participation the disorder manifests oneself. Second, we determined whether women without PPGP differ from women with PPGP according to the entities of the ICF at the same moment shortly after delivery (Chapter 3). There were significant and clinical relevant major 
differences between both groups with regard to the domains of pain, activities and participation and contextual factors. Third, we tried to identify subgroups of women with PPGP on the responses of a number of the most important risk factors in the transition from acute to chronic pain $[19,201$. We identified thee significant and clinical relevant different subgroups. Biopsychosocial variables were powerful in detecting subgroups. Nevertheless, differences between the derived groups could not be reduced into differences between the outcomes of physical examination as currently used by researchers in the field of PPGP. Throughout the diagnostic process in daily practice, it seems to be important to focus attention to a history taking in which biopsychosocial variables occupy a major place (Chapter 3).

The ICF seems a powerful heuristic classification to describe and investigate pregnancy-related pelvic girdle pain. The biomedical aspects have to be required within the biopsychosocial approach rather than presented as something separate and apart. The approach focuses on interactions in various domains.

The Maastricht PPGP Cohort and Intervention study focused on those interactions when developing a model to evaluate the association between different prognostic factors with persistent symptoms of PPGP. Evaluation at different points during pregnancy and after delivery is necessary because the weighting of the physical, psychological and social factors may change over time. During the early phases (pregnancy and the first days after delivery) the biological factors may predominate, but over time psychological and social factors may take over in accounting for pain and disability. The randomized controlled trial is also designed within the biopsychosocial approach. In this study, diagnostics took place within all domains of the ICF $[8,21]$.

\section{Components of PPGP}

At the moment, PPGP is an entity characterized by pain in the lumbar-pelvic region often combined with feelings of instability and "catching the leg" when walking [22] [21, 23]. Primary focus/burden for women is pain in the lumbarpelvic region during the initial period of pregnancy and secondly pain and limitations in activities during the last period of pregnancy [24]. Moreover, women suffer more from the limitations in activities and restrictions in participation than pain after delivery [10] . Environmental and personal factors could have positive or negative effects on pain, activities and participation. 


\section{Etological factors}

The Maastricht PPGP Cohort study ( $\mathrm{n}=7526)$ evaluated the association between potential determinants and the onset of PPGP. (Bastiaanssen et al. submitted) An important identified determinant is a history of pelvic girdle or low back pain preceding the current pregnancy. Additionally, younger age, smoking during and before pregnancy and multiparty is significantly associated with the onset of PPGP. Studies investigating the association between a history of pelvic girdle or low back pain and the onset of pelvic girdle pain in the index pregnancy reported results consistent with the results found in our study $[1,24-$ 30]. Younger age was also significant associated with the onset of PPGP. Several previous studies have been noted the same association about age $[26,30,31]$ although not in some others $[6,29]$. In the Maastricht PPGP Cohort study, there was also found a significant but not strong association between parity and the onset of pelvic girdle pain in the index pregnancy. Many other studies found the same association. $[24,26]$

Due to the hormonal changes during pregnancy, associations between several hormonal factors (such as relaxin concentration and the former use of oral contraceptives) and the onset of PPGP have been studied. However, results are conflicting. An association between the onset of pelvic girdle pain and serum concentrations of relaxin has been reported $[32,33]$ but not confirmed[34]. The association with the onset of PPGP and former use of oral contraceptives is also not clear $[25,35-37]$. Therefore, hormonal factors could play a role in the onset of pregnancy-related pelvic girdle pain but their role is still unclear [38].

\section{Prevalence}

Pain in the lower back, buttocks, symphysis, groins or radiation into the legs starting at some time during pregnancy, is a common physical symptom in our study [1]. Of the 7526 women, $84 \%$ reported pain in any or all of these areas at some time during pregnancy. Women with a history of pelvic girdle or low back pain are more likely to develop complaints (98\%) than women without a history of pelvic girdle or low back pain (Figure 3). Moreover, the study reported that women with a history of pelvic girdle or low back pain not only have a higher prevalence during the index pregnancy but PPGP started also earlier in pregnancy. 


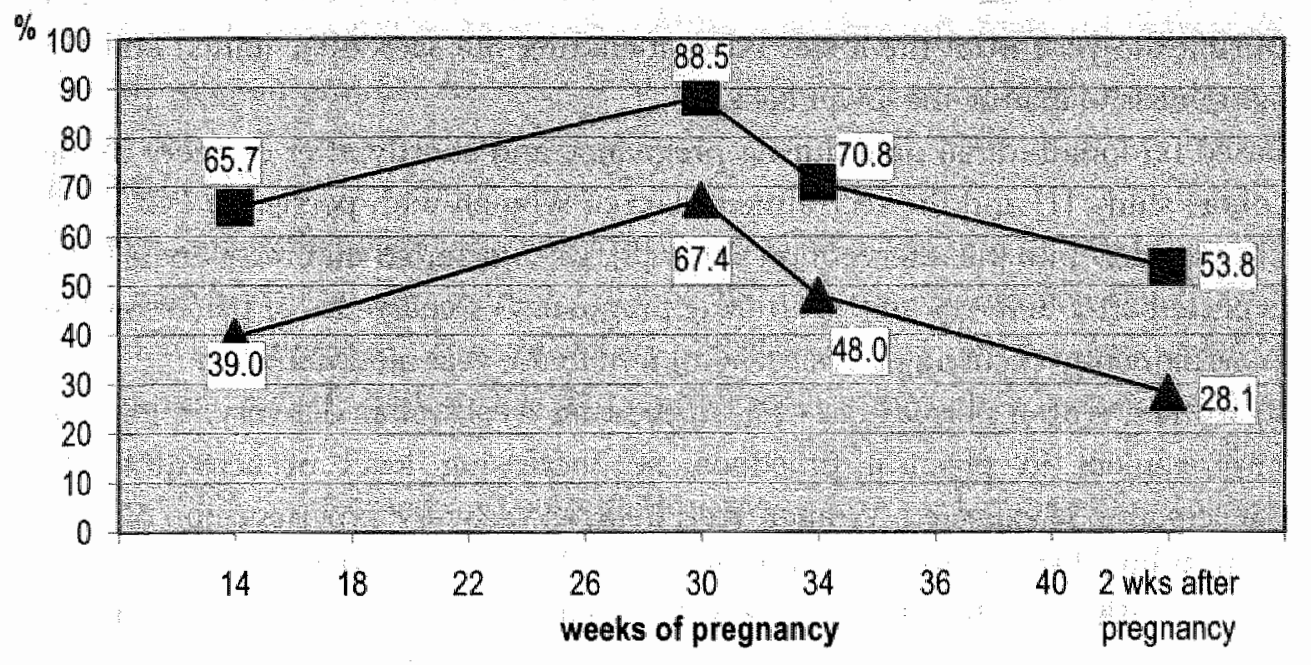

Figure 3 The point prevalence of PPGP during pregnancy for women with ( $\mathbf{n}$ ) and without ( $\Delta$ ) a histoy of LBP/PPGP (Bastiaanssen et al. BMC Public Health $5 ; 1$ with permission of the author [1]

This difference persisted during the whole pregnancy. However, prevalence drops considerably short after delivery $[1,8]$ (Figure 4). 35\% of the women reported pain at three weeks after delivery, $35.1 \%$ one year after delivery. Yet, only $6.4 \%$ of the women indicated that an intervention was necessary during the year after delivery. Other studies also noted a high prevalence during pregnancy and a considerable drop in the prevalence shortly after delivery [39, $40]$.

\section{Prognosis}

Data of the enrolment out of the cohort into the intervention study described the in/exclusion process from 10 days after delivery until 3 weeks after delivery. Women with persistent PPGP 10 days after delivery $(n=869)$ in which an intervention would be necessary were contacted and visited at home. Three weeks after delivery we excluded 650 women out of the 869 because of a quick recovery (without any treatment) during the last two weeks after delivery (Figure 4) [8].

Longitudinal data of the Maastricht PPGP Cohort study showed that $30.7 \%$ of the women that recovered from PPGP in the first weeks after delivery, reported one or more episodes of recurrent pain in the year after delivery. Both women 
with persistent and recurrent pain reported that pain localization changed during the year from the lower back (including the sacro-iliac joints) and the symphysis to mainly the lower back.

Based on longitudinal data during pregnancy and shortly after delivery in the cohort study [1] and the recruitment data of women with persistent PGPP out of the cohort into the intervention study [8], we concluded that recovery is to be expected after delivery and not during pregnancy. Recurrence of pain seems to be a frequently occurring physical symptom in the year after delivery.

In women with a normal recovery in the first weeks after delivery, a gradual improvement in physical functions, an increasing level of activities and participation is expected. Women with delayed recovery experience no or only small improvements in physical functions, activities and participation, or pain does not decrease. In this group, psychosocial factors may also be present and will delay recovery, as in other benign chronic pain conditions (Chapter 3 ).

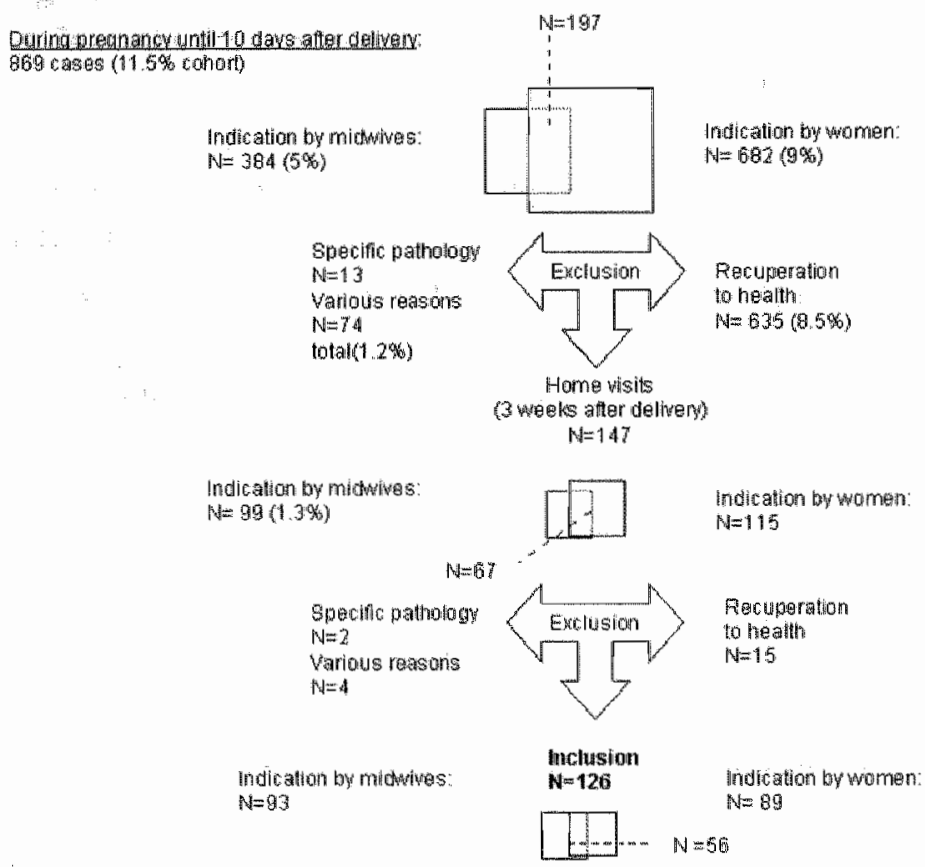

Figure 4 Enrolment out of the Maastricht cohort study in to the interoention study [8]

In the literature, there is also some consensus about a relative good prognosis after delivery $[1,7,24,25,27,29,32,39,41,42]$. However $r_{r}$ the methodological quality of most of the studies is low to moderate (Table 2). Some studies[25, 27, 
39] included a reprehensive group of women during pregnancy at baseline. However, they excluded all women without complaints from the follow-up directly after enrolment.

\section{Prognostic factors}

To discriminate between women with a normal recovery or a delayed recovery after delivery, it is important to identify prognostic factors associated with persistent symptoms. The Maastricht PPGP cohort study developed a conceptual model within the biopsychosocial approach to evaluate that association.

Linton [20] performed a systematic review on relationships between psychological factors and neck and back pain. Linton concluded that psychological factors are strongly associated with a change from acute to chronic pain with greater disability. In addition, it is identified that psychological factors in general have a bigger impact on disability caused by low back pain than biomedical or biomechanical factors. The patient's attitudes and emotions are important. The perception of pain as "a catastrophe" and conditions such as depression and fear are all highly associated with increased pain and disability.

These factors may also be of importance in women with pregnancy-related pelvic girdle pain because, as in non-pregnancy-related low back pain, there is no obvious tissue damage that explains long-lasting pain and disability [10].

The literature state that the only factors on which consensus are reached is a previous history of low back pain and a previous history of pregnancy-related pelvic girdle pain during pregnancy[10, 24, 25, 27, 43]. Recent data of the Maastricht PPGP cohort study in the Netherlands underscore the significance of a previous history (Bastiaanssen et al. Submitted).

\section{Dingnostics}

Within the Maastricht PPGP Cohort and Intervention study [8], diagnostics took place within all domains of the ICF. To provide insight into the health problem, a systematic history is taken concerning body functions and structures (pain, movement related functions and structures related to the pelvic region), limitations in the domains of activities and participation and finally the influence of contextual factors. We used a simple diagnostic triage [17]. Physical examination focused on body functions and structures. Limitations in activities, restrictions in participation, pain and the influence of contextual 
Table 2 Prospective cohorts during pregnancy and after delivery; levels of eoidence

\begin{tabular}{|c|c|c|c|c|}
\hline $\mathrm{A}^{\circ} \quad \mathrm{a}$ & $\mathbb{N}$ & / cases & $\begin{array}{l}\text { Inception cohort of } \\
\text { people with the } \\
\text { condition of interest but } \\
\text { free of the outcome of } \\
\text { interest }\end{array}$ & $\begin{array}{l}\text { Reproducible inclusion } \\
\text { and exclusion criteria }\end{array}$ \\
\hline (Albert et al 2001)t & 1789 & 1405 & $x \quad \therefore \quad \therefore$ & $x$ \\
\hline (Berget al. 1988) & 862 & 179 & * & $x$ \\
\hline $\begin{array}{l}\text { (Kristiansson et al. } \\
\text { 1996a; Kristiansson et } \\
\text { al. 1996b) }\end{array}$ & 200 & & * & $\mathbf{x}$ \\
\hline $\begin{array}{l}\text { (Ostgaard and } \\
\text { Andersson 1992; } \\
\text { Ostgaard et al. 1991a; } \\
\text { Ostgaard et al. 1991b) }\end{array}$ & 917 & & * & $\mathbf{x}$ \\
\hline (Larsen et al. 1999)t & 1600 & 1227 & * & $x$ \\
\hline (To and Wang 2003)\# & 326 & & * & $x$ \\
\hline $\begin{array}{l}\text { (Bastiaanssen et al. } \\
2005 \text { ) }\end{array}$ & 7526 & & * & $x$ \\
\hline
\end{tabular}

$A=$ meets 5 criteria, $B=$ meets 4 of the level $A$ criveria, $C=$ meets 3 of the level $A$ criteria, $D=$ prospective cohort, measurement only during pregnancy, cases followed until one year after,

factors is measured with self-reported questionnaires whose psychometric qualities are already well known[44-63] [8].

Physical examination in the research field of PPGP focused mostly on some diagnostic tests and on a pain referral area specific for sacro-iliac joint pain.

Commonly used tests are the posterior pelvic pain provocation test or thigh thrust [21], palpation of the long dorsal sacro-iliac joint ligament [64], the Patrick 's fabere test $[22,65]$, palpation of the symphysis $[22,65,66]$, the active straight leg raise test [67] and the hip adduction strength [68] (Table 3). Evidence did not reach a satisfactory level for all tests. Besides methodological problems in the selection of the study populations, a comparison with a diagnostic standard was lacking in all studies. Recent research $[69,70]$ on the reliability and validity of pain provocation and mobility tests of the sacro-iliac joint reported that studies of the sacro-iliac joint pain provocation and mobility tests showed poor methodological quality. The authors concluded that it is questionable whether any sacro-iliac joint test is of any value for clinical practice [22, 69-71]. An important issue is the absence of correct knowledge of a reference or diagnostic standard. 
Table 2 continued

\begin{tabular}{|c|c|c|c|}
\hline $\begin{array}{l}\text { Follow-up of at least } \\
80 \% \text { of participants }\end{array}$ & $\begin{array}{l}\text { Statistical adjustment for } \\
\text { confounders }\end{array}$ & $\begin{array}{l}\text { Reproducible description of } \\
\text { the outcome measures }\end{array}$ & $\begin{array}{l}\text { Level of evidence } \\
(A, B, C, D)\end{array}$ \\
\hline - & - & 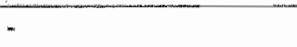 & D \\
\hline - & - & $\mathrm{x}$ & $\mathrm{C}$ \\
\hline$x$ & $=$ & $x$ & B \\
\hline$x$ & - & $x$ & $\mathrm{~B}$ \\
\hline - & - & - & D \\
\hline - & - & x & C \\
\hline$x$ & $x$ & * & $A$ \\
\hline
\end{tabular}

meets 1 or 2 of the level A criteria, $†$ After inclusion, only cases are measured during follow-up, delivery, $\ddagger$ prospective cohort after delivery

It has been suggested that pain over the sacro-iliac joint region with an onset during pregnancy is specific for PPGP [21, 22] but evidence remains unclear. Very recently, a study that evaluated pain referral areas in a non-pregnant population concluded that there were no differences in dermatome distribution between patients with and without sacro-iliac joint pain as compared with a reference standard. [70] They concluded that overall pain referral maps are not useful in patients with sacro-iliac joint pain.

\section{Intervention}

The experimental intervention of the Maastricht PPGP randomized controlled trial is designed within the biopsychosocial approach [8]. The start of the treatment sessions was about three weeks after delivery. Three weeks after delivery is a critical moment in the course of PPGP because prevalence data stabilize after a considerable drop at that time and remain thereafter at the same level during the year after delivery.

Group discussions with experienced physiotherapists and interviews of women with PPGP out of the cohort gave insight into the most striking characteristics 


\begin{tabular}{|c|c|c|c|}
\hline & $N$ & $\begin{array}{l}\text { Independent } \\
\text { interpretation of test } \\
\text { results }\end{array}$ & $\begin{array}{l}\text { Independent } \\
\text { interpretation of the } \\
\text { diagnostic standard }\end{array}$ \\
\hline During pregnancy & 3 & & \\
\hline $\begin{array}{l}\text { Posterior Pelvic Pain } \\
\text { Provocation(Ostgaard et } \\
\text { al. } 1994 \text { ) } \\
\text { /high thrust } \\
\text { Patrick's faber test }\end{array}$ & 72 & $*$ & - \\
\hline (Wormslev et al. 1994) & 40 & * & - \\
\hline $\begin{array}{l}\text { (Albert et al. 2000) } \\
\text { Palpation of the } \\
\text { symphysis }\end{array}$ & 2269 & - & - \\
\hline (Albert et al. 2000 & 2269 & - & - \\
\hline $\begin{array}{l}\text { Kristiansson and } \\
\text { Svardsudd } 1996 ;\end{array}$ & 200 & $x$ & - \\
\hline Wormslev et al. 1994) & 40 & $\mathrm{x}$ & - \\
\hline \multicolumn{4}{|l|}{ After delivery } \\
\hline $\begin{array}{l}\text { Long dorsal sacroiliac } \\
\text { ligament (Vleeming et } \\
\text { al.2002) }\end{array}$ & 178 & $x$ & - \\
\hline $\begin{array}{l}\text { Active Straight Leg } \\
\text { Raise test(Mens ot al. } \\
\text { 2001) }\end{array}$ & 200 & $x$ & - \\
\hline $\begin{array}{l}\text { Hip Adduction } \\
\text { Strenght(Mens et al. } \\
\text { 2002) }\end{array}$ & 75 & $x$ & - \\
\hline
\end{tabular}

$A=$ meets 5 criteria, $B=$ meets 4 of the level $A, C=$ meets 3 or 2 of the level $A$ criteria, $D=$ weets

of current treatment approaches in the Netherlands. Those characteristics were a pain contingent regimen of avoiding and limiting several day-to-day activities and an accent on biomedical factors. Therapists were often highly concerned about their patient's pain themselves. However, women with PPGP being interviewed were irritated about this regimen in an increasing degree after the start of the treatment sessions. The regimen was too strict and on a number of points not geared to the wishes and concerns of the women. These aspects contributed to a lack of compliance and an unremitting uncertainty about a good prognosis and in particular about reassuming certain day-to-day activities after delivery. 


\begin{tabular}{|c|c|c|c|}
\hline $\begin{array}{l}\text { Selection of people } \\
\text { suspected, but not } \\
\text { known, to have the } \\
\text { disorder }\end{array}$ & $\begin{array}{c}\text { Reproducible } \\
\text { description of the test } \\
\text { and diagnostic standard }\end{array}$ & $\begin{array}{c}\text { At least } 50 \text { people with } \\
\text { and } 50 \text { people without } \\
\text { the disorder }\end{array}$ & $\begin{array}{l}\text { Level of evidence } \\
\text { (A, B, C D ) }\end{array}$ \\
\hline$x$ & - & - & D \\
\hline - & - & - & D \\
\hline * & $=$ & $x$ & $D$ \\
\hline$x$ & - & $x$ & $D$ \\
\hline * & - & $x$ & C \\
\hline - & - & - & D \\
\hline & 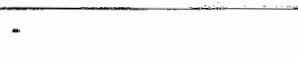 & - & D \\
\hline & - & - & $D$ \\
\hline - & - & $=$ & $D$ \\
\hline
\end{tabular}

I or 2 of the level A criterin, 6 months until 5 years after delivery

Therapists did not realize the nature of this problem although they did mention problems with compliance. Therefore, in our study, women's worries about their condition were major targets of the experimental intervention. Patienttherapist relationship, education, and the promotion of an active lifestyle rather than avoiding of activities were considered important. Theoretical concepts of self-management $[72,73]$ and fear avoidance techniques [74] were integrated in the study protocol. A dimension of interest was education. Current treatment approaches focus on the transfer of information about biomechanical explanatory models. However, the etiological basis of these models remains unclear and the question presents itself if this kind of information meets the 
Table 4 a Characteristics of included randomized clinical trails

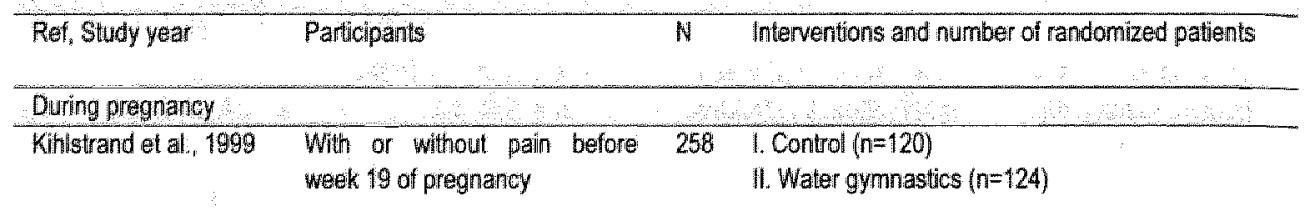

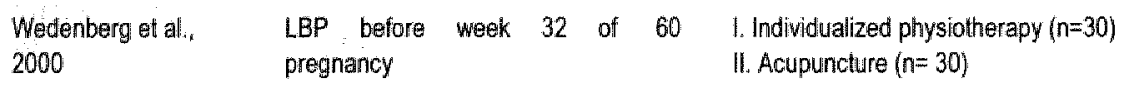

Kvorning et al, 2004 PPGP or LBP within 24 to $37 \quad 72 \quad$ I. Control $(n=35)$

weeks of pregnancy $\quad$ II. Acupunciure $(n=37)$

Eldan ef al, 2005 PPGP within 12 to 31 weeks of 386 1. Standard treatment $(n=130)$

pregnancy

General informatiom and advice by a experienced physiatherapist, a pelwic belt and home exercise programme)

II. Standard treatment + acupuncture $(n=125)$

III. Standard treatment + stabilising Exercises $(n=134)$

\begin{tabular}{|c|c|c|c|}
\hline After delivery & & & \\
\hline Mens el all, 2000 & $\begin{array}{l}\text { Persistent PPGP after } 6 \text { weeks } \\
\text { to } 6 \text { months after delinery }\end{array}$ & 44 & $\begin{array}{l}\text { 30-min videotape with information, ergonomic } \\
\text { advice and how to use a pelvic belt sent to all three } \\
\text { groups } \\
\text { I. Conlrol: refrain from exercises }(n=16) \\
\text { II. Control: Home placebo exercises }(m=14) \\
\text { Ill. Home-training of the diagonal trunk musclle } \\
\text { system }(n=16)\end{array}$ \\
\hline Siuge at al., 2004 & $\begin{array}{l}\text { PPGP after pregnamcy wiltin } 3 \\
\text { weeks after deliwery }\end{array}$ & 81 & $\begin{array}{l}\text { 1. Control. Physiotherapy whout specific stabilising } \\
\text { exercise }(n=39) \\
\text { 11. Physiotherapy plus focus on specific stabilising } \\
\text { exercises }(n=39)\end{array}$ \\
\hline $\begin{array}{l}\text { Bastiaenen at al }{ }_{*} \\
2004,2005\end{array}$ & PPGP 3 waeks after delivery & 126 & $\begin{array}{l}\text { Control. Current physiotherapy approach } \\
\text { (including specific stabilising exercise) ( } n=64 \text { ) } \\
\text { If. Biopsychosocial approach including self- } \\
\text { management, graded exposure techiniques and } \\
\text { coordinative (stabilising) exercises (n=62) }\end{array}$ \\
\hline
\end{tabular}




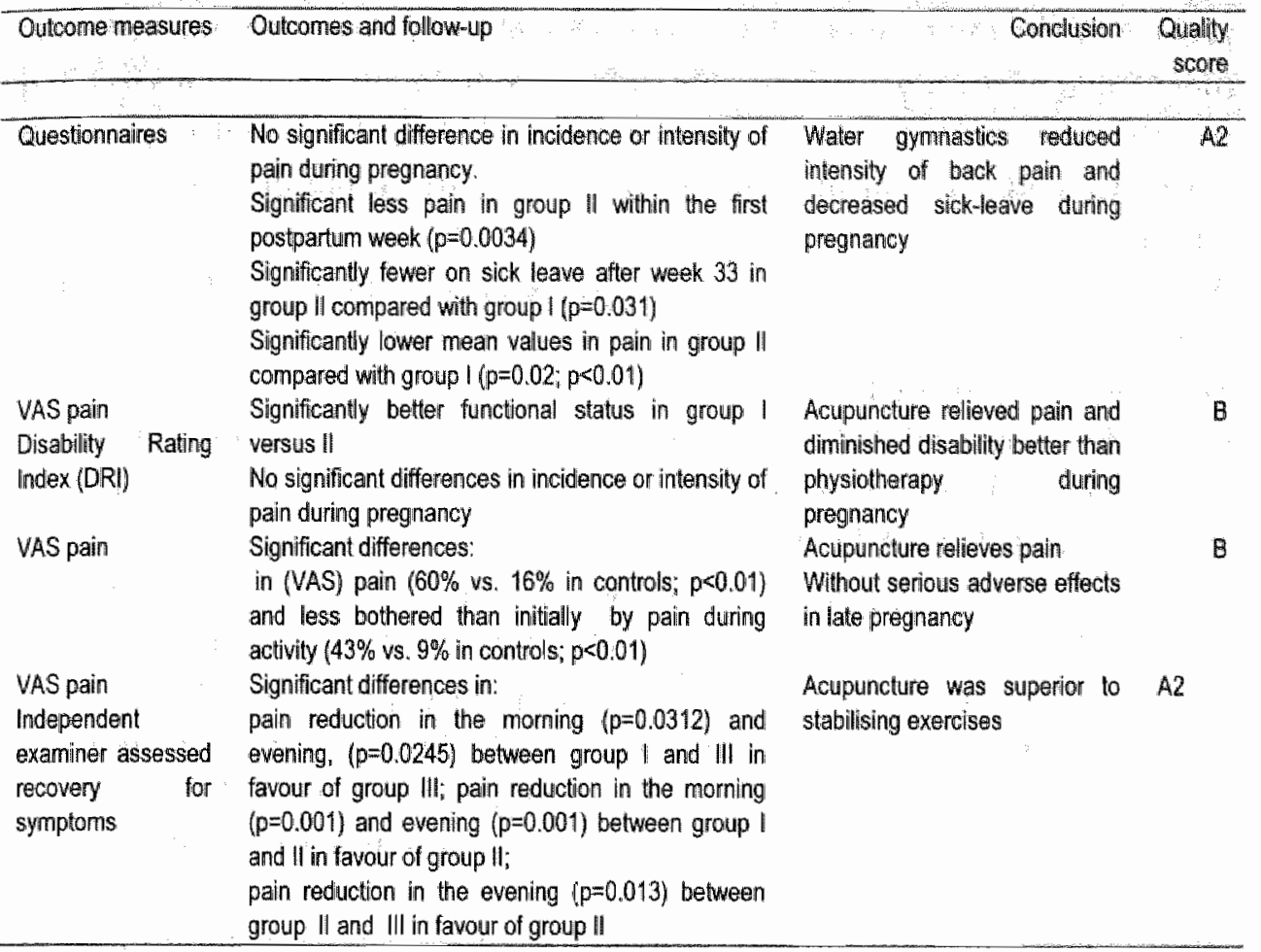

$\begin{array}{ll}\text { VAS pain } & \text { No significiant differences th mean change: } \\ \text { Gobal impression } & \text { in pain (VAS-100) from baseline. } \\ \text { of improvement (3- } & \text { in global improvement } \\ \text { point Likent). NHP } & \text { in physical mobility } \\ \text { PPPP test } & \end{array}$

VAS pain

Oswestry

Disability

LBP

Questionnare

SF -36

RDQ,

Main Complaint

Global perceived

effect

TSK

VAS pain

$S F-36$

IPA
Significant differences between groups in favour of group II in:

pailu intensity

Disability

Quality of life

Significant difference between groups in favour of group II in:"

Disability ( $p=0.05$ )(two-tailed)

Subgroup analyses with severe disabled women ( $R D Q \geq 13$ at baseline) reported that severe disabled women gained most by the biopsychosocial appiroach RDQ(p=0,003)(two tailed)
Training of the diagonal trunk muscles systems, without individual coaching, has no additional value above instructions and use of a pelvic bell without axercises

An individualized approach with specific stabilizing exercises appears to be more effective than physical therapy without specific stabilizing exercises

Results fawoured the hypotheses. Women's worries about their condilion were major targets 
worries and needs of the women with PPGP. Recent research on low back pain hypothesized that the aim of education should be reconceptualization of the problem [75]. Information about pain should be focused on the dynamic functioning of nervous system with a focus on the components of nociception and the adaptability of the nervous system including the neural response to inactivity and movement control. In our study protocol, we included information about dynamic pain processes.

A basic principle for selection of eligible women in our study was that inclusion criteria must have a meaningful influence in goal setting for treatment. Therefore, we focused on criteria such as a delay in recuperation and restrictions in normal daily activities associated with PPGP. Results of the RCT are described in chapters 5 and 6 (level A2). Women with severe limitations in activities gained most by the developed intervention compared to women treated according to the current treatment approaches. There was a rapid and significant improvement relative to the current approaches on a pain-contingent basis and the improvement was also enduring during the year after delivery. The improvement concerning limitations in activities, activity avoidance and autonomy in self-care was also persisting during the year after delivery.

Within the current treatment approaches of PPGP, results of various therapeutic interventions have been published but except two studies [76, 77], their effectiveness remains unproven. Furthermore, the majority of the studies are methodologically flawed (Table 4a-b). Except three studies [8, 76, 83], all studies were performed during pregnancy. There was a large variation in timing of the intervention was given (between 11 weeks of pregnancy and 6 months after delivery). The timing of the interventions and the outcome measurement may have influenced the results[86]. One study [79] performed an intervention during pregnancy (start of the sessions in week 15-18). However, the last follow-up measurement was arranged within the first week after delivery. There is a good chance that the short-term effects of giving birth and the very good prognosis of PPGP in the first period after delivery influenced the outcomes on that moment. The sample size varied between 44 [83] and 258 participants [79]. Two studies [78, 83] had a very small sample size and may have lacked power to detect a clinically relevant difference. The heterogeneous nature of the studies concerning participants, outcome measurements, timing of the measurements and interventions made it difficult to synthesize and compare the results of the various studies [86]. 
Table $4 b$ Characteristics of clinical controlled trials

\begin{tabular}{|c|c|c|c|c|}
\hline Ref, Study year & Participants & N & Intervention and comparison group & Outcomes and lollow-up \\
\hline \multicolumn{5}{|l|}{ During pregnancy } \\
\hline $\begin{array}{l}\text { Mantie et al. } \\
1981\end{array}$ & $\begin{array}{l}\text { Primiparaous } \\
\text { with or withoul: } \\
\text { pain before } \\
\text { pregnancy } \\
\text { week } 16\end{array}$ & 208 & $\begin{array}{l}\text { 1. Control } \\
\text { II. Two classes ergonomic back care } \\
\text { advice. }\end{array}$ & $\begin{array}{l}\text { Significanl difference in } \\
\text { (troublesome, severe) backache } \\
(p<0.01)\end{array}$ \\
\hline $\begin{array}{l}\text { Ostgaard el al., } \\
1994\end{array}$ & $\begin{array}{l}\text { Pregnant } \\
\text { women with or } \\
\text { without pain, } \\
\text { before week } \\
18\end{array}$ & 407 & $\begin{array}{l}\text { 1. Control ( } n=145 \text { ) } \\
\text { II. Leaflet and } 2 \text { classes of modiffed } \\
\text { back school } \\
\text { education and training program } \\
\text { ( } n=123 \text { ) } \\
\text { III. As group II but individually and } \\
\text { for longer periods } \\
+ \text { exercises at home }(n=139)\end{array}$ & $\begin{array}{l}\text { Significantly better functional } \\
\text { status in group III compared with } \\
\text { group I eight weeks postipartum } \\
\text { (p<0.05) } \\
\text { Significantly higher reduction in } \\
\text { sick leave in group III compared } \\
\text { with group I ( } p<0.05 \text { ) }\end{array}$ \\
\hline $\begin{array}{l}\text { Dumas et al., } \\
1995\end{array}$ & $\begin{array}{l}\text { Women early } \\
\text { in pregnancy } \\
\text { (after week } \\
\text { 12) with or } \\
\text { without pain }\end{array}$ & 65 & $\begin{array}{l}\text { 1. Sedantary controls ( } n=38 \text { ) } \\
\text { II. Exercise classes for pregnant } \\
\text { women ( } n=27)\end{array}$ & $\begin{array}{l}\text { No significant differences in: } \\
\text { pain prevalence and; } \\
\text { functional status }\end{array}$ \\
\hline $\begin{array}{l}\text { Noren et all, } \\
4997\end{array}$ & $\begin{array}{l}\text { Pregnant } \\
\text { women with } \\
\text { LBP or PGP } \\
\text { between week } \\
11-36\end{array}$ & 135 & $\begin{array}{l}\text { 1. Control ( } n=81 \text { ) } \\
\text { II. Indiwidualized physiotherapy ( } n= \\
\text { 54) }\end{array}$ & $\begin{array}{l}\text { Significantly fewer on sick leave } \\
\text { in group llcompared will group I } \\
\text { (p<0.001) } \\
\text { Significant reduction in pain } \\
\text { intensity ( } p<0.05 \text { ), no } \\
\text { comparison }\end{array}$ \\
\hline
\end{tabular}

A recently published study $[76,84]$ evaluated the effect of specific stabilizing exercises of the abdominal muscles compared with physical therapy without specific stabilizing exercises, after delivery. The results of this study showed that a treatment program with specific stabilizing exercises, integrated functionally, is effective in reducing pain, improving functional status and improving health-related quality of live after delivery. However, the active intervention consisted of about 60 treatment sessions ( 3 times a week for 20 weeks) and an extensive amount of training by the women themselves at home, during that time.

In conclusion, there seems to be evidence for a positive effect of active treatment shortly after delivery, within the scope of a biopsychosocial approach, including a coordinative exercise therapy and theoretical concepts of selfmanagement and graded exposure techniques. 
Practical consequences for the development of the guideline

\section{During Pregnancy}

First, curring pregnancy the emphasis lies on excluding specific pathology (red flags): Second, education and a "stay active" approach are advocated. Physiotherapists should play an important role in the acceptance of PPGP as a common physical symptom during pregnancy with a good prognosis shortly after delivery. Therefore, physiotherapists are explicitly asked not to label the complaints as a biomedical diagnosis. [87]

Because the only evident etiological factors are smoking, history of low back pain, younger age and parity, primary prevention is not recommended and should not be part of physiotherapeutic intervention in PPGP. Moreover, given the very high prevalence of PPGP during pregnancy, success rate of primary prevention is expected to be minimal. However, the advice "stop smoking" for all who want to get pregnant should be underlined.

Table 5 Key points in history taking of women with PPGP or LBP

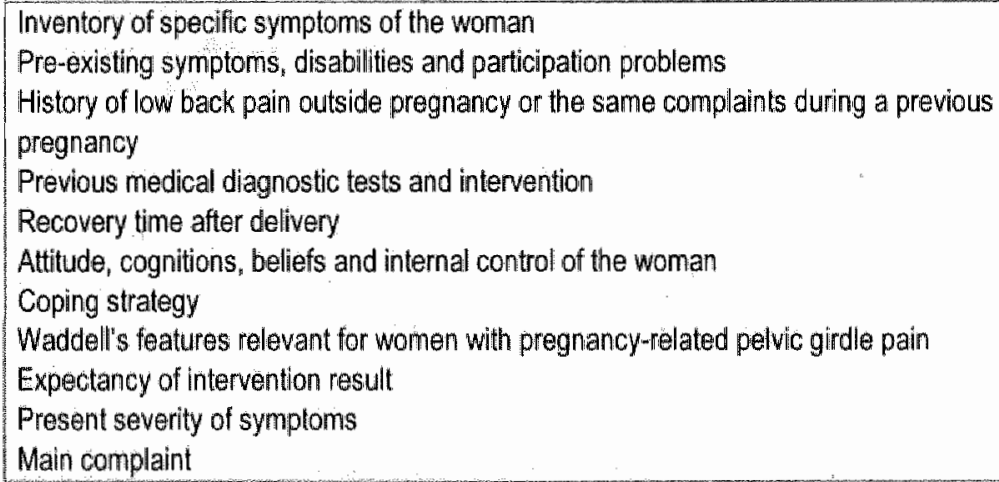

\section{After delivery}

The first six months

The primary goal of an intervention shortly after delivery is a quick return to normal daily activities and secondary prevention of a chronic health problem. Physiotherapists have a task to stimulate women with PPGP to pick up their full range of daily activities again, as soon as possible after delivery. 


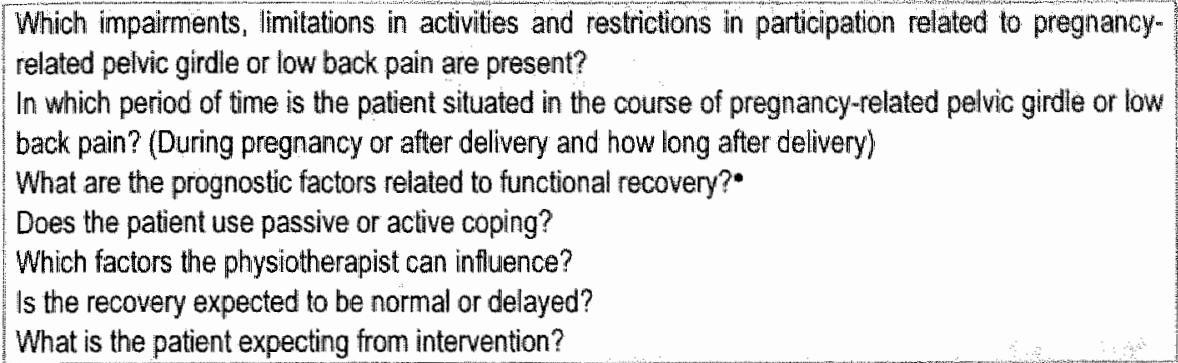

- Functional recovery is defined as the percentage patients who reconered with respect to pain control, limitations in activities and restrictions in participation

Diagnostics take place within all domains of the ICF. (Table 5) A simple diagnostic triage [17] is used. Physical examination focused on body functions and structures. Diagnostic tests and pain referral maps developed in the current research field of PPGP are not used to diagnose the complaints or to evaluate them after treatment. The diagnostic and evaluation process is supported by reliable and valid measurements for documentation and evaluation of the complaints. Limitations in activities, restrictions in participation, pain and the influence of contextual factors (yellow flags) are measured with self-reported questionnaires that are already extensively investigated on psychometric qualities. Also the woman's current demands and expectancy of treatment are of major importance (yellow flags). For the guideline, a selection is made out of a wide range of eligible questionnaires. Besides psychometric qualities, the feasibility of the instruments for the use in daily practice for an individual physiotherapist was an important criterion.

Combining the information from referral, history taking and physical examination completes the diagnostic process. Table 6 presents some questions of which the answers will summarize the relevant information from the diagnostic process for setting treatment goals and contents of the intervention. If prognostic factors that are probably associated with delayed recovery (a history of low back pain outside pregnancy or PPGP during a previous pregnancy, avoidance of certain activities, pain-related fear or overt pain behavior) are present, psychological factors are most likely also responsible for reporting of pain and delayed recovery [20,74]. These features have been thoroughly studied in patients with low back pain and are likely equally 


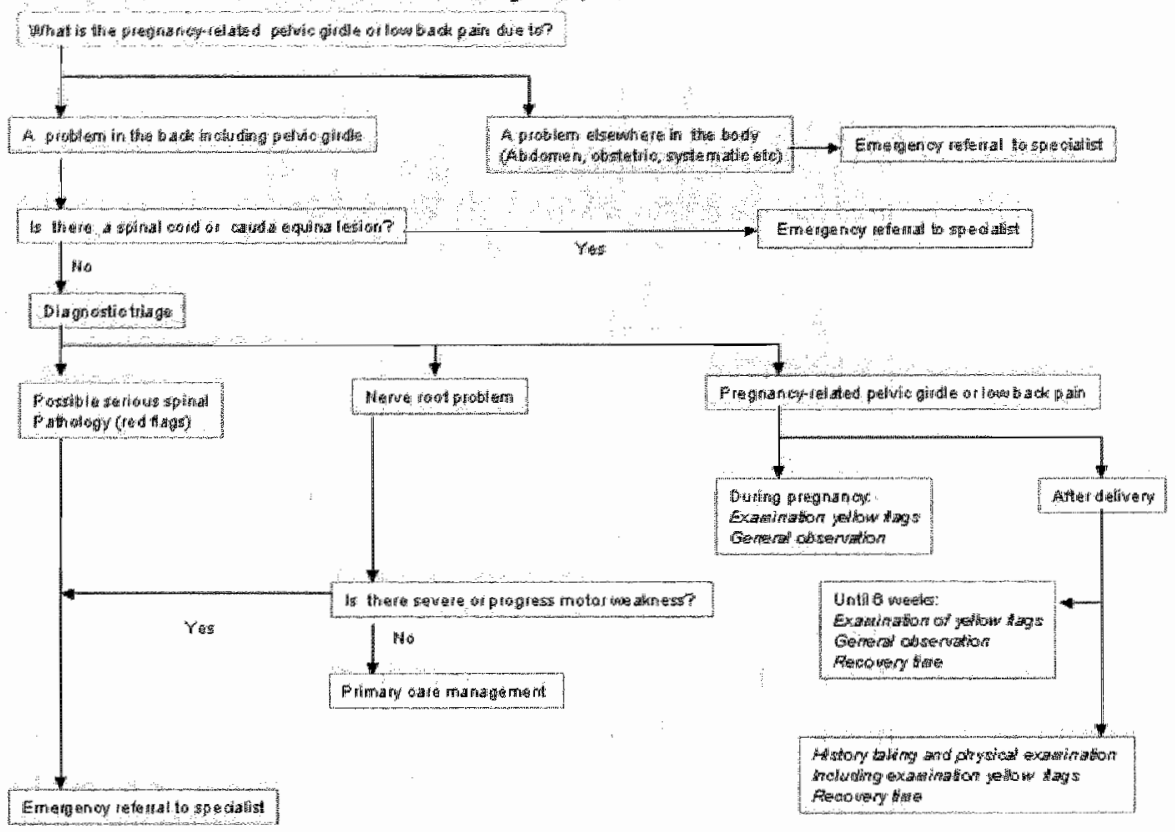

Figure 5 Diagnostic process

applicable in those with pregnancy-related pelvic girdle pain. Moreover, signs of overt pain behavior indicate the need for behavioral treatment goals and interventions for physiotherapists.

In the case of pain and disability in the first six weeks after delivery, simple and brief interventions may be sufficient to address fear-avoidance and assure resumption of normal daily activities again, after delivery. However, some women continue to have residual activity limitations and pain despite reassurance about 6 weeks after delivery. These women may benefit from being stepped up to brief, structured interventions that influence factors that are possibly responsible for poor progress, improve active self-management strategies, increase physical exercise (including coordinative exercises), support resumption of normal activities and provide supervised exposure to the feared activity. Generally, a time contingent policy will be followed in which the woman set the pace by means of goal setting themselves. 


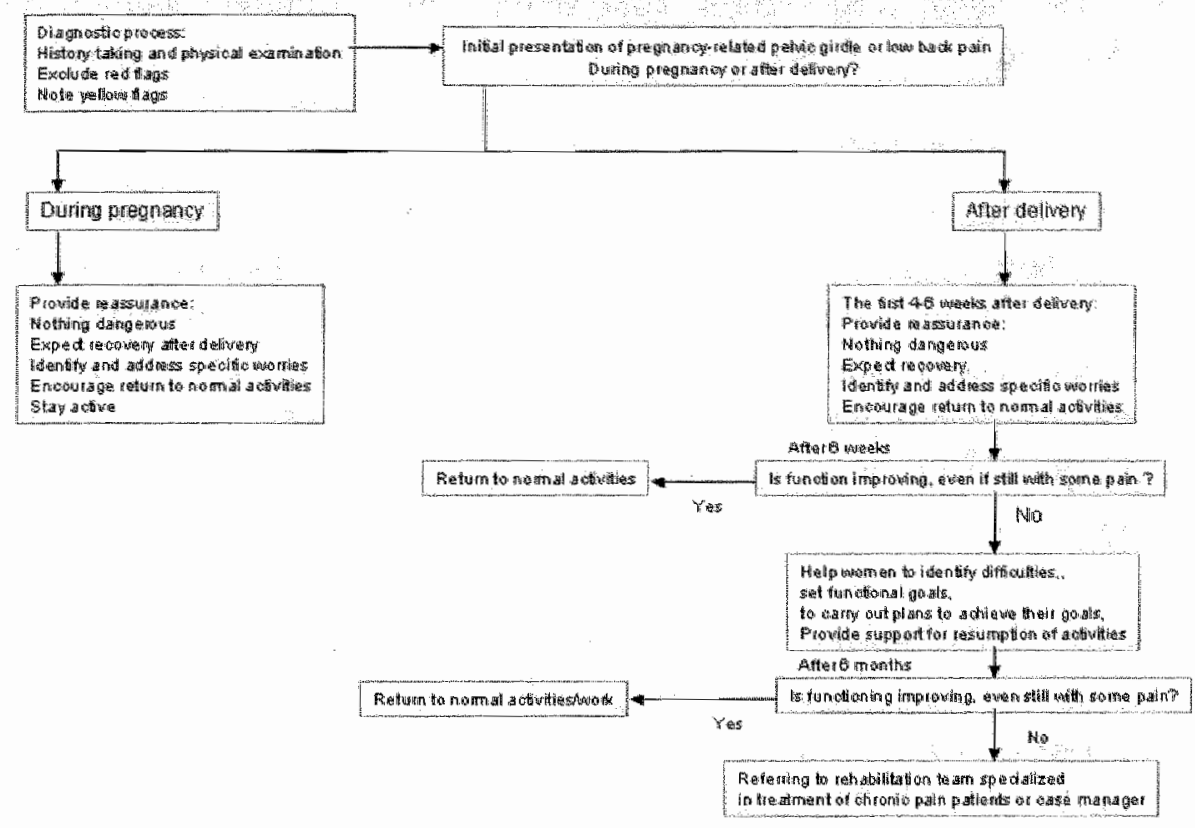

Figure 6 Therapeutic process

From 6 months after delivery

A small part (about $20-25 \%$ of the women who already participated in an intervention by a physiotherapist (Chapter 6) continue to have persistent limitations in activities, restrictions in participation and pain. A more intensive rehabilitative intervention by a multidisciplinary team may be appropriate for those women because they are at risk for chronic work role and housekeeping disability. They need an intervention that targets return to work or role performance at home. The use of such a stepped care as intervention model [88] is explained in Table 7 .

\section{Education}

The aim of education in the guideline is reconceptualization of the problem [75] with a focus on the dynamic feature of pain including the neural response to inactivity and movement control and the influence of environmental factors. Knowledge about the prevalence and the course of PPGP including pain flairups after delivery, problem solving, goal setting, communication skills, the concept about pain-related fear and available knowledge about etiology, 
prognostic factors and are also essential. Also useful in daily practice is knowledge about ergonomics concerning care of little children and housekeeping.

\section{The role of the physiotherapist}

The role of the physiotherapist is to teach and encourage women to identify possible causes of everyday problems in activities or participation, to find a number of potential solutions, select one, then try it and finally evaluate the results and possibly adjust the solution. The physiotherapist also has a role in teaching en encouraging the women in short and long-term goal setting. Another important role is assisting women in understanding their symptoms. Labelling the complaints with a biomedical diagnosis is not recommended.

Table 7 A stepped care approach for managing PPGP and LBP

\begin{tabular}{|c|c|c|c|}
\hline $\begin{array}{l}\text { Lewel } \\
\text { of care }\end{array}$ & Targeted women & Objestives & Provider \\
\hline Step 1 & $\begin{array}{l}\text { Al women during } \\
\text { pregnancy until the first } 6 \\
\text { weeks after delivery }\end{array}$ & $\begin{array}{l}\text { Identify and address } \\
\text { specific worries, } \\
\text { encourage return to normal } \\
\text { activities }\end{array}$ & $\begin{array}{l}\text { Midwife, general } \\
\text { practitioner, } \\
\text { physiotherapist }\end{array}$ \\
\hline Step 2 & $\begin{array}{l}\text { Women with activity } \\
\text { limitations continuing at } \\
6-8 \text { weeks after delivery }\end{array}$ & $\begin{array}{l}\text { Help women to identify } \\
\text { difficulties; set functional } \\
\text { goals and carry out plans } \\
\text { to achieve their goals. } \\
\text { Provide support for } \\
\text { resumption of activities } \\
\text { and exercise }\end{array}$ & $\begin{array}{l}\text { Special trained } \\
\text { physiotherapist, case } \\
\text { manager supported by } \\
\text { self-care educational } \\
\text { materials }\end{array}$ \\
\hline Step 3 & $\begin{array}{l}\text { Women with significant } \\
\text { disability in familly or work } \\
\text { roles about } 6 \text { moniths after } \\
\text { delwery. Women with co- } \\
\text { morbid memial iliness } \\
\text { which may impede } \\
\text { recowery efforts }\end{array}$ & $\begin{array}{l}\text { Interventions lo restare } \\
\text { family and work role } \\
\text { function. Graded exercise } \\
\text { program. Treatment of co- } \\
\text { morbid mental illness if } \\
\text { present }\end{array}$ & $\begin{array}{l}\text { Referral for rehabilitation } \\
\text { team speciallized in } \\
\text { freatment of chronic pain } \\
\text { patients or case manager : }\end{array}$ \\
\hline
\end{tabular}

\section{Evaluation}

Evaluation of short-term goal setting on a regularly basis, is an important feature of the theoretical concept of self-management. The evaluation takes place at the beginning of each treatment session in cooperation with the women based on action planning or goal setting during the former session. Evaluation 
of the whole treatment process during and after the treatment period takes place by using reliable and valid measurements that cover the domains of the ICF. Treatment should be terminated if the health problem is resolved or treatment goals are reached. Improvement of functioning is the most important treatment goal even when there is still pain. Treatment should also be terminated if no more positive treatment effects can be expected.

\section{Recommendations}

Results of the Maastricht PPGP Cohort and Intervention study are encouraging to change the way of thinking about PPGP by researchers, caregivers and patients. The adoption of the ICF as a classification to describe and investigate PPGP guided several interesting study questions. Pain, a point of special interest should be investigated and described alongside the activities and participation domains. Etiological factors with statistical significance (history of low back pain outside pregnancy or PPGP, smoking, younger age and parity) do not provide preventive steps in a physiotherapeutic treatment approach although the advice "stop smoking" for all women who wants to get pregnant should be underlined. Results of our study concerning prevalence and prognosis guided to the important advice to health care providers to take their role in the acceptance of PPGP as a common physical symptom during pregnancy with a good prognosis shortly after delivery. Labelling the complaints with a biomedical diagnosis should not be advocated. A distinction between the treatment approach during pregnancy and after delivery is recommended. Recovery is expected in the period after delivery and not during pregnancy. However a small part of women continue to have persistent limitations in activities, restrictions in participation and pain, 6 months after delivery. They become chronic pain patients. Diagnostics should take place in all domains of ICF and should be supported by reliable and valid measurements on pain, limitations in activities, participation and contextual. factors. Specific tests developed to diagnose PPGP do not give useful additional information to the diagnostic process. The basic assumption of the therapeutic process is women's needs and worries. A "stay active" approach is advocated during pregnancy. The primary goal of an intervention shortly after delivery is a quick return to normal daily activities and secondary prevention of chronic disability. Health care providers have a task to stimulate women with PPGP to pick up their full range of daily activities again, as soon as possible after 
delivery. Our results indicated that concepts of cognitive behavioural treatment approaches such as self-management and exposure techniques should be incorporated. The above-mentioned consequences of the Maastricht Cohort and Intervention study are reflected in the Dutch clinical practice guideline for physiotherapy management of PPGP.

Not every woman with PPGP should be referred to a physiotherapist. Midwives may adequately support many women during pregnancy and the period of lying-in. The general practitioner may also support many women. This means that parts of this guideline may also be useful for physicians and midwives.

The results of the Maastricht Cohort and Intervention study initiated new research questions about the understanding and management of PPGP. Comparable with the research field of low back pain outside pregnancy, there is little known about the specific biobehavioural mechanism that leads to chronic pain and disability [89]. One of the reasons might be, especially in this group of patients, that the components of the treatment approach and patient-treatment interactions do not match patient characteristics in an optimal way. A possible way of improving treatment efficacy is to match treatment to patient characteristics. Lntil now treatment of PPGP has been based on the current models where intervention is matched to biomedical diagnosis. However, this approach has little ground when the etiological basis of the biomedical diagnosis is unknown. The choice becomes empirical, delivered on a trial-anderror basis depending on researchers' or health care providers' experience and preferences [90]. It has also become clear in the field of musculoskeletal disorders that patients with the same medical conditions and ostensibly the same level of physical pathology can respond differently to the same treatment [90]. Recently, developing methods for matching patients to treatments that are most likely to benefit them has become an important research priority. One possible way is the development of clinical decision rules based on allimportant prognostic factors. Another way is identifying patients at risk for the development of persistent pain and disability by statistical techniques like cluster analyses [91] [92].

Treatment outcome studlies are also of crucial importance to guide matching research. More theory-driven studies should be performed. There is a need for better specifications of how treatment tactics relate to clinical outcome [89].

Women with significant disability in family or work roles about 6 months after delivery should be referred to a multidisciplinary team specialized in treatment 
of chronic pain patients. The use of a stepped care model is attractive to integrate into routine care because the primary intention is to limit disability starting with brief simple interventions, stepped up to structured and more complicated of a stepped care as an intervention model for PPGP needs further research.

Finally, it is also quite difficult to apply treatment protocols developed for research studies in "real-world" settings. There is a lack of empirically tested theoretical concepts and procedures for understanding the processes between the steps, beginning with conceptualization of the appropriate intervention to the final desired clinical outcome. There is a need to better understand the ingredients of the treatment responsible for the transitions leading to that desired outcome. Education is a dimension that could play an important additional role. There is a critical need in the research of PPGP to explore extensively above-mentioned research areas. A better understanding of the interactions in women with PPGP is a challenge in future research.

\section{Conclusion}

Consequences of the Maastricht Cohort and Interventions guided to a change in the way of thinking about PPGP. Biomedical aspects have to be required within the biopsychosocial approach rather than presented as something separate and apart. PPGP is a common physical symptom with a good prognosis after delivery. The basic assumption of the therapeutic process is women's needs and worries. A stay active approach is advocated during pregnancy. The primary goal of an intervention shortly after delivery is a quick return to normal daily activities and secondary prevention of chronic disability.

\section{Acknowledgements}

The funding for this study was provided by the Health Care Insurance Board (College voor zorgverzekeringen (VZ) in the Netherlands as a part of a research project titled "Peripartum pelvic pain during pregnancy and after delivery". 


\section{References}

1. JM Bastiainssen, RA de Bie, CHG Bastiaenen, A Heuts, MEAL Kroese, GGM Essed, PA wan den Brandt: Etiology and prognosis of pregnancy-related pelvic girdle pain; design of a longitudinal study. BMC Public Health 2005, 5:1 URL hittp/ www biomedcentral com/1471-2458/5/1

2. A Fast, D Shapito, EJ Ducommun, LW Friedmann, T Bouklas, Y Floman: Lowback pain in pregnancy. Spine 1987, 12.368-71.

3. A Fast Low back pain during pregnancy. Phys Med Rehabil 1999, 13:509-519.

4. MJ Mantle, RM Greenwood, HL Currey: Backache in pregnancy. Rheumatol Rehabil 1977, 16:95-101.

5. M MacEvilly, D Buggy: Back pain and pregnancy: a review. Pain 1996, 64:40514.

6. IM Mens, A Vlleeming, R Stoeckart, HJ Stam, CJ Snijders: Understanding peripartum pelvic pain. Implications of a patient survey. Spine 1996, 21:1363-9.

7. HC Ostgaard, GB Andersson, K Karlsson: Prevallence of back pain in pregnancy Spine 1991, 16.549-52.

8. CHG Bastiaenen, RA de Bie, PMJC Wolters, JWS Vlaeyen, JM Bastiaanssen, ABA Klabbers, A Heuts, PA van den Brandt, GGM Essed: Treatment of pregnancy-related pelvic girdle and/or low back pain after delivery design of a randomized clinical trial within a comprehensive prognostic cohort study. BMC Public Health 2004, 4:67

URL:h.tp/ / www biomedcentral.com/1471-2458/4/67

9. HC Ostgaard, $\mathbb{E}$ Roos Hansson, $\mathrm{G}$ Zetherstrom: Regression of back and posterior pelvic pain after pregnancy. Spine 1996, 21:2777-80.

10. WH Wu, OG Meijer, K Uegaki, JM Mens, JH van Dieen, PI Wuisman, HC Ostgaard: Pregnancy-related pelvic girdle pain (PPP), I: Terminology, clinical presentation, and prevalence. Eur Spine I 2004, 13:575-89.

11. HJM Hendriks, Ev H., E Reitsma, A Verhoeven, Ph van der Wees: Methode voor de centralle richtlijnontwikkeling en implementatie. In: Methode voor de centrale richtlijnontwikkeling en implementatie. Amersfoort: KNGF/ NPi / CBO; 1998.

12. HJM Hendriks, IW Brandsma, H Ettekoven, Ph van der Wees, GE Bekkering: Improving the quality of physiotherapy practice. A method of development and implementation of national practice guidelines. Physiotherapy $2000,86.535-$ 547.

13. HIM Hendriks, H Ettekoven, GE Bekkering, A Verhoeven: Implementatie van KNGF-Richtlijnen. FysioPraxis 2000, 2:9-13.

14. WHO: Intemational Classification of Functioning Disability and Health. Geneva: World Health Organization; 2001.

15. RJ Gatchel, $G$ Bell: The biopsychosocial approach to spine care and research. Spine 2000, 25:2572. 
16. GWaddell, M Tulder van: Chncal guidelines. In: The back pain revolution pp. 283-322. Edinburglw: Churchill Livingstone; 2004: 283-322

17. G Waddell: Diagnostic triage. In: The Back Pan Revolution, vol Chapter 2. pp. 9-26. Edinburgh, London, New York, Philadelphia, Sydney, Toronto: Churchil Livingstone; 1998: 9-26.

18. G Waddell, K Burton: Information and advice for patients. In: The back pain revolution. pp. 323-342. Edinburgh: Churchill Livingstone; $2004: 323-342$.

19. SI Linton, K Boersma: Early identification of patients at risk of developing a persistent back problem: the predictive validity of the Orebro Musculoskeletal Pain Questionnaire. Clin J Pain 2003, 19:80-6.

20. SJ Linton: A review of psychological risk factors in back and neck pain. Spine 2000, 25:1148-56.

21. HC Ostgaard, G Zetherström, E Roos Hansson: The posterior pelvic pain provocation test in pregnant women. Eur Spine J 1994, 3:258-60.

22. H Albert, $\mathrm{M}$ Godskesen, J Westergaard: Evaluation of clinical tests used in classification procedures in pregnancy-related pelvic joint pain: Eur Spine J 2000, 9:161-6.

23. B Sturesson, G Uden, A Uden: Pain pattern in pregnancy and "catching" of the leg in pregnant women with posterior pelvic pain. Spine 1997, 22:1880-3.

24. P Kristiansson, K Svardsudd, B von Schoultz: Back pain during pregnancy; a prospective study. Spine 1996, 21:702-9.

25. G Berg, M Hammar, J Moller Nielsen, U Linden, J Thorblad: Low back pain during pregnancy. Obstet Gynecol 1988, 71:71-5.

26. EH Endresen: Pelvic pain and low back pain in pregnant women--an epidemiological study. Scand I Rheumatol 1995, 24:135-41.

27. E Larsen, C Wilken-Jensen, A Hansen, D Jensen, S Johansen, $H$ Minck, M Wormslev, M Davidsen, T Hansen: Symptom-giving pelvic girdle relaxation in pregnancy I:Prevalence and risk factors. Acta Obstet Gynecol Scand 1999, 78:105-110.

28. R Orvieto, A Achiron, Z Ben Rafael, I Gellernter, R Achiron: Low-back pain of pregnancy. Acta Obstet Gynecal Scand 1994, 73:209-14.

29. WW To, MW Wong: Factors associated with back pain symptoms in pregnancy and the persistence of pain 2 years after pregnancy. Acta Obstet Gynecol Scand $2003,82: 1086-91$.

30. SM Wang, P Dezinno, I Maranets, MR Berman, AA Caldwell Andrews, ZN Kain: Low back pain during pregnancy: prevalence, risk factors, and outcomes. Obstet Gynecol 2004, 104:65-70.

31. DB Stapleton, AH MacLennan, P Kristiansson: The prevalence of recalled low back pain during and after pregnancy: a South Australian population survey. Aust N Z J Obstet Gynaecoll 2002, 42:482-5.

32. P Kristiansson, K Svardsudd, B von Schoultz: Serum relaxin, symphyseal pain, and back pain during pregnancy. Am J Obstet Gynecol 1996, 175:1342-7.

33. AH MacLennan: The role of the hormone relaxin in human reproduction and pelvic girdle relaxation. Scand J Rheumatol Suppl 1991, 88:7-15. 
34. A Hansen, DV Jensen, E Larsen, C Wilken Jensen, LK Petersen: Relaxin is not related to symptom-giving pelvic girdle relaxation in pregnant women. Acta Obstet Gynecol Scand 1996, 75:245-9.

35. J Brynhildsen, S Ekblad, M Hammar: Oral contraceptives and low back pain. Attitudes among physicians, midwives and physiotherapists. Acta Obstet Gynecol Scand 1995, 74:7147.

36. LF Saugstad: Is persistent pelvic pain and pelvic joint instability associated with early menarche and with oral contraceptives? Eur J Obstet Gynecol Reprod Biol 1991, 41,203-6.

37. H Svensson, $G$ Andersson, A Hagstad, $P$ Jansson: The relationship of low-back pajn to pregnancy ans gynecologic factors. Spine 1990, 15:371-375.

38. JM Bastiaanssen, RA De Bie, CHG Bastiaenen, GGM Essed, PA Van den Brandt: A historical perspective on pregnancy-related low back and/or pelvic girdle pain. Eur J Obstet Gynecol Reprod Biol 2005,120:3-14.

39. H Albert, M Godskesen, J Westergaard: Prognosis in four syndromes of pregriancy-related pelvic pain. Acta Obstet Gynecol Scand 2001, 80:505-10.

40. HC Ostgaard, GBJ Andersson: Low back pain post partum. Spine 1991:1-10.

41. HC Ostgaard, GB Andersson: Postpartum low-back pain. Spine 1992, 17:53-5.

42. HC Ostgaard, GB Andersson, M Wennergren: The impact of low back and pelvic pain in pregnancy on the pregnancy outcome. Acta Obstet Gynecol Scand 1991, 70:21-4.

43. HC Ostgaard, GB Andersson: Previous back pain and risk of developing back pain in a future pregnancy. Spine 1991, 16:432-6.

44. JS Richards, C Nepomuceno, M Rilles, Z Suer: Assessing pain behavior: the UAB Pain Behavior Scale. Pain 1982, 14:393-8.

45. JWS Vlaeyen, DFM Pernot; AMJ Kole-Snijders, JA Schuerman, wH Eek, NH Groenman: Betrouwbaarheid en validiteit van een Nederlandse versie van de Pain Behavior Scale (PBS). Ned Tijdschr Psychol 1990, 45:184-189.

46. M Roland, $R$ Morris: A study of the natural history of back pain. Part I: development of a reliable and sensitive measure of disability in low-back pain. Spine 1983, 8:141-4.

47. GH Guyatt, B Kirshner", R Jaeschke: Measuring health status: what are the necessary measurement properties? J Clin Epidemiol 1992 $45: 1341-5$.

48. Al Beurskens, HC de Vet, AJ Koke, E Lindeman, GJ van der Heijden, W Regtop, PG Knipschild: A patient-specific approach for measuring functional status in. low back pain. J Manipulative Physiol Ther 1999, 22:144-8.

49. WA van der Kloot, RA Oostendorp, J van der Meij, J van den Heuvel: De Nederlandse versie van McGill pain questionnaire: een betrouwbare pijnvragenlijst. Ned Trijdschr Geneeskd 1995, 139:669-73.

50. $\quad \mathbb{R}$ Melzack: The MoGill Pain Questionnaire: major properties and scoring methods. Pain 1975, 1:277-99.

51. M Cardol, RJ de Haan, BA de Jong, GAM van den Bos, IJM de Groot: Psychometric properties of the impact on participation and autonomy questionnaire. Arch Phys Med Rehabil 2001, 82:210-216. 
52. Ej Swinkels Meewisse, RA Swinkels, AL Verbeek, JW Vlaeyen, RA Oostendorp: Psychometric properties of the Tanpa Scale for kinesiophobia and the fearawoidance beliefs questionnaire in acute low back pain. Man Ther 2003, 8:29-36.

53. L Goubert, G Crombez, $S$ Van Damme, JW Vlaeyen, P Bijttebier, I Roelofs: Confirmatory factor analysis of the Tampa Scale for Kinesiophobia: invariant two-factor model across low back pain patients and fibromyalgia patients. Clin J Pain 2004, 20:103-10.

54. MIL Sullivan, SR Bishop, J Pivik: The pain catastrophizing scale: development and validation. Psychol Assess 1995, 7:524-532.

55. S v Damme, G Crombez, P Bijttebier, L Goubert, Bv Houdenhove: A confirmatory factor analysis of the Pain Catastrophizing Scale: invariant factor structure across clinical and non-clinical populations. Pain 2002, 96:319-324.

56. AT Beck, RA Steer; MG Garbin: Psychometric properties of the beck depression inventory: twenty-five years of evaluation, Clin Psychol Rev 1988, 8:77-100.

57. AT Beck, CH Ward, M Medndelson, J Mock, J Erbaugh.: An inventory for measuring depression. Arch Gen Psychiatry 1960, 4:561-571.

58. AL Wesley, RJ Gatchel, JP Garofalo, PB Polatin: Toward more accurate use of the Beck Depression Inventory with chronic back pain patients. Clin J Pain 1999, 15:117-21.

59. D Watson, LA Clark, G Carey: Positive and negative affectivity and their relation to anxiety and depressive disorders. J Abnorm Psychol 1988, 97:346-53.

60. J Ware, K Snow, M Kosinski: SF-36 Health Survey: manual and interpretation guide. The Fealth Institute, New England Medical 1993.

61. J Ware, M Kosinski, S Keller: SF-36 physical and mental summary scales: A user's manual. The Health Institute, New England Medical 1994.

62. P Dolan: Modeling valuations for EuroQol health states. Med Care 1997, 35:1095-108.

63. JWS Vlaeyen, NJ Teeken Gruben, ME Goossens, MP Rutten van Molken, RA Pelt, H wan Eek, PHTG Heuts: Cognitive-educational treatment of fibromyalgia: a randomized clinical trial. I. Clinical effects. I Rheumatol 1996, 23:1237-45.

64. A Vleeming, HJ de Vries, JM Mens, JP van Wingerden: Possible role of the llong dorsal sacroiliac ligament in women with peripartum petvic pain. Acta Obstet Gynecol Scand 2002, 81:430-6.

65. M Wormslev, AM Juul, B Marques, H Minck, L Bentzen, TM Hansen: Clinical examination of pelvic insufficiency during pregnancy. An evaluation of the interobserver variation, the relation between clinical signs and pain and the relation between clinical signs and physical disability. Scand J Rheumatol 1994, 23:96-102.

66. P Kristiansson, K Svardsudd: Discriminatory power of tests applied in back pain during pregnancy. Spine 1996, 21:2337-43.

67. JM Mens, A Vleeming, CJ Snijders, BW Koes, HJ Stam: Reliability and validity of the active straight leg raise test in posterior pelvic pain since pregnancy. Spine 2001, 26:1167-71. 
68. JM Mens, A Vleeming, CISnijders, I Ronchetti, HJ Stam: Reliability and validity of hip adduction strength to measure disease severity in posterior pelvic pain since pregnancy: Spine 2002, 27:1674-9.

69. : P van der Wurf, RH Hagmeijer, W Meyre: Clinical tests of the sacroiliac joint. A systemic methodological review. Part 1: reliability. Man ther 2000, 5:30-6.

70. P van der Wurff; Buijs, GJ Groen: Sacroillac joint pain: clinical asessment and diagnostic accuracy. Thesis. UMC Utrecht; 2004.

71. : P van der Wurf, W Meyne, RH Hagmeijer. Clinical tests of the sacroiliac joint. Man Ther 2000, 5:89-96.

72. I Barlow, $\mathrm{C}$ Wright, J Sheasby, A Turner, J Hainsworth: Self-management approaches for people with chronic conditions: a review. Patient Educ Couns $2002,48: 177-87$.

73. JE Moore, M Von Korff, D Cherkin, K Saunders, K Lorig: A randomized trial of a cognitive-behavioral program for enhancing back pain self care in a primary care setting. Pain 2000, 88:145-53.

74. TWS Vlaeyen, SJ Linton: Fear-avoidance and its consequences in chronic musculoskeletal pain: a state of the art. Pain 2000, 85:317-332.

75. GL Moseley, MK Nicholas, PW Hodges: A randomized controlled trial of intensive neurophysiology education in chronic low back pain. Clin J Pain 2004, 20:324-30.

76. B Stuge, E Laerum, G Kirkesola, N Vollestad: The efficacy of a treatment program focusing on specific stabilizing exercises for pelvic girdle pain after pregnancy: a randomized controlled trial. Spine 2004, 29:351-9.

77. H Elden, L Ladfors, MF Olsen, HC Ostgaard, H Hagberg: Effects of acupuncture and stabilising exercises as adjunct to standard treatment in pregnant women with pelvic girdle pain: randomised single blind controlled trial. BMJ 2005, 330:761.

78. K Wedenberg, B Moen, A Norling: A prospective randomized study comparing acupuncture with physiotherapy for low-back and pelvic pain in pregnancy. Acta Obstet Gymecol Scand 2000, 79:331-5.

79. M Kihlstrand, B Stenman, S Nilsson, O Axelsson: Water-gymnastics reduced the intensity of back/low back pain in pregnant women. Acta Obstet Gynecol Scund 1999, 78:180-185.

80. GA Dumas, JG Reid, LA Wolfe, MP Griffin, MJ McGrath: Exercise, posture, and back pain during pregnancy. Part 1. Exercise and posture. Clin. Biomech. 1995, 10:98-103.

81. GA Dumas, JG Reid, I.A Wolfe, MP Griffin, MJ McGrath: Exercise, posture, and back pain during pregnancy. Part 2. Exercise and back pain. Clin. Biomech. $1995,10: 104-109$.

82. HC Ostgaard, G Zetherstrom, E Roos Hansson, B Svanberg: Reduction of back and posterior pelvic pain in pregnancy. Spine 1994, 19:894-900.

83. JMA Mens, CJ Snijders, HJ Stam: Diagonal trunk muscle exercises in peripartum pelvi pain: a randomized clinical trial. Phys Ther 2000, 80:11641173. 
84. B Stuge, MB Veierod, $\mathbb{E}$ Laerum, $N$ Vollestad: The elficacy of a treatment program focusing on specific stabilizing exercises for pelvic girdle pain after pregnancy: a two-year follow-up of a randomized clinical triall. Spine 2004 , 29:E197-203.

85. L Noren, S Ostgaard, TF Nielsen, HC Ostgaard: Reduction of sick leave for lumbar back and posterior pelvic pain in pregnancy. Spine 1997, 22:2157-60.

86. B Stuge, G Hilde, N Vollestad: Physical therapy for pregnancy-related low back and pelvic pain: a systematic review. Acta Obstet Gynecol Scand 2003, 82:98390.

87. I Hazemeijer, JJ Rasker: Fibromyalgia and the therapeutic domain. A philosophical study on the origins of fibromyalgia in a specific sociall setting. Rheumatology 2003, 42:507-15.

88. BHK Balderson, $M$ Von Korf: The stepped care approach to chronic low back pain. In: Pain Research an Clinical Management Edited by $S$ Linton, vol. 12. Amsterdam: Elsevier; 2002.

89. JW Vlaeyen, S Morley: Cognitive-behavioral treatments for chronic pain: what works for whom? Clin J Pain 2005, 21:1-8.

90. DC Turk: The potential of treatment matching for subgroups of patients with chronic pain: lumping versus splitting. Clin J Pain 2005, 21:44-55.

91. K Boersma, Sf Linton: Screening to identify patients at risk: profiles of psychological risk factors for early intervention. Clin J Pain 2005, 21:38 43.

92. N Hobro ${ }_{r}$ J Weinman, M Hankins: Using the self-regulatory model to cluster chronic pain patients: the first step towards identifying relevant treatments? Pain 2004, 108:276-83. 
$\mathbf{1 5 8}$ - CONSEQUERCES 
CHAPTER EIGHT

Epilogue 
160 - EPILOUE 


\section{Epilogue}

In this epilogue some characteristics of the intervention study and the embedding of the study in the cohort study are discussed. The embedding of the intervention study in a cohort study had advantages and disadvantages. A disadvantage turned out to be that the number of women with persistent PPGP who were seeking treatment, was considerably lower than expected. However, the advantages of the embedding made up for that. We were able to investigate the prevalence, etiological and prognostic factors of PPGP of the total source population $(n=7526)$ of the participants in an extensive way. We were able to do that even before the enrolment in the intervention study, during pregnancy. By doing so, we could choose a time-window for the start and duration of an active intervention carefully. A considerable drop of women with PPGP within the first three weeks after delivery and a stabilising of the figures immediately afterwards confirmed our preliminary hypothesis (developed during interviews with women with PPGP) that the start of the active intervention about three weeks after delivery was reasonably well timed.

For the intervention study we chose as primary outcome limitations in activities. However, because a particular focus of the intervention study was to reduce limitations in activities by tackling biopsychosocial issues, we also included outcome measures to asses the effect of our intervention on participation, fear-avoidance, global perceived effect, main complaint and pain. We chose a group of patients with persistent PPGP about three weeks after delivery. Women are at an early stage of persistent PPGP about that time. Most women recovered within the first three weeks after delivery without any treatment. The outcomes were measured over a period of 12 months when recurrence rates of pain in such patients can be substantial. Recurrence of pain turned out to be a normal phenomenon in both the intervention and cohort studies with rates of $35 \%$.

We decided not to include a no treatment or a minimum treatment group for practical, ethical and methodological reasons. The presence of a no treatment group is difficult to justify because current management support early intervention, even during pregnancy when recovery is not to be expected. For that particular reason we decided not to exclude women who received an intervention during pregnancy but only to exclude women who already received treatment in the first three weeks after delivery. Discussions with 
women with PPGP from the cohort and experienced physiotherapists in this field drew attention to the advantages of two active interventions. Only women in the usual care group were free to decide not to choose for treatment (current approach).

Participating physiotherapists in the experimental intervention group showed the potential to shift from a model of care with a clearly biomedical view to a broad approach that incorporates biopsychosocial factors. Both the educational course received by the physiotherapists and the intervention they delivered was brief and appropriate for implementation in daily practice.

The randomized clinical trial had high internal validity shown by an adequate recruitment out of the cohort, remote system of randomization, blinding of the research-physiotherapist and researcher involved in the measurements and in the analyses. Trial participants were not aware of the specific contents of the interventions or the study hypothesis.

Figures of the follow-up during the year after delivery made clear that a considerable part of the participants who enrolled in the intervention study (and members of the cohort with PPGP) were probably destined to have a good functional prognosis sometimes even without any treatment, in the first three months after delivery. Therefore an important signal to actually start with an active intervention in the future is not only pain and limitations in activities but also women's own worries and needs. Is she able to tackle here problems in a positive, confronting and active way or is she more or less reluctant to pick up daily activities influenced by her worries? As the results of the trial made clear; a brief and simple intervention in primary care (about 7-9 sessions) tackling biopsychosocial issues during the first three months after delivery is effective. A very small part of the women that did not functionally recover enough in primary care should be considered as chronic pain patients and referred to more specialist-oriented care (stepped care model).

The only published study with proven effectiveness [1]in the field of PPGP shortly after delivery focused on stabilising exercises of the abdominal musculature. However, the active intervention consisted of about 60 treatment sessions ( 3 times a week for 20 weeks) and an extensive amount of training by the women themselves at home, during that time. The intervention did not focus on women's needs and worries. We believe that it is very difficult to implement such an intervention in daily care and it seems unlikely to be applicable in the Dutch situation. 
Although we tailored our intervention on an individual basis as much as possible under the circumstances of the trial, it was still more or less a one-sizefits-all approach. It might have obscured the potential effectiveness of intervention targeted more specifically to women for whom it is more likely to be of benefit. The results of subgroup analyses underpin this hypothesis. Future research should be focused on tools that are useful to detect biopsychosocial aspects that are predictive of poor outcomes. Additionally, the investigation of the effectiveness of particular treatment components within the identified subgroups is a challenge for future research.

\section{Clinical implications and personal view}

The encouraging results of the Maastricht Intervention Study potentially could change the way of thinking about PPGP by researchers, caregivers and patients. A focus on characteristics of the self-management approach of the experimental intervention is relevant because of the positive findings of our study. The selfmanagement approach has implications for daily, clinical practice. Implication of those characteristics in the field of PPGP is a complicated matter. First of all, the biomedical view is still deeply entrenched in the way most caregivers and their patients think. A pain contingent approach with (relative) rest and avoidance of certain activities is important. Second, self-management is not well defined and is often confused with patient-education. However, the purpose of self-management education is to provide patients with the skills to live an active and meaningful life with their health problem. Self-management programs are building on patient perceived disease-related problems and assist patients with problem solving and gaining the confidence to deal with these problems[2]. An appealing description of self-management is given by Barlow[3]:

"Self-management refers to the individual's ability to manage the symptoms, treatment, physical and psychosocial consequences and life style changes inherent in living with a (chronic) health problem. Efficacious self-management encompasses ability to monitor one"s condition and to effect the cognitive, behavioral and emotional responses necessary to maintain a satisfactory quality of life." 
One of the most important consequences for clinicall practice is the emphasis on the central role of the patient in managing the health problem. The approach is aimed at helping patients in maintaining or picking up life roles (again) and managing negative emotions like pain-related fear and depression. This approach leads to some major differences from the current pain contingent approach. It is a broad approach not focusing on specific localized joint problems (sacroiliac joints and symphysis) or even the whole pelvic girdle but on all domains of the ICF (impairments, activities and participation). Personal and environmental interactions are taken into account also. The shift from a biomedical to a biopsychosocial approach is not to mistake or misunderstand. A biopsychosocial attitude is not a matter of "leaving or ignoring the biomedical domain" but a matter of integrating all relevant aspects and paying attention to diagnostics as well as intervention regarding impairments, activities and participation. A typical example of this attitude is demonstrated during skills training. During this training women are asked to make a shift from "What do I have?" to "What can I do." Action planning and problem solving in daily activities are both key elements of the skills training. Action planning and problem solving need training and evaluation, education alone is not enough. Collaborative partnership and shared responsibility between physiotherapists and the women become important. An example of shared responsibility is that signs and symptoms must not be ignored but physiotherapists and women have to learn to interpret them adequately. Therefore, adequate timing is necessary to choose when and which diagnostics and interventions should take place (during pregnancy or after delivery). Equally important is to learn which activities are helpful to become active again. Graded exposure of those activities that are avoided is integrated in the protocol. After an initial period of learning these skills, it becomes the task of the women themselves in collaborative partnership with their physiotherapist.

For both the women and the physiotherapists this is a rather new policy. The approach appeals to the major part of the participating women. In general, they are willing to accept the responsibility to manage their own condition and solve their problems with guidance from the physiotherapists. They quickly pick up the time contingent approach. Nevertheless, there is some hesitation among a number of the participating physiotherapists about their role in the intervention protocol during the educational training prior to the trial. Once they are be engaged by the patients, they like their supporting role towards the women to create plans that will help them to achieve their goals. The shift from a pain 
contingent approach to a time contingent approach and the radical change in the character of the patient-therapist relationship seems to be easier for the women than for the therapists. Afterwards, both the women and the physiotherapists found the intervention protocol attractive and useful.

For a number of physiotherapists (not involved in our study), the hesitation towards the shift from a pain contingent policy to a time contingent policy within the biopsychosocial approach still exists. A clinical practice guideline for physiotherapists is designed to inform, guide and support physiotherapists in their way to change their approach. The aim of a clinical practice guideline is to improve quality of care by translating new research findings into practice. Mostly guidelines should not demand too much change in existing practice routines of the targets users (physiotherapists in the field of PPGP). Nevertheless, positive results of our study guided us from the existing practices routines of the physiotherapists into the needs and worries of women as major point of action when designing the guideline.

Finally, our efforts were rewarded by a telephone call from one of the participants of the experimental intervention group. About one and a half year after finishing the experimental intervention program she phoned us and told that she was pregnant again. She experienced the same complaints as during the last pregnancy but this time it was not a problem. She said. "I know that I can do everything that I want to do with the support of action plans about my activities. That helps. I do not need any treatment at all because I know that the pain and limitations in activities will be diminishing when I gradually increase my activities again after delivery. There will always be some days with pain, less or more. Nevertheless, the pain does not frighten or bother me anymore."

\section{References}

1. B Stuge, E Laerum, G Kirkesola, N Vollestad: The efficacy of a treatment program focusing on specific stabilizing exercises for pelvic girdle pain after pregnancy: a randomized controlled trial. Spine 2004, 29:351=9.

2. K Lorig: Partnerships between expert patients and physicians. Lancet 2002, 359:814-5.

3. J Barlow, C Wright, I Sheasby, A Turner, I Hainsworth: Self-management approaches for people with chronic conditions: a review. Patient Educ Couns 2002, 48:177-87. 
$166 \cdot$ EPLOOUE 


\section{APPENDIX}

\section{KNGF richtlijn zwangerschapsgerelateerde bekkenpijn \\ Praktijkrichtlijn, Verantwoording en toelichting, Schematisch overzicht}

Caroline HG Bastioenen, Erik JM Hendriks, Amold TM Bernards, Marieke van Engelenburg. Pytha Albers- Heitner, John van der Meij, Marga HM

Grupping-Morel, Rob A de Bie 


\section{Praktijk richtlijn}

\section{A Inleiding}

Deze KNGF- richtlijn beschrijft het diagnostisch en therapeutisch proces bij vrouwen met zwangerschapsgerelateerde bekkenpijn (ZGBP) die tijdens de zwangerschap en/of na de bevalling (maximaal 9 maanden na de bevalling) zijn ontstaan. De richtiijn is van toepassing als er in de anamnese een duidelijke relatie bestaat tussen de zwangerschap en het ontstaan van de pijn, beperkingen en participatieproblemen. In de richtlijn wordt onderscheid gemaakt tussen bekkenpijn die is ontstaan (1) tijdens de zwangerschap en (2) na de bevalling. In de bijbehorende verantwoording en toelichting worden de in de richtlijn gemaakte keuzes nader toegelicht.

Beoogde gebruikers van de richtlijn

De KNGF- richtlijn is bedoeld voor fysiotherapeuten werkzaam in de eerste en tweede lijn. Verwacht wordt dat een fysiotherapeut inzicht heeft in een normaal zwangerschapsverloop en de lichamelijke en biopsychosociale factoren en veranderingsprocessen die gerelateerd zijn aan de zwangerschap en de bevalling. Voor een adequate toepassing van de richtlijn is tevens kennis gewenst over kinder - en babyhantering.

Voor behandeling van patiënten die zich presenteren met aspecifieke rugkllachten die niet gerelateerd zijn aan de zwangerschap wordt verwezen naar de KNGF richtlijn lage rugpijn en de NVMT richtlijn 'lage-rugpijn'. Voor behandeling van de bekkenbodem en/of van (stress) urine-incontinentie wordt verwezen naar richtlijn stress-urine incontinentie.

\section{Afbakening zwangerschapsgerelateerde bekkenpijn}

Er is geen duidelijke definitie van bekkenpijn te geven. Om deze reden wordt hier het begrip probleemoriëntatie geïntroduceerd.

\section{Tijdens de zwangerschap}

Bij ZGBP tijdens de zwangerschap staat in eerste instantie de pijn in het gebied van het bekken/lage rug voorop. In een later stadium van de zwangerschap treden de ervaren beperkingen in activiteiten en participatieproblemen meer op de voorgrond. 
Na de beoalling

Bij vrouwen met ZGBP na de bevalling, staan vooral beperkingen in activiteiten en participatieproblemen op de voorgrond.

\section{Omvang van hef probleem}

\section{Prevalentie van bekkenpijn tijdens de zwangerschap}

De prevalentie van ZGBP in Nederland is bij 14 weken zwangerschap $45 \%$ en bij 30 weken $70 \%$; van hen heeft $13 \%$ een actieve hulpvraag. Internationaal. worden prevalentie cijfers vermeld die variëren van $45 \%$ tot $89 \%$.

\section{Prevalentie wan bekkenpijn na de bevalling}

Twee weken na de bevalling is de prevalentie van ZGBP onder Nederlandse vrouwen gedaald tot $31 \%$, hiervan heeft $15 \%$ een actieve hulpvraag of geeft de verloskundige aan dat fysiotherapeutische behandeling noodzakelijk is. Zes maanden na de bevalling is de prevalentie 29\% En stijgt één jaar na de bevalling tot $35 \%$. Deze cijfers zijn vergelijkbaar met de prevalentie cijfers van aspecifieke lage rugpijn in de Nederlandse bevolking (niet zwanger). Internationaal wordt direct na de bevalling een prevalentie $67^{\circ} \%$ en na één jaar van $37 \%$ gemeld.

\section{Etiologische factoren}

Uit epidemiologische gegevens blijkt dat $98 \%$ van de vrouwen die een historie heeft in of buiten de zwangerschap van lage rugklachten ZGBP krijgt. Daarnaast zijn roken, een jonge leeftijd en het aantal doorgemaakte zwangerschappen van invloed op het ontstaan van ZGBP.

\section{Prognostische factoren}

De literatuur op het gebied van prognostische factoren bij deze aandoening is beperkt. Factoren die het herstell ongunstig beïnvloeden zijn pijnklachten gelokaliseerd in het gebied van de lumbale wervelkolom en het aantal pijnlocaties. Factoren zoals bewegingsangst, pijngedrag, verwachting van het resultaat van een behandeling, somberheid en gespannenheid zijn nog nauwelijks in deze groep onderzocht maax lijken van invloed te zijn op ZGBP. 


\section{Rol van de fysiotherapeut}

\section{Tijdens de zwangerschap}

Tijdens de zwangerschap bestaat er voor de meeste vrouwen met ZGBP geen indicatie fysiotherapie. Ter verbetering van de beperkingen in activiteiten en participatieproblemen is de verloskundige de eerst aangewezen persoon. Bij een actieve hulpvraag is een kortdurende fysiotherapeutische begeleiding met een beperkte doelstelling mogelijk. Deze begeleiding bestaat voornamelijk uit het geven van informatie, voorlichting en geruststelling. Oefentherapeutische verrichtingen zoals gewrichtsmobilisatie en spierversterking, alsmede coördinatie van aanspanning van de stabiliserende musculatuur zijn in deze fase slechts bij uitzondering geïndiceerd.

\section{Na de bevalling}

$\mathrm{Na}$ de bevalling is fysiotherapie geîndiceerd als er onvoldoende verbetering van de beperkingen in activiteiten en/of participatieproblemen wordt geconstateerd. De primaire doelstelling is preventie van chronische pijn en disfunctioneren.

De eerste weken na de bevalling begeleidt de fysiotherapeut alleen indien nodig. Het geven van informatie en voorlichting zijn de belangrijkste verrichtingen met als doel geruststelling. Actief oefenen is (nog) niet geïndiceerd. Na een periode van vier à zes weken wordt het oefenen geleidelijk geïntensiveerd, waarbij het accent met name ligt op coördinatie van aanspanning van de stabiliserende musculatuur. De fysiotherapeut heeft een rol bij het herleren of aanleren van (nieuwe) vaardigheden en oppakken van activiteiten. In een later stadium is de patiènt meer in staat haar eigen verantwoordelijkheid te nemen over uitvoering van activiteiten de hantering van haar klachten/aandoening. De rol van de fysiotherapeut is begeleidend. De fysiotherapeut informeert de patiënt hoe om te gaan met de pijn, etiologie en prognose van ZGBP.

\section{Samenwerking met andere disciplines}

Goede samenwerking en afstemming van het te voeren beleid met de huisarts, medisch specialist en/of verloskundige geschiedt conform de hiervoor ontwikkelde handreikingen Indicatiestelling, Verwijsbrief, Consultatie, Tussentijds contact en Verslaggeving. Het is belangrijk dat de verschillende 
hulpverleners inzicht hebben in elkanders werkwijze en deskundigheid en dat de informatieverstrekking aan de patiënt wordt afgestemd. Belangrijk hierbij is dat beseft wordt dat de impact van het verstrekken van een emotioneel beladen diagnose als "bekkeninstabiliteit" grote gevolgen kan hebben voor de verwachting van de patiënt ten aanzien van haar herstel, en voor de relatie tussen patiënt en hulpverlener(s). De term bekkeninstabiliteit wordt daarom in de richtlijn niet gehanteerd.

De diagnostiek vindt geheel plaats op basis van de gepresenteerde klachten en is primair aangrijpingspunt voor de inhoud van de behandeling. Vragen van patiënten omtrent baringshoudingen, het inleiden van de bevalling en andere aan bevalling gerelateerde zaken worden in alle gevallen verwezen naar de verloskundige of gynaecoloog.

\section{Samenvatting rol fysiotherapeut bij ZGBP}

\section{Reden verwijzing ZGBP}

Tijdens de zwangerschap (kortdurende interventie)

Te grote afname van het activiteitenniveau in relatie tot de duur van de zwangerschap.

Een sterk toenemende onzekerheid over de (on)mogelijkheden van bewegen en activiteiten tijdens de zwangerschap

Na de bevalling (beoordeeld drie weken na de bevalling)

Onvoldoende herstel met betrekking tot activiteiten en participatie De patiënt is niet of onvoldoende in staat zelfstandig het gewenste niveau van functioneren te bereiken

\section{B Diagnostisch proces}

\section{Verwijzing en aanmelding}

Er wordt in verwijzende en terugverwijzende zin samengewerkt met huisarts, medisch specialist of verloskundige. Is de patiënt verwezen door éen van deze disciplines dan dient de verwijzing medische verwijsgegevens te bevatten die wijzen op ZGBP. Andere verwijsgegevens zijn: de verwijsreden, relevante gegevens met betrekking tot de medische voorgeschiedenis en eventueel aanvullend onderzoek, medicijngebruik, nevenaandoeningen en relevant 
geachte psychosociale factoren (gele vlaggen; psychosociale factoren, welke kunnen wijzen op een verhoogde kans op voortbestaan of chroniciteit van de klachten). De fysiotherapeut neemt contact op met de verwijzer wanneer de verwijzing onvoldoende gegevens bevat.

Het doel van het diagnostisch proces is het inventariseren van de ernst en de aard van het gezondheidsprobleem van de patiënt en de mate van beinvloedbaarheid van deze problemen door fysiotherapie. Bij vrouwen met ZGBP onderzoekt de fysiotherapeut welke probleemgebieden op de voorgrond staan. Op dit moment is het niet mogelijk om een stoornis in de anatomische structuur of functie(s) als oorzaak van de klachten aan te kunnen geven. Het moment van aanmelding of verwijzing (tijdens de zwangerschap of na de bevalling) is van belang voor de inhoud en de omvang van het diagnostisch proces.

Tijdens de zwangerschap kan de diagnostiek beperkt blijven, terwijl na de zwangerschap uitgebreidere diagnostiek in de rede ligt. Belangrijke elementen in de diagnostiek na de bevalling zijn de beperkingen in ADL, participatieproblemen en prognostische factoren zoals bewegingsangst, pijngedrag, somberheid, gespannenheid en (irreële) gedachten die de patiënt zelf heeft ten aanzien van de oorzaak en het voortbestaan van de klachten.

Het uitgangspunt is dat specifieke pathologie wordt uitgesloten. Wanneer de fysiotherapeut een specifieke oorzaak vermoedt, neemt hij contact op met de huisarts of verloskundige.

\section{Anamnese}

\section{Tijdens de zwangerschap}

Hulpvraag, doelen en verwachtingen van de patiënt;

Inventariseren de klachten, co-morbiditeit en contra-indicaties;

Beloop van de klachten;

Vaststellen van het activiteitenniveau:

Welke activiteiten denkt de patiënt dat ze niet kan (mag) uitvoeren?

Wat zijn de specifieke problemen hierbij?

Welke informatiebehoefte is er over het beloop van haar klachten?

Wat denkt de patiënt zelf over de oorzaak en het mogelijk voortbestaan van de klachten na de bevalling?

Aanbevolen meetinstrument: PHODA (Photograph series of Daily activities) 
Na de bevalling

Maak onderscheid tussen aspecifieke en specifieke pathologie, waarbij het signaleren van zogenaamde rode vlaggen (tekenew/signalen on problematiek woijzend op een specifieke oorzank van lage nigpin en anmullende diagnostiek vereist) van belang is Denk hierbij aan:

Gynacologische/obstetrische complicaties

Zeruwwortelprikkeling

Specifieke andoeningen wervelkolom

Reumatische aardoeningen

Infecties, thmoren etc.

Belangrije criteria:

Is de oorsprong van de pijnklachten wel of niet gerelateerd aan het houding en bewegingsapparaat (indien niet gerelateerd ann houding of beweging $\rightarrow$ rode vlng)

Wisselen de klachten bij activiteiten en verandering wan houding (indien de klachten hetzelfde blijoen $\rightarrow$ rode vlag)

Cave: de ernst van de pijnklachten is niet gerelateerd an aspecifieke dan wel specifieke pathologie.

Beloop van de klachten in de tijd

Begin en ontstaanswijze van de klachten

Beloop in de tijd

Etiologische factoren:

- eerdere episodes van lage rugklachten buiten de zwangerschap

- $\quad$ eerdere zwangerschapsgerelateerde bekkenpijn

- $\quad$ sociaal economische status

- leefstijlfactoren; met name roken

Nevenaandoeningen

Welke medische / therapeutische interventies hebben plaatsgevonden?

Medicingebruik

Gebruik van hulpmiddelen

Arbeidsgerelateerde factoren:

Zwangerschapsverlof / ziekteverzuin

Beroep

Wijze van omgaan met de klachten

Maakt patiënt zich zorgen (bijvoorbeeld over een gestelde of vermoede diagnose door arts, verloskundige of andere hulpverlener gesteld)? 
Wat denkt de patiënt zelf over de oorzaak van haar klachten (in het bijzonder factoren die patient omschrijft als uitlokkend ${ }_{r}$ verergerend of opnieuw oplopen van letsel).

Onzekerheid over welke activiteiten ze kan uitvoeren

Welke informatie en van wie heeft patiënt over de aandoening (media, zwangerschapsgymnastiek, familie en vriendenkring en wat is de invloed hiervan op haar activiteiten en ideeën)

Is de patiênt in staat op een gemiddelde dag de pijn te verminderen en hoe.

Hoe schat patiënt het risico in dat:

De pijn blijft bestaan,

- Lichamelijke inspanning de pijn verergert,

- Toename van pijn een teken is dat de activiteit gestopt moet worden.

Hoe voelt patiènt zich dat ze nog klachten heeft;

- Is ze teleurgesteld of boos,

- Benoemt ze haar klachten in superlatieven,

- Is er sprake van verlies van vertrouwen of conflicten met hulpverleners,

- Zijn er vragen om specialistisch onderzoek,

- Is er een toenemende ongerustheid over een mogelijke ernstige afwijking?

Hoe is de gezondheid van de baby.

Hoe is de hulp van de omgeving georganiseerd.

Aanbevolen meetinstrumenten

Om de bevindingen te objectiveren en het resultaat van het handelen te evalueren, wordt aanbevolen bij de anamnese en het lichamelijk onderzoek gebruik te maken van de meetinstrumenten:

VAS - schaal: draaglijkheid wan pijn in deze week

VAS - schaal: verwachting patiënt over welslagen van de behandeling

Roland Disability Questionnaire (RDQ)

Patient Specifieke Klacht met behulp van VAS - schaal

Impact on Participation and Autonomy (IPA)

- Subschalen zelfverzorging en gezinsrol

Screeningslijst (selectie) acute rugpijn

Photograph series of Daily activities (PHODA)

Mate algeheel herstel (evaluatief instrument om behandelresultaat te meten) 
Aandachtspunten bij het opstellen van de hulpvraag

Welke activiteiten en handelingen in het dagelijks leven worden als problematisch ervaren?

Hoe belangrijk zijn beperkingen (in activiteiten) en hoe vaak moeten ze worden uitgevoerd?

Wat is de verwachting van de patient over het resultaat wan fysiotheraple?

Zijn deze verwachtingen reeel en hoe ziet patiënt haar eigen rol?

\section{Onderzoek}

Aan de hand van anamnestische gegevens formuleert de fysiotherapeut de onderzoeksdoelstellingen met als doel om door middel van inspectie / observatie in rust en beweging en tijdens lichamelijk onderzoek de anamnestische bevindingen te verifiëren. Uitgangspunt hierbij is het niveau van activiteiten en participatie. De fysiotherapeut tracht tevens relevante stoornissen in functies te achterhalen. Hierbij wordt gekeken naar afgenomen actieve stabiliteit en coördinatie van vooral de buikspieren en rug-extensoren en een verminderde algehele conditie)

Indien de fysiotherapeut radiculaire uitstraling vermoedt, wordt een neurologisch onderzoek uitgevoerd. Dit bestaat uit een SLR-test en het onderzoeken van de spierkracht, sensibiliteit en peesreflexen van de desbetreffende spinale zenuw. De behandeling van patiënten met lage rug en bekkenpijn met radiculaire uitstraling valt buiten het bereik van de richtlijn. Bij een positieve testuitslag (uitstralende pijn voor 70 graden, verergering van pijn bij dorsiflexie van de voet en/of pijnvermindering bij knieflexie) wordt contact opgenomen met de huisarts.

Indien de fysiotherapeut van mening is dat er tevens sprake is van (stress) urine-incontinentie, wordt verwezen naar een daarvoor opgeleide fysiotherapeut.

Observatie tijdens en na de zwangerschap

asymmetrie in houding en beweging,

voorzichtig en aarzelend bewegen,

een waggel of schuifelgang.

"catching the leg" (ofwel slepen met een been tijdens het maken van een stap; dit wordt na de bevalling vaker subjectief aangegeven, is echter zelden objectief vast te stellen). 


\section{Functie onderzoek}

Het functieonderzoek bestaat uit het testen (en/of meten, vastleggen, verifiëren) van de stoomissen in functies en anatomische structuren die in de anamnese naar voren zijn gekomen.

In het onderzoek inventariseert de fysiotherapeut de stoornissen in functies en beperkingen in activiteiten. Hiervoor worden bij voorkeur actieve onderzoeksmethoden gebruikt.

\section{Tijdens de zwowngerschap}

Kort orièterend actief onderzoek van de lumbale wervelkolom, heupen en onderste extremiteiten.

De verder te onderzoeken functies en activiteiten komen voort uit de ananinese en in het bijzonder uit de hulpvraag van de patiënt en haar problemen ten aanzien van de ADL en bevindingen van de PHODA.

Het onderzoek naar de beperkingen in activiteiten is voornamelijk gericht op activiteiten zoals tillen, opstaan, gaan zitten, lopen etc. Het pijngedrag wordt geobserveerd en vastgelegd met de Pijn Gedragschaal.

Na de bewalling

Orienterend onderzoek van functies;

Gewrichtsfuncties van de lumbale wervelkolom en onderste extremiteiten beoordelen op mobiliteit, bewegingsverloop en provocatie van klachten;

Spierfunctie: rug en buikmusculatuur.

De verder te onderzoeken functies en activiteiten komen voort uit de anamnese en in het bijzonder uit de hulpvraag van de patiënt en haar problemen ten aanzien van de ADL en bevindingen van de PHODA.

Ter afsluiting van het onderzoek (tijdens de zwangerschap en na de bevalling) vult de fysiotherapeut de Pijn Gedragschaal in. De geobserveerde periode bestrijkt de gehele duur van het rechtstreekse contact met de patiënt.

\section{Analyse ter formulering van de fysiotherapeutische diagnose}

Op basis van de verzamelde gegevens wordt het gezondheidsprobleem geformuleerd. De fysiotherapeut maakt een inschatting van de gezondheidstoestand, belemmerende en bevorderende factoren voor herstel en beoordeelt of er een indicatie is voor fysiothemapie of gewerkt kan worden 
volgens de KNGF-richtlijn. Indien er geen indicatie is voor fysiotherapie wordt de pattiènt terugverwezen naar de huisarts.

De fysiotherapeut dient de volgende vragen te kunnen beantwoorden:

Zijn de gesignaleerde bevindingen consistent?

Welke problemen / aandachtsgebieden staan op de voorgrond?

In welk stadium van de zwangerschap of na de bevalling verkeert de patiènt?

Welke belemmerende en/of bevorderende factoren zijn beïnvloedbaar door fysiotherapie?

Wat is de prognose voor herstel?

Welke stoornissen in functies en beperkingen in activiteiten en zijn door fysiotherapie te beünvloeden?

Wat verwacht de patiënt van de behandeling?

Het is belangrijk, het binnen het diagnostische proces gemaakte onderscheid, tussen vrouwen met klachten tijdens de zwangerschap en na de bevalling, te handhaven.

\section{Conclusie}

Alvorens behandeldoelen en een behandelplan op te kunnen stellen, moet de fysiotherapeut antwoord hebben op de volgende vragen:

(1) Is er sprake van zwangerschap gerelateerde bekkenpijn?

(2) Is er een indicatie voor fysiotherapeutische behandeling?

(3) Kan worden behandeld volgens de KNGF-richtlijn ZGBP?

Tijdens de zwangerschap

Tijdens de zwangerschap zijn vooral de belemmerende factoren en de prognose voor herstel, van belang. Tijdens de zwangerschap staan meestal de beperkingen in activiteiten als gevolg van de pijn en onzekerheid over het herstel op de voorgrond.

Na de bevalling

Blijven de klachten na de bevalling bestaan en is er geen duidelijke verbetering te constateren in de eerste weken, is er een indicatie voor fysiotherapie.

$\mathrm{Na}$ beantwoording van genoemde vragen kunnen in samenspraak met de patiënt, de individuele behandeldoelen worden geformuleerd en het behandelplan worden opgesteld. 
interfereert immers met actieve stabiliteit en coördinatie van met name de buikspieren en rug - extensoren). Het gebruik van krukken wordt eveneens niet gestimuleerd, maar in sommige gevallen kan het tijdens de zwangerschap een hulpmiddel zijn om het looppatroon te verbeteren. Het gebruik van een rolstoel wordt nadrukkelijk ontraden. Indien wenselijk kan de fysiotherapeut de patiënt tips aanreiken om onder andere het in - en uitstappen van de auto te vergemakkelijken door bijvoorbeeld een plastic zak op de zitting te leggen. (Men glijdt hierdoor makkelijker in de stoel maar de zak moet wel voor het rijden worden verwijderd). De uiteindelijke keuze van het gebruik van hulpmiddelen ligt bij de patiënt zelf.

\section{Streven man zelfstandigheid van de patiënt}

Een belangrijk behandelaspect is het stimuleren van de patiënt tot een actieve leefstijl in overeenstemming met het stadium van de zwangerschap. De fysiotherapeut informeert de patiënt over bewegingsactiviteiten (mogelijk in groepsverband) tijdens en na de zwangerschap. De fysiotherapeut en patiënt streven actief naar een afname van de afhankelijkheid van de patiënt.

\section{Eindevaluatie en afsluiting}

De huisarts c.q. verloskundige wordt op de hoogte gesteld van de bevindingen van het diagnostisch proces en de gegeven informatie.

\section{Na de bevalling}

Voorlichting en informatie geven over ZGBP, het verwachte herstel in de eerste weken na de bevalling en stimuleren van actief gedrag. Bij niet (voldoende) optredend herstel is actieve oefentherapie geindiceerd volgens een gedragsmatige aanpak.

Fysiotherapeutische verrichtingen na de bevalling (de eerste 4 weken)

Bij verwijzing na de bevalling is het belangrijk rekening te houden met het tijdstip na de bevalling. De eerste 4 weken na de bevalling begeleidt de fysiotherapeut alleen indien nodig. In dit stadium zijn voorlichting en reactivering belangrijk en is oefenen (nog) niet geïndiceerd.

Informeren en adviseren 
De informatie en het advies komen in deze fase grotendeels overeen zoals beschreven tijdens de zwangerschap. Het is belangrijk de patiënt te informeren over de in het algemeen gunstige prognose voor herstel.

\section{Hulpwiddelen}

Het gebruik van hulpmiddelen door de patiënt wordt in deze fase nadrukkelijk ontraden. De fysiotherapeut geeft informatie en tips over activiteiten die van belang zijn door de verzorging van de baby (in bad doen, voeden, kind meenemen in huis en buitenshuis). De fysiotherapeut moet op de hoogte zijn van de voor - en nadelen van verschillende babydraagzakken aankleedkussens $_{r}$ en positionering hiervan, tips en hulpmiddelen om het baden, voeden en vervoeren van de baby te vergemakkelijken. De uiteindelijke keuze van het gebruik van hulpmiddelen ligt bij de patiënt zelf.

\section{Fysiotherapeutische verrichtingen vanaf 4 weken na de bevalling}

Indien de klachten na 4 weken blijven bestaan of indien er sprake is van onvoldoende toename van activiteiten en participatie dan is oefenen geïndiceerd.

De doelstellingen zijn:

Vergroting van kennis en inzicht wan de patient met betrekking tot de (prognose van de) andoening en het eigen functioneren, Opbouw van activiteiten en participatic.

Positieve beïnoloeding wan biopsychosociale factoren (integratie tussen biomedische, psychologische en sociale factoren) die geassocieend zijn met het voortbestan wan. klachten mits deze binnen de behandelwogelijkheden on de fysiotherapeut liggen.

\section{Informeren en adviseren.}

De fysiotherapeut geeft informatie over de aard en het beloop van de aandoening, de relatie tussen belasting en belastbaarheid en het belang van een actieve leefstijl. Gedoseerde bewegingen en activiteiten zijn niet schadelijk voor de lage rug en bekken. Er zijn geen specifieke activiteiten of bewegingen die vermeden moeten worden of juist op een bepaalde (andere) wijze moeten worden uitgevoerd. De fysiotherapeut legt uit dat pijn in de lage rug en/of bekken niet schadelijk is en dat toename van pijn ook niet samengaat met beschadiging van structuren. Van belang is dat de patiënt leert dat zij na de bevalling haar activiteiten gedoseerd gaat verhogen waarbij in de eerste weken na de bevalling een herstelperiode in acht wordt genomen. Er wordt informatie verstrekt over de invloed van stemming en vermoeidheid op pijn. Tevens wordt er informatie gegeven hoe te handelen bij recidieven en exacerbaties. Er wordt 
uitgelegd dat (toename van) pijn in het bekken en/of de lage rug bij bewegen normaliter niet leidt tot een schade.

De eigen verantwoordelijkheid van de patiênt is erg belangrijk. De patiënt leert om zelfistandig korte en lange termijndoelen te stellen en deze op haalbaarheid te toetsen. De fysiotherapeut heeft een begeleidende rol. In het begin is deze rol voornamelijk gericht op het aanleren van nieuwe vaardigheden zoals het zelfstandig leren stellen van deze korte en lange termijndoelen. Daarna is de rol veel meer gericht op het stimuleren van continuering van de aangeleerde vaardigheden en het opbouwen van activiteiten en participatie: De inbreng van de patiènt bij de invulling van het eigen programma wordt steeds belangrijker. Op deze manier worden de voorwaarden gecreëerd waarbij de patiënt zelf in staat wordt gesteld om zelf keuzen te maken bij eventuele noodzakelijke aanpassingen in haar leefwereld. Om deze reden worden er dan ook geen leefregels gegeven.

\section{Trainen van functies en vaardigheden}

In deze KNGF- richtlijn is gekozen voor oefenen ter stabilisatie van het bekken, toegepast in activiteiten in het dagelijks leven. De opbouw kent drie fasen:

1. Ademhaling, aanspanning - en ontspanningsoefeningen;

2. Combinatie van deze oefeningen met verschillende uitgangshoudingen en bewegingen;

3. Aandacht voor doel van de handeling waarbij actief spanning in de stabiliserende spieren opgebouwd kan worden.

De belangrijkste doelstelling is niet spierversterking maar beïnvloeding van het coördinatiepatroon van aanspanning van de stabiliserende musculatuur. Op geleide van een tijdcontingente aanpak gaat conditieverbetering een steeds belangrijkere rol spelen en wordt geoefend op basis van fysiologische trainingsprincipes. Voor het hervatten en/of uitbreiden van activiteiten wordt een tijdgebonden oefenprogramma gehanteerd. Tijdgebonden wil zeggen: een stapsgewijze opbouw van activiteiten op basis van een vooraf afgesproken tijdsduur en niet op basis van pijn. De patiènt heeft aan de hand van het stellen van korte en lange termijndoelen een belangrijke rol in de gekozen opbouw.

\section{Hulpuiddelen}

Het gebruik van hulpmiddelen door de patiënt (zoals bekkenband, krukken, rolstoel en dergelijke) wordt in deze fase nadrukkelijk ontraden. 


\section{Evaluatie en afsluiting}

Bij aanvang van iedere nieuwe behandelsessie worden de door de patient geformuleerde korte en lange termijn doelen expliciet besproken. De fysiotherapeut bewaakt de eigen begeleidende rol bij problemen. De patient denkt in principe zelf na over mogelijke oplossingen en maakt pas een keuze als er meerdere ideeën aan bod zijn geweest. Belangrijk aspect hierbij is dat de patiënt in staat wordt gesteld om zo nauwkeurig mogelijk de oorzaak van het probleem in de uitvoering van een activiteit vast te stellen.

Naast deze continue evaluatie vindt er na een behandelperiode van 6 weken een tussentijdse uitgebreide evaluatie en bij afsluiting van de behandelperiode een eindafsluiting plaats. Deze evaluaties zijn gericht op de gestelde behandeldoelen (in termen van het verbeteren van de stoornissen functies en toename van activiteiten en participatie).

De evaluatie geschiedt door een (korte) anamnese (van de status presens) en de geadviseerde (gekozen) meetinstrumenten. Toename van activiteiten en het zelf ervaren herstel staan hierbij centraal.

De behandeling wordt beëindigd als de behandeldoelen geheel of gedeeltelijk zijn bereikt en de verwachting bestaat dat de patiënt deze doelen zelfstandig kan bereiken. Indien ex geen verbetering is opgetreden maakt de fysiotherapeut samen met de patiënt een inschatting of er in de komende periode verbetering kan worden verwacht. Indien de inschatting is dat de patiènt het maximaal mogelijke heeft behaald wordt de behandeling ook beëindligd. De eindevaluatie vindt plaats na een periode van maximaal 3 maanden.

\section{Afshiting, verslaggeving en versinglegging}

De huisarts wordt (eventueel) tussentijds, maar in ieder geval na het beëindigen van de behandelepisode, geïnformeerd over de behandeling. Informatie wordt verstrekt over behandeldoelen, behandelresultaten en gegeven informatie. 


\section{Verantwoording en toelichting}

\section{A Inleiding}

De KNGF-richtlijn zwangerschapsgerelateerde bekkenpijn (ZGBP) vormt een leiddraad voor het fysiotherapeutisch handelen bij vrouwen met klachten tijdens en/of na de bevalling. In de richtlijn worden het diagnostisch en therapeutisch proces beschreven conform het methodisch fysiotherapeutisch handelen en er is aandacht voor preventie.

De onderbouwing van deze richtlijn is zoveel mogelijk op wetenschappelijke bewijswoering gebaseerd. Daar waar de literatuur geen uitkomst bood is gebruik gemaakt van de recent uitgevoerde cohort - en interventie studies aan de Universiteit Maastricht (Maastricht Cohort and Intervention study on pregnancy-related pelvic gircle pain (PPGP)). In de "Verantwoording en Toelichting" wordt de gebruikte methode toegelicht, gevolgd door de wetenschappelijke onderbouwing van het fysiotherapeutisch handelen als vermeld in het praktijkdeel. Een KNGF - richtlijn kan worden beschouwd als "the state of the art" momentopname op het gebied van ZGBP inzake fysiotherapeutisch handelen waarmee het handelen van de fysiotherapeut wordt geoptimaliseerd.

Een KNGF - richtlijn is gedefinieerd als "Een systematisch ontwikkelde, vanaf centraal niveau geformuleerde leidraad, die door deskundigen is opgesteld en gericht op de inhoud van het methodisch fysiotherapeutisch handelen bij bepaalde gezondheidsproblemen en op (organisatorische) aspecten die met de beroepsgroep te maken hebben.

\section{Doelstellingen van de KNGF - richtlijnen}

De doelstelling van de richtlijn is het beschrijven van de "optimale fysiotherapeutische zorg" van vrouwen met bekkenpijn, leidend tot functioneel herstel, terugkeer naar het gewenste niveau van participatie, zelfredzaamheid en het voorkomen van (of leren omgaan met) recidieven, excacerbaties en disfunctioneren, gebaseerd op de huidige wetenschappelijke inzichten.

Op basis van onderzoeksgegevens is bekend dat er een grote variatie bestaat in de doelen, verrichtingen en omvang van de fysiotherapeutische zorg. (Nivel) 
Naast bovengenoemde doelstellingen is de KNGF - richtlijn expliciet bedoelt om:

- De zorg in de gewenste richting te veranderen op basis van huidige wetenschappelijke inzichten en de uniformiteit en de kwaliteit van de zorg te verhogen;

- De taken en verantwoordelijkheden van beroepsgroepen af te bakenen, inzichtelijk te maken en onderlinge samenwerking te stimuleren;

- De fysiotherapeut te ondersteunen bij het nemen van beslissingen.

Om de richtlijn toe te kunnen passen worden aanbevelingen geformuleerd in termen van deskundigheidseisen die noodzakelijk zijn om volgens de richtijin te kunnen handelen.

\section{Klinische vraagstellingen}

De werkgroep die deze richtlijn heeft voorbereid, heeft antwoord gezocht op de volgende klinische vragen:

- Hoe groot is het probleem van bekkenpijn?

- Welke onderdelen van het fysiotherapeutisch diagnostisch onderzoek zijn betrouwbaar, valide en bruikbaar in de praktijk?

- Welke onderdelen van het fysiotherapeutisch diagnostisch proces zijn minimaal nodig om de behandeldoelen, een behandelplan en een prognose te kunnen formuleren?

- Welke vormen van behandeling en preventie zijn wetenschappelijk te onderbouwen en zinvol?

- Welke vormen van behandeling dienen naar de mening van de werkgroep genoemd te worden ondanks gebrek aan wetenschappelijke onderbouwing?

\section{Samenstelling en werkwijze van de werkgroep}

De richtlijn is ontwikkeld door een monodisciplinaire werkgroep van inhoudsdeskundigen in de periode van mei 2002 tot en met mei 2005. Alle werkgroepleden hebben verklaard geen conflicterende belangen te hebben bij de te ontwikkelen KNGF - richtlijn. Aanvankelijk is er gewerkt aan de ontwikkeling van een ontwerprichtlijn. Publicatie hiervan is uitgesteld vanwege het beleid van het KNGF om ontwerprichtlijnen om te zetten naar KNGF richtlijnen. De richtlijn is ontwikkeld conform de "Methode voor 
Richtlijnontwikkeling en Implementatie" [1-3]. In de methode zijn de praktische aanwijzingen geformuleerd om de strategie te vermelden waarmee de literatuur is verzameld, inclusief de zoektermen, de geraadpleegde bronnen en de periode waarover de literatuur is verzameld. Dit geldt eveneens voor de criteria voor het in - of uitsluiten van de literatuur en de wijze waarop de aanbevelingen zijn gebaseerd. Voor zover mogelijk is de KNGF - richtlijn in overeenstemming met andere mono - of multidisciplinaire richtlijnen, maar wijkt goeddeels af van de Europese richtlijn omdat deze is opgesteld vanuit een biomechanisch perspectief. Een conceptrichtlijn is voor beoordeling aan externe referenten (de werkgroep tweede kring) voorgelegd voor commentaar.

\section{Opbouw, producten en implementatie van de richtlijn}

De richtlijn is opgebouwd uit drie delen, namelijk:

1. de praktijkrichtlijn;

2. een schematisch overzicht van de kernpunten van de richtlijn en;

3. een verantwoording en toelichting.

Uit didactische overwegingen en om de bruikbaarheid in de praktijk te bevorderen is gekozen voor deze driedeling. De delen van de richtlijn zijn ieder afzonderlijk zelfstandig te lezen. De Verantwoording en Toelichting bevat een uiteenzetting van de keuzen die zijn gemaakt bij de totstandkoming van de richtlijn. Naast de literatuur hebben vakinhoudelijke ontwikkelingen en andere overwegingen (zoals praktische implicaties) een rol gespeeld bij het opstellen van deze richtlijn. Deze KNGF - richtlijn wordt geïmplementeerd volgens een standaard implementatiestrategie[2] [1,3].

\section{Literatuurverzameling}

De gebruikte publicaties werden verzameld met behulp van de Index Medicus, het "Cochrane Rehabilitation \& Related Therapies Field" van de Universiteit Maastricht en het Documentatiecentrum van het Nederlands Paramedisch Instituut. Ten aanzien van de aandoening is gezocht op de trefwoorden: posterior pelvic pain, pregnancy-related pelvic joint pain, pregnancy-related pelvic girdle pain, peripartum pelvic pain, post-partum pelvic pain, pelvic girdle relaxation, low back pain, pregnancy, zwangerschap, bekkenpijn en bekkeninstabiliteit. Met betrekking tot de diagnostiek is gezocht op de woorden, diagnosis, pregnancy, classification, posterior pelvic pain provocation test, Asymmetric Straight Leg Raising Test. Met betrekking tot interventies is 
gezocht op de woorden: intervention, oefentherapie, bewegingstherapie, rugscholing, back school, zwangerschapsgymnastiek en hydrotherapie. Daarnaast zijn secundaire referenties uit de gevonden studies opgespoord. De gevonden studies zijn beoordeeld aan de hand van kwaliteitscriteria zoals deze beschreven worden door EBRO-lijsten. Op het gebied van zwangerschapsgerelateerde bekkenpijn tijdens de zwangerschap en vooral na de bevalling heeft tot op heden nog vrij weinig wetenschappelijk onderzoek heeft plaatsgevonden dat gebruikt kan worden ter onderbouwing van de richtlijn. Mede daarom is aanvullend gebruik gemaakt van literatuur met betrekking tot etiologische en prognostische factoren en de behandeling van chronische benigne (lage rug) pijn. De verschillende pijnsyndromen die binnen deze groep van aandoeningen vallen, presenteren een grote diversiteit aan biomedische diagnosestellingen. Echter, ze vertonen wel opvallende overeenkomsten ten aanzien van prognostische factoren voor het ontwikkelen van chronische klachten [4]. Verder is ter onderbouwing gebruik gemaakt van recente onderzoeksgegevens uit de cohort en interventie studie naar zwangerschapsgerelateerde bekkenpijn van de capaciteitsgroep Epidemiologie, Universiteit Maastricht (Maastricht Cohort and Intervention study on Pregnancy-related Pelvic Girdle Pain [5, 6]). De gegevens van deze studies zijn verzameld in de periode 2000 tot en met 2002 in de gehele provincie Limburg, het zuidoostelijk deel van Noord-Brabant en het zuidelijke gedeelte van Gelderland ter plaatse de regio Nijmegen - Arnhem. De populatie van de cohort studie bestaat uit in principe uit gezonde zwangere vrouwen die in voldoende mate de Nederlandse taal (mondeling en schriftelijk) beheersen. Deze cohort studie bevat nauwelijks allochtone vrouwen.

Bij de interpretatie van de resultaten uit de literatuur is rekening gehouden met de verschillen in onderzoeksdesign. De gebruikte studies zijn beoordeeld op de mate van bewijskracht. Hiervoor is onder meer gebruik gemaakt van de beoordelingslijsten en criteria van het Evidence Based Richtlijnen Overleg (EBRO), ontwikkeld onder auspiciën van het kwaliteitsbestuur van de Gezondheidszorg (CBO), die op basis van consensus zijn samengesteld voor richtlijnontwikkeling in Nederland. Voor de categorieën diagnose en prognose heeft de werkgroep naar analogie met de EBRO-criteria eigen criteria opgesteld (Tabel 1a). 
Tabel 1a Indeling van onderzoeksresultaten naar mate van bewijjskracht met betrekking tot diagnose, prognose en interventie

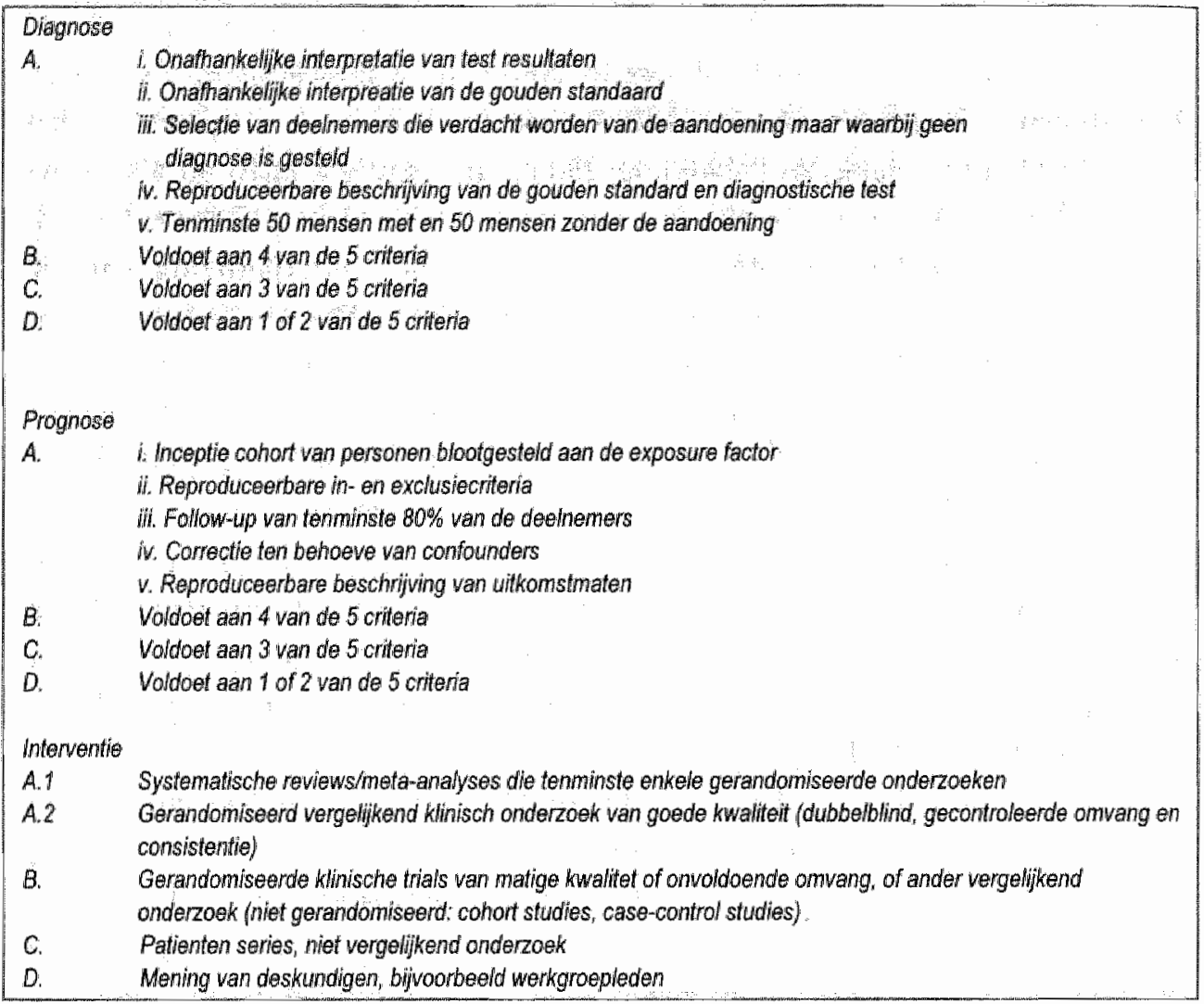

Op basis van de analyse van de literatuur zijn, na bespreking in de werkgroep, conclusies getrokken over de effectiviteit van de afzonderlijke interventies, gevolgd door een aanbeveling. Deze conclusies hebben ook weer een bepaald niveau van aanbeveling, afhankelijk van de mate van bewijs en de beschikbare literatuur (Tabel 1b). Indien wetenschappelijk bewijs afkomstig is uit systematische reviews/ meta-analyses, (gerandomiseerde) klinische studies en vergelijkend onderzoek krijgen de aanbevelingen, afhankelijk van de mate van bewijskracht, niveau 1, 2, of 3 . Als het wetenschappelijke bewijs niet voorhanden of onbekend is, maar het onderwerp is zo belangrijk dat opname in de richtlijn gewenst is, zijn de aanbevelingen op basis van consensus (niveau 4). Aanbevelingen van niveau 4 zijn gebaseerd op de mening van deskundigen en/of op consensus binnen de werkgroep. Bij het opstellen van de 
Tabel ib Nivenus van geformuleerde amberelingen op basis oam het onderliggend wetenschappelijk bewijs

\begin{tabular}{|c|c|}
\hline 1 & 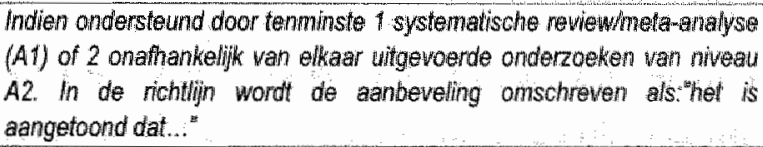 \\
\hline 2 & 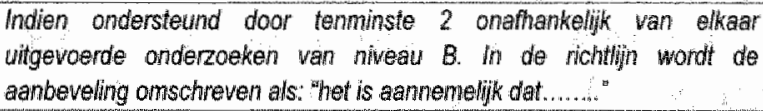 \\
\hline 3 & 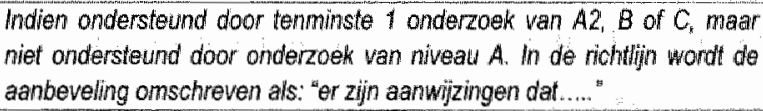 \\
\hline 4 & $\begin{array}{l}\text { Op grond var de mening wan de werkgroepleden. In de richtlin wordt de } \\
\text { aanbeveling omschreven als: "de werkgroep is van mening dat...." }\end{array}$ \\
\hline
\end{tabular}

aanbevelingen zijn naast gezondheidswinst ook bijwerkingen en risico's overwogen.

Wanneer er geen klinisch relevant effect is aangetoond in de beschikbare onderzoeken op niveau $\mathrm{A}_{s} \mathrm{~B}$, of $\mathrm{C}$ dan krijgt de aanbeveling de formulering " $\mathrm{Er}$ is onvoldoende bewijs dat...". Indien bij de aanbeveling niveau D staat vermeldt, betekent dit dat het een aanbeveling van de werkgroep betreft (niveau 4 ). In alle andere gevallen staat het niveau erbij vermeld.

\section{Afbakening van het gezondheidsprobleem}

De richtlijn heeft betrekking op aspecifieke zwangerschapsgerelateerde lage rug - en bekkenpijn. Pijnklachten die een specifieke oorzaak hebben zoals een hernia, zenuwwortel prikkeling, tumoren, trauma en gynaecologische of urologische complicaties vallen buiten deze richtlijn en indien geïndiceerd wordt er naar de KNGF- richtlijn lage rugpijn[7] en/of de NVMT richtlijn lage rugpijn[8] verwezen. Voor de behandeling van een complicatie als stress - urine incontinentie wordt naar de desbetreffende richtlijn[9] verwezen.

Ondanks het ontbreken van een pathosfysiologische grondslag van de klachten zijn internationaal verschillende diagnostische concepten en classificatie strategieën ten behoeve van de klinische diagnostiek ontwikkeld. Deze concepten en classificatie strategieën zijn grotendeels ontwikkeld op basis van klinische expertise en patroonherkenning. Binnen de afzonderlijke strategieën zijn echter verschillende afwegingen gemaakt met betrekking tot de aard en het belang van de belangrijkste symptomen op het gebied van pijn(locaties) en 
activiteiten; met name de psychosociale aspecten zijn nog niet in kaart gebracht. De onderlinge overeenstemming tussen deze classificatiestrategieën is dan ook zeer klein. Omdat een goede definitie van zwangerschapsgerelateerde bekkenklachten ontbreekt, is gekozen voor een probleemoriëntatie waarbij de aandoening voornamelijk wordt beschreven in stoornissen, vaardigheden, participatie en prognostische of interne(persoonsgebonden) en externe factoren. [10] Omdat de prevalentie en de behandeling van de aandoening tijdens de zwangerschap en na de bevalling verschillen is er in de richtlijn voor gekozen deze beide fasen in het beloop van de klachten apart te beschrijven.

\section{Tijdens de zwangerschap}

De pijn kan al vroeg tijdens de zwangerschap beginnen (eerste trimester). Gemiddeld heeft $22 \%$ van de 6004 vrouwen met pijn aan de achterkant (80\%) (uit het cohort $n=7526$ ) gedurende de zwangerschap ook pijn aan de voorkant (op en rond de symfyse en/of in de liezen). Regelmatig wordt er uitstraling naar andere delen van het bekken en naar de achterzijde van de bovenbenen gerapporteerd. De pijnklachten zijn duidelijk houdingsafhankelijk en aspecifiek.

Bewegingen die vaak als pijnlijk aangegeven worden zijn omdraaien in bed, opstaan uit een stoel en schokkende bewegingen zoals het maken van een misstap of fietsen door een kuiltje. Ook bewegingen of houdingen die gedurende langere tijd worden uitgevoerd of volgehouden geven op den duur meer pijn. Op het moment van uitvoeren van een activiteit is er meestal geen klachtentoename; na enige uren of de volgende dag echter wel. In een aantal gevallen kunnen er karakteristieke veranderingen optreden ten aanzien van het looppatroon. Er treedt een typisch waggelend looppatroon op met een breder gangspoor dan gebruikelijk wordt gesignaleerd waarbij de patiënt aangeeft dat zij moeite heeft om eén been naar voren te brengen tijdens het maken van een stap. Soms treedt dit verschijnsel in beide benen op. Over het algemeen nemen bij de meeste vrouwen de pijnklachten geleidelijk toe tijdens het vorderen van de zwangerschap. In het laatste trimester nemen de pijnklachten echter geleidelijk weer wat af, in de regel vaker bij vrouwen die voor de eerste maal zwanger zijn dan bij vrouwen die al één of meerdere malen bevallen zijn. Alhoewel een geleidelijke afname van het activiteitenniveau gedurende de zwangerschap als normaal wordt beschouwd, is bij vrouwen met klachten deze afname in activiteiten groter en begint eerder in het beloop van de zwangerschap. Ook de arbeidsparticipatie neemt bij deze vrouwen eerder af. 
De activiteiten die in de loop van de tijd geleidelijk vermeden wordeth verschillen per persoon. In deze fase worden veel vrouwen ook wat onzekerder en weten niet goed meer welke activiteiten ze wel en niet mogen (kunnen) doen. Actieve en passieve copingstijlen spelen hierbij een rol. Onder actieve coping wordt verstaan het proberen te functioneren ondanks de pijn, bijvoorbeeld door het zoeken van afleiding, door zelfactiviteit en een actieve leefstijl. Passieve coping refereert aan het zich afhankelijk opstellen van anderen om de pijn onder controle te houden of het beperken van activiteiten [11].

\section{Na de bevalling}

Over het algemeen verminderen de pijnklachten tijdens het kraambed snel. Een heel kleine groep vrouwen ontwikkelt pas klachten in het kraambed. Deze vrouwen klagen met name over pijn in de regio van de symfyse en hebben moeite met bewegingen als opstaan uit een stoel of bed, omdraaien in bed en traplopen.

Bij vrouwen die na de bevalling klachten blijven houden is de aard van de pijnklachten is niet wezenlijk verschillend met de situatie tijdens de zwangerschap. Echter de functionele gevolgen en de bijbehorende problemen op het niveau van participatie verschillen wel, alsmede de teleurstelling dat het einde van de zwangerschap niet tevens het einde van de klachten inluidt. De activiteiten die niet of onvoldoende kunnen worden uitgevoerd en de consequenties hiervan ten aanzien het gezinsleven en verzorging van kind(eren) worden als (zeer) hinderlijk en moeilijk ervaren. Daarnaast wordt het beroep doen op de partner als niet meer zo vanzelfsprekend als tijdens de zwangerschap ervaren en maken veel vrouwen zïch zorgen over de invulling van de snel naderende terugkeer naar betaalde arbeid. Er bestaat duidelijke aarzeling en onzekerheid om bepaalde activiteiten die tijdens de zwangerschap problemen opleverden en achterwege werden gelaten, te hervatten. Een kleine groep vrouwen gaat ernstig gebukt onder haar klachten, heeft veel pijn en problemen met het uitvoeren van activiteiten en op het gebied van participatie. Bij een aantal van deze vrouwen zijn tijdens het kraambed de pijnklachten zo ernstig dat ze nauwelijks in staat zijn zelfstandig het bed te werlaten. 


\section{Omvang van het probleem}

De literatuur is niet eenduidig over de prevalentie/incidentie van ZGBP. Mede door de verschillen in afbakening en doel van de studies lopen deze cijfers nogal uiteen.

\section{Tijdens de zwangerschap}

Nederlandse prevalentie schattingen zijn verricht op basis van Maastricht Cohort studie [5]. De prevalentie van pijnklachten in de regio van de lage rug en bekken bij 14 weken zwangerschap is binnen dit cohort $45 \%$. Bij 30 weken zwangerschap is dit $70 \%$, terwijl dit in de periode van 34 tot 40 weken daalt naar $48 \%$. Tijdens de zwangerschap heeft $9 \%$ van het totale aantal vrouwen binnen de cohort studie een actieve hulpvraag.

Internationale prevalentie schattingen zijn slechts beschikbaar uit Scandinavië, de Verenigde Staten, Israẻl, Zuid-Afrika en Nigeria [12]. De cijfers wisselen tijdens de zwangerschap van $45 \%$ [13] tot $89 \%$ [14]. Andere studies rapporteren cijfers die binnen deze spreiding liggen [15], [16], [17], [18], [19], [20], [21] , [22] [23], [24], [25], [26]. Een mogelijke reden voor het ontbreken van studies in andere landen is dat zwangerschapgerelateerde bekkenpijn daar waarschijnlijk niet gezien wordt als een aparte aandoening maar als een normaal bijverschijnsel van zwangerschap[12].

\section{Na de beoalling}

De prevalentie van pijnklachten twee weken na de bevalling is $31 \%$, waarvan $15 \%$ een actieve hulpvraag of geeft de verloskundige aan dat behandeling noodzakelijk is. Zes maanden na de bevalling geeft $29 \%$ van de vrouwen pijn aan in het bekken/lage rug gebied, terwijl dit éen jaar na de bevalling stijgt tot $35 \%$. Deze ciffers geven echter geen indruk over de ernst van de pijn en op de vraag of deze vrouwen ook daadwerkelijk een hulpwraag hebben.

Internationaal vergelijkingsmateriaal is schaars. Er zijn maar een paar enkele studies voorhanden met betrekking tot de prevalentie van bekkenpijn na de bevalling. Deze studies zijn voornamelijk retrospectief [27] of hebben betrekking op een heel kleine groep vrouwen [28]. De enige studie die gegevens verzameld heeft van een groep vrouwen van grotere omvang $(n=917)$ en met een follow-up periode tot éen jaar na de bevalling is in Zweden geweest [29]. Dit onderzoek [29] vermeldt dat direct na de bevalling $67 \%$ van de vrouwen lage rug - of bekkenpijnklachten heeft. Een jaar na de bevalling is dit $37 \%$. Van 
de vrouwen die herstellen na de bevalling blijkt de meerderheid (23\%) kort na de bevalling (binnen 1 maand) te herstellen, $6 \%$ van de vrouwen herstelt dan nog in de periode van 1 maand na de bevalling tot het einde van de follow-up periode; 1 jaar na de bevalling.

Op basis van bovenstaande formuleert de werkgroep de volgende aanbeveling:

Het is aannemelijk dat ZGBP een normanl lichamelijk verschijnsel is tijdens de zwangerschap met een snelle afname van de pijn kort na de beorlling (niveau 2).

\section{Etiologische factoren}

In de literatuur worden een groot aantal factoren genoemd die de ontstaanswijze van zwangerschapsgerelateerde bekkenpijn zouden kunnen verklaren. Deze studies zijn voomamelijk verricht in de laatste 25 jaar (Tabel 2). Er is echter weinig overeenstemming tussen deze verschillende studies. Een van de mogelijke oorzaken zou kunnen zijn dat de onderzochte populaties op een aantal belangrijke karakteristieken van elkaar verschillen. De genoemde etiologische factoren zijn globaal in te delen in hormonale factoren (relaxine, de invloed van het gebruik van anticonceptie) [24, 27, 30-32], demografische factoren van de moeder (leeftijd, BMI, aantal zwangerschappen, eerdere episodes van lage rug klachten of zwangerschapsgerelateerde klachten, roken, alcoholgebruik, beroep, socio-economische status, sportbeoefening, hypermobiliteit, opleiding, baringshouding, kunstverlossingen, epiduraalanesthesie en keizersnede) $[15]\{[14],[19,26,31,33][34,35][13][22,25$, 36] en demografische factoren van het kind (geboortegewicht, meerlingzwangerschappen, omvang schedel) [26, 34, 37].

Uit de Maastrichtse cohort studie blijkt dat de enige factor met een duidelijk positieve relatie ten aanzien van het ontstaan van ZGBP een historie is van éen of meerdere eerdere episodes van lage rugklachten buiten de zwangerschap of lage rug - en bekkenklachten tijdens een eerdere zwangerschap (Bastiaanssen et al. Submitted). Andere factoren die in veel mindere mate van invloed lijken zijn roken, leeftijd (jong), en het aantal doorgemaakte zwangerschappen.

Op basis van bovenstaande formuleert de werkgroep de volgende aanbeveling:

Het is aannemelijk dat etiologische factoren niet beinvloedbaar zijn door de fysiotherapeut (niveau 2). Aansluiting bij het advies te stoppen met roken woor iedere orouw die zwanger wil worden is echter wel belangrijk. 
Tabel 2 prospecheve cohorten gedurende de zwangerschnp en na de bevalling; niven wan bewis

\begin{tabular}{|c|c|c|c|c|}
\hline . & $\mathbb{W}$ & / cases & $\begin{array}{l}\text { Inception cohort wan } \\
\text { people: biooligesteld aan } \\
\text { de expositiefactor }\end{array}$ & $\begin{array}{l}\text { Reproduceerbare inclusie } \\
\text { en exciusie criteria }\end{array}$ \\
\hline (Albert at al. 2001) & 1789 & $\sqrt{405}$ & $x$ & $x$ \\
\hline (Berg ell al. 1988) & 362 & $\sqrt{79}$ & $x^{2}$ & $x$ \\
\hline $\begin{array}{l}\text { Kristansison et al. } 1996 \mathrm{a} \\
\text { Kristiansson et al. } 1996 \mathrm{~b} \text { ) }\end{array}$ & 200 & & $x$ & $x$ \\
\hline $\begin{array}{l}\text { (Ostgaard and Andersson } \\
\text { 1992; Ostgaard et al. } \\
\text { 1991a; Ostgaard ot al. } \\
\text { 1991b) }\end{array}$ & 917 & & $x$ & x \\
\hline (Larsen et al. 1999)† & 1600 & 1227 & $x$ & $x$ \\
\hline (To and Wong 2003) & 326 & & $x$ & $x$ \\
\hline (Bastiaarissen et al. 2005) & 7526 & & x & $x$ \\
\hline
\end{tabular}

\section{Prognostische factoren en beloop}

In de literatuur maken slechts Ostgaard [31]en Albert [38] onderscheid tussen factoren die bijdragen in het ontstaan van ZGBP en de factoren die van invloed zijn op het beloop van deze klachten. Pijn in de regio van alleen de symfyse wordt door Albert beschouwd als een positieve prognostische factor (vrouwen met vrijwel alleen klachten in deze regio hebben een gunstiger prognose dan vrouwen met klachten in de regio van de SI-gewrichten). Dit in tegenstelling tot Ostgaard, die geen enkel prognostisch belang aan dit symptoom toeschrijft. Ostgaard beschrijft dat de prognose van vrouwen met pijnklachten in het gebied van de lumbale wervelkolom of een combinatie van pijnklachten binnen het gebied van de lumbale wervelkolom en bekkengordel ongunstiger is dan bij vrouwen met alleen pijnklachten aan de achterzijde van het bekken. De wetenschappelijke onderbouwing van het gemaakte onderscheid is echter niet helder $[39,40]$.

Onderzoek op het gebied van lage rugklachten en aspecifieke pijnklachten van het houding - en bewegingsapparaat is vaak gericht op prognostische factoren. Er is een toenemend bewijs dat een biomedisch beleid van artsen en fysiotherapeuten bij deze groep van aandoeningen onvoldoende effect sorteert en dat de invloed van biopsychosociale factoren op het voortbestaan van deze klachten belangrijker is dan biomechanische factoren [41] [42-44]. Deze factoren zijn bijvoorbeeld bewegingsangst, depressie, somberheid, gespannenheid, catastroferen, pijngedrag en verwachting van de resultaten van een behandeling. 


\begin{tabular}{|c|c|c|c|}
\hline $\begin{array}{l}\text { Follow-up van tenminnnste } \\
80 \% \text { of participants }\end{array}$ & $\begin{array}{l}\text { Cortectie ten behoeve van } \\
\text { confounders }\end{array}$ & $\begin{array}{l}\text { Reproduceerbare } \\
\text { beschtiliving wan de } \\
\text { uitkonistmaat }\end{array}$ & $\begin{array}{l}\text { Niveau van bewijs } \\
(A, B, C, D)\end{array}$ \\
\hline - & - & - & D \\
\hline - & - & $x$ & $c$ \\
\hline * & - & $x$ & B \\
\hline$x$ & - & $x$ & B \\
\hline - & - & - & D \\
\hline - & * & $x$ & $c$ \\
\hline * & $x$ & $x$ & $A$ \\
\hline
\end{tabular}

Ondanks dat deze factoren bij ZGBP belangrijk lijken te zijn is het onderzoek ten aanzien van deze factoren nog in volle gang. Een aanbeveling ten aanzien wan de beïnvloedbaarheid door de fysiotherapeut is daarom nog niet mogelijk.

Biopsychosocianl model

Deze richtlijn maakt onderscheid tussen ZGBP gedurende de zwangerschap en daarna. In beide perioden kunnen klachten zowel berusten op specifieke dan wel aspecifieke pathologie leidend tot stoornissen en beperkingen in activiteiten en participatie. Als er een duidelijke relatie is tussen de ernst van de stoornissen en beperkingen / participatieproblemen dan is er sprake van biomechanische pijn - leidend tot consistente bevindingen (reproduceerbaar). In het traditionele (biomedische) ziektemodel zijn deze klachten uitgaande van weefselbeschadiging rechtstreeks beìnvloedbaar door behandeling van de onderliggende stoornissen en beperkingen in activiteiten[10].

Echter de werkgroep neemt aan dat ZGPB het resultat is van interactie tussen biologische, psychische en sociale factoren, leidend tot stoornissen en beperkingen in activiteiten en participatie. $\mathrm{Om}$ deze reden wordt de biopsychosociale benadering geintroduceerd. Psychosociale factoren kunnen een belangrijke rol spelen bij het voortbestaan van de klachten [10]. De fysiotherapeut inventariseert en analyseert wat de belemmerende en bevorderende factoren zijn voor herstel. De biomedische aspecten dienen te worden te geintegreerd in de biopsychosociale benadering in plaats van beschreven en onderzocht te worden als een apart onderdeel. De interactie tussen de verschillende domeinen (functiestoornissen, activiteiten en 
participatie) staat hierbij centraal waarbij de invlloeden van omgevingsfactoren, persoonlijke factoren en de aandoening van belang zijn[10].

\section{Doelgroep}

Om deze KNGF - richtlijn adequaat te kunnen uitvoeren dienen fysiotherapeuten kennis te hebben van het natuurlijk beloop van ZGBP tijdens de zwangerschap, na de bevalling en tijdens de kraambedperiode en de fase hier direct aansluitend (globaal tot een termijn van 4 weken na de bevalling). Tevens dienen zij kennis te hebben van belemmerende en bevorderende factoren ten aanzien van herstel, gedragsgeoriënteerde behandelprincipes, methodieken ten aanzien van voorlichting, de methodiek en wetenschappelijke onderbouwing ten aanzien van spierfunctie - en coördinatietraining in het gebied van buik, rug en bekkenbodem musculatuur. Ten aanzien van de diagnostiek en behandelmogelijkheden in het gebied van de bekkenbodem en stress-urine incontinentie wordt verwezen naar de inhoud van desbetreffende richtlijn(en).

\section{Rol van de fysiotherapeut}

Tijdens de zwangerschap

Het algemene doel van de fysiotherapeutische behandeling tijdens de zwangerschap is de patiënt met zwangerschapsgerelateerde bekkenpijn te begeleiden in de geleidelijke (natuurlijke) afname van het activiteitenniveau tot de bevalling. De begeleiding is van beperkte omvang en niet intensief van aard. Bij de voorlichting wordt het stappenplan van Van der Burght en Verhulst (1996) gevolgd. In het voorlichtingsproces worden 6 stappen onderscheiden, waarbij een blijvende gedragsverandering de laatste stap is. Deze eindstap is niet te zetten als de voorgaande stappen niet zijn gezet.

Stap 1. Open stam

De fysiotherapeut sluit met het voorlichten aan bij de beleving, verwachting,vragen en zorgen van de patiënt.Belangrijke vragen zijn wat houdt de patiënt het meeste bezig en welke zorgen belemmeren de patiënt om open te staan voor informatie over gedragsverandering. Het kan zijn dat de patiënt de positieve gevolgen van gedragsverandering wel kent, maar geen positieve verwachtingen heeft over de gedragsverandering. Het kan zijn dat de patiënt denkt dat de voordelen 
voor haar niet van toepassing zijn. Ook kan het zijn dat de patiënt zich niet in staat acht om het gewenste gedrag uit te voeren.

\section{Stap 2. Begrijpen}

De informatie moet zodanig worden aangeboden dat de patient het begrijpt en het kan onthouden. Belangrijk is: niet te veel informatie per keer, wat moet eerst en welke informatie kan later, de boodschap in een andere vorm herhalen of uitleggen met behulp van hulpmiddelen (folders,video). De fysiotherapeut controleert of de patiènt de informatie inderdaad begrepen heeft.

Stap 3. Willen

De fysiotherapeut inventariseert wat een patiënt (de)motiveert om iets te doen. Belangrijk is hierbij: welke voordelen heeft het oefenen voor de patiënt, ervaart deze steun of druk van mensen uit de nabije omgeving, heeft de patiënt het gevoel dat hij invloed op zijn situatie kan uitoefenen. De patiënt probeert de kansen op succes in te schatten. Gaat het lukken om het gewenste gedrag uit te voeren? De fysiotherapeut biedt ondersteuning en informatie over mogelijkheden en alternatieven. Er worden haalbare afspraken gemaakt.

Stap 4. Kunnen

De patiënt moet in staat zijn om het gevraagde gedrag uit te kunnen voeren. De benodigde functies en vaardigheden moeten worden geoefend. Belangrijk is om te inventariseren welke praktische problemen de patiënt verwacht en samen met de patiënt na te gaan hoe deze problemen opgelost kunnen worden.

Stap 5. Doen

Dit omvat het daadwerkelijk uitvoeren van het nieuwe gedrag. De fysiotherapeut maakt met de patiënt heldere, concrete en haalbare afspraken en stelt concrete doelen. Indien mogelijk wordt positieve feedback gegeven.

Stap 6. Blijuen doen

De patiënt zal het gedrag na de behandeling moeten blijven vertonen. Tijdens de behandeling moet de fysiotherapeut met de patiënt 
bespreken of hij denkt dat hij daarin zal slagen. Belangrijk is om na te gaan wat moeilijk is voor de patiënt, wat stimulerend werkt en of er beloningen voor korte en lange termijn zijn. Wat helpt de patiënt om na terugval de draad weer op te pakken?

Ondanks het feit dat de patiënt tijdens de zwangerschap wel degelijk ernstige klachten kan hebben is gezien de prevalentie cijfers de prognose van de klachten goed. De begeleiding richt zich dan ook met name op het geven van informatie en het activiteitenniveau in relatie tot de duur van de zwangerschap. Het is op dit moment in het beloop van de aandoening niet mogelijk aan te geven welke patiënten chronische klachten zullen ontwikkelen (een zeer kleine groep) en welke patiënten niet. Nader onderzoek hieromtrent vindt thans (2005/2006) plaats.

\section{Na de bevalling}

Algemeen doel van de fysiotherapeutische behandeling na de bevalling is de patiênt met gevolgen van ZGBP te laten terugkeren naar een volledig (of gewenst) niveau van activiteiten en participatie en het voorkómen van chronische klachten.

Indien er sprake is van aspecifieke lage rugpijn die niet gerelateerd is aan de zwangerschap kan gebruik gemaakt worden van de KNGF - richtlijn lage rugklachten[7] of de NVMT richtlijn lage rugklachten[8].

In de eerste weken na de bevalling ondersteunt de fysiotherapeut alleen indien nodig (actieve hulpvraag). Vanaf vier weken na de bevalling zal de fysiotherapeut indien geindiceerd en/of de patiënt niet adequaat met de klachten omgaat behandeling inzetten. De fysiotherapeut maakt daarbij onder meer gebruik van gedragsgeoriënteerde principes, waarin het bewegend functioneren centraal staat. Gebruikmaking van gedragsgeoriënteerde principes houdt in dat de behandeling wordt gericht op het gedrag van de patiènt en op situaties waarin dit gedrag zich voordoet. Belangrijke kenmerken van deze behandeling zijn onder meer een actieve participatie van de patiënt en het tijdgebonden handelen. Deze kenmerken komen nadrukkelijk naar voren bij behandelmethodieken die gebaseerd zijn op "self-management principles" [45]. Belangrijke kenmerken van zelfmanagement zijn[46, 47] [48]:

Een tijdgebonden handelen warbij de patient het tempo bepaalt ann de hand oan zogenaande nctieplamnew. 


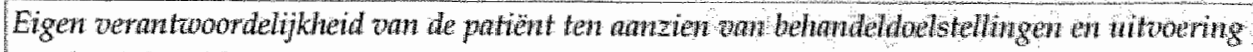
oan het behandelphar.

Leren formuleren, witooren en eadueren wan korte en lange tewaijndoelen door de pationt zilf.

Op basis van bovenstande fornuleerde de werkgropp de nolgewde ambeweling:

Het is angetoond dat het stimuleren van zelfmanagenent gevich op het omgann tan aspecifieke lage rugklachten effectief is (nizean 1 ).

\section{Samenwerking met andere disciplines}

De fysiotherapeut dient zich in de samenwerking met de (verwijzende) disciplines bewust te zijn van de aard van de informatieverstrekking met betrekking tot de diagnose. De diagnose "bekkeninstabiliteit" is een onderwerp dat veel vragen en onzekerheden oproept. In het bijzonder het gebruik van de term "instabiliteit" roept bij patiènten een aantal negatieve associaties op. Deze term wordt dan ook binnen deze richtlijn niet gebruikt. De diagnostiek is uitsluitend gebaseerd op het gepresenteerde klachtenpatroon. Therapeutische maatregelen zijn tot op heden nog weinig door wetenschappelijk onderzoek onderbouwd of gevalideerd (NVOG standpunt bekkeninstabiliteit 1996). De NVOG heeft op grond van deze onzekerheden ernstige bezwaren tegen de dreigende commercialisering van dit klachtencomplex. In het bijzonder geldt dit voor de adviezen ten aanzien van zwangerschap en bevalling die niet op wetenschappelijk onderzoek worden gebaseerd en daarom niet gefundeerd zijn. De fysiotherapeut dient zich in de communicatie met patiënt en (verwijzende) hulpverleners te beperken tot de informatie die verworven is uit het fysiotherapeutisch diagnostisch en therapeutisch proces en dient zich te onthouden van adviezen over onder andere de baringshouding, inleiden van de bevalling vanwege pijnklachten etcetera. Vragen van patiënten op dit terrein worden in alle gevallen verwezen naar de behandelend verloskundige of gynaecoloog.

De reden voor een kortdurende verwijzing van vrouwen tijdens de zwangerschap is een te grote afname van het activiteitenniveau en sterk toenemende onzekerheid over de mogelijkheden van bewegen tijdens de zwangerschap alsmede (ermee gepaard gaande) pijnklachten.

Verwijzing na de bevalling is geïndiceerd wanneer er sprake is van een onvoldoende opbouw en/of stagnatie in activiteiten en participatie. De patient is niet of onvoldoende in staat zelfstandig haar gewenste niveau van functioneren te bereiken. 


\section{B Diagnostisch proces}

\section{Verwijzing en aanmelding}

Er wordt in verwijzende en terugverwijzende zin samengewerkt met huisarts, medische specialist of verloskundige. Is de patiënt verwezen door één van deze disciplines dan dient de verwijzing gegevens te bevatten die wijzen op ZGBP. Van belang voor de inhoud van het diagnostisch proces is:

1. Het moment van aanmelding; tijdens de zwangerschap of na de bevalling.

Tijdens de zwangerschap volstaat een veel korter inventarisatie dan bij persisterende pijn en beperkingen in activiteiten een aantal weken na de bevalling.

2. De inventarisatie van de klachten binnen alle domeinen van de International Classifications of Functions (ICF)[10]; (functie)stoornissen, activiteiten en participatie alsmede de beïnvloedende factoren (omgeving -en persoonlijke factoren).

3. Terughoudendheid ten aanzien van de interpretatie van de uitkomsten van het lichamelijk onderzoek; in het bijzonder van de diagnostische tests is gerechtvaardigd. Op dit moment is onvoldoende bekend wat de bijdrage van een specifieke diagnostische test of een symptoom is op de uiteindelijke klinische betekenis van de klachten[49]

De taak van de fysiotherapeut richt zich op de inventarisatie van de probleem/aandachtsgebieden die op de voorgrond staan. De hulpvraag van de patiënt is het uitgangspunt (Figuur 1 Het diagnostisch proces).

\section{Anamnese}

Door middel van het afnemen van de anamnese tracht de fysiotherapeut een zo duidelijk mogelijk beeld te krijgen van het gezondheidsprobleem van de patiënt. De eerste stap die in het proces van vragen stellen gemaakt moet worden, is het onderscheid maken tussen specifieke (rode vlaggen=biomedische risicofactoren) en aspecifieke aandoeningen. Hierbij is geen onderliggend pathofysiologisch mechanisme objectiveerbaar).

Bij het maken van dit onderscheid wordt in grote lijnen gebruik gemaakt van de "diagnostic triage" zoals die ontwikkeld is voor lage rugklachten door Waddell [41] [50]. De volgorde van de gestelde vragen is hierbij van groot belang. De eerste twee vragen zijn of de oorsprong van de pijnklachten ligt in het houding 
-en bewegingsapparaat en of deze klachten sterk wisselen onder invloed van fysieke activiteiten. Een positief antwoord op beide vragen duidt op een aspecifieke aandoening. De intensiteit van de pijn is geen onderscheidend criterium tussen specifieke en aspecifieke klacliten.

"Rode olaggen"zijn tekenen/signalen van bijwoorbeeld gynaecologische complicaties
tijdens zwangerschap of na de bevalling of spimate problematiek wijzend op een
specifieke oorzaak voor de pijn. Deze "rode vlaggen"kunten duiden op een emstige
aandoening en vereisen aanoullende diagnostiek. Voorbeelden van deze
tekenen/signalen kunnen progressieve pijntoename, neurologische witval, geen
verandering van pijnintensiteit gedurende de dng of bij wisselen vam houding of
beweging zijn. Soms is de algemene gezondheidstoestand hierbij betrokken.

Is het onderscheid tussen specifieke en aspecifieke klachten eenmaal gemaakt dan richt de anamnese zich op de "gele vlaggen". Dit zijn vragen betreffende de voornaamste hulpvraag van de patiënt, de voomaamste klacht, de gevolgen voor het dagelijks leven, factoren die de klachten verergeren, verlichten of in stand houden, de beleving van de klachten en de gevolgen daarvan. Belangrijk is ook om inzicht te krijgen in de verwachting van de patiënt van de behandeling.

"Gele olaggen"zijn psychosociale factoren die van invloed kunnen zijn op het vaortbestaan van pijn, beperkingen van activiteiten en restricties binnen de participatie. Voorbelden hieroan zijn (bewegings)angst, depressie, somberheid, catastrofrerende gedachten ozer de aorzaak en het voortbestaan van de klachten, verwachting van de behandeling, tevredenheid met de nieuwe gezinssituatie.

Anamnese tijdens de zwangerschap

Tijdens de zwangerschap ligt de nadruk voornamelijk op de onzekerheid van de patiënt ten aanzien van welke activiteiten ze denkt wel of niet te mogen (kumnen) uitvoeren. Gedachten over de oorzaak van haar klachten, het mogelijk voortbestaan hiervan na de bevalling en de wijze waarop de zwangere nu met haar klachten omgaat, komen globaal aan bod.

\section{Anammese na de bevalling}

De anamnese na de bevalling gaat veel uitgebreider in op beperkingen van activiteiten, participatie. Gedachten van de patiënt met betrekking tot de oorzaak van de klachten, verwachting van de behandeling en formuleren van de hulpvraag nemen een belangrijke plaats in. Persoonsgebonden factoren als somberheid, gespannenheid, gedachten van de patiënt ten aanzien van de 
Dit vindt plaats aan de hand van de volgende vragen:

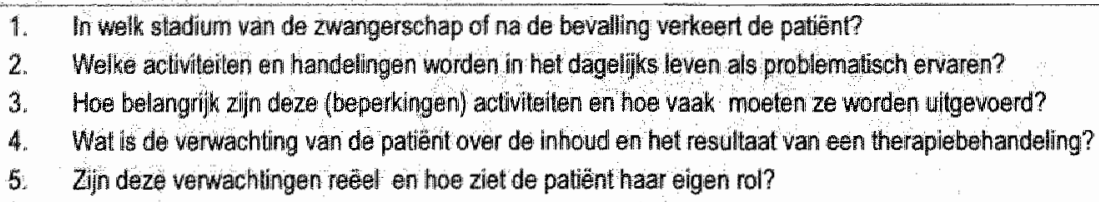

\section{Onderzoek}

Het onderzoek heeft een oriënterend karakter en is gericht op problemen op het gebied van de activiteiten en participatie.

Het doel is om een inschatting te maken van het niveau van bewegend functioneren en de voorwaarden met betrekking tot behandeling in kaart te brengen. De strategie voor het onderzoek is afhankelijk van de in de anamnese verkregen informatie. Het onderzoek bestaat uit inspectie in rust, inspectie in beweging en het lichamelijk onderzoek op basis van verkregen informatie uit de anamnese.

\section{Onderzoek tijdens de zwangerschap}

Het onderzoek tijdens de zwangerschap kan beperkter van omvang blijven dan na de bevalling. De observatie tijdens de zwangerschap kan een "catching the leg" fenomeen laten zien. Het "catching the leg" fenomeen [63] is voor het eerst in Scandinavië beschreven en hiermee wordt bedoeld dat de patiënt problemen ervaart tijdens het lopen, bij het naar voren brengen van een been. Het been gaat "slepen". Dit fenomeen is echter na de bevalling niet vaak meer objectief vast te stellen. Het wordt subjectief wel iets vaker door de patiënt beschreven. Ook het waggelend lopen verdwijnt na de bevalling meestal vrij snel.

\section{Onderzoek na de bevalling}

$\mathrm{Na}$ de bevalling vindt naast observatie een oriënterend onderzoek plaats van functies en coördinatie. De verder te onderzoeken functies en activiteiten komen voort uit de anamnese. Uit de literatuur bekende diagnostische tests ter vaststelling van ZGBP zijn in te delen in pijnprovocatie testen en testen om de stabiliteit van de bekkengordel vast te stellen. Aanvullend wordt er gebruik gemaakt van nauw omschreven pijnlocaties. De beschreven pijnprovocatietesten zijn; de "Posterior Pelvic Pain Provocation test(PPPP)[64], 
palpatie van het longitudinaal dorsaal sacro-iliacaal ligament[65], Patricks's fabere test[66, 67] en palpatie van de symfyse[66-68]. Ten behoeve van de stabiliteit van de bekkengordel worden de Active Straight Leg Raise test (ASLR) en de adductie kracht van de heup beschreven[69]. (Tabel 3)

De bewijskracht van de onderzochte diagnostische studies is echter van onvoldoende kwaliteit (Tabel 3). Buiten methodologische problemen met betrekking tot de selectie van de studiepopulatie is bij geen enkel onderzoek naar de validiteit van een van deze meetinstrumenten een vergelijking met een "gouden standaard" betrokken. Recent onderzoek naar de betrouwbaarheid en validiteit van pijnprovocatie en mobiliteit van het sacroiliacale gewricht[70-72] onderschrijft de lage methodologische kwaliteit van deze studies. Bovendien vragen de auteurs zich af of er een diagnostische test te ontwikkelen is voor het sacroiliacale gewricht met enige waarde voor de klinische praktijk.

Nauw omschreven pijnlocaties worden in de literatuur[64, 66] beschreven als kenmerkend voor ZGBP. Echter ook hier is onvoldoende wetenschappelijk bewijs voorhanden. Een zeer recente studie naar specifieke pijngebieden gerelateerd aan het sacroiliacale gewricht leverde geen wetenschappelijke onderbouwing voor deze veronderstelling.[72]

Op basis van bovenstaande formuleerde de werkgroep de volgende aanbeveling:

Er is onvoldoende bewijs voor het gebruik wan diagnostische tests die specifiek ontwikkeld zijn om zwangerschapsgerelateerde bekkenpijn wast te stellen.

\section{Analyse ter formulering van de fysiotherapeutische diagnose}

Op basis van de verzamelde gegevens wordt tijdens de analyse het gezondheidsprobleem geformuleerd. De fysiotherapeut maakt een inschatting van de gezondheidstoestand, van de belemmerende en bevorderende factoren en beoordeelt of er een indicatie is voor fysiotherapie en/of gewerkt kan worden volgens de KNGF - richtlijn. Indien er geen indicatie is voor fysiotherapie wordt de patiënt terugverwezen naar de huisarts.

De fysiotherapeut dient de volgendle vragen kunnen beantwoorden:

- Zijn de gesignaleerde bevindingen consistent?

- Welke problemen/aandachtgebieden staan op de voorgrond?

- In welk stadium van de zwangerschap of na de bevalling verkeert de patiënt? 
Tabel 3 Diagnostische studies; niveau van bewijs

Onathankelihe interpreatio

Inathankelijke interpretatis

N

wan de test resultaten

van de gouden standaro

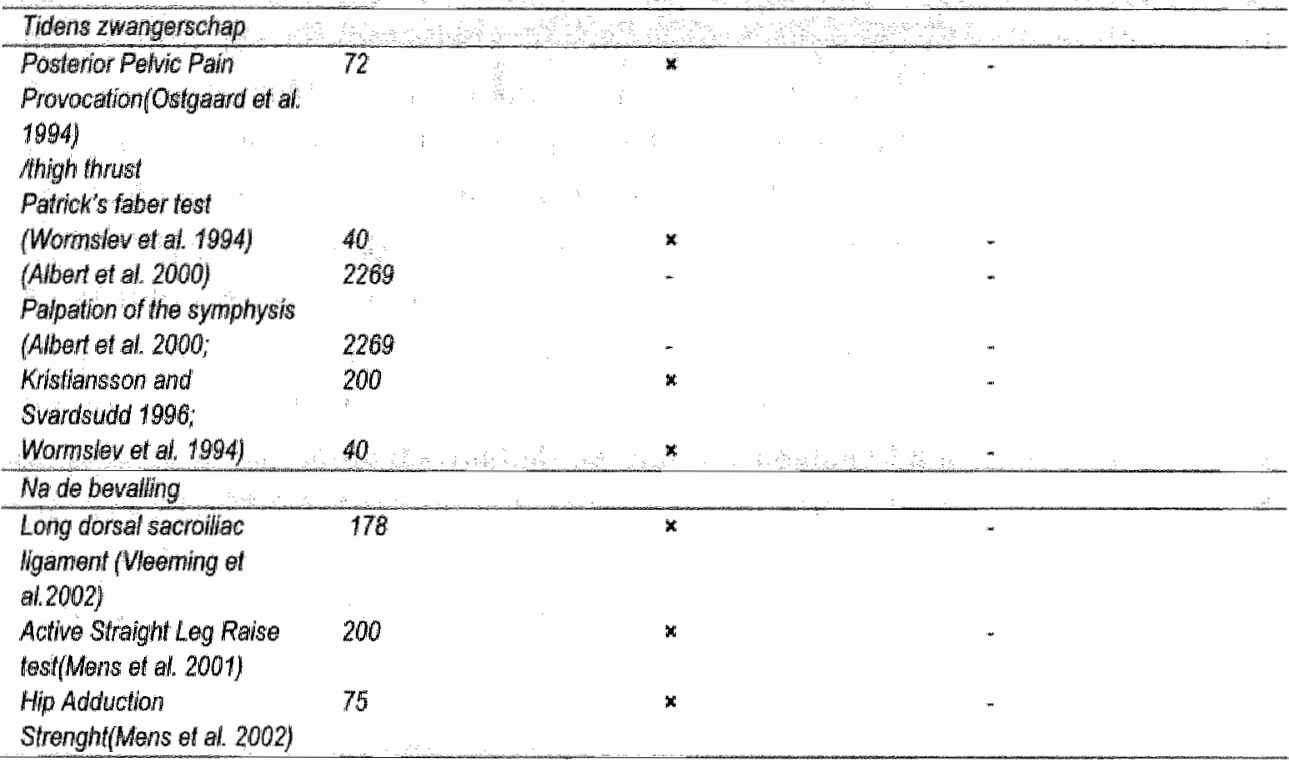

$A=$ voldaen 5 criteria, $B=$ valdoen 4 criteria, $C=$ voldoen 1 of 2 criteria, $D=$ voldoen 1 of 2 criteria,

- Welke belemmerende en/of bevorderende factoren zijn beïnvloedbaar door fysiotherapie?

- Wat is de prognose voor herstel?

- Welke stoornissen in functies en beperkingen in activiteiten kunnen beïnvloed worden door de fysiotherapeut?

- Wat verwacht de patiënt van de behandeling?

Alvorens behandeldoelen en een behandelplan op te kunnen stellen, moet de fysiotherapeut antwoord hebben op de vragen of er sprake is van ZGBP, een indicatie is voor een fysiotherapeutische behandeling en er behandeld kan worden volgens de KNGF - richtlijn.

\section{Behandelplan}

Het behandelplan is een hulpmiddel om de behandeling te structureren, controleren en te evalueren. In het behandelplan worden de individuele behandeldoelen, verrichtingen en de strategie voor de behandeling in nauwe samenwerking met de patiënt vastgelegd. Al naar gelang van de uitkomsten 
Veroolg tabel 3

\begin{tabular}{|c|c|c|c|}
\hline $\begin{array}{c}\text { Selectie van mensen die } \\
\text { verdacht worden van de } \\
\text { aandoening zonder } \\
\text { diagnose }\end{array}$ & $\begin{array}{l}\text { Reproduceerbare } \\
\text { beschriping ven da test en } \\
\text { gouden standaard }\end{array}$ & $\begin{array}{c}\text { Tenminste } 50 \text { mensen met } \\
\text { en } 50 \text { mensen zonder de } \\
\text { aandoeningr }\end{array}$ & $\begin{array}{l}\text { Niveau van bewisg } \\
(A, B, C . D)\end{array}$ \\
\hline & 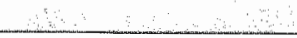 & $\ldots$ & 3 \\
\hline$x$ & - & $=$ & 0 \\
\hline- & - & $=$ & D \\
\hline$x$ & 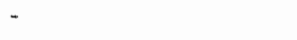 & $x$ & $D$ \\
\hline$x$ & - & $x$ & D \\
\hline$*$ & - & $x$ & $C$ \\
\hline- & - & - & $D$ \\
\hline & - & $\therefore \quad$ & $\bar{D}$ \\
\hline - & & & \\
\hline - & " & * & $\mathrm{D}$ \\
\hline - & . & . & D \\
\hline
\end{tabular}

6 maanden tot 5 jar na de bevaling

van het diagnostisch proces worden verschillende accenten in de behandeling gelegd.

Tijdens de zwangerschap

Tijdens de zwangerschap is het hoofddoel gelegen in de begeleiding van de gelleidelijke afname van het activiteitenniveau passend bij het stadium van de zwangerschap tot aan de bevalling.

Na de beoalling

Het hoofddoel van de behandeling na de bevalling bij patiënten met ZGBP, is een terugkeer naar een volledig (of gewenst) niveau van activiteiten en participatie en het voorkomen van chronische klachten.

De patient is actief betrokken bij de opzet van het behandelplan, heeft eev actieve rol bij het bepalen wan de behandeldoelen en een grote verantwoordelijkheid in het behalen wan deze doelstellingen. De behandeldoelen zijn tijdgebonden. 
Tabel 4a Karakeristeieken van geincludeerde gerandowisserde trials

\begin{tabular}{|c|c|c|c|}
\hline Ref, Studie jaar & Deelnemers & $\mathbb{N}$ & $\begin{array}{l}\text { Interventies en aantallen gerandomiseerde } \\
\text { deeinemers }\end{array}$ \\
\hline \multicolumn{4}{|l|}{ Tjjderis zwangerschap } \\
\hline Winlstrand et al, 1999 & $\begin{array}{l}\text { Met of zonder piin voor } 10 \text { ate } \\
\text { week zwangerschap }\end{array}$ & 258 & $\begin{array}{l}\text { 1. Controle }(n=120) \\
\text { fl. Water gymnastiek }(n=124)\end{array}$ \\
\hline
\end{tabular}

Wedenberg et al., 2000

Lage rugklachten voor de 32 ste week zwangerschap

60 . Individuele fysiotherapy $(n=30)$

II. Acupuntuur $(n=30$
Kworning et al., 2004

ZGBP of lage rugklachten binnen de 2fssie tot de $37^{\text {ste }}$ week zwangerschap

Elden et al. , 2005
ZGBP van week 12 tot week 31 van de zwangerschap
72 L. Controle $(n=35)$

II. Acupunctuur $(n=37)$

386 I. Standaard behandeling $(n=130)$ ( informatie and advies door envaren fysiotherapeut, bekkenband en oefenprogramma thuis)

II. Standaard behandeling + acupunctuur $(n=125)$ III. Standaard behandeling + stabiliserende oefeningen $(n=131$

\begin{tabular}{|c|c|c|c|}
\hline Na de bevalling & & & \\
\hline Mens et al., 2000 & $\begin{array}{l}\text { Persisterende ZGBP van } 6 \\
\text { weken tot } 6 \text { maanden na de } \\
\text { bevalling }\end{array}$ & 44 & $\begin{array}{l}\text { 30-min videotape met informatie, ergonomische } \\
\text { advizen en het gebruik van een bekkenband voor } \\
\text { alle groepen } \\
\text { I. Controle: geen oefeningen }(n=16) \\
\text { I. Control: placebo oefeningen thuss }(n=14) \\
\text { lil. training thuis wan de schuine buikspieren }(n=16)\end{array}$ \\
\hline Stuge et all, 2004 & $\begin{array}{l}\text { ZGBP binnen } 3 \text { weken na de } \\
\text { bevalling }\end{array}$ & 81 & $\begin{array}{l}\text { 1. Controle. Fysiotherapy zonder stabiliserende } \\
\text { aefeningen ( }=39 \text { ) } \\
\text { II. Fysiotherapy plus focus op stabitiserende } \\
\text { aefeningen }(n=39\end{array}$ \\
\hline $\begin{array}{l}\text { Bastiaenen of al } \\
2004,2005\end{array}$ & ZGBP 3 weken na de bevalling & 126 & $\begin{array}{l}\text { 1.Controle. Huidige pijncontingente } \\
\text { benadering(inclusief stabiliserede oefeningen) } \\
(n=64) \\
\text { I.. Biopsychosocial benadering inclusief self- } \\
\text { management, graded exposure lechnieken en } \\
\text { coordinatieve oefeningen ( } n=62 \text { ) }\end{array}$ \\
\hline
\end{tabular}




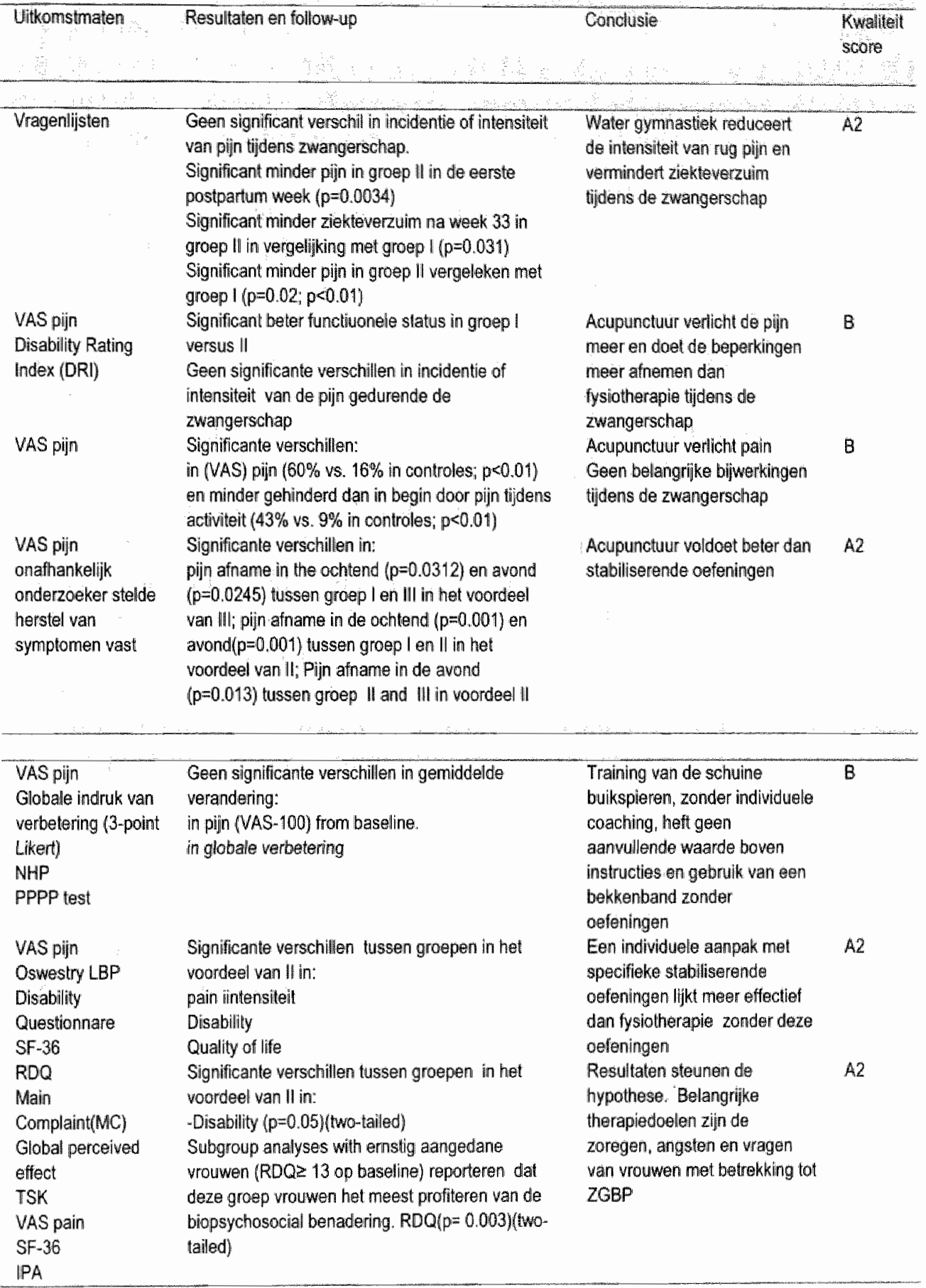




\section{Therapeutisch proces}

De aanbevelingen in het therapeutische proces zijn primair gebaseerd op de beschikbare wetenschappelijke evidentie. Bij het ontbreken daarvan zijn de aanbevelingen gebaseerd op consensus. Ter onderbouwing van de richtlijn is systematisch gezocht naar publicaties over de effectiviteit van fysiotherapie bij ZGBP( Tabel 4a-b).

Er zijn nog maar weinig studies op dit terrein verricht: Een systematische zoekactie leverde uiteindelijk 7 gerandomiseerde $[6,73-79], 4$ niet gerandomiseerde studies $[15,39,40,80]$ op van matige tot goede kwaliteit en 1 descriptieve review [81]. De studies werden beoordeeld met de EBRO criteria. De methodologische kwaliteit van een aantal van deze studies is beperkt (Tabel 4a). De timing van de interventie (tijdens de zwangerschap of na de bevalling) en de metingen hebben waarschijnlijk de resultaten beïnvloed [82].

Eén studie[73] voerde een interventie uit tijdens de zwangerschap (start behandelsessies in week 15-33), echter de laatste follow-up meting vond plaats in de eerste week na de bevalling. Er is een redelijke kans dat de korte termijn effecten van de bevalling en de goed prognose van ZGBP kort na de bevalling. de resultaten hebben beïnvloed. De omvang van de studie populatie verschilde van 44[77] tot 386[76]deelnemers. Twee studies hadden een erg kleine studiepopulatie en hierdoor waarschijnlijk onvoldoende power om klinisch relevante verschillen te kunnen vaststellen. Het heterogene karakter van de studies met betrekking tot deelnemers, uitkomstmaten, timing van de metingen en interventies maakt het moeilijk om de resultaten onderling te vergelijken.[81] De meeste interventies zijn niet gebaseerd op een duidelijke theoretische grondslag. Positieve resultaten ten aanzien van een fysiotherapeutische interventie tijdens de zwangerschap worden niet gerapporteerd.

Een recent gepubliceerde studie[78, 79] evalueert het effect van specifieke stabiliserende oefeningen van de buikmusculatuur vergeleken met fysiotherapie zonder deze oefeningen. Deze interventie vindt plaats kort na de bevalling. Resultaten van deze studie laten zien dat de interventie effectief is ten aanzien van pijnvermindering, verbetering van de functionele status en verbetering van kwaliteit van leven. Echter, de generalisatie van de resultaten van deze studie is waarschijnlijk beperkt vanwege de gekozen inclusiecriteria. Deze waren nauw omschreven pijnlocaties, een positieve PPPP-test en een positieve ASLR test. 
Tabel $4 b$ Karakteristieken van klinische gecontroleerde studies

\begin{tabular}{|c|c|c|c|c|}
\hline Ref, Studie jaar & Deenemers & N. & Interventie en controle groep & Uhiomsten en follow up \\
\hline \multicolumn{5}{|l|}{ During pregnancy. } \\
\hline Mantle ef al, 1981 & $\begin{array}{l}\text { Primipara met en } \\
\text { zonder pijo foor woek } \\
16 \text { van de } \\
\text { zwangerschap }\end{array}$ & 208 & $\begin{array}{l}\text { 1. Controle } \\
\text { II. } 2 \text { bjeenkomsten } \\
\text { ergonomische adviezen voor } \\
\text { ngiklachten }\end{array}$ & $\begin{array}{l}\text { Significants verschilien } \\
\text { in rugklachiten }(p<0.01)\end{array}$ \\
\hline $\begin{array}{l}\text { Ostgaard et al. } \\
1994\end{array}$ & $\begin{array}{l}\text { Zwangere vrouwen met } \\
\text { en zonder pijh woor } \\
\text { week } 18 \text { van de } \\
\text { zwangerschap }\end{array}$ & 407 & $\begin{array}{l}\text { 1. Controle ( } n=145 \text { ) } \\
\text { 11. Folder en } 2 \text { bijeenkomsten van } \\
\text { nugschool educatie met } \\
\text { trainingsprogram ( } n=123 \text { ) } \\
\text { II. Als groep if maar op } \\
\text { individuele basis en voor langere } \\
\text { periodes + oefeningen thuis } \\
(n=139)\end{array}$ & $\begin{array}{l}\text { Significant betere } \\
\text { functionele status in } \\
\text { groep III wergeleken } \\
\text { met } 1, \text { acht weken } \\
\text { postpartum }(p<0.05) \\
\text { Significant grotere } \\
\text { reductie in } \\
\text { zieketverzum in groep } \\
\text { III vergeleken met } \\
\text { groep } 1 \text { p<0.05) }\end{array}$ \\
\hline Dumas ef al., 1995 & $\begin{array}{l}\text { Zwangere vrouwen met } \\
\text { en zonder pijn }\end{array}$ & 65 & $\begin{array}{l}\text { 1. Controles }(n=38) \\
\text { 1. Oefengroepen voor zwangere } \\
\text { vrouwen }(n=27)\end{array}$ & $\begin{array}{l}\text { Geen significant } \\
\text { verschillen in. } \\
\text { - pijn prevalentie en: } \\
\text { - functionole status }\end{array}$ \\
\hline Noren ef al. 1997 & $\begin{array}{l}\text { Zwangere vrouwen met } \\
\text { ZGBP tussen week } 11- \\
36 \text { zwangerschap }\end{array}$ & 135 & $\begin{array}{l}\text { 1. Controles }(n=81) \\
\text { 11. Individuele fysiotherapie }(n= \\
\text { 54) }\end{array}$ & $\begin{array}{l}\text { Significant munder } \\
\text { ziekteverzuim in groep } \\
\text { II vergeleken met groep } \\
1 \text { ( } p<0.004) \\
\text { Significante reductie in } \\
\text { pijn intensiteit ( } p<0.05 \text { ), } \\
\text { geen vergelijking } \\
\text { tussen de groepen }\end{array}$ \\
\hline
\end{tabular}

De Maastrichtse interventiestudie [6] rapporteert eveneens positieve resultaten bij een interventie kort na de bevalling. Deze interventie is gebaseerd op zelfmanagement en graded exposure technieken. Er worden positieve resultaten gerapporteerd ten aanzien van beperkingen in activiteiten, bewegingsangst en participatie (Bastiaenen et al. Submitted).

Op basis van bovenstaande formuleerde de werkgroep de volgende aanbeveling:

Het is aannemelijk dat een fysiotherapeutische behandeling kort na de bevalling gebaseerd op zelfmanagement en graded exposure technieken in conbinatie met stabiliserende oefeningen van de buikmusculatuur effectief is (niveau 2). 


\section{Behandeldoelstellingen}

Tijdens de zwongerschap

Begeleiden in een afnemend niveau wan activiteiten, passend bij het stadium van de zwangerschap. Het geven van voorlichting ten aanzien van ZGBP en stimuleren om na de bevalling de normale activiteiten zo snel als mogelijk te hervatten.

\section{Na de bevalling}

De belangrijkste doelstelling is de snelle terugkeer naar normale dagelijkse activiteiten en secundaire preventie van een chronisch gezondheidsprobleem. Het geven van voorlichting over ZGBP neemt ook hier weer een belangrijke plaats in.

\section{Educatie}

Het doel van educatie is reconceptualisatie van het gezondheidsprobleem[83]. Een belangrijk kenmerk is dat veel aandacht gegeven wordt aan het dynamisch karakter van pijn, met medeneming van de neurale respons op inactiviteit en bewegingscontrole en de invloed van interne en externe factoren. Daarnaast is kennis ten aanzien van de prevalentie van ZGBP tijdens de zwangerschap en na de bevalling van belang.

Trainen van functies en vaardigheden

- Stabiliserende oefeningen van de rompmusculatuur, beginnend bij ademhaling en ontspanningsoefeningen en daarna opbouwend in zwaarte. $[78,84]$

- Vaardigheden horende bij zelf-management technieken[45-47] en graded exposure $[60,85]$ zoals het opstellen, uitvoeren en evalueren van actieplannen ten behoeve van de korte en lange termijndoelen, probleemoplossen van dagelijkse activiteiten, het nemen van de eigen verantwoordelijkheid ten aanzien van het management van het gezondheidsprobleem. Daarnaast wordt de patiënt vertrouwd gemaakt met de graduele opbouw van de activiteiten die vermeden worden. 


\section{Tussentijdse evaluatie en eindevaluatie}

Naast een 'continue' evaluatie volgens zelf-management principes gedurende de behandeling vindt een uitgebreide evaluatie plaats tussentijds dat wil zeggen minimaal om de zes weken of eerder wanneer noodzakelijk en aan het eind van de behandeling. De keuze van de evaluatie-instrumenten moet gericht zijn op de individuele subdoelen en probleemgebieden.

\section{Evaluatie en verslaglegging}

De fysiotherapeut informeert de verwijzer eventueel tussentijds, maar in ieder geval. na het beëindigen van de behandelingperiode over de (individueel vastgestelde) behandeldoelen, het behandelproces en de behandelresultaten. Verslaggeving naar de verwijzer geschiedt conform de KNGF-richtlijn 'Informatieverstrekking huisarts'. Voor de inhoud van de verslaglegging van de fysiotherapeut wordt verwezen naar de KNGF-richtlijn 'Fysiotherapeutische Verslaglegging.

\section{Juridische betekenis van de richtlijnen}

KNGF-richtlijnen zijn geen wettelijke voorschriften, maar op onderzoeksgegevens en op consensus gebaseerde aanbevelingen waaraan zorgverleners zich kunnen spiegelen voor een verantwoorde zorg. Aangezien de aanbevelingen hoofdzakelijk zijn gebaseerd op consensus vanwege de schaarse onderzoeksgegevens, moeten zorgverleners op basis van hun professionele autonomie afwijken van de richtlijn als de situatie van de patiènt dat vereist. Wanneer de fysiotherapeut van de richtlijn afwijkt, dient hij dit te beargumenteren en te documenteren.

\section{Herziening}

Deze KNGF-richtlijn is een eerste uitwerking van klinische vragen rond de diagnostiek, behandeling en preventie van de meest voorkomende gezondheidsproblemen bij vrouwen met bekkenpijn en/of aspecifieke lage rugpijn. Ontwikkelingen die de fysiotherapeutische zorg bij deze patiëntengroep kunnen verbeteren, kunnen de huidige inzichten zoals beschreven in de richtlijn doen veranderen. In de methode voor 
26. EH Endresen Pelvic pain and low back pain in pregnant women-an epidemiological study. Scand I Rheumatol 1995, 24:135-41.

27. H Svensson, G Andersson, A Hagstad; P Jansson: The relationship of low-back pain to pregnancy ans gynecologic factors. Spine $1990,15.371-375$.

28. A Hansen, DV Jensen, B Larsen, C Wilken Jensen, LK Petersen: Relaxin is not related to symptom-giving pelvic girdle relaxation in pregnant women. Acta Obstet Gynecol Scand 1996, 75:245-9.

29. HC Ostgaard, GB Andersson: Postpartum low-back pain. Spine 1992, 17:53-5.

30. P Kristiansson, K Swardsudd, B von Schoultz: Back pain during pregnancy: a prospective study Spine 1996, 21:702-9.

31. HC Ostgaard, GB Andersson: Previous back pain and risk of developing back pain in a future pregnancy. Spine 1991, 16:432-6.

32. LF Saugstad: Is persistent pelvic pain and pelvic joint instability associated with early menarche and with oral contraceptives? Eur J Obstet, Gynecol, Reprod Biol 1991, 41:203-6.

33. HC Ostgaard, GB Andersson, $K$ Karlsson: Prevalence of back pain in pregnancy. Spine 1991, 16:549-52.

34. JM Mens, A Vleeming, R Stoeckart; HJ Stam, CJ Snijders: Understanding peripartum pelvic pain. Implications of a patient survey. Spine 1996, 21:1363-9.

35. $Z$ Worku: Prevalence of low-back pain in Lesotho mothers. I Manipulative Physiol Ther 2000, 23:147-54.

36. DB Stapleton, AH MacLennan, P Kristiansson: The prevalence of recalled low back pain durimg and after pregnancy: a South Australian population survey. Aus NZ IObstet Gynaecol 2002, 42:482-5.

37. LF Saugstad: Persistent pelvic pain and pelvic joint instability. Eur J Obstet Gynecol Reprod Biol 1991, 41:197-201.

38. H Albert, M Godskesen, J Westergaard: Prognosis in four syndromes of pregnancy-related pelvic pain. Acta Obstet Gynecol Scand 2001, 80:505-10.

39. GA Dumas, JG Reid, LA Wolfe, MP Griffin, MJ McGrath: Exercise, posture, and back pain during pregnancy. Part 1. Exercise and posture. Clin. Biomech. 1995, 10:98-103.

40. GA Dumas, JG Reid, LA Wolfe, MP Griffin, MJ MeGrath: Exercise, posture, and back pain during pregnancy. Part 2. Exercise and back pain. Clin. Biomech. 1995, 10:104-109.

41. RA Deyo, M Battie, AJ Beurskens, C Bombardier, P Croft, B Koes, A Malmivaara, M Roland, M Von Kouff, G Waddell: Outcome measures for low back pain research. A proposal for standardized use. Spine 1998, 23:2003-13.

42. SI Linton: A review of psychological risk factors in back and neck pain. Spine 2000, 25:1148-56.

43. SJ Linton: Early identification and intervention in the prevention of musculoskeletal pain. Am J Indus Medicine 2002, 41:433-42.

44. SI Linton, $\mathrm{K}$ Boersma: Early identification of patients at risk of developing a persistent back problem: the predictive validity of the Orebro Musculoskeletal Pain Questionnaire. Clin J Pain 2003, 19:80-6. 
45. J Barlow, C Wright, I Sheasby, A Turner, J Hainsworth Self-managenent approaches for people with dronic conditions: a review: Pat Educ Couns 2002, 48:177-87.

46. K Lorig: Partmerships between expert patients and physicians. Lancet 2002, 359:814-5.

47. JE Moore, M Von Korff, D Cherkin, K Saunders, K Lorig: A randomized trial of a cognitive-behavioral program for enhancing back pain self care in a primary care setting: Pain 2000, 88:145-53.

48. M Von Korf, BH Balderson, K Saunders, DL Mighoretti, EH Lin, S Berry, IE Moore, A Turner: A trial of an activating intervention for chronic back pain in primary care and physical therapy settings. Pain 2005, 113.323-30.

49. C Bastiaenen: Diagnostiek bij zwangerschapsgerelateerde bekkenpijn. Stimulus $2004,4: 400-415$.

50. RA Deyo, J Rainville, DL Kent: What can the history and physical examination tell us about low back pain? JAMA 1992, 268:760-5.

51. M Roland, $\mathbb{R}$ Morris: A study of the natural history of back pain. Part I: development of a reliable and sensitive measure of disability in low-back pain. Spine 1983, 8:141-4.

52. M Cardol, RJ de Haan, GA van den Bos, BA de Jong, I] de Groot: The development of a handicap assessment questionnaire: the Impact on Participation and Autonomy (IPA). Clim Rehabil 1999, 13:411-9.

53. M Cardol, RJ de Haan, BA de Jong, GAM van den Bos, IJM de Groot: Psychometric properties of the impact on participation and autonomy questionnaire. Arch Phys Med Rehabil 2001, 82:210-216.

54. AJ Beurskens, HC de Vet, AJ Koke, E Lindeman, GJ van der Heijden, W Regtop, PG Knipschild: A patient-specific approach for measuring functional status in low back pain. J Manipulative Physiol Ther 1999, 22:144-8.

55. WA van der Kloot, RA Oostendorp, J van der Meij. J van den Heuvel: De Nederlandse versie van McGill pain questionnaire': een betroumbare pijnvragenlijst. Ned Tijdschr Geneeskd 1995, 139.669-73.

56. R Melzack: The McGill Pain Questionnaire: major properties and scoring methods. Pain 1975, 1:277-99.

57. JW Vlaeyen, NJ Teeken Gruben, ME Goossens, MP Rutten van Molken, RA Pelt,$H$ van Eek, PH Heuts: Cognitive-educational treament of fibromyalgia: a randomized clinical trial. I. Clinical effects. I Rheumatol 1996, 23;1.237-45.

58. JWS Vlaeyen, PHTG Heuts: Gedragsgeoriënteerde behandelingsstrategieën bij rugpipn, NUGI 742 edn. Houten/Diegem: Bohn Stafleu Van Loghum; 2000.

59. SI Linton, $\mathrm{K}$ Hallden: Can we screen for problematic back pain? A screening: questionnaire for predicting outcome in acute and subacute back pain. Clin I Pain 1998, 14:209-15.

60. JW Vlaeyen, I de Jong, M Gellen, PH Heuts, G van Breukelen: Graded exposure in vivo in the treatment of pain-related fear: a replicated single-case experimental design in four patients with chronic low back pain. Behav Res Ther 2001, 39:151-66. 
61. K Kugler, Wiin, J, Gelen, M, de Jong, J, Vlaeyen, J.W.S: the photograph series of daily activities (PHODA) cd-rom version. In: Book the photograph series of daily activities (PHODA) ca-rom version. Heerlen: IRV, School for Physiotherapy, Heerlen, the Netherlands; 1999.

62. JWS Vlaeyen, DFM pernot, AMI Kole-Snijders, JA Schuerman, vH Eek, NH Groenman. Betrouwbaarheid en validiteit van een Nederlandse versie van de Pain Behavior Scale (PBS). Ned Tijdschr Psychol 1990, 45:184-189.

63. B Sturesson, G Uden, A Uden. Pain pattern in pregnancy and "catching" of the leg in pregnant women with posterior pelvic pain. Spine 1997, 22:1880-3.

64. HC Ostgaard, G Zetherstrón, $E$ Roos Hansson: The posterior pelvic pain provocation test in pregnant women. Eur Spine J 1994, 3:258-60.

65. A Vleeming, HI de Vries, JM Mens, JP van Wingerden: Possible role of the long dorsal sacroiliac ligament in women with peripartum pelvic pain. Acta Obstet Gynecol Scand 2002, 81:430-6.

66. H Albert, M Godskesen, I Westergaard: Evaluation of clinical tests used in classification procedures in pregnancy-related pelvic joint pain. Eur Spine J 2000, 9:161-6.

67. M Wormslev, AM Juul, B Marques, H Minck, L Bentzen, TM Hansen: Clinical examination of pelwic insufficiency during pregnancy. An evaluation of the interobserver variation; the relation between clinical signs and pain and the relation between clinical signs and physical disability. Scand J Rheumatol 1994, 23.96-102.

68. P Kristiansson, $\mathrm{K}$ Swardsudd: Discriminatory power of tests applied in back pain during pregnancy. Spine 1996, 21:2337-43.

69. JM Mens, A Vleeming, CJ Snijders, I Ronchetti, HJ Stam: Reliability and validity of hip adduction strength to measure disease severity in posterior pelvic pain since pregnancy. Spine 2002, 27:1674-9.

70. P van der Wurf, W Meyne, RH Hagmeijer: Clinical tests of the sacroiliac joint. Main Ther 2000, 5:89-96.

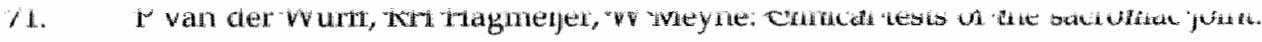
A systemic methodological review. Part 1: reliability. Man Ther 2000, 5:30-6.

72. Pan der Wurff, I Buijs, GJ Groen: Sacroiliac joint pain: clinical asessment and diagnostic accuracy. UMC Utrecht; 2004.

73. M Kihlstrand, B Stenman, S Nilsson, O Axelsson: Water-gymnastics reduced the intensity of back/low back pain in pregnant women. Acta Obstet Gynecol Scand 1999, 78:180-185.

74. K Wedenberg, B Moen, A Norling: A prospective randomized study comparing acupuncture with physiotherapy for low-back and pelvic pain in pregnancy. Acta Obstet Gynecol Scand 2000, 79:331-5.

75. N Kvorning, C Holmberg, L Grennert, A Aberg, I Akeson: Acupuncture relieves pelvic and low-back pain in late pregnancy. Acta Obstet Gynecol Scand $2004,83246-50$.

76. H Elden, L Ladfors, MF Olsen, HC Ostgaard, H Hagberg: Effects of acupuncture and stabilising exercises as adjunct to standard treatment in 
pregnant women with pelwic girdle pain: randomised single blind controlled trial. BM] 2005, 330:761.

77. JMA Mens, CI Snijders, H] Stam: Diagonal trunk muscle exercises in peripartum pelvi pain: a randomized clinical trial. Phys Ther 2000, 80:11641173.

78. B Stuge, E Laerum, G Kirkesola, N Vollestad: The efficacy of a treatment program focusing on specific stabilizing exercises for pelvic girdle pain after pregnancy: a randomized controlled trial. Spine 2004, 29:351-9.

79. B Stuge, MB Veierod, E Laerum, $\mathrm{N}$ Vollestad: The efficacy of a treatment program focusing on specific stabilizing exercises for pelvic girdle pain after pregnancy: a two-year follow-up of a randomized dinicall trial. Spine 2004, 29:E197-203.

80. HC Ostgaard, G Zetherstrom, E Roos Hansson, B Svanberg: Reduction of back and posterior pelvic pain in pregnancy. Spine 1994, 19:894-900.

81. B Stuge, G Hilde, N Vollestad: Physical therapy for pregnancy-related low back and pelvic pain: a systematic review. Acta Obstet Gynecol Scand 2003, 82,98390.

82. GE Bekkering, AJ Engers, $M$ Wensing, HJ Hendriks, MW van Tulder, RA Oostendorp, LM Bouter: Development of an implementation strategy for physiotherapy guidelines on low back pain. Aus J Physiother 2003, 49:208-14.

83. GL Moseley, MK Nicholas, PW Hodges: A randomized controlled trial of intensive neurophysiology education in chronic low back pain. Clin J Pain 2004, 20:324-30.

84. CA Richardson, GA Jull: Muscle control-pain control. What exercises would you prescribe? Man Then 1995, 1:2-10.

85. IR Jong de, JWS Vlaeyen, MJ Geilen, PHTG Heuts, G Crombez: Graduele exposure in viwo bij pijngerelateerde vrees. Ned Tijdschr Fysiotherapie 2002, $112: 50-57$. 


\section{Schematisch overzicht}

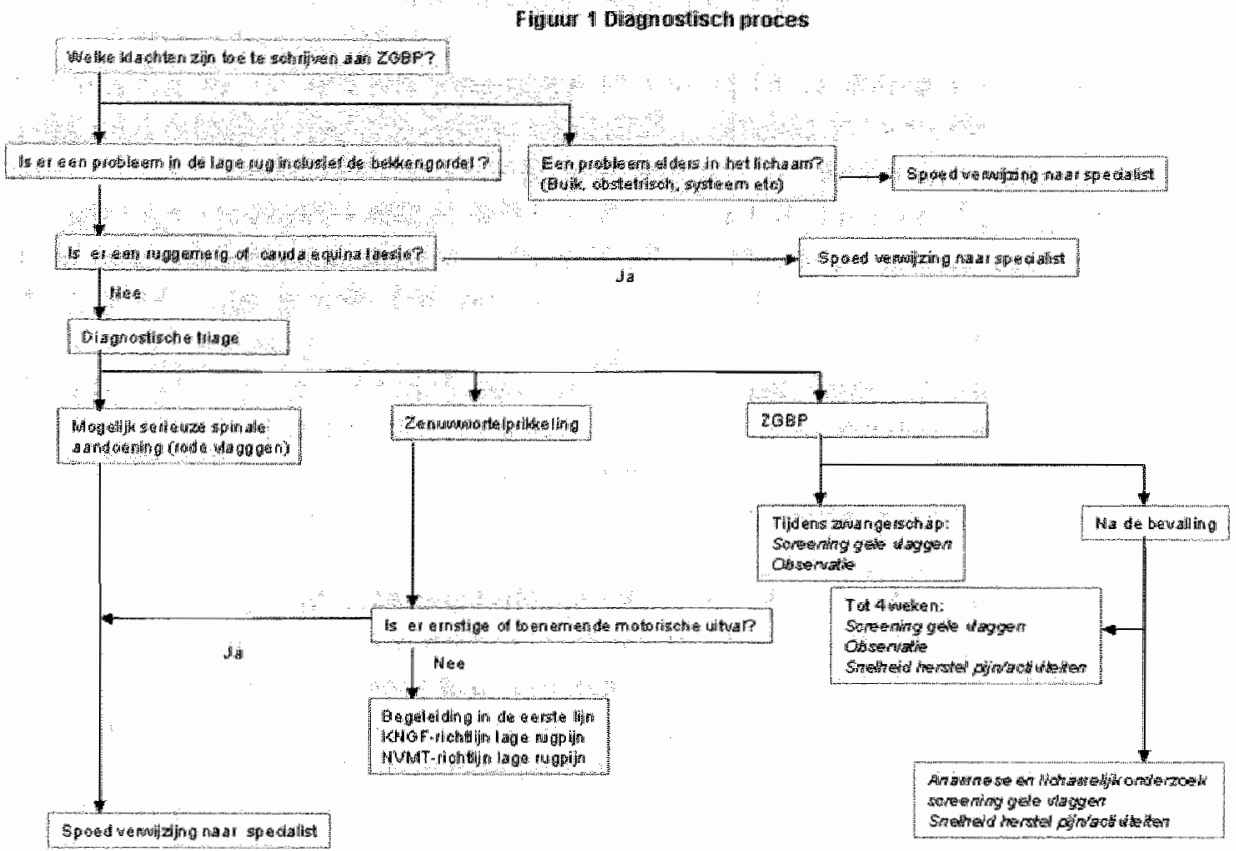


Funur 2 I herapentisch process

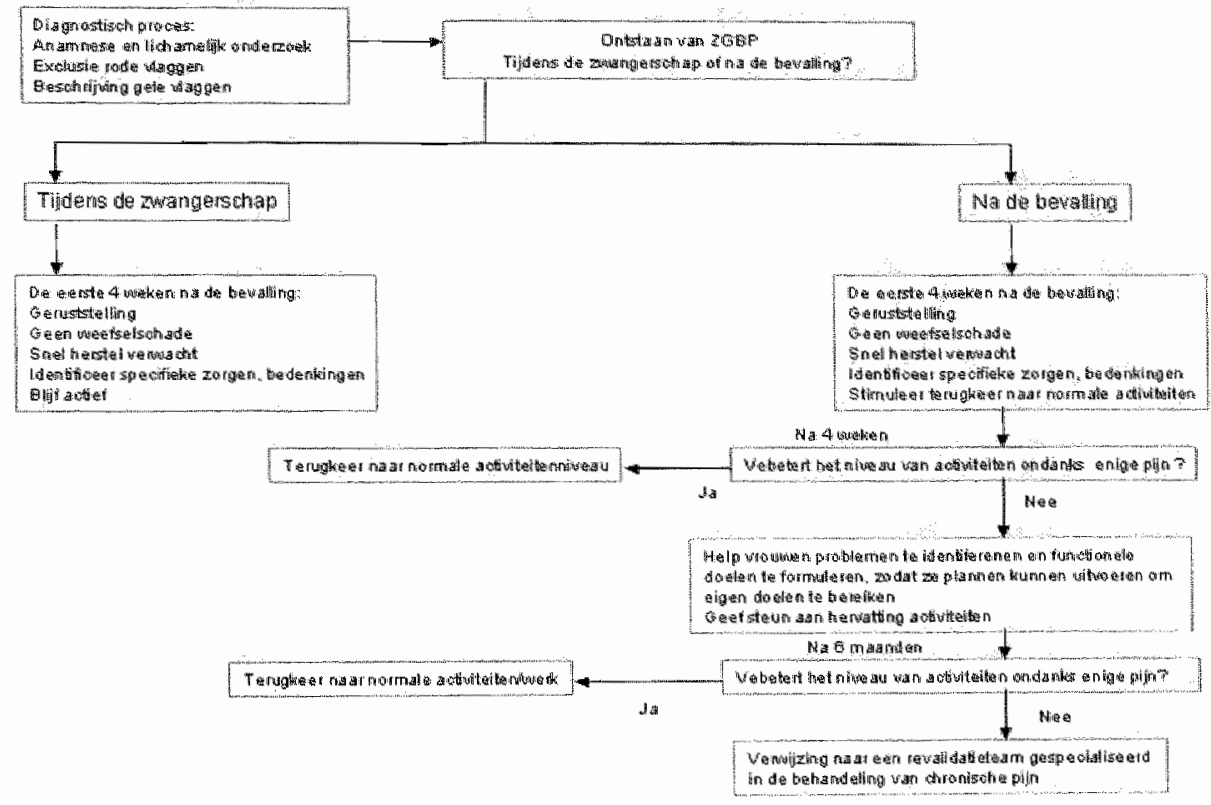


229 - RICHTLIN BEKKENPIN 


\section{Summary/ Samenvatting}

\section{Summary}

This thesis presents the results of a study with is carried out within a large research project on pregnancy-related pelvic girdle pain (PPGP) during pregnancy untill one year after delivery; the Maastricht Cohort and Intervention study on PPGP. The research project consists of a large prognostic cohort study $(n=7526)$ and a randomized controlled trial $(n=126)$, which are carried out alongside each other.

Pregnancy-related pelvic girdle pain is a common and frustrating complaint during pregnancy with often-adverse effects after delivery. Pain and limitations in activities are major complaints.

The current thesis discusses the management of pregnancy-related low back pain in primary care and focused for the greater part on the effectiveness of a tailor-made intervention based on some self-management and fear avoidance techniques, three wreeks after delivery. Because of a lack of a clear definition we used in this thesis an extensive description of PPGP including all women who experience some form of pregnancy-related pain in the lower back and/or pelvic girdle originated within the musculoskeletal system.

At first, in Chapter 2 the agreement on definitions on pregnancy-related pelvic girdle pain used by 4 commonly used diagnostic strategies are explored. This validity study is embedded in the ongoing cohort study. The first 89 women, who met the inclusion criteria of the randomized controlled trial, participated in this study. Data are collected during a home visit by a research-physiotherapist. Every woman is classified 4 times running on the same data but every time by means of a different strategy. Kappa is used to measure agreement between the examined strategies and disagreement is interpreted as a difference in the definition. Differences turned out to be outweighing the similarities. The investigated strategies represented clearly different selections of women having pregnancy-related pelvic girdle pain. There were a large amount of problems concerning content validity, biases in work-up evaluation, a non-systematic application of validated and standardized questionnaires and a limited knowledge about the etiology. These problems contributed to the disagreement in the final diagnosis of the investigated authors. 
Second, in Chapter 3 a new way to describe clinical findings of women having persistent pregnancy-related pelvic girdle pain is explored. The used statistical techniques were series of cluster analyses followed by discriminant analyses. Cluster analyses are a group of empirical techniques to describe clinical findings in an unprejudiced way. A first group of cluster analyses based on similarity in the outcomes of currently used diagnostic strategies could not localize clusters that significantly and clinically differed from each other. A second group of cluster analyses is performed on the responses of a number of the most important risk factors in the transition from acute to chronic pain. A solution with three clusters was the maximal subdivided classification. Taken together, after meeting the exclusion criteria for specific pathology, currently used biomedical variables did not contribute to an adequate understanding of PPGP, three weeks after delivery. Coming diagnostic research has to focus more attention on variables as the impact of limitations in activities, restrictions in participation, pain experience last week depression, pain-related fear, pain catastrophyzing and expectancy of treatment results.

Chapter 4 describes the design of a randomized controlled trial within the comprehensive prognostic cohort study. The pragmatic randomized controlled trial is designed to evaluate the effectiveness of a tailor-made treatment program with respect to biopsychosocial factors in primary care. Inclusion was at three weeks after delivery. The aim of the experimental intervention was to increase the level of activities. The effects of the experimental intervention and usual care are evaluated as they are applied in primary care. This chapter focuses on choices regarding recruitment procedures, in/exclusion criteria and the development of a well-timed intervention.

Chapter 5 discusses the short-term results of the randomized controlled trial. Because of a quick recovery in two weeks time after delivery, we included only 126 women three weeks after delivery. There is a statistical and clinical relevant difference in improvement on the primary outcome (RDQ) in favour of the experimental intervention. In general, women were willing to accept the responsibility to manage their own condition and solve their problems with guidance from the physiotherapists. Women's individual worries and concerns about their condition were major targets.

In chapter 6 the long-term results and the costs of the randomized controlled trial are discussed. Primary outcome concerned limitations in activities (RDQ). Additionally an economic evaluation is performed. Follow-up measurements are performed until one year after delivery. Results of this trial indicate a rapid 
and significant improvement of women attending of the intervention program relative to usual care. The improvement concerned limitations in activities, activity-avoidance and autonomy in self-care. Although not significant, costs of sick leave in the UC group were about twice as high when compared to the intervention group. Differences remained stable in sub group analyses.

Although results showed that pain decreased extensively in both study groups, recurrence of pain episodes is a quite common phenomenon in the year after delivery. Importantly, the decrease in the level of pain experience was similar in. both study groups and independent from the differences in improvement on resumption of normal activities; participation and reduced fears between both groups. It seems that pain flare-ups are rather common but in all probability better manageable in the experimental intervention group than in the usual care group.

Chapter 7 described the consequences of the outcomes of the Maastricht Cohort and Intervention study on pregnancy-related pelvic girdle pain (PPGP) for the development of a clinical practice guideline based for physiotherapists. The guideline was developed in the Netherlands and consisted a methodological approach to the diagnostic and therapeutic processes involved. The results of this study guided to a change of the approach of women with PPGP in the Netherlands. PPGP is a common physical symptom during pregnancy with a good prognosis after delivery. A distinction between the treatment approach during pregnancy and after delivery is advocated. Diagnostics should take place within domains of the ICF. Management of women with PPGP should take place within the biopsychosocial approach. A stay active approach is advocated during pregnancy. The primary goal of an intervention shortly after delivery is a quick return to normal daily activities and secondary prevention of chronic disability.

Chapter 8 , the epilogue reflected on some characteristics of the intervention study, the embedding of the study in the cohort study, on the clinical implications and the personal view of the author.

We were able to investigate the prevalence, etiological and prognostic factors of PPGP of the total source population in an extensive way and even before the enrolment in the intervention study. By doing so, we could choose a timewindow before the start of an active intervention carefully. We decided not to include a no treatment or a minimum treatment group for practical, ethical and methodological reasons. Participating physiotherapists in the experimental intervention group showed the potential to shift from a model of care with a 
clearly biomedical view to a broad approach that incorporates biopsychosocial factors. Both the educational programme received by the physiotherapists and the intervention they delivered was brief and appropriate for implementation in daily practice: Although we tailored our intervention on an individual basis as much as possible under the circumstances of the trial, it was still more or less a one-size-fits-all approach. It might have obscured the potential effectiveness of an intervention targeted more specifically to women for whom it is more likely to be of benefit. Future research should be focused on tools that are useful to detect biopsychosocial aspects that are predictive of poor outcomes. Additionally, the investigation of the effectiveness of particular treatment components within the identified subgroups is a challenge for future research.

Finally, the appendix introduces the developed clinical practice guideline for the physiotherapy management in the Netherlands in its entirety

\section{Samenvatting}

In dit proefschrift worden de resultaten beschreven van een studie naar zwangerschapsgerelateerde bekkenpijn. Deze studie is uitgevoerd in het kader van een groot onderzoeksproject naar zwangerschapsgerelateerde bekkenpijn tijdens de zwangerschap tot éen jaar na de bevalling. Het onderzoeksproject bestaat uit een prognostische cohort studie $(n=7526)$ en een gerandomiseerde gecontroleerde interventiestudie $(n=126)$; de Maastricht Cohort en Interventie studie naar zwangerschapsgerelateerde bekkenpijn.

Zwangerschapsgerelateerde bekkenpijn is een veel voorkomende en frustrerende klacht tijdens de zwangerschap. Na de bevalling kunnen de gevolgen soms nog lange tijd blijven voortduren.

$\mathrm{Bij}$ gebrek aan een algemeen geaccepteerde omschrijving van zwangerschapsgerelateerde bekkenpijn wordt in deze studie de volgende definitie gehanteerd: onder zwangerschapsgerelateerde bekkenpijn wordt pijn bedoeld waarvan het ontstaan gerelateerd is aan de zwangerschap, gelokaliseerd is in het gebied van de bekkengordel en/of lage rug en waarvan de oorsprong gelegen is in het houdings- en bewegingsapparaat.

Dit proefschrift richt zich voornamelijk op de beschrijving en resultaten van de interventiestudie. Tevens zijn er in het kader van het fysiotherapeutische beleid in de eerste lijn twee verkennende diagnostische studies uitgevoerd. Tot slot wordt de ontwikkeling van een richtlijn bekkenpijn voor de fysiotherapeut besproken. De cohort studie bestudeert de prevalentie, etiologie, prognose en 
de ernst van zwangerschapsgerelateerde bekkenpijn tijdens de zwangerschap tot één jaar na de bevalling. De resultaten van deze studie worden elders beschreven.

Hoofdstuk 2 is een verkennende diagnostische studie. In dit hoofdstuk worden de overeenkomsten en verschillen tussen de 4 meest toegepaste diagnostische strategieën ten behoeve van bekkenpijn geëvalueerd. De eerste 89 vrouwen uit het cohort die deelnamen aan de interventiestudie, participeerden in deze studie. De data werden verzameld tijdens een huisbezoek: Een onderzoeksfysiotherapeut bezocht de vrouwen 3 weken na de bevalling en nam een gestandaardiseerd onderzoeksprotocol af. Dit protocol bestond uit een anamnese en lichamelijk onderzoek. ledere vrouw werd 4 maal ingedeeld (gediagnosticeerd), steeds op basis van dezelfde dataset maar een andere strategie. Een verschil in indeling werd geïnterpreteerd als een verschil in de definitie van zwangerschapsgerelateerde bekkenpijn. De verschillen tussen de strategieèn bleken uiteindelijk veel groter te zijn dan de overeenkomsten. leder van de onderzochte diagnostische strategieën selecteerde andere vrouwen "lijdende" aan al dan niet bekkenpijn of lage rugpijn. Er werden tevens een grote hoeveelheid problemen geconstateerd die voornamelijk betrekking hadden op de validiteit van deze strategieën.

Hoofdstuk 3 onderzocht vervolgens een nieuwe weg om tot een meer adequate beschrijving te komen van de karakteristieken van vrouwen met zwangerschapsgerelateerde bekkenpijn. Hierbij werd gebruik gemaakt van verschillende series cluster analyses. Cluster analyses zijn een groep van empirische statistische technieken met als doel personen (cases) in te delen in verschillende groepen (clusters) op basis van vooraf verzamelde data. Hierbij worden vooraf geen aannames geformuleerd over de karakteristieken van deze groepen maar worden de kenmerken van de "natuurlijke groepering" op basis van de data geëxploreerd. Bij deze technieken is de keuze van de variabelen op basis waarvan de clustering plaatsvindt van belang. In eerste instantie is in deze studie gekozen voor een clustering op basis van de meest gebruikte variabelen uit de huidige diagnostische strategieèn. Er bleken echter geen duidelijk te onderscheiden groepen van personen te herkennen op basis van deze variabelen. Een tweede reeks van cluster analyses op basis van de voornaamste risicofactoren ten aanzien van het voortbestaan van de klachten gaf een clusterstructuur te zien van drie ten opzichte van elkaar te onderscheiden groepen. Deze groepen waren echter niet terug te brengen tot verschillen in uitkomsten van lichamelijk onderzoek. De conclusie van deze studie was dat na 
uitsluiting van specifieke pathologie de huidig meest gebruikte variabelen uit het lichamelijk onderzoek niet bijdragen tot een beter begrip van zwangerschapsgerelateerde bekkenpijn. Toekomstig onderzoek zou zich meer moeten richten op variabelen als beperkingen in activiteiten, restricties in de participatie, ervaren pijn de laatste week, depressie, pijn gerelateerde vrees, catastroferen en de verwachting van het behandelingsresultaat.

In hoofdstuk 4 wordt het design besproken van de gerandomiseerde interventiestudie. De studie is ingebed in de cohort studie; deelnemers die instromen in de interventiestudie zijn al participanten van de cohort studie. Het moment van instroom is drie weken na de bevalling. Het doel van deze pragmatische interventiestudie is de evaluatie van een speciaal voor dit doel ontworpen begeleidingsprogramma door de fysiotherapeut in vergelijking met de huidige zorg. Het doel van het begeleidingsprogramma is het verhogen van het niveau van activiteiten. Hierbij wordt gebruik gemaakt van "selfmanagement" technieken als actieplannen en het oplossen van dagelijkse problemen bij de uitvoering van activiteiten. Tevens wordt de onzekerheid en terughoudendheid tot het hervatten van de normale activiteiten benaderd met technieken uit het vrees-vermijdingsmodel. De studie is uitgevoerd in de eerste lijn.

Hoofdstuk 5 beschrijft de korte termijn resultaten van de interventiestudie op 3 maanden na de bevalling. Uiteindelijk zijn 126 deelnemers ingestroomd in de studie. Dit lage aantal in verhouding tot het aantal deelnemers van het cohort $(n=7526)$ wordt veroorzaakt door het snelle herstel in de eerste weken na de bevalling. Tijdens de zwangerschap geeft meer dan $70 \%$ van de deelnemers zwangerschapsgerelateerde bekkenpijn aan. In de eerste drie weken na de bevalling is het herstel echter snel. De vrouwen die uiteindelijk participeerden in de interventiestudie hadden drie weken na de bevalling zwangerschapsgerelateerde bekkenpijn en een actieve hulpvraag. Er was een statistisch en klinisch relevant verschil te constateren in het voordeel van de experimentele interventie ten aanzien van de primaire uitkomstmaat (RDQ); verhoging van het activiteitenniveau. Over het algemeen waren de deelnemers duidelijk bereid om hun verantwoordelijkheid te nemen ten aanzien van hun eigen gezondheid en conditie en konden met begeleiding van de fysiotherapeut snel hun eigen actieplannen opstellen en dagelijkse problemen oplossen. De individuele zorgen en wensen ten aanzien van het functioneren waren de uitgangspunten tijdens deze begeleiding. 
Hoofdstuk 6 beschrijft de lange termijn resultaten en de kosten van de interventiestudie. Primaire uitkomstmaat was de beperking in activiteiten (RDQ). Tevens vond er een economische evaluatie plaats op basis van een kostendagboekje. Follow-up metingen vonden plaats op 3 maanden (korte termijn) 6 maanden en 1 jaar na de bevalling. De resultaten laten een snelle en significante verbetering zien van de deelnemers in de interventiegroep ten opzichte van de deelnemers in de controle groep. De verbetering heeft betrekking op de beperkingen in het activiteiten niveau, terugdringen van de vermijding van bepaalde activiteiten en de autonomie in de zelfverzorging. De kosten met betrekking tot het ziekteverzuim na afloop van het bevallingsverlof zijn in de controle groep ongeveer twee maal zo hoog als in de experimentele interventiegroep. De verschillen zijn echter niet significant. Subgroep analyses lieten overeenkomstige resultaten zien.

Alhoewel de resultaten een sterke afname van de pijn in de beide onderzoeksgroepen laten zien, is een terugkerende episode van de pijn in het jaar na de bevalling toch normaal in beide groepen. Deze afname van pijn is vergelijkbaar in beide groepen maar onafhankelijk van de verbetering in het activiteiten niveau, de toename van de participatie en de vermindering van vermijding van activiteiten. Het lijkt erop dat deze oplevingen van pijn waarschijnlijk beter te hanteren zijn door de deelnemers in de interventie groep dan van de controle groep.

Hoofdstuk 7 beschrijft de consequenties van de resultaten van de interventie en de cohort studie voor de ontwikkeling van een richtlijn bekkenpijn voor fysiotherapeuten in Nederland. De resultaten van de Maastricht Cohort en Interventie studie leiden tot een verandering in de benadering van vrouwen met zwangerschapsgerelateerde bekkenpijn in Nederland.

Zwangerschapsgerelateerde bekkenpijn blijkt een normaal symptoom tijdens de zwangerschap met een goed prognose na de bevalling. In de richtlijn wordt een onderscheid gemaakt in aanpak tijdens de zwangerschap en na de bevalling, door de fysiotherapeut. De diagnostiek door de fysiotherapeut dient alle domeinen van de ICF (International Classification of Functions) te bestrijken. Tijdens de zwangerschap wordt een "blijf actief" beleid aanbevolen. De belangrijkste doelstelling van een interventie kort na de bevalling is een snelle terugkeer naar de normale dagelijkse activiteiten.

In hoofdstuk 8 wordt tenslotte een korte reflectie gegeven van de voornaamste karakteristieken van de interventiestudie. Tevens worden de voor en nadelen van de inbedding in de cohort studie beschreven. 
De appendix bevat een integrale beschrijving van de richtijn bekkenpijn, bestaande uit een praktijkrichtlijn, de verantwoording en literatuur en een schematisch overzicht 


\section{Acknowledgements}

\section{Thanks to}

Geen proefschrift zonder de mensen die hebben bijgedragen om dit project tot een goed einde te brengen. Het was voor mij een groot genoegen en eer met jullie allen te mogen samenwerken. Een bijzonder woord van dank hierbij voor de drie promotoren. Jullie hebben mij de ruimte en de tijd gegeven om mijn eigen weg te vinden in dit bijzondere onderzoeksveld. Ik heb mij altijd gesteund gevoeld in onderzoeksland. Bovendien hebben jullie mij de nodige taaiheid bijgebracht om niet te snel tevreden te zijn met het resultaat.

Promotores Rob de Bie - Piet van den Brandt - Gerard Essed

Inhoudelijke ondersteuning Pieter Wolters Janneke Bastiaanssen · Johan Vlaeyen - Pieter Leffers - Ton Lenssen. Annie Heuts - Marielle Goossens - Jeroen de Jong - Peter Heuts - Jan Schouten - Erik Hendriks - John van der Meij . Marieke van Engelenburg . Nol Bernards . Pytha Albers . Marga Grupping Gerda Kraag - Bart Staal Arianne Verhagen. Jan Mens - Foekje Stelma

Logistieke ondersteuning Conny de Zwart - Gonnie Klabbers - Jos Slangen . Harrie van Montfort - Suzanne Siegelaar - Natalie Slangen - Memic en Mailmerge

Met medewerking van 126 patiènten 7526 deelnemers cohort 53 fysiotherapeuten en therapeuten mensendieck en cesar 2 ergotherapeuten .73 verloskundige praktijken 13 poli's verloskunde - KNGH - NVFB - revalidatiecentrum Blixembosch. Hogeschool Zuyd patièntenvereninging : KNOV $\cdot$ NPI

Morele ondersteuning (buiten alle bovengenoemde) - Kim . Andrea. Cristel Nicole - Daniêlle Coby YYolanda . Marijke - alle collegae docenten epidemiologie Last but not least; vrienden - paranimfen . Familie - Gijs · Jeroen - Bart en Peter 


\section{Thoughts, beliefs, concerns, worries}

"Ik heb nog nooit zo goed begrepen hoe wanhopig al die wrouwen zich voelen die tegen hun wil zwanger zijn en er alleen via de Poort der Zeven Smarten van verlost kunnen worden. Ik ben in ieder getal onverstoorbaar van aard en laat me niet imponeren door werhalen van "vriendinnen"; ondanks de zeer afschuwelijke verhalen van Agnes bij haar tweede. De vroedvroww wertelde haar tijdens de batensweeèn alleen maar verhalen over rugpijnen, inscheuren, verlostangen, blaww aangelopen kinderen en navelstrengen die om het nekje heen zaten. Help, ik heb helemaal geen zin meer om te bevallen. Maar heb je wel eens gedacht ann het gevoel van paniek van de vrouw die zwanger was van haar eerste kind, bij het zien van die buik die monsterachtig groot werd, om te eindigen met onbegrijpelijke pijnen?

"Zo, een primipara? Dan hebben we de tijd. Trouwens het ziet er niet naar uit dat "we" veel pijn hebben. "Wat wisten die meiden ervan? De verloskamer zag er als alle martelkamers onheilspellend wit. Gelukkig was de dokter er en was hij niet die nacht overleden of op wintersport gegaan en vervangen door een beginneling, nog zo'n spookbeeld! Verder ging het er alleen maar on stoicijns te zijn. Ze weigerde om een Oud-Strijdster wan het Bevallingslegioen te worden, zo'n vrouw voor wie han zwangerschappen oorlogen zijn en iedere bevalling de slag bij Verdun.

Even voor middernacht verandert de pijn van register. Jowel, meisje, jij bent niet de baas. Had je er maar niet aan moeten beginnen! Het is precies wat ze dacht toen het wagentje wan de achtbaan aan zijn laatste duikolucht begon en het te laat was on te roepen: "Ik wil eruit!"Je denkt nooit genoeg na voor je een kartje koopt. Tenslotte wordt de Grote Tovenaar (dokter) erbij gehaald. "Alsjeblieft, wees wat liever. Zeg dat je me dapper vindt. Je ziet dnt ik niet schreeuw mar het is afschuwelijk zo'n pijn te hebben. Doe iets, jij die alles kunt."

Een eigen gezicht, Benôte Groult 
Het kost meer moeite dan je denkt,

Ook als je denkt

Het zal wel veel meer moeite kosten dan ik denk

Dan kost het toch meer moeite

Dan je denkt

Het duurt veel korter dan je denkt

Ook als je denkt

Het zal wel korter duren dan ik denk

Dan duurt het toch

Nog korter dan je denkt

(uit Liedje, Judith Herzberg)

\section{Curriculum Vitae}

1958 Geboren te Geleen

$1976-81$ Opleiding Fysiotherapie Heerlen

1981-99 Fysiotherapeut

1994-96 Studie Bewegingswetenschappen

Universiteit Maastricht

$1999-2004$ Onderzoeker

Capaciteitsgroep Epidemiologie

Universiteit Maastricht

2004 - heden Uniwersitair docent

Capaciteitsgroep Epidemiologie

Universiteit Maastricht

Getrouwd met Peter Heuts

Moeder van Gijs, Jeroen en Bart 